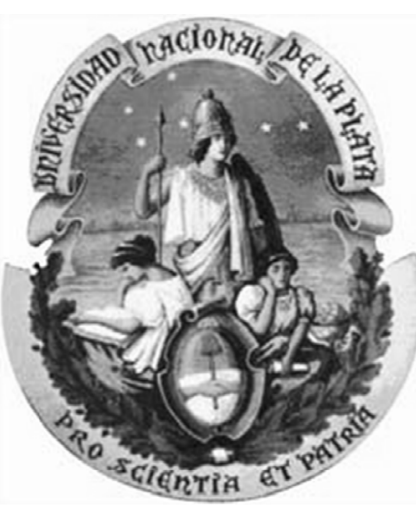

UNIVERSIDAD NACIONAL DE LA PLATA

FACULTAD DE CIENCIAS JURÍDICAS Y SOCIALES

MAESTRÍA EN RELACIONES INTERNACIONALES

Tesis de maestría

\title{
Acción racional, conflicto y seguridad colectiva en la posguerra fría
}

\author{
Rafael Daló
}

1996 
Director: Ángel Pablo Tello

Profesor Titular Ordinario de Relaciones Internacionales

(Universidad Nacional de La Plata)

Director de la Maestría en Defensa Nacional y Estrategia

(Universidad Nacional de La Plata)

Investigador Categoría B de la Universidad Nacional de La Plata

Co Director: Francisco Naishtat

Profesor Titular Ordinario de Filosofía

(Universidad de Buenos Aires)

Profesor Adjunto Ordinario de Lógica

(Universidad Nacional de La Plata)

Coordinador Area de Epistemiología y Estudios Filosóficos de la Acción

(Instituto Gino Germani UDA)

Jurado de la Tesis

\section{Gladys Lechini}

Directora de la Escuela de Relaciones Internacionales

(Universidad Nacional de Rosario)

Profesora Titular Ordinaria de Relaciones Internacionales

(Universidad Nacional de Rosario)

Investigadora del CONICET

\section{Leiser Madane}

Director del Departamento de Filosofía

(Facultad de Filosofía y Letras de la Universidad Nacional de Buenos Aires)

Profesor Titular Ordinario de Filosofía Política

(Universidad Nacional de La Plata)

Investigador del CONICET

\section{Dr. Norberto Consani}

Profesor Titular Ordinario de Derecho Internacional

(Universidad Nacional de La Plata)

Director de la Maestría en Relaciones Internacionales

(Universidad Nacional de La Plata)

Director del Instituto de Relaciones Internacionales

(Universidad Nacional de La Plata)

\section{Calificación: Sobresaliente}




\section{Presentación}

Con esta tesis presentada por el Magister en Relaciones Internacionales Rafael Daló, iniciamos una nueva Serie dentro de las publicaciones del Instituto.

Tenemos el propósito de editar todas las Tesis que se vayan aprobando en el marco de la Maestría en Relaciones Internacionales que desde 1987, anualmente, se viene desarrollando en nuestra Universidad.

En la presentación de las mismas, figurarán los nombres, un currículum abreviado de los Directores/Co Directores y del Jurado, como así también la calificación obtenida en la evaluación de la tesis.

Prof. Dr. Norberto E. Consani 


\section{INTRODUCCIÓN}

\section{a) Objetivos y estructura del trabajo.}

¿Cómo actúan los estados en sus relaciones internacionales? ¿Cuáles son sus objetivos y formas de acción? ¿Puede establecerse un criterio de racionalidad que permita clasificar las acciones de los actores internacionales en racionales o irracionales? ¿Tal criterio es sólo estratégico o también moral? ¿Son posibles las relaciones éticas o con respeto al derecho entre los estados? ¿Qué condiciones son en tal caso necesarias para un efectivo cumplimiento del derecho internacional? ¿Es factible, en el nuevo marco de creciente globalización, un mecanismo de seguridad colectiva eficiente que pueda constituirse en una respuesta organizativa aplicable a la solución del "problema de poder" de los estados en la sociedad internacional? ¿Es posible una evolución, a partir de la posguerra fría, hacia una sociedad internacional más racional (no sólo estratégica sino también éticamente), en la que las relaciones de fuerza dejen su lugar al derecho?

He aquí los principales interrogantes a los que el presente trabajo intentará echar luz. Para ello, buscaré armonizar mis dos grandes fuentes de formación y preocupación intelectual, la filosofía y las relaciones internacionales, esperando contar con la inspiración necesaria para lograr combinar de manera natural la precisión del científico social y el humanismo de los estudios filosóficos. En términos generales, me propongo entonces:

1) Elaborar, en base a un análisis lógico- filosófico de la acción intencional, un modelo interpretativo de la acción individual y su racionalidad.

2) Extender ese modelo a la interpretación de las acciones de los distintos actores internacionales (en particular de los más relevantes, los estados).

3) En base al mencionado modelo, efectuar un estudio personal de la lógica del conflicto y la cooperación internacional a partir del cual investigar una posible solución cooperativa, a través de la instauración de un auténtico régimen de seguridad colectiva, al llamado "problema de poder" de los estados (es decir, a la falta de cooperación y de respeto al derecho internacional derivada de la ausencia de un poder soberano por encima del de los estados).

4) Investigar, a partir de las referidas reflexiones sobre la racionalidad de la acción, acerca de los límites materiales y principios éticos a ser respetados por un organismo efectivo de seguridad colectiva internacional.

5) Examinar, siempre de acuerdo a mi análisis de la racionalidad de la acción, las circunstancias, peligros y oportunidades ofrecidos por la posguerra fría para la constitución de un eventual organismo de seguridad colectiva eficiente y para la evolución hacia una sociedad internacional más racional.

6) Aportar elementos que enriquezcan el enfoque institucionalista de las relaciones internacionales y contribuyan a sentar las bases de una perspectiva más amplia que ayude a una mejor comprensión de la actual sociedad internacional.

Mi trabajo consta de cinco partes. Mientras la primera parte está dedicada a cumplir con el primer objetivo, la segunda hace lo propio con el segundo objetivo, de manera que sólo una vez definido el modelo interpretativo de la racionalidad y la acción de los estados se pasa a estudiar sus implicancias en el análisis del conflicto, la cooperación y la seguridad colectiva internacional. En ese sentido, la tercera, cuarta y quinta partes abordan respectivamente los objetivos tercero, cuarto y quinto. El sexto objetivo, en tanto, habrá de irse cumpliendo progresivamente a lo largo de todo el trabajo.

El camino que lleva a definir los parámetros y criterios de la racionalidad de la acción de los actores de la sociedad internacional se inicia en la primera parte con un estudio crítico de las últimas y más refinadas reflexiones de la filosofía de la acción en el análisis de la conducta del individuo, en 
especial de la cada vez más difundida y vigente teoría de la elección racional (Rational Choice). En ese sentido, en el primer capítulo me preocupo por establecer primero ciertas distinciones iniciales relativas al tema de la racionalidad, para luego pasar a un estudio detallado de la mencionada teoría de la elección racional. Este capítulo incluye también una revisión de las principales críticas formuladas a dicha teoría, que son agrupadas en dos líneas, una teórica propiamente dicha y otra moral. El examen de la primera línea crítica sirve para dejar sentadas las conexiones y compatibilidades de la teoría de la elección racional con otros enfoques como el de la racionalidad limitada. Por otro lado, mi adhesión a la crítica a los distintos intentos de extensión del criterio de maximización de la utilidad esperada a la interpretacion de la acción moral, constituye un análisis inicial de la problemática a ser desarrollada más extensamente en la cuarta parte.

En el segundo capítulo, mi atención se centra en la elaboración de mi propio punto de vista acerca de la racionalidad de la acción. En ese sentido, he diseñado un modelo tendiente a la descripción, explicación y predicción de la acción individual que, partiendo de una asociación original entre la teoría de la elección racional (con mi crítica incluida), la teoría aristotélica del silogismo práctico y el método hipotético deductivo, constituye lo que creo es un punto de vista novedoso sobre la racionalidad y la acción del individuo. Dicha perspectiva apunta a enriquecer la teoría de la elección racional, especialmente en la caracterización de la racionalidad de la acción bajo incertidumbre y en la consideración de la moralidad de la acción. Al mismo tiempo, el modelo permite establecer una tipología de acciones racionales perfectas, racionales imperfectas e irracionales, dejando abierto el camino para su aplicación a la interpretación de la acción en los distintos terrenos de las actividades humanas.

La segunda parte comienza examinando algunas advertencias a tener en cuenta en la aplicación del modelo propuesto al análisis de la racionalidad de la acción de los estados en las relaciones internacionales. Más precisamente, el capítulo 3 se refiere al problema que pueden representar, tanto para la teoría de la elección racional como para mi propio punto de vista, las conclusiones del teorema de Arrow sobre el peligro derivado de la antropomorfización de los colectivos. El análisis al respecto me ha servido no sólo para despejar esos temores sino también para extender el modelo de racionalidad de la acción estudiado a los demás actores, aparte de los estados, que constituyen la sociedad internacional.

Una vez hechos los reparos y salvedades del capítulo 3, el capítulo 4 pasa a la aplicación directa de mi modelo interpretativo de la acción individual y de su racionalidad a la acción de los estados y demás actores internacionales. Esto conduce, a su vez, a descubrir las potencialidades del referido modelo para la elaboración de un nuevo enfoque de las relaciones internacionales que, en la línea del enfoque institucionalista, integre los supuestos básicos del realismo con otros tomados de los enfoques idealista y de la interdependencia, permita la superación de las críticas del enfoque clásico- realista, dando cuenta de una realidad internacional en la que entran a la vez el conflicto y la cooperación, la interdependencia y la dependencia, la continuidad y el cambio. El capítulo termina entonces distinguiendo los aportes de mi punto de vista en la construcción de lo que de una manera un tanto ambiciosa he denominado "realismo idealista".

La tercera parte constituye una aplicación del modelo a la investigación de la relación entre racionalidad estratégica y conflicto, al análisis del pasaje del conflicto a la cooperación y al estudio de la vinculación entre cooperación estratégica y racionalidad moral. En ese sentido, el quinto capítulo procura aplicar los estudios y conclusiones de los primeros dos al análisis de la relación entre la racionalidad estratégica de los individuos y la formación del Estado como garante de la acción moral y legal. En particular, me he propuesto estudiar el pensamiento de Maquiavelo y de Hobbes desde la perspectiva de la teoría de la elección racional criticada en el primer capítulo y de mi propio modelo interpretativo inspirado en ella. Dicho estudio obedece a distintos intereses, por un lado una interpretación nueva de Maquiavelo y Hobbes, por otro, una introducción al tema de la cuádruple relación entre racionalidad estratégica, conflicto, cooperación y racionalidad moral, y en tercer lugar, la obtención de elementos a ser utilizados en mi análisis de la seguridad colectiva internacional. 
El capítulo 6 constituye una extensión de las conclusiones del capítulo 5 al estudio del conflicto y la cooperación en la sociedad internacional. En particular, se trata del análisis de la factibilidad de un auténtico mecanismo de seguridad colectiva que, sobre la base de las Naciones Unidas, brinde solución al denominado "problema de poder" de los estados en la sociedad internacional. En ese sentido, después de asimilar el estado de anarquía internacional con el juego del dilema del prisionero (en coincidencia con el enfoque institucionalista), se efectúa un repaso de los intentos históricos de seguridad colectiva desde la Liga de las Naciones a la Organización de Naciones Unidas, señalando a partir de mi análisis de la lógica de la acción colectiva los motivos que han evitado que dichos organismos se constituyan en auténticos garantes de la paz y la seguridad mundiales. Para terminar el capítulo, enumero los que desde mi perspectiva teórica de la acción colectiva deberían ser los requisitos a cumplir por una organización de seguridad colectiva que garantice efectivamente el respeto del derecho internacional.

Ya en la cuarta parte, el capítulo 7 hace referencia a los parámetros de amplitud material y juicio moral a tener en cuenta por las entidades colectivas, invitando a reflexionar sobre los límites materiales y morales del Estado. En lo relativo a los límites materiales, se adopta la perspectiva de la teoría del Public Choice (elección pública), pertinente por su íntima relación con la teoría de la elección racional y por su potencial para la explicación de la acción cooperativa tanto de los individuos como de los estados. El segundo punto del capítulo 7 se refiere a los límites morales y de derecho susceptibles de ser impuestos a los estados, en su acción interna, con la perspectiva de ampliar estas reflexiones en el siguiente capítulo, en el que se hace una analogía con los límites morales y de derecho (en este caso de derecho internacional) imponibles a los estados en su acción externa. En ese sentido, después de examinar distintas corrientes de la filosofía política, me inclino por la alternativa de la ética universalista como base de una fundamentación objetiva de las normas de derecho.

El capítulo 8, como se ha dicho, resulta una extensión al ámbito de las relaciones internacionales de las consideraciones llevadas a cabo en relación a los individuos en el capítulo 7. De ahí que comience con un análisis basado en la teoría de la elección pública acerca de la medida material de un eventual bien público internacional de seguridad colectiva, para después pasar a una reflexión, a la luz del escepticismo realista y de las crecientes discrepancias manifestadas en la Conferencia de Viena sobre los Derechos Humanos de 1993, acerca de la medida o patrón moral sobre la cual basar el derecho internacional a ser defendido por un auténtico organismo de seguridad colectiva y a ser aceptado y respetado por la comunidad internacional

En lo que respecta a la quinta parte, ésta se ocupa de estudiar las características particulares de la posmodernidad en general y de la posguerra fría en particular destacando los peligros y oportunidades a que los se enfrenta la idea de la constitución de un auténtico organismo de seguridad colectiva internacional. En ese sentido, el capítulo 9 comienza con una caracterización general de lo que se ha dado en llamar la "reacción posmoderna", para después describir las dos posiciones enfrentadas que en ella se incluyen y tomar partido por aquélla que interpreta a la posmodernidad como una radicalización de la modernidad.

El capítulo 10, luego de establecer vinculaciones entre la posmodernidad y el fenómeno de la posguerra fría, procura señalar las oportunidades ofrecidas, a partir del final de la guerra fría, para la superación de los peligros inherentes a la "radicalización" de la modernidad mediante la constitución de una sociedad global más cooperativa garantizada por un eventual mecanismo efectivo de seguridad colectiva internacional. Por último, describo la que considero es una serie de factores de riesgo para la seguridad internacional, aplicando mi interpretación de la racionalidad de la acción de los actores internacionales al estudio de elementos de irracionalidad fuertemente presentes en la sociedad internacional de la posguerra fría en posturas como el dogmatismo ideológico, el nacionalismo extremo, el fundamentalismo, la indiferencia frente a la desigualdad entre países desarrollados y subdesarrollados y la persistencia en el uso de la fuerza como medio de solución de los conflictos. 


\section{b) La ubicación del trabajo en el marco de los estudios internacionales.}

Antes de entrar de lleno en mi trabajo, resultará interesante encontrar su ubicación teórica respecto de los enfoques que han dominado el terreno de las relaciones internacionales durante este siglo. Con este propósito, valdrá la pena examinar las características definitorias de tales enfoques, para lo cual habré de basarme en las clasificaciones adoptadas en dos trabajos de Arenal $(1984,1989)$, en el análisis de Dougherty y Pfaltzgraff (1990) y en la compilación de Baldwin (1993). Debo aclarar que, dada la complejidad y el riesgo que implica el embarcarse en una clasificación completa y rigurosa de la inmensa cantidad de enfoques teóricos que toman por objeto de estudio a las relaciones internacionales, así como de sus discusiones e interconexiones, me limitaré a describir los supuestos esenciales de aquellas concepciones que han tenido mayor influencia y desarrollo. En ese sentido, la siguiente enumeración, así como la correspondiente descripción de cada enfoque, tendrán un carácter tentativo y no exhaustivo, y pretenderán simplemente identificar el marco general de los problemas y discusiones básicas de la disciplina.

\section{I) El enfoque clásico.}

Con orígenes en la antigüedad, es la manera en que fueron entendidas las relaciones internacionales por más de trescientos años, a partir del Renacimiento y de la afirmación del Estado como forma imperante de organización política y social. La base de este esquema "descansa en la teoría política que, como reflejo de una realidad que experimenta un proceso de concentración y secularización del poder a nivel de entidades políticas y de descentralización a nivel internacional, se desarrolla e impone desde la Edad Moderna, de la mano, entre otros, de Maquiavelo y Hobbes" (Arenal 1989). En general, este enfoque no constituye una visión sistemática más allá de entender a las relaciones internacionales como una lucha de poder entre estados soberanos en la que la paz se conserva a partir del equilibrio de poder (estudiado ya por Tucídides en su Historia de la Guerra del Peloponeso) a partir de la formación de una alianza de Estados débiles en contra de la potencia perturbadora de dicho equilibrio.

\section{II) El idealismo.}

Los supuestos del enfoque clásico del equilibrio de poder no fueron cuestionados sino hasta después de la Primera Guerra Mundial, cuando la reflexión acerca de los horrores de la contienda condujo al surgimiento de la doctrina idealista. El idealismo reconoce como antecedente al Kant de La paz perpetua (1795) y tiene como figura característica al presidente norteamericano Woodrow Wilson. Sus supuestos distintivos son los siguientes:

1) Los estados no son los únicos actores internacionales, sino también los organismos internacionales y los individuos.

2) En la forma de actuar de los estados influye su forma de gobierno.

3) Los estados pueden y deben comportarse de acuerdo a los mismos principios morales absolutos que guían la conducta de los individuos y, para animarlos a ello, hay que institucionalizar a escala mundial el interés común de todos los pueblos en alcanzar la paz y la prosperidad. El estudio de las relaciones internacionales aparece como una ireneología o ciencia de la paz.

4) La paz puede lograrse a través de los organismos internacionales y de la elaboración de marcos jurídicos que permitan mantener la seguridad colectiva.

5) Cuanto más se parezca el funcionamiento de la sociedad internacional al funcionamiento interno de un estado, más cerca se estará de la paz. 


\section{III) EI realismo.}

Durante el período de entreguerras, ortodoxos del enfoque clásico e idealistas comienzan a protagonizar el primer gran debate teórico de las relaciones internacionales. El fracaso de la Liga de las Naciones y el desencadenamiento de la Segunda Guerra Mundial parece dejar demostrada cierta ingenuidad de los idealistas, dando paso luego del conflicto a la renovada puesta en vigencia del enfoque clásico llevada a cabo por el realismo.

Con el nombre general de realismo se conoce entonces a los desarrollos que rescatan y actualizan al enfoque clásico a partir de la Segunda Guerra Mundial. Tales desarrollos consisten básicamente en el planteo, elaboración, refinamiento y justificación histórico- práctica de los supuestos esenciales del enfoque clásico. Así, las principales hipótesis de esta perspectiva, de contribución decisiva para el desarrollo de las relaciones internacionales, son las siguientes:

1) Existe una rígida separación entre la política interna y la internacional.

2) "Los estados y los estadistas son los actores fundamentales de las relaciones internacionales. Los seres humanos sólo cuentan en cuanto miembros de un estado. Las relaciones internacionales son y deben interpretarse como relaciones interestatales" (Arenal 1989).

3) Los estados soberanos operan de manera racional estratégica, eligiendo la alternativa menos costosa de entre las disponibles, en función del interés nacional (definido en términos de poder) y de la relación de fuerzas.

4) La lucha por el poder y por la paz constituye el factor fundamental. Las relaciones internacionales son esencialmente conflictivas. En un mundo de estados en el que no hay una autoridad superior, el mecanismo que permite evitar que un estado imponga su hegemonía es el equilibrio de poder.

5) Los principios morales en abstracto no pueden aplicarse a la acción política internacional. Frente al respeto del derecho predomina la razón de Estado y la ética de las consecuencias.

El principal representante de este enfoque es Hans Morgenthau y su obra Politic among Nations (1948), aunque también se destacan los aportes de Schwarzenberger, Kennan, Kissinger, StrauszHupé y, desde la sociología histórica, Aron y Hoffman.

\section{IV) El enfoque científico.}

Surge en los años cincuenta y sesenta, a partir de la renovada influencia de las ciencias duras en las ciencias sociales y de su pretensión no sólo de describir, sino también de explicar y predecir los acontecimientos de la sociedad internacional. Entre los principales intereses generales de este enfoque están los siguientes:

1) Atención a los métodos científicamente precisos con el deseo de elevar las relaciones internacionales a la categoría de ciencia.

2) Adaptación de teorías, proposiciones, marcos conceptuales e ideas de otras disciplinas.

3) Intento de relacionar fenómenos estudiados por otras disciplinas con fenómenos similares en la esfera internacional.

4) Atención a los problemas de recolección de datos.

5) Esfuerzo de elaboración de teorías desde una perspectiva acumulativa.

Dentro del gran abanico de teorías y autores que pueden ser englobados en este enfoque, se distinguen dos grandes corrientes:

a) La corriente sistémica. 
Esta perspectiva considera a la sociedad internacional como un amplio y complejo sistema que puede tomar distintas formas, compuesto por un cierto número de subsistemas y actores. Entendiendo por sistema a una serie de elementos interrelacionados y distinguibles por ciertas regularidades, la característica principal de esta línea, a la que pertenecen Mc Clelland, Kaplan y Rosecrance, es la de intentar brindar modelos explicativos del "sistema internacional" a partir de la forma en que se relacionan sus actores. En ese sentido, se buscan modelos analíticos de los que puedan obtenerse consecuencias aplicables por analogía a la comprensión de la sociedad internacional. Distinguiendo entre fuerza y potencia (la capacidad operativa de usar la fuerza) y entre poder potencial y poder efectivo (en acto), dichos autores sostienen la existencia de una tendencia al equilibrio homeostático de fuerzas (más exactamente de poderes), es decir del sistema de fuerzas (de poder).

La noción de sistema no es exclusiva del enfoque científico (Aron (1962) entre otros la ha reconocido y aplicado), si bien ha alcanzado en su seno su mayor desarrollo. Kaplan (1957), por ejemplo, estudia a la sociedad internacional como un sistema de acción, analizando las interacciones de sus diversos actores y planteando por primera vez los posibles (y no sólo los conocidos) sistemas resultantes de tales interacciones: multipolaridad, bipolaridad flexible, bipolaridad rígida, confederación de estados, imperio universal y equilibrio múltiple por el terror (sistema de veto por unidad).

b) La corriente behaviorista.

Dentro del enfoque científico, el behaviorismo constituye la amplia e influyente corriente doctrinal que centra su indagación en el análisis del comportamiento, es decir de las acciones e interacciones de los diferentes actores internacionales. Si bien constituye una corriente bien definida, pueden distiguirse para su estudio dos terrenos de investigación específica:

b1) La teoría de la toma de decisiones.

Esta línea, en la que sobresalen entre otros el trabajo pionero de Snyder, Bruck y Sapin (1954) y el de Allison (1971), surge con los cuestionamientos a la visión del Estado como actor unificado, centrando su estudio en el proceso de toma de decisiones de aquellos agentes (actores) cuyos actos son actos de Estado (los tomadores de decisiones). Sus principales hipótesis teóricas son las que siguen:

1) El comportamiento del sistema internacional se explica desde los estados y no solamente a partir de las interacciones de los estados.

2) Se respetan los postulados del paradigma clásico, pero se aclara que la acción de un estado tiene lugar a partir de un proceso de toma de decisiones del que participan los responsables de la política exterior del estado, quienes analizando las utilidades y probabilidades atribuidas a las alternativas disponibles y suponiendo que son racionales, intentarán llevar al máximo la utilidad esperada.

3) El proceso de toma de decisiones de un estado puede explicarse a partir de relaciones lógicas entre un conjunto de variables consideradas por los decisores (variables individuales, de rol, gubernamentales, sociales, sistémicas) y las acciones de política exterior.

4) La explicación del proceso de toma de decisiones toma en cuenta:

1- La recreación del momento de la decisión subjetiva, es decir, la imagen de la situación a partir de la cual el decisor decide.

2- El marco decisorio interno y el contexto macropolítico externo.

3- La información de los tomadores de decisiones.

4- Las motivaciones, objetivos, normas, y valores de los tomadores de decisiones. 
5) De acuerdo al número de actores que intervienen en la toma de decisiones, pueden distinguirse diferentes tipos de estructuras de este proceso tales como las de líder predominante, grupo solo o múltiples actores autónomos.

b2) La teoría de juegos.

La teoría de juegos puede considerarse un caso especial o bien un desarrollo ulterior de la teoría de la decisión, ya que también basa su estudio en la acción y la decisión racional. En particular, consiste en la aplicación a las relaciones internacionales de los desarrollos teóricos iniciados a partir de Neumann y Morgenstern (1944). En ese sentido, vale citar aquí a John C. Harsanyi, Premio Nobel de Economía 1993 por sus aportes a esta teoría, quien señala que "ciertamente, aparte de la vida económica, probablemente hay pocas áreas del comportamiento social donde el cálculo racional de los juegos sea más importante que en la política internacional" (Harsanyi 1961:371).

A partir de la década del sesenta y hasta la de los setenta, el enfoque científico entró en sucesivos debates metodológicos y teóricos con el realismo, el principal de los cuales tuvo como centro de atención la disputa abstracción- relevancia. Mientras los defensores del enfoque científico acusaban a los realistas de falta de generalidad y rigor teórico, estos respondían atacando la escasa relevancia práctica de los aportes "cientificistas". El resultado de este debate fue una severa crítica a los excesos interpretativos cometidos por los "científicos", tanto a su frecuentemente exagerado nivel de abstracción como a su abuso de la estadística y el cálculo conducente a la pérdida de vista de los problemas relevantes.

En particular, la corriente sistémica fue criticada, además de por su abstracción y falta de contenido empírico, por su simplificación de las partes a un sistema totalizador en el que se ignoraban numerosos factores, por el organicismo de algunos autores y por su marcado carácter ideológico conservador, resistente a la consideración de las tensiones provocadoras del cambio. En cuanto al behaviorismo, más allá de las críticas comunes a todo el enfoque científico, la teoría de las decisiones ganó cada vez mayor aceptación. Por otra parte, respecto a la aplicación de la teoría de juegos a las relaciones internacionales, el optimismo inicial fue seguido por numerosas críticas, entre ellas las relativas a las dificultades técnicas implicadas por la complejidad de los juegos de más de dos jugadores y a las dificultades éticas de la teoría. Esto ha llevado a sus partidarios a cuidar y a refinar sus análisis, que se han demostrado apropiados para el estudio de temas puntuales como el de la relación entre conflicto y cooperación.

Se tiene entonces que como consecuencia de este debate el enfoque científico pudo asimilar gran parte de sus críticas, librándose de sus excesos interpretativos y pasando a constituirse en una sólida herramienta del realismo y, posteriormente, del neorrealismo y del institucionalismo.

\section{V) El enfoque de la interdependencia o liberal.}

Surge a finales de la década de los setenta a raíz del nuevo clima de distensión que se va generando luego de la guerra de Vietnam, clima que favorece la toma de conciencia de los cambios que se venían produciendo en las relaciones internacionales desde la Segunda Guerra Mundial. A esto se le suma la insatisfacción de los medios académicos acerca de la capacidad del enfoque clásico- realista para dar cuenta de una realidad internacional cada vez más compleja, lo que lleva a plantear la decadencia del esquema estatocéntrico.

Reconociendo como sus antecesores a los estoicos, Kant y al idealismo, los trabajos más representativos de esta línea son los de Keohane y Nye $(1972,1977)$, así como el de Krasner (1983). Sumariamente, sus principales postulados son los siguientes:

1) Rechazo a las hipótesis realistas sobre el papel central de los estados y respecto de la conflictividad esencial de la sociedad internacional. "El mundo, como consecuencia del acelerado desarrollo social, económico, científico-técnico y comunicacional, está caracterizado por el creciente fenómeno de la interdependencia y de la cooperación, y se ha transformado realmente en 
una sociedad mundial". "Este fenómeno ha originado nuevos problemas y retos, ha suscitado necesidades y demandas nuevas y ha dado lugar a la aparición de valores e intereses comunes al conjunto de esa sociedad mundial. Las relaciones internacionales no se corresponden, por lo tanto, con el modelo exclusivamente conflictivo e interestatal del paradigma clásico- realista, sino que responden a un modelo basado más en factores culturales, tecnológicos y económicos que estrictamente políticos" (Arenal 1989). Las relaciones internacionales son ahora de tres tipos, interestatales, transgubernamentales y transnacionales. La naturaleza de la sociedad internacional ya no es puramente conflictiva, sino también cooperativa.

2) Aparición de nuevos actores internacionales, tanto a nivel intergubernamental como no gubernamental, con un nivel cada vez mayor de protagonismo y autonomía que tiende a limitar el poder de los estados y a desdibujar la concepción estatocéntrica de la sociedad internacional.

3) Cuestionamiento de la visión del Estado como actor unitario y racional a partir de la consideración de distintos grupos de presión con influencia en el proceso de toma de decisiones.

4) Desaparición de la tradicional distinción entre la esfera interna y la internacional.

5) No existe una relación mecánica entre poder y resultados, los actores más débiles cuentan con espacios de negociación donde articular sus intereses.

6) La agenda internacional se vuelve más completa y desjerarquizada, borrándose la distinción entre problemas de baja y alta política, es decir otorgando importancia a problemas no sólo estratégicos o políticos, sino también económicos, culturales o ecológicos, entre otros.

7) Los estados se preocupan menos por el poder y la seguridad en tanto se vuelve más difícil el empleo de la fuerza militar.

8) Rechazo al pesimismo realista sobre las instituciones internacionales, a las que se les atribuye la capacidad de facilitar la cooperación.

Si bien ha puesto de manifiesto la nueva complejidad de las relaciones internacionales, el enfoque de la interdependencia no alcanza por sí solo a constituirse en una alternativa al realismo, ya que "una cosa es reconocer los cambios que se han producido, como el incremento de la interdependencia y la aparición de nuevos actores, y otra muy diferente argumentar que de ello se derive un nuevo tipo de política internacional, (...) sobre todo cuando la investigación realizada hasta el presente continúa demostrando el papel decisivo del Estado y la importancia del sistema de estados" (Arenal 1989). En ese sentido, las tensiones y conflictos de los años setenta y tempranos ochenta debilitan este enfoque y lo conducen a una reformulación de sus hipótesis que lo acercan al realismo, dando lugar a una nueva perspectiva teórica, el llamado institucionalismo o neoliberalismo.

\section{VI) El enfoque de la dependencia.}

Al igual que el de la interdependencia, este enfoque es fruto de la toma de conciencia de la complejidad de la nueva realidad internacional. Sin embargo, su perspectiva ideológica es muy diferente, ya que la interpretación de las relaciones internacionales, en especial de las económicas, no se plantea en términos de interdependencia sino de dependencia, es decir en términos de desigualdad, dominación y explotación.

Las características más relevantes de este enfoque, también llamado neomarxista, son las siguientes:

1) La consideración del mundo como un único sistema económico dominado por el capitalismo trasnacional.

2) "La naturaleza del sistema internacional es, así, conflictiva, si bien, frente al realismo, se considera que la causa de ello está en la naturaleza y en los intereses del propio sistema capitalista 
mundial", cuya característica fundamental es "la desigualdad económica global y el intercambio desigual entre el centro y la periferia" (Arenal 1989).

3) Aunque se introduce la noción de cambio y la posibilidad de superación del actual sistema, la imagen del mundo de este paradigma es muy pesimista.

4) La unidad de análisis principal es el propio sistema capitalista mundial. No existe distinción entre la esfera interna y la internacional.

5) El sistema se estudia como un todo, más que a través de sus actores. Sin embargo, se considera que los actores internacionales principales son las clases sociales trasnacionales, las empresas trasnacionales, las organizaciones no gubernamentales y los movimientos de liberación nacional, entre otros.

6) Aunque tomado solamente como una superestructura, el Estado tiene un papel decisivo en las relaciones de dominación y explotación.

7) Dependencia entre el Norte y el Sur, entre el centro y la periferia, lucha entre pueblos opresores y oprimidos.

8) Tiende a dominar una visión de las relaciones internacionales como un juego de suma cero, en el que siempre hay un ganador y un perdedor. Ello supone la negación de la existencia de valores, intereses y objetivos comunes y globales.

El enfoque de la dependencia surge tanto como una reacción a las insuficiencias del paradigma clásico- realista, como en respuesta a las teorías del desarrollo económico de los años cincuenta y sesenta. Sin embargo, "su análisis fundamental sobre la naturaleza desequilibrada del sistema internacional se basa en una simplificación interpretativa y sobre una visión unilateral y exclusiva de la interdependencia como dependencia, que reduce a extremos incomprensibles la actual sociedad global" (Arenal 1989).

\section{VII) EI neorrealismo.}

El neorrealismo, entre cuyos principales representantes se encuentran Waltz (1979), Gilpin (1981) y Grieco (1988), se ha propuesto como desafío la revigorización del realismo clásico integrándolo en un marco contemporáneo basado en el análisis comparativo, definiendo conceptos claves de manera más clara y coherente y desarrollando proposiciones susceptibles de corroboración empírica. Los principales supuestos de esta nueva reformulación del enfoque clásico son los siguientes:

1) Conservación de las principales premisas filosóficas y de los rasgos esenciales de la imagen del mundo de los realistas clásicos.

2) Los estados siguen siendo los elementos fundamentales de las relaciones internacionales, esencialmente conflictivas.

3) El poder existe menos como un fin en sí mismo que como un componente necesario de una relación política.

4) Los estados se comportan como actores unitarios estratégicamente racionales, buscando maximizar su poder a través de un cálculo de costos y beneficios acerca de los cursos alternativos de acción a su disposición.

5) Se admite la existencia de nuevos actores y fuerzas en la sociedad internacional, aunque se rechaza que esto haya dado lugar a una nueva sociedad mundial no interestatal que haga necesaria una nueva perspectiva teórica.

6) Las influencias y condicionamientos de la estructura de poder del sistema internacional son puestas explícitamente y en el mismo nivel junto a la lucha por el poder y el interés nacional, como los principios rectores de la política internacional. 
7) Se presta especial atención a la actual estructura anárquica del sistema internacional para explicar las relaciones internacionales, en especial a las influencias y condicionamientos de dicha estructura sobre la política exterior de los estados.

8) En situación de anarquía, los estados se preocupan por la seguridad, están dispuestos al conflicto y fallan en la cooperación aún frente a intereses comunes.

9) Las instituciones internacionales afectan las perspectivas de cooperación sólo de manera marginal.

10) Sólo una transformación estructural, es decir del principio organizativo que condiciona la interacción de las partes, puede alterar la naturaleza anárquica del sistema internacional.

Acusado de "determinismo estructural", el neorrealismo se defiende sosteniendo que "si bien los elementos estructurales ejercen una poderosa influencia restrictiva en el comportamiento político, no considera toda la conducta política humana determinada por la estructura dentro de la cual se organiza la comunidad política"."Tampoco acepta la crítica de que el mundo del "Estado como agente" represente una negación del papel de aquellos individuos o grupos que actúan como los encargados concretos de tomar decisiones" (Dougherty y Pfaltzgraff 1990:138).

Sin embargo, el neorrealismo ha heredado la mayoría de las críticas generales de las que era susceptible el enfoque clásico- realista, entre ellas las siguientes:

- Falta de valores. Aceptación resignada de la amoralidad en las relaciones internacionales y consecuente justificación de acciones éticamente inaceptables en función del equilibrio de poder del sistema.

- Falta de respuestas al problema de la guerra más allá del inestable balance de poderes.

- Conservadorismo y justificación de la hegemonía de las grandes potencias.

- Insuficiencia para la interpretación de una sociedad global crecientemente cooperativa (si bien se reconoce la existencia de nuevos actores y de un mayor nivel de cooperación).

\section{VIII) El institucionalismo.}

Es el enfoque que en la actualidad se ha constituido en la más seria alternativa al neorrealismo. Como se dijo, se trata de un punto de vista surgido a partir de la autocrítica de los partidarios del enfoque liberal o de la interdependencia, quienes pasan a mostrarse más proclives a aceptar ciertos supuestos del realismo pero también a criticar otros de sus principios por medio de la aplicación de las herramientas de la teoría de juegos al análisis del conflicto y la cooperación. Entre los trabajos más relevantes de este enfoque deben citarse los de Keohane (1983, 1984, 1992), Stein (1983), Lipson (1984), Axelrod (1984) y Axelrod y Keohane (1986). Algunos de sus supuestos esenciales son los siguientes:

1) Reconocimiento del papel de los estados como principales actores internacionales. Sin embargo, se atibuye a las instituciones internacionales un rol importante.

2) Se reconoce a los estados como actores unitarios racionales que maximizan su utilidad esperada en base al cálculo egoísta de costos y beneficios.

3) Reconocimiento de la importante influencia de la anarquía internacional, entendida como ausencia de gobierno común, en la explicación de las acciones de los estados.

4) Si bien se reconoce la creencia realista acerca de que la anarquía restringe el deseo de los estados a la cooperación, se afirma que estos pueden trabajar juntos, especialmente si son ayudados por las instituciones internacionales.

5) Mantenimiento de una visión optimista sobre las perspectivas de la cooperación internacional. 
El principal motivo de debate entre neorrealistas e institucionalistas (también llamados neoliberales) se refiere al criterio de racionalidad sostenido por los estados. Mientras los institucionalistas afirman, en primera instancia, que los estados maximizan sus utilidades absolutas, sin preocuparse por las ganancias de los demás, los neorrealistas responden con la teoría de la utilidad relativa (relative gains). Para estos últimos, en la decisión de una acción no sólo influyen las ganancias absolutas que pueda obtener un estado, sino también la consideración de las ganancias que puedan obtener los demás y que eventualmente puedan llegar a volverse en su contra en una sociedad internacional anárquica, insegura y cambiante. Es decir, según los neorrealistas la consideración de la utilidad relativa y no sólo de la absoluta determinaría un nivel menor de cooperación que el presentado por los institucionalistas. Sin embargo, el institucionalismo ha sabido responder a esta crítica a través de diferentes análisis que incorporan adecuadamente la problemática de la utilidad relativa al marco de su enfoque. Baste por ahora la presentación de esta discusión a la que habré de referirme con más detalle en la tercera parte.

Teniendo en cuenta los distintos enfoques presentados aquí, las siguientes investigaciones apuntan a fundar las bases de un enfoque comprensivo de las relaciones internacionales que:

- Partiendo de una visión crítica de la teoría de la elección racional, aceptada por institucionalistas y neorrealistas como modelo interpretativo de la acción de los estados, enriquezca la interpretación de la acción estratégica de los actores internacionales permitiendo, además, la descripción de la acción ética conforme al derecho internacional.

- Permita analizar de manera análoga la forma en que se dan las decisiones, acciones e interacciones de los actores de las relaciones internacionales, sean estados, individuos, organismos, empresas o grupos, integrándolas de manera natural y armónica en el marco de la nueva, interdependiente y compleja sociedad internacional.

- Destaque, en consonancia con institucionalistas y neorrealistas, la importancia de los valores, de las creencias, de la información y de la comunicación en los procesos subjetivos de toma de decisiones de los mencionados actores internacionales.

- Conjugue, en coincidencia con el enfoque institucionalista y a partir de un estudio behaviorista depurado, los supuestos básicos del realismo con otros tomados de los enfoques idealista y de la interdependencia, intentando dar cuenta de una realidad internacional en la que entran a la vez el conflicto y la cooperación, la interdependencia y la dependencia, la continuidad y el cambio.

- En ese sentido, no sólo admita sino resalte la importancia de las relaciones cooperativas entre los estados y demás actores internacionales, y no sólo de las conflictivas, considerando al ámbito de las relaciones internacionales en una situación mixta alejada de los extremos de conflicto y cooperación total.

- Apunte a la superación dialéctica de las posiciones realistas e idealistas, mediante la explicación de la cooperación (acción cooperativa) a partir del análisis lógico del conflicto.

- No excluya, la existencia de situaciones de dependencia política, económica y tecnológica, ni el hecho de que ciertas acciones y relaciones de los estados puedan ser de dominación, explotación, inequidad o injusticia.

- No se limite a describir las condiciones para la cooperación en estado de anarquía, sino que ataque las causas de dicho estado inhibidor de la cooperación intentando establecer las condiciones para la instauración de un auténtico mecanismo de seguridad colectiva que permita un paso ordenado y con justicia desde la actual estructura anárquica del sistema internacional a una estructura de tipo jerárquico que, sin llegar a constituir un gobierno mundial, alcance al menos para garantizar que las acciones estratégicas de los estados sigan un camino conforme al derecho internacional.

- Considere las circunstancias especiales ofrecidas por la distensión post guerra fría para la consolidación de un auténtico organismo de seguridad colectiva internacional, así como los peligros y oportunidades abiertos en esa dirección por la posmodernidad en general. 
- Permita estudiar, a partir de la discusión filosófica analítica acerca de la racionalidad, la decisión y la acción, fenómenos como el fundamentalismo, el nacionalismo extremo o la persistencia en el uso de la fuerza en las relaciones internacionales.

- Sostenga junto con el idealismo que la paz, la libertad y la justicia son valores cuya concreción no puede ser dejada en manos de los caprichos y vaivenes del balance de poder y que, en el marco de las nuevas características de la sociedad mundial, constituye un deber de la teoría de las relaciones internacionales el intentar al menos (contando con las nuevas herramientas teóricas, teniendo en cuenta las enseñanzas del enfoque clásico- realista y sin caer en una posición ingenua) el estudio de las fórmulas que conduzcan a la solución del problema de la guerra. 


\section{PRIMERA PARTE}

\section{LA RACIONALIDAD DE LA ACCION DE LOS INDIVIDUOS}

\section{1 - La racionalidad de la acción y la teoría de la elección racional.}

\section{1- La racionalidad y la acción.}

Tanto el discurso como la acción son susceptibles de ser declarados racionales o irracionales. Discurso y acción difieren, sin embargo, en múltiples aspectos, lo que conduce a su vez a formas distintas de caracterizar y analizar su racionalidad. En el caso del discurso científico, fílosófico o de cualquier clase, el establecimiento de su racionalidad se halla conectado con el problema de la verdad, más precisamente con la conservación de la verdad de los enunciados. Un discurso racional es aquel que respeta las leyes de la lógica, aquel cuya forma argumentativa no permite deducir falsedades a partir de verdades. En el caso de las acciones, en cambio, no tiene sentido hablar de su verdad o falsedad. Las acciones son un algo concreto que, en tanto hechos dados en el mundo, no son en sí mismas susceptibles de ser catalogadas como verdaderas o falsas. ¿Sobre qué base puede entonces establecerse la racionalidad o la irracionalidad de una acción?

Primeramente hay que explicitar a qué se hace referencia cuando aquí se habla de "acción". En ese sentido, compartiré la aceptada interpretación que define a la acción humana como a la producción de un cambio que transforma un estado de cosas p en un estado de cosas distinto p' (la omisión queda incluida como un tipo de acción). Debe aclararse que no toda acción puede ser declarada racional o irracional, sino sólo la acción razonada, voluntaria y conciente, es decir el tipo de acción que la filosofía analítica, en especial a partir de Anscombe (1957) y Davidson (1963), ha dado en llamar acción intencional. En cuanto al concepto de racionalidad, coincidiré con Elster (1986, 1989, 1990), en que se trata de un concepto normativo. En particular, sostendré que hablar de racionalidad supone contar con un criterio normativo que permita discernir entre la acción o el discurso "buenos", fundados, correctos, y la acción o el discurso "malos", infundados, incorrectos.

En el caso del discurso, como se ha dicho, el criterio normativo que sirve de parámetro es el respeto de las leyes de la lógica, que asegura la obtención de conclusiones verdaderas a partir de premisas verdaderas. En el terreno de la acción, encontrar un criterio regulador que permita distinguir entre acciones correctas e incorrectas resulta, como se verá, más complicado.

Además, sólo en lo relativo a la acción, y debido a que ésta constituye un factum dado en el mundo, el concepto de racionalidad, normativo, adquiere también una dimensión empírica y puede ser usado para comprender, explicar y predecir la conducta. En ese sentido, la teoría de la elección racional constituye un modelo de interpretación de la acción que, habiendo traspuesto ya hace tiempo los límites de la ciencia económica en donde tuvo su origen, ha penetrado las demás ciencias sociales llevando a cabo valiosos esfuerzos en la descripción, explicación y predicción de las accion individual a partir de la determinación de un criterio normativo de racionalidad: la maximización de la utilidad esperada por el agente.

Personalmente coincidiré en gran medida con esta teoría, pero me permitiré hacerle dos críticas, una en el plano de la propia teoría y otra a sus intentos por abarcar a la acción moral. Así, tomando en cuenta tales críticas, procuraré encontrar un modelo general abarcativo que integre la teoría de la elección racional con algunas contribuciones personales a la interpretación de la acción.

Antes de seguir, nótese que la distinción entre racionalidad del discurso y racionalidad de la acción se corresponde con la conocida división entre racionalidad teórica y práctica, áreas en las que por lo general se divide al estudio del tema. Además, téngase claramente en cuenta que si bien en la primera parte se hablará de acciones de individuos, en la segunda se hará una estricta analogía con 
las acciones de política exterior de los estados y demás actores internacionales, de modo tal que el lector debe estar prevenido de que las referencias a las acciones de los individuos tendrán correspondencia con las relativas a las de los actores de la comunidad internacional. Así como la acción y el discurso de los actores sociales constituyen la empiria propiamente dicha de las ciencias sociales en general, la acción y el discurso de los actores de la sociedad internacional contemporánea, constituyen la empiria propiamente dicha de un estudio científico de las relaciones internacionales en particular. Si como sostiene Habermas (1985), el papel de la filosofía es el de constituirse en guardiana de la racionalidad, mi trabajo será en gran parte una manifestación de dicho papel en el terreno de las relaciones internacionales.

\section{2- La teoría de la elección racional.}

\subsection{1- Características principales.}

En lo que sigue voy a intentar hacer una exposición de los principales supuestos de la teoría de la elección racional (Rational Choice). Dicha exposición, necesariamente parcial, tendrá un carácter introductorio y se orientará a definir las nociones esenciales sobre las cuales me apoyaré para proceder, en los siguientes capítulos, a elaborar un punto de vista personal sobre la acción individual y colectiva.

El estudio de la racionalidad de la acción del individuo ha alcanzado su mayor grado de complejidad a partir del desarrollo de la teoría de la elección racional. Como ya se ha señalado, la teoría tiene su origen en la economía, más precisamente en el análisis de la acción de los agentes económicos, lo que no resulta extraño si se tiene en cuenta que es en el terreno de las acciones con intereses económicos donde la imposibilidad de distinguir entre acciones racionales e irracionales o, más concretamente, el hecho de efectuar una acción irracional, se traduce casi inmediatamente en costos monetarios contantes y sonantes. Lejos de conformarse con sus logros de teoría económica, la Rational Choice se ha expandido hacia las demás disciplinas sociales con el ambicioso objetivo de establecer un marco interpretativo general para la explicación, descripción y predicción de la elección de la acción de un individuo en relación a su situación específica.

El modelo de la elección racional basa sus principales conclusiones en la que se conoce como teoría estricta o restringida de la racionalidad, teoría que intenta explicar la acción individual y colectiva apelando exclusivamente a motivaciones individuales egoístas orientadas al resultado. En la interpretación restringida de la racionalidad se estipula que las preferencias del agente deben cumplir el requisito de consistencia, es decir, deben satisfacer las condiciones de integridad y transitividad. Al respecto, los teóricos de la elección racional sostienen la necesidad de consensuar una teoría amplia o extendida de la racionalidad en la que el juzgamiento de la racionalidad de la acción no se limite a reclamar la consistencia de las preferencias, sino que también exija que éstas involucren un concepto de racionalidad con un sentido más sustancial, moral o social, a partir del cual la acción no egoísta pueda ser explicada. Los intentos en ese sentido han sido infructuosos, como se mostrará más adelante, por lo que la fuerza de la teoría ha quedado más bien limitada a la interpretación, desde la perspectiva de la racionalidad restringida, de la acción estratégica egoísta. Desde ya debe dejarse bien en claro, a fin de evitar falsas interpretaciones, que esto no implica que se niegue la existencia o la importancia de aquellas acciones orientadas en criterios no estratégicos individualistas tales como la acción moral o la acción expresiva, a las que se busca integrar. Tampoco debe entenderse que la teoría de la elección racional o en mi modelo a apoyarse en ella toman al hombre como a una máquina racional infalible. Por el contrario, se trata de caracterizaciones teóricas, de simples modelos que, adoptando un racionalismo crítico moderado y a partir de herramientas como la lógica o las cuantificaciones propias de la teoría de los juegos, procuran interpretar no sólo la acción racional sino también la irracional (para hablar de lo irracional se debe definir previamente qué es lo racional). Tales modelos se ocupan de analizar aquellas acciones racionalizables o susceptibles de ser racionalizadas con el objeto de echar luz a temas como el del paso del conflicto a la acción cooperativa. De esto no se deduce que el individuo 
se comporte o deba comportarse constantemente de manera racional, ni que se le quite valor a las conductas motivadas por la pasión o la necesidad expresiva (a menos que se den en situaciones que sí requieran de una conducta racional, como en la aplicación de una política a nivel nacional o internacional). Los individuos se conducen a menudo de forma irracional y emocional, pero a los efectos del análisis teórico, la teoría de la elección racional supone un comportamiento racional simplemente debido a que encuentra metodológicamente provechoso a este presupuesto . Si se supusiera que los comportamientos humanos son esencialmente emotivos, neuróticos, psicóticos o absurdos, entonces no sería posible ninguna teoría social.

Por último, debe aclararse también que así como el individuo habla sin ser conciente de la estructura del lenguaje, éste puede llevar perfectamente a cabo una acción racional (y en consecuencia conciente) sin tener conciencia de la forma en que se estructura dicha acción racional, forma que tanto el modelo de la teoría de la elección racional como el mío procuran desentrañar a partir de un distanciamiento analítico que pretende describir los elementos que llevan a que actuemos como actuamos.

Una vez hechas las anteriores advertencias, podemos introducirnos más profundamente en las características de la teoría de la elección racional tomando como referencia los artículos de Harsanyi (1977) y de Naishtat (1992).

Según Harsanyi, el modelo de la Rational Choice ha logrado reemplazar la noción de sentido común acerca de la racionalidad de la acción, por otra más general, más precisa, y conceptualmente mucho más rica, por una noción de racionalidad de "implicaciones filosóficas significativas". Esto es así debido a que en la formación de la teoría de la elección racional convergen cuatro niveles de estudio de la racionalidad de la acción.

a) El nivel de sentido común o concepto medios-fines de la racionalidad.

En este nivel la acción de un agente se considera racional cuando y sólo cuando se dota de los mejores medios para alcanzar un fin dado (tal sería su criterio de racionalidad). Como señala Harsanyi, en la vida cotidiana, cuando se habla de "comportamiento racional", en la mayoría de los casos se está pensando en un comportamiento que comprende la elección de los mejores medios disponibles para acceder a un fin dado.

El concepto medios-fines de la racionalidad ya se halla definido en la teoría de la acción de Aristóteles, a quien volveré a referirme en la presentación de mi propio punto de vista.

b) El nivel preferencias-oportunidades.

El concepto medios-fines de la racionalidad no resulta suficiente para explicar los cambios de fines. Para hacerlo, la teoría económica introdujo un concepto más amplio de racionalidad que define a la conducta racional como una elección entre fines alternativos, sobre la base de un conjunto dado de preferencias y un conjunto dado de oportunidades (es decir de posibles alternativas). Los cambios de fines se explican a partir de un conjunto estable de preferencias. Si el agente elige un fin dado, entonces tiene que abandonar fines alternativos. Por ejemplo, si la preferencia de un individuo es acceder a un nivel superior de educación, puede optar por inscribirse en una universidad privada o pública (si no tiene dinero para la cuota), o bien hacer un curso de nivel terciario. En esta forma, tres fines diferentes se explican a partir de una misma preferencia estable.

Abandonar los fines alternativos es el costo de oportunidad que el agente paga por perseguir un fin específico. Por lo tanto, en este nivel, la acción racional consiste en elegir el fín específico que implique el menor costo de oportunidad, después de hacer una cuidadosa consideración de los costos de oportunidad relativos a la elección de los distintos fines contenidos en la preferencia.

Se observa que el modelo preferencias-oportunidades subsume el modelo medios-fines. 
c) El modelo Bayesiano de decisión paramétrica.

La teoría económica ha demostrado que si el conjunto de preferencias de un agente satisface ciertos requisitos (transitividad, completitud, no inconmensurabilidad, preorden, continuidad), entonces este conjunto de preferencias puede representarse mediante una función de utilidad que asocia un número real a cada preferencia. Siguiendo el ejemplo anterior, se supone que el agente puede por caso asignar un valor 3 de utilidad al acceso a estudios universitarios, un valor 2 a los estudios terciarios y un valor 1 a los cursos de capacitación. De acuerdo con esto, la conducta racional del agente definida por el modelo preferencias-oportunidades sería equivalente a la maximización de utilidades, es decir, a la maximización de la función de utilidad. Este criterio de racionalidad de la acción es aplicable al análisis de la conducta humana bajo certeza, en condiciones en las que el agente puede predecir inequívocamente el resultado de las acciones que puede efectuar (al menos como una aproximación). Pero no es sino en este tercer nivel que la teoría extiende el análisis a la acción humana bajo riesgo y bajo incertidumbre. Ambos, riesgo e incertidumbre se refieren a situaciones en las que el agente no puede predecir de manera inequívoca los resultados de su acción, sino sólo a partir de la atribución de probabilidades objetivas (riesgo) o subjetivas (incertidumbre) a aquellos estados de cosas de los que no se tiene una información completa. De manera que en caso de riesgo o de incertidumbre no basta con referirse a utilidades sino a utilidades esperadas.

Por lo tanto, la principal conclusión de la teoría de la decisión Bayesiana es proponer como criterio más abarcativo de racionalidad, incluyendo a la acción bajo riesgo y bajo incertidumbre, a la maximización de la utilidad esperada, que será en definitiva, como ya se adelantó, el criterio de racionalidad de la acción adoptado por la teoría de la elección racional.

Se tiene que los dos niveles anteriores de racionalidad (medios-fines y preferencias-oportunidades) resultan ser ahora casos particulares del modelo Bayesiano de decisión paramétrica.

\section{d) La teoría de juegos.}

El modelo anterior requiere todavía de un paso suplementario de generalización. En efecto, los agentes racionales no sólo toman sus decisiones en un entorno natural de riesgo e incertidumbre, sino que además se mueven en un entorno social, es decir, orientan sus acciones en función de las posibles acciones de otros agentes racionales, sabiendo que estos últimos hacen lo mismo. En esta situación, denominada situación de juego, la decisión paramétrica no es más que un caso particular, aquél en el que el otro es la naturaleza, actuando exclusivamente al azar. Pero cuando los otros son unidades de decisión racionales, es decir orientadas por la regla de la maximización de la utilidad esperada, se vuelve posible anticipar la conducta de los agentes a partir de los análisis de la teoría de juegos a los que recurre la teoría. Dichos análisis permiten en principio, y a partir del estudio de matrices en las que se especifican las utilidades alternativas a los distintos cursos de acción posibles en el "juego", descubrir la solución de ese juego y, en base a ella, explicar y predecir las estrategias de los "jugadores", suponiendo que estos actúan de manera racional (de acuerdo al criterio de la maximización de la utilidad esperada).

La teoría de juegos se ubica en el nivel más abarcativo de la interpretación de la acción, constituyendo el núcleo de la teoría de la elección racional. Sus inicios se remontan a la década del veinte, cuando el matemático Emile Borel trazó algunas de sus ideas fundamentales, pero no es sino hasta la aparición del trabajo de von Neumann y Morgenstern (1944) que adquiere notoriedad. Desde ese momento, la teoría de juegos ha ido mejorando sus planteos y ampliando su campo de aplicación, transformándose en una difundida y aceptada teoría interpretativa de la conducta racional de dos o más unidades de decisión en interacción recíproca.

Según Elster (1982), el éxito de la teoría de juegos consiste en su capacidad de abarcar simultáneamente tres conjuntos de interdependencias que impregnan la vida social: 
1) La recompensa de cada agente depende de la elección de todos, es decir, no sólo de su propia acción sino también de las acciones elegidas por los demás actores que intervienen en el juego.

2) La recompensa de cada agente depende de la recompensa de todos los agentes intervinientes en el juego, debido a que se supone que todos eligen de manera de maximizar su recompensa.

3) La elección de cada agente depende de la elección de todos. Cuando un agente elige una acción, debe tomar en cuenta lo que harán los demás, ya que una acción que es óptima frente a un conjunto determinado de acciones o estrategias adoptadas por los demás no es necesariamente óptima frente a otro conjunto. "Para llegar a una decisión, el actor tiene, pues, que prever las decisiones de los otros, sabiendo que estos tratan de prever las de él" (Elster 1982:41).

Elementos fundamentales de la situación de juego son la información disponible por los jugadores y su posibilidad de diálogo, factores que toman relevancia a la hora de definir las diferentes clases posibles de juegos. En ese sentido, la teoría distingue entre juegos con información completa e incompleta, con información perfecta e imperfecta, cooperativos y no cooperativos, así como entre juegos de suma cero y de suma no nula. Más adelante, a medida que vaya siendo necesario, se analizarán las características de los mencionados juegos y se profundizará sobre otros conceptos importantes de la teoría.

\subsection{2- Una crítica a la teoría de la elección racional.}

Tanto el neorrealismo como el institucionalismo, los enfoques más actualizados en el terreno de estudio de las relaciones internacionales, tienden a incorporar a la teoría de la elección racional de manera acrítica. En contraste con esto, en el presente punto me permitiré llevar a cabo una serie de observaciones a dicha teoría de las que se derivará, en el siguiente capítulo, un modelo un tanto diferente y a mi entender más comprensivo de la acción y su racionalidad que será aplicado, en la segunda parte, a la interpretación de la acción de los actores internacionales. En ese sentido, las mencionadas observaciones se referirán a las dos áreas en las que la teoría de la elección racional ha recibido objeciones, al ámbito de la acción estratégica (al de la teoría propiamente dicha) y al ámbito de la acción moral (a los intentos de la teoría de extender sus postulados a la interpretación de la acción ética).

\section{1) Una crítica en el plano estratégico.}

Las principales críticas que la teoría de la elección racional ha recibido en relación a su interpretación de la acción estratégica hacen referencia a la complejidad que aparece en los cálculos cuando se cuenta con gran cantidad de variables y más de dos agentes, a la dificultad en la cuantificación de utilidades y probabilidades subjetivas y a la consecuente tendencia a la simplificación y al falseamiento de los problemas. Según esta crítica, el individuo no actúa normalmente como supone la teoría, ya que no dispone en todo momento de una configuración clara y simultánea de todas las alternativas a su alcance. En ese sentido, los numerosos trabajos de Herbert Simon introducen la noción de "racionalidad limitada", a la vez que sustituyen el concepto de "maximización" por el de "satisfacción". Los agentes, según Simon, no cuentan con una matriz que dé cuenta de todas las alternativas disponibles, de las cuantificaciones de valor de cada una y de las evaluaciones de probabilidad respectivas, sino que examinan las distintas alternativas secuencialmente hasta que llegan a una que responde a sus patrones mínimos de aceptabilidad. Es decir, Simon sugiere que el agente no busca la alternativa de maximización sino que rechaza las soluciones insatisfactorias hasta que llega a una lo suficientemente satisfactoria para permitirle actuar. Steinbruner (1974) va más allá en su crítica a la teoría utilitaria clásica del actor racional. Su teoría "cibernética" de la decisión sostiene que los individuos normales se desempeñan de manera adaptativa, simplificando situaciones complejas, controlando un pequeño conjunto de variables 
críticas y reduciendo la incertidumbre por medio del control de estas variables dentro de límites satisfactorios, sin recurrir a cálculos elaborados.

La teoría de la elección racional ha respondido a las críticas planteadas por estos enfoques señalando la vaguedad de sus conceptos, en especial de el de "satisfacción". Elster (1986) afirma que tales posiciones no explican cómo hacer para definir los niveles de aspiración mínimos (de satisfacción de los agentes), ni cuáles variables deben ser dejadas de lado en cada situación, dificultades que debilitan sobremanera su interpretación de la acción racional. En todo caso, los enfoques señalados no son inconciliables con la teoría de la elección racional, sino que resultan complementarios con ella. La teoría de la elección racional representa un modelo más abarcativo, complejo y sofisticado de la interpretación de la acción, lo que no implica que en la vida cotidiana, en situaciones de incertidumbre en las que el agente no pueda cuantificar utilidades $o$ probabilidades, o bien en problemas de gran complejidad de cálculos, el agente no proceda según criterios de racionalidad más simples, ya sea desistiendo de la consideración de la estrategia de los demás (según una racionalidad paramétrica independiente de la teoría de juegos) o bien adoptando conciente o intuitivamente criterios como el de la racionalidad limitada o el de la simple racionalidad medios-fines del sentido común (todos subsumidos por el más amplio criterio de la maximización de la utilidad esperada en una situación social). En ese sentido, en el capítulo 2 pretenderé hacer un aporte a la teoría de la acción que enriquezca la interpretación de la teoría de la elección racional respecto de la descripción, explicación y predicción de la acción del individuo en situaciones de riesgo o incertidumbre.

En relación a la teoría de juegos propiamente dicha, la teoría de la elección racional ha reconocido, junto con el resto de las disciplinas sociales y como se señaló en la introducción, sus dificultades y riesgos. Así, ha sabido canalizar su aplicación al estudio de temas en los que resulta valiosa y relevante, sobre todo al análisis del conflicto y la cooperación en el que tanto las opciones (cooperar o no cooperar) como los actores ("yo" y "cualquier otro") pueden ser reducidos a dos.

\section{2) Una crítica en el plano moral.}

El segundo conjunto de críticas a la teoría de la elección racional se refiere a las dificultades que ésta ha afrontado en su intento de extender su criterio normativo a la interpretación de la acción ética o moral.*

Tal como se adelantó, una de las características del modelo de la Rational Choice es su tendencia a expandirse fuera de la economía abarcando a las demás disciplinas sociales. El traslado de dicho modelo del ámbito de la acción económica al de la acción humana en general plantea sin embargo, una serie de dificultades entre las cuales resalta la justificación dentro de la teoría de aquellas acciones llevadas a cabo en contemplación de principios éticos y de normas morales y legales derivadas de ellos. Al respecto, debe distinguirse claramente la expresión "dimensión normativa de la racionalidad" (la inherencia al concepto de racionalidad de un criterio que permita distinguir entre acciones correctas e incorrectas), de la de "racionalidad de las normas" (el intento de aplicar ese criterio a las acciones efectuadas con respeto a distintos tipos de normas).

Elster (1986, 1989) encara explícitamente el problema que las normas en general plantean al modelo de la elección racional. Los principios morales, así como las normas jurídicas y sociales en general constituyen ejemplos de lo que Elster toma en general como normas sociales orientadoras de la acción. Es en este sentido que Elster (1986) presenta a la "teoría de las normas sociales" como una de las alternativas posibles para:

a) Completar la teoría de la elección racional.

b) Reemplazar a la teoría de la elección racional.

En lo que concierne a la primera opción, habría dos maneras de completar o conciliar las teorías nombradas: 
a1) Insertar las normas como constricciones constitutivas del mundo del agente.

a2) Integrarlas a las preferencias (las funciones de utilidad) de los agentes.

Tanto en a1 como en a2 se tropieza, no obstante, con dificultades. Con respecto a a1, si las normas se consideran constricciones de los estados de naturaleza, no se puede explicar la libertad inherente al agente de llevar a cabo acciones que violen su propia norma. Esta libertad, sin embargo, es un dato constitutivo de la noción de norma, en tanto que la misma implica un acatamiento voluntario por parte del agente. Por lo tanto, con la solución al el modelo no podría explicar la verdadera cuestión a resolver, la de por qué los agentes acatan las normas en ciertas circunstancias pero no en todas.

Más atractiva resulta a mi juicio la alternativa a2, es decir el intento de incluir los principios morales dentro del conjunto de preferencias. La consideración de un principio moral llevaría en ese caso a un reordenamiento de las preferencias (a preferir la cooperación al egoísmo, por ejemplo) sobre las que se aplica el criterio estratégico. Sin embargo, esto no sirve para explicar, por ejemplo, la acción del agente moral no egoísta que actúa por deber, aún en contra de sus preferencias individuales. La acción solidaria de quien prefiere la solidaridad es estratégica, aunque satisfaga cierto criterio moral no está estrictamente orientada por dicho criterio, sino por las preferencias estratégicas de tal agente. Además, los casos de acciones moralmente relevantes, y de los que no puede dar cuenta la teoría, son aquéllos en los que el agente deja de lado sus preferencias individuales y orienta sus pasos hacia el bien común según un criterio moral general, aunque pueda verse por ello estratégicamente perjudicado. Tal como admite Elster y como lo señala Naishtat (1992a) y (1993b), es obvio que existe una serie de acciones humanas que no están orientadas a la consecución de resultados, sino que se presentan como instancias de normas presupuestas por los agentes. La diferencia irreductible entre los planos estratégico y normativo consiste en el papel que desempeñan las consecuencias de la acción en ambos casos. Mientras en el plano estratégico las consecuencias son el sentido de la acción, en tanto ésta constituye un medio para traer un estado preferido de cosas al mundo, en el plano normativo las consecuencias son indiferentes para el agente. Los principios morales son ejemplos de tales normas, explicables más naturalmente desde criterios normativos sociales o morales que apelando a criterios estratégicos de maximización. Hay, por lo tanto, casos en que las normas son prioritarias al cálculo estratégico individual en el orden explicativo de la acción, casos en que las normas ejercen un poder independiente, no reductible a un ajuste utilitario de costos. "Quien obedece a una pauta normativa no está dispuesto a considerar las alternativas a la norma como si se tratase de preferencias de menor rango. $\mathrm{O}$ bien las alternativas a la norma se desechan en bloque, o bien lo que rige la acción no es una norma" (Naishtat 1993b). En rigor, si una acción está gobernada por una norma, ninguna expansión del conjunto de preferencias del agente debiera alterar esa conducta. Además, toda reducción de sus posibilidades de cumplir con la norma debería dejarlo ante la imposibilidad de prever el curso futuro de su acción. Estas dos últimas características son incompatibles, sin embargo, con la representación de las preferencias por una función continua de utilidad.

La alternativa que le quedaría a la teoría de las normas sociales sería la que se llamó b, es decir la de sustituir, en la elección de la acción, a la teoría de la elección racional. Sin embargo, Elster rechaza de plano esta posibilidad argumentando que existen innumerables ejemplos de conductas tradicionales descartadas cuando se presentan oportunidades que el individuo encuentra que sirven mejor a sus metas. No obstante, no menciona a la conducta moral. En cuanto a los casos en que la recurrencia a las normas permite explicar acciones en las que la elección racional falla, Elster señala que esta recurrencia tiende a ser "ad hoc y ex post facto", por lo que la acción en base a normas (incluyendo a los principios morales), refractaria al modelo de la elección racional, sería irrelevante para la empiria social a pesar de las evidencias en contrario. En El cemento de la sociedad (1989), el pensamiento de Elster asume una posición más proclive a tratar este tipo de conductas como empíricamente relevantes. Allí atribuye a las normas sociales el papel de motivaciones no racionales de la acción cooperativa. No me parece que éste sea un enfoque correcto, sobre todo para las normas o principios morales para las que la ética ha elaborado numerosos criterios de 
racionalidad moral. Sin embargo, tampoco me parece que haya motivos para "sustituir" la teoría de la elección racional por una teoría de las normas, sino que bastaría con que esta última complementara a la primera. Decimos "complementar" y no "completar" internamente como planteaba Elster en la alternativa a), es decir, se sumaría una tercera opción a las sostenidas por el autor. A propósito de esto, la sociología empírica recoge tres formas de cumplimiento de las normas:

a) El cumplimiento de la norma por imitación.

b) El cumplimiento de la norma por mero temor a un castigo.

c) El cumplimiento de la norma por "internalización", por hallarla razonable y justa.

En el primer caso, característico de las normas y costumbres sociales, puede alegarse la interpretación de Elster (1989), es decir, atribuirles el carácter de motivaciones irracionales de la acción cooperativa. En el segundo caso, característico de la obediencia a normas jurídicas, la acción de seguir la norma es netamente racional y estratégica. En el caso c), típico de la acción en base a normas o principios morales, el agente también actúa de manera racional (razonada, fundamentada), pero no de manera racional estratégica, sino a través de una forma de racionalidad ligada a la justicia y no a las consecuencias de la acción, es decir, a partir de un criterio de racionalidad moral. De modo que aquí adquiere relevancia el análisis de la racionalidad de la acción en base a normas o principios morales, antes que el de otro tipo de normas. La acción moral, en obediencia a normas o principios morales, tiene su propia forma de racionalidad.

En lo que respecta a la acción guiada por normas jurídicas o legales, ésta podrá explicarse o bien en términos de cualquier acción estratégica (en el caso de que su respeto se deba al deseo de evitar las sanciones subsecuentes de la transgresión de la norma), o bien como una acción moral (en el caso de que su respeto se deba a la creencia en el valor moral contenido en la norma jurídica). Una ley puede obedecerse por temor a la sanción derivada de su incumplimiento o bien por el convencimiento en su justicia.

Habiendo dejado de lado las sugerencias de Elster, examinemos ahora brevemente algunas conclusiones que sobre la acción gobernada por normas y principios, elaboran Amartya Sen (1982) y John Harsanyi (1977) en la misma compilación de Elster (1986).

Para Sen, en acciones tales como el voto no obligatorio, la disciplina ecológica o la productividad en el trabajo, en las que el control recíproco del cumplimiento de acuerdos vinculantes de cooperación es inverosímil, los agentes suelen actuar como si estuviesen maximizando la utilidad colectiva antes que la individual. La explicación que el autor presenta de esta conducta maximizadora global apela precisamente a las normas. En las circunstancias de las acciones mencionadas, los agentes producirían una suspensión de la racionalidad estratégica individual y orientarían sus conductas por normas. Según Sen, esto no significaría que los agentes cambien sus preferencias, sino la regla de acción. Cabría preguntarse por qué harían tal cosa y sobre qué criterio, si existiera alguno, se inspirarían esas normas.

Paso ahora a Harsanyi (1977), quien sostiene que los juicios de valor moralmente racionales llevan implícitos la maximización del nivel de utilidad promedio de todos los individuos de la sociedad. Mientras la teoría de juegos es una teoría sobre intereses individuales conflictivos, la ética sería la teoría de los intereses comunes de la sociedad en su conjunto. De este modo, Harsanyi tanto como Sen introducen la ética utilitarista en el modelo.

Se tiene que la alternativa Sen-Harsanyi consiste en tomar al individuo moral como a aquel que en determinadas circunstancias deja de lado la maximización de sus utilidades individuales a cambio del criterio moral utilitarista de la maximización de la utilidad colectiva (la utilidad promedio de los individuos de la sociedad). Antes de seguir hay que dejar en claro la diferencia entre la segunda de las opciones sugeridas por Elster para completar la teoría de la elección racional con una teoría de las normas (opción a2), y esta nueva alternativa: una cosa es la inclusión de principios morales en 
las preferencias, o lo que es lo mismo, la aplicación de un criterio moral (universalista, utilitarista, particularista, religioso o de otro tipo) en la ordenación de las preferencias a ser consideradas en la aplicación del criterio estratégico, mientras que otra cosa es la aplicación de un criterio moral a un conjunto de preferencias individuales previamente dado, en reemplazo del criterio estratégico individual. Teniendo en cuenta las numerosas objeciones a la inclusión de los principios dentro de las preferencias, la alternativa de Sen-Harsanyi consiste en tomar como criterio moral aplicable a las preferencias dadas al criterio moral utilitarista, extendiendo el criterio estratégico de la maximización de la función de utilidad individual, a la función de utilidad social. De manera que, según se deriva de estos autores, los agentes tendrían una doble función de utilidad, el agente estratégico maximizaría la utilidad individual pero en ciertas circunstancias la dejaría de lado para tomar la utilidad social. En este sentido, la alternativa Sen- Harsanyi sería un intento de complementar la teoría de la elección racional por medio del utilitarismo ético. Desde esta interpretación, el agente moral puro sería el que en todos los casos se refiriera a la utilidad social.

Creo, sin embargo, que si bien el criterio de la maximización de la utilidad esperada resulta adecuado como base para un estudio empírico del amplio espectro de las acciones estratégicas, no lo es para el de las acciones morales. La alternativa Sen-Harsanyi es susceptible de todas las fuertes y fundadas críticas hechas al utilitarismo moral. Todo utilitarismo recae en lo que aparece como una de las confusiones conceptuales más difundidas de la época contemporánea: la identificación entre utilidad y valor, la corriente asociación de lo útil con lo bueno y de lo inútil con lo malo o carente de valor. Sin embargo, es evidente que existen tanto acciones buenas pero inútiles (la acción del filósofo o la del artista), como malas y útiles (el homicidio por dinero). En ese sentido, todos coincidimos en calificar de morales a acciones tales como ayudar a un enfermo o cumplir una promesa, acciones que no siempre resultan útiles para el agente ni para la sociedad en su conjunto. La "solución final" de Hitler al "problema judío" o la matanza indiscriminada de niños musulmanes a manos del ejército servio- bosnio constituyeron acciones moralmente repugnantes, pero no estratégicamente irracionales. En ambos casos existía un fin preciso (la eliminación de los judíos del Tercer Reich, el terror y la desaliento del enemigo en la antigua Yugoslavia), que se trató de conseguir por medio de una acción considerada como la más adecuada (maximizadora de la utilidad) para el logro de tales propósitos en las referidas situaciones estratégicas. La extensión del criterio de la racionalidad estratégica al terreno de la acción moral, en la forma del utilitarismo ético, puede llegar a la justificación moral de las acciones referidas en los anteriores ejemplos: tanto los nazis como los irregulares servios habrían obrado en defensa de los intereses comunes de la "nación germana" o del "pueblo servio", maximizando lo que ellos consideraban la utilidad promedio de estos colectivos. Cuesta, sin embargo, calificar tales acciones como racionales, ya que uno se da cuenta intuitivamente de su inadecuación moral. Como señala Hidalgo (1993), "encontramos ejemplos de acciones intuitivamente renuentes a ser consideradas prima facie racionales (...), en aquéllas que conciernen a las violaciones a los derechos humanos, a la tortura, al asesinato, que tan cómodamente pueden "racionalizarse" en términos de metas y creencias de sus agentes y que, sin embargo, parecen exigir una revolución que las descalifique". Todo lo cual conduce a reafirmar la consideración de la racionalidad en dos dominios distintos, el estratégico y el ético, con criterios también diferentes y muchas veces contradictorios. En ese sentido, he aludido ya a la necesidad de lograr una teoría amplia de la racionalidad que complemente los aciertos de la teoría restringida en el análisis de la acción estratégica, con una perspectiva sustantiva de la racionalidad que incorpore el juzgamiento moral de la acción.

De manera que para poder describir, explicar, predecir y fundamentalmente justificar de manera completa una acción, no alcanza con extender el criterio estratégico a la utilidad social, sino que se debe contar necesariamente con otro tipo de criterio normativo moral. La alternativa Sen-Harsanyi no es inherente a la teoría de la elección racional ni la única posición posible, en el terreno moral, que puede compatibilizarse con ella. De la misma manera que en el intento de incluir los principios morales dentro de las preferencias, cualquiera puede ser el criterio moral a tener en cuenta en el juzgamiento ético de la acción, y no necesariamente el utilitarista. Al respecto, los ejemplos vistos 
dejan planteada la pregunta acerca del criterio moral a adoptar. En el capítulo 7 examino distintas alternativas, así como una reflexión sobre la posibilidad de una ética política, inclinándome por los criterios sugeridos por las corrientes de la ética universalista.

Puede agregarse además que, en la medida en que un criterio normativo estratégico (a partir del cual se discierne el deber ser instrumental estratégico) así como un criterio normativo moral (a partir del cual se discierne el deber ser moral) orientan acciones en el mundo, tienen implicancias empíricas. Es decir que no sólo las acciones estratégicas sino también las acciones en correspondencia a principios morales son hechos de la realidad concreta, por lo que estarán también incluídas en la dimensión empírica (práctica) de la racionalidad. Así, podrá haber acciones que satisfagan los dos criterios, uno o ninguno. Acerca de cuál criterio deba prevalecer en aquellos casos contradictorios, me referiré en el siguiente capítulo, en el que daré mi propio punto de vista acerca de la racionalidad de la acción. En ese sentido, procuraré elaborar un modelo general que comprenda a la acción moral y contribuya a solucionar algunos de los problemas de la teoría de la elección racional. 


\section{2- Un modelo interpretativo de la acción racional individual.}

\section{1- Introducción.}

Pretenderé en el presente capítulo diseñar una teoría o modelo interpretativo de la acción del individuo y su racionalidad que sintetice mi propio punto de vista sobre la cuestión y constituya la base de apoyo para encarar, a partir de la segunda parte, un análisis original de la acción de los estados y demás actores internacionales. En procura de este objetivo tendré fundamentalmente en cuenta los aportes de la teoría de la elección racional, contando obviamente con mi crítica a ésta, así como distintas referencias al método hipotético- deductivo popperiano y al silogismo práctico aristotélico.

Debo aclarar que este capítulo constituye en realidad una versión reducida del original incluido en la presentación de mi tesis, el que comprendía además la formalización completa del modelo y el estudio de sus conexiones con otras disciplinas, aspectos que han sido separados en un Apéndice final para facilitar la tarea del lector y evitar su dispersión. En ese sentido, advierto que tanto este capítulo como el Apéndice que lo complementa constituyen los segmentos más arduos y complicados del trabajo. Sin embargo, el contenido de esta sección resulta básico para la comprensión de las ideas más importantes de la tesis, de manera que aquellos lectores que la superen se verán recompensados con un más fácil entendimiento de los sucesivos capítulos. En tanto, los lectores no familiarizados con el lenguaje de la filosofía de la acción y que puedan llegar a tener inconvenientes en la lectura no deberán desalentarse, ya que tendrán oportunidad de ver reiterados y aclarados la mayoría de los conceptos a lo largo de todo el trabajo.

\section{2- La construcción del modelo.}

\subsection{1- Condicionalidad de la acción racional estratégica.}

Jon Elster comienza la primera parte de su Introducción a Rational Choice ("La naturaleza y alcance de la teoría de la elección racional") de la manera siguiente: "La teoría de la elección racional es, antes que nada, una teoría normativa. Ella nos dice qué debemos hacer para alcanzar nuestras metas de la mejor manera en que sea posible. No nos dice cuáles deben ser nuestras metas."..."la teoría de la elección racional ofrece imperativos condicionales, concernientes a los medios antes que a los fines" (Elster 1986:1). El mismo autor también sostiene en otro lugar que "la acción racional está orientada hacia resultados"..."La racionalidad es esencialmente condicional y está orientada hacia el futuro". "Sus imperativos son hipotéticos, es decir, condicionales sobre los futuros resultados que uno espera alcanzar" (Elster 1989:120).

En el terreno de la conducta estratégica, coincido totalmente con estas afirmaciones de Elster que, por otro lado y tal como se ilustra en el Apéndice, concuerdan con las intuiciones aristotélicas fundantes de la filosofía de la acción. La teoría de la elección racional y la teoría de juegos en particular pueden ayudar a comprender una acción relativa a una situación estratégica complicada, pero no deben hacer perder de vista el carácter condicional medios-fines de la racionalidad del sentido común, que no desaparece por el hecho de que el agente tome en cuenta, en la elección de su acción (medio), a las acciones de los demás individuos involucrados en su situación.

Actuar racionalmente significa, en el terreno estratégico, elegir la mejor de entre las distintas acciones posibles en una situación dada. El individuo elabora, adopta y descarta permanentemente distintas "hipótesis de acción", proposiciones condicionales del tipo "Si estoy en una situación $\mathrm{S}$, entonces debo efectuar la acción A", que vinculan su situación específica con una acción elegida de entre las distintas alternativas, tanto en la más elemental situación instrumental como en la más compleja situación estratégica. Respecto del "deber" estratégico presente en los imperativos hipotéticos que conforman las hipótesis de acción hay que aclarar que su sentido equivale al de "ser estratégicamente bueno", adecuado, correcto, apropiado a la situación del agente. Precisamente, la 
manera en que el agente decide una acción estratégicamente adecuada a su situación es, como se señaló, a través de la referencia a un criterio normativo estratégico de racionalidad. Por lo tanto, puede ensayarse el inicio de la construcción de la forma lógica de una hipótesis de acción de la siguiente manera:

CE

$\mathrm{S}$ a ----> A a

Siendo: a: agente individual.

S: predicado "encontrarse en una situación S".

CE: criterio normativo estratégico.

A: predicado "efectuar la acción A".

De acuerdo a estas definiciones, el condicional puede leerse así: "Si a es un agente en una situación $\mathrm{S}$, entonces, según el criterio estratégico $\mathrm{CE}$, resulta adecuado que a efectúe la acción $\mathrm{A}$ ".*

\subsection{2- La situación del agente.}

Todo individuo es un individuo en situación. Las características de cada situación pueden ser esquematizadas de acuerdo a una serie de factores que la definen, constituyendo en cada caso lo que desde Anscombe (1957) se conoce como "descripción" de una acción. La siguiente enumeración y descripción de los referidos factores característicos de la situación tenida en cuenta por el agente me permitirá avanzar en la construcción de mi modelo.

a) En primer lugar, el individuo cuenta con un conjunto $\mathrm{C}$ de creencias, resultado de su historia $\mathrm{y}$ experiencia personal, y que incluye la realización de acciones en las más variadas situaciones, similares o disímiles a la que se le presenta.

b) El individuo experimenta una serie de deseos y aspira a ciertos fines, todo lo cual puede subsumirse diciendo que cuenta con un conjunto $\mathrm{P}$ de preferencias. Las preferencias, así como en general toda la caracterización de la situación, reflejan la cosmovisión del agente, el sentido que atribuye a sus acciones en el "mundo de la vida" del que habla la filosofía alemana.

c) Para realizar sus preferencias, el individuo puede optar llevar a cabo cualquier acción Ai, de un conjunto A de acciones posibles.

d) El individuo tiene a su disposición un conjunto $\mathrm{M}$ de medios materiales, que de por sí acotan el rango de acciones posibles. Al respecto, debe distinguirse entre la acción como medio y los medios materiales disponibles para su concreción: cuando alguien dice que "quien quiere el fin quiere los medios", los medios a los que se refiere son tanto las acciones como los medios materiales necesarios para llevarlos a cabo, en cambio, cuando para predecir la acción de un individuo o de un estado se recomienda "tener en cuenta las intenciones más que los medios, ya que es difícil tener intenciones si no se tienen los medios", la referencia es a los medios materiales necesarios para la acción. "Querer es poder" es un lindo proverbio, pero comprobadamente falso. Se pueden tener los deseos, pero sin los medios materiales necesarios será imposible la acción que los satisfaga, lo que no descarta que la persistencia en sus intenciones pueda conducir al agente a conseguir satisfacerlas "por otros medios" (otras acciones que involucren a su vez otros medios materiales). En cuanto a la frase que dice "Deber implica poder", si en un adelanto al siguiente punto se la traduce como "Efectuar una acción correcta (adecuada, apropiada) en una situación dada implica poder hacerlo", resulta corroborada por esta interpretación. Para que alguien efectúe una acción apropiada en una situación dada, debe tener el poder de hacerlo, es decir, no sólo la voluntad, sino también los medios y condiciones materiales necesarios. Por ejemplo, si se tiene el deseo de viajar de una ciudad a otra puede optarse entre viajar en avión, tren o automóvil, sin embargo, si no hay líneas férreas que las unan la acción "ir en tren" está de por sí descartada. A su vez, esto también coincide 
con la caracterización de la deliberación hecha por Aristóteles, quien afirma que "se delibera sobre los medios pero no sobre los fines" y que "se delibera sobre lo posible". Es decir, se delibera sobre los medios (las acciones) pero no sobre cualquiera sino sobre los medios posibles (las acciones posibles a partir de los medios materiales disponibles).

Se tiene que el contenido de los conjuntos C, P, M, y A define una determinada descripción de una acción. Cuando el agente lleva a cabo la acción, lo hace a partir de su propia descripción. No obstante, un observador externo que no conozca las intenciones del agente podrá explicar la misma acción a partir de descripciones distintas. Agréguese que, tal como se adelantó, la situación problemática en la que se encuentra el agente que decide la acción puede ser estratégica, en el caso en que sea necesario considerar la racionalidad de otros individuos implicados en la situación, o meramente instrumental (paramétrica), en el caso en que dicha consideración sea irrelevante, como en el caso de los ejemplos aristotélicos examinados en el Apéndice. Del mismo modo, la situación (y en consecuencia la acción) puede o no tener implicancias morales, según afecte o no a terceros, circunstancia que será tenida en cuenta más adelante.

A partir de estas reflexiones, puede pasarse a enriquecer la elaboración de la forma lógica de la hipótesis de acción iniciada en 2.2.1, para lo cual servirá sintetizar formalmente la serie de conjuntos que caracterizan a la situación del agente de la siguiente manera:

a) $\mathrm{C}=\{\mathrm{C} 1, \ldots, \mathrm{Ci}, \ldots, \mathrm{Cn}\}=$ Conjunto de creencias del agente.

b) $\mathrm{P}=\{\mathrm{P} 1, \ldots, \mathrm{Pi}, \ldots, \mathrm{Pn}\}=$ Conjunto de preferencias ordenadas del agente. Como se observó en el análisis inicial de la teoría de la elección racional, el concepto de preferencia abarca a los más ambiguos conceptos de deseo, fin, intención y motivación. Las preferencias están ordenadas de acuerdo al orden de utilidad establecido por el agente, es decir fu(Pi) $>\mathrm{fu}(\mathrm{Pi}+1)$.

c) $\mathrm{A}=\{\mathrm{A} 1, \ldots, \mathrm{Ai}, \ldots, \mathrm{An}\}=$ Conjunto de acciones posibles para satisfacer las preferencias.

d) $\mathrm{M}=\{\mathrm{M} 1, \ldots, \mathrm{Mi}, \ldots, \mathrm{Mn}\}=$ Conjunto de medios materiales disponibles.

Por lo tanto, una forma más completa de formalización lógica de la hipótesis de acción es la siguiente:

$\mathrm{CE}$

S (C.P.M.A) a ----> Ai a

Siendo: a: agente individual.

$\mathrm{S}$ : predicado "encontrarse en una situación $\mathrm{S}$, definida por los

conjuntos $\mathrm{C}, \mathrm{P}, \mathrm{M}$ y A".

$\mathrm{CE}$ : criterio normativo estratégico.

A: predicado "efectuar la acción Ai".

El condicional se lee ahora de la siguiente manera: "Si a es un agente en una situación S, definida por los conjuntos $\mathrm{C}, \mathrm{P}, \mathrm{M}$ y A, entonces, según el criterio estratégico $\mathrm{CE}$, resulta adecuado que a efectúe la acción Ai".

\subsection{3- Criterio normativo estratégico de racionalidad.}

La acción adecuada a una situación dada no puede establecerse sino a partir de la referencia a cierto criterio normativo de racionalidad. Es el criterio normativo el que define qué es lo correcto o adecuado y qué es lo incorrecto o inadecuado en relación a la acción. Para Aristóteles, por ejemplo, el parámetro de racionalidad estratégica y moral era la acción del hombre prudente. La filosofía contemporánea de la acción, como se ha visto en el capítulo 1, hace referencia a una serie de criterios, entre ellos el de la racionalidad limitada, el de la racionalidad paramétrica y el de la teoría 
de la elección racional. Se observó al respecto que el criterio de maximización de la utilidad esperada propuesto por la teoría de la elección racional resulta el más abarcativo y sofisticado, y que por lo tanto ofrece mayores garantías de obtención de una acción adecuada. Sin embargo, también se hizo notar que en la vida cotidiana, en situaciones de incertidumbre en las que no se puede cuantificar utilidades o probabilidades, o bien en problemas de gran complejidad de cálculos, el agente procede según criterios de racionalidad más simples, ya sea desistiendo de la consideración de la estrategia de los demás (según una racionalidad paramétrica independiente de la teoría de juegos) o bien adoptando conciente o intuitivamente criterios como el de la racionalidad limitada o el de la simple racionalidad medios-fines del sentido común. De ahí que la propuesta de formalización lógica de la hipótesis de acción encarada en este capítulo se refiera de manera general a cualquier criterio estratégico de racionalidad. Se tiene entonces que, en particular, el modo de simbolizar una hipótesis de acción estratégica, a la que se arribara mediante el criterio de la teoría de la elección racional sería el siguiente:

ER

S (C.P.M.A) a ----> Ai a

Aquí, ER denota que la relación entre el antecedente y el consecuente de la hipótesis de acción ha sido establecida de acuerdo a la teoría de la elección racional.

Llegado este punto, resulta interesante pasar a una serie de apreciaciones relativas al carácter de la explicación de la acción ofrecida por la teoría de la elección racional.

Según Elster (1986:2), "una vez que hemos construido una teoría normativa de la elección racional, podemos empezar a emplearla para propósitos explicativos. Podemos preguntar si es que una acción dada fue llevada a cabo porque era racional". Para ello no es suficiente mostrar que la acción ha sido correcta, ya que la gente es a veces conducida por accidente o por una coincidencia a hacer lo que de hecho es mejor para ella. Debe mostrarse, además, que la acción surgió "merced a un apropiado tipo de conexión entre deseos, creencias y evidencia". Elster encara este problema en la tercera parte del artículo referido ("La estructura de la explicación de la elección racional"). Allí, define a la explicación de la acción del individuo dada por la teoría de la elección racional como una variedad de explicación intencional. La explicación intencional de la acción es aquélla que supone la existencia de un agente inteligente con una finalidad intrínseca a la acción, con una intención referida a un fin. Así como una explicación causal da las causas (q) de un fenómeno (x) en relación con una ley que expresa una relación causal comprobada ( $\mathrm{q}->\mathrm{x}$ ), la explicación intencional (pragmática) explica la acción de manera análoga, a través de sus motivos e intenciones. Una explicación intencional consiste en mostrar que el actor hizo lo que hizo por una razón, considerada causalmente eficiente para producir la acción. En ese sentido, Elster se apoya en argumentos de Davidson (1963) y (1980), en lo concerniente a la relación entre intencionalidad y racionalidad, para delinear la estrategia básica de su explicación que, como señala Barranco de Busaniche (1993), consiste en suponer al actor como racional (según el criterio de su teoría) para poder así analizar intencionalmente la acción, retrocediendo inferencialmente desde la misma hasta los deseos y creencias que la originaron. Lo dicho se adapta perfectamente a mi perspectiva, dentro de la cual la situación del agente y los elementos que la componen constituyen la causa, en sentido pragmático, de la acción. De ahí que toda explicación de una acción vaya unida a una descripción de la acción (a una tipificación de los elementos de la situación del agente), y que distintas descripciones de una misma acción puedan dar lugar a distintas explicaciones (distinta atribución de motivos e intenciones (preferencias) del agente).

Según Elster, la explicación dada por la teoría de la elección racional está definida no sólo por la explicación intencional sino también por otras relaciones adicionales. En particular, la explicación intencional aspira a demostrar la triple relación entre la acción (A), un set de creencias ("cognitions") (C) sostenidas por un individuo y un set de deseos (D) que pueden serle imputados. Esta triple relación queda definida por tres condiciones: 
1) Dado C, A es el mejor medio de realizar D.

2) $\mathrm{C}$ y D causan $\mathrm{A}$.

3) C y D causan A "qua razones" (es decir, C y D causan A de manera voluntaria y directa).

El paso de la simple explicación intencional a la explicación de la teoría de la elección racional exige, para Elster, que en primera instancia se agreguen dos condiciones de consistencia:

4) El set de creencias $C$ es internamente consistente.

5) El set de deseos D es internamente consistente.

Sin embargo, Elster no se conforma con la mera consistencia de las creencias, sino que afirma que para que una acción sea racional, las creencias en las que se sustenta deben ser racionales en el sentido de estar basadas en la evidencia disponible. Es decir:

(1 b) La creencia tiene un grado máximo de plausibilidad inductiva, dada la evidencia.

(2 b) La creencia es causada por la evidencia disponible.

(3 b) La evidencia causa la creencia "en sentido estricto".

Más adelante, Elster agrega una condición débil, acerca de la cantidad de evidencia a recolectar antes de formar una creencia:

(N) La cantidad de información a recolectar se encuentra entre los niveles inferior y superior definidos por la situación problemática, incluyendo los deseos del agente.

Se tiene entonces la sexta relación:

6) La relación entre C,D y A satisface (1 b),(2 b),(3 b) y (N).

Una última relación es tenida en cuenta para excluir el comportamiento akrático (debilidad de la voluntad de quien, juzgando una acción X mejor que una acción $Y$, elige Y por no poder resistirse a su inminente disponibilidad):

7) Dado C, A es la mejor acción respecto al set completo de deseos sopesados.

Se tiene, por lo tanto, que una acción no puede considerarse racional, para Elster, si no cumple con alguno de estos requisitos tanto desde el punto de vista de un observador objetivo como desde el agente que la ejecuta. De esto se infiere que la obediencia al criterio de maximización de la utilidad esperada no basta para afirmar la racionalidad de una acción, sino que además se deben satisfacer las condiciones antes enumeradas. El criterio normativo estratégico completo de la teoría de la elección racional puede formularse entonces como el respeto al criterio de la maximización de la utilidad dadas ciertas condiciones (las numeradas del 1 al 7 por Elster en su caracterización de la explicación dada por la teoría). En ese sentido, según Elster (1990), la acción racional involucra en realidad tres procesos de optimización: encontrar la mejor acción para deseos y creencias dados, formar la creencia mejor fundada de acuerdo a la evidencia dada y recolectar la cantidad correcta de evidencia para deseos y creencias previas.

Teniendo en cuenta las definiciones hechas al describir la situación del agente en 2.2.2, puedo arriesgarme a hacer, desde mi punto de vista, algunas modificaciones a la serie de condiciones propuesta por Elster. En ese sentido, las condiciones que propongo para complementar el criterio de la maximización de la utilidad esperada, es decir, para definir el criterio normativo estratégico completo de la teoría de la elección racional y, en consecuencia, para caracterizar el modo de su explicación, son las siguientes:

1) Dados C, P, A y M, Ai es el mejor medio de realizar P.

2) C y P causan Ai.

3) $\mathrm{C}$ y $\mathrm{P}$ causan $\mathrm{Ai}$ "qua razones". 
4) P es internamente consistente.

5) $\mathrm{C}$ es internamente consistente.

6) Ci tiene un grado máximo de plausibilidad inductiva, dada la evidencia.

7) $\mathrm{Ci}$ es causada por la evidencia disponible.

8) La evidencia causa $\mathrm{Ci}$ "en sentido estricto".

9) La cantidad de información a recolectar se encuentra entre los niveles inferior y superior definidos por la situación problemática, incluyendo las preferencias del agente.

La anterior relación 7 queda implícita ahora al tomarse, en lugar del concepto de deseos, el de preferencias.

\subsection{4- Carácter hipotético- deductivo de la acción racional.}

1) Situación subjetiva y situación objetiva.

La teoría de la elección racional y la teoría de juegos en particular han encontrado dificultades para dar cuenta de los juegos de información incompleta, aquéllos en los que a diferencia de los de información completa, al menos uno de los jugadores no tiene información total acerca de los parámetros que definen el juego, es decir, de las funciones de utilidad de los participantes, de sus distintas alternativas estratégicas, de los resultados de esas alternativas o de la información disponible de cada jugador. Sucede que en situaciones con información incompleta el agente no puede predecir de manera inequívoca los resultados de su acción. Es el caso de la situación de riesgo, cuando el agente conoce al menos las probabilidades objetivas asociadas a todos los posibles resultados, y el de la situación de incertidumbre, cuando aún algunas de las probabilidades objetivas pueden serle desconocidas. En caso de incertidumbre, la teoría de la elección racional compensa la carencia de definición en las reglas del juego modelando las incertidumbres de cada jugador como probabilidades subjetivas. Así, al asignar una probabilidad subjetiva a cada estado de cosas posible, el agente transforma un juego incompleto en uno completo, artificialmente construido, al que se le puede aplicar la teoría de la elección racional. Se tiene que, al elegir su acción, el agente racional en una situación de incertidumbre procurará maximizar su utilidad esperada, siendo ésta la utilidad del estado de cosas que juzga como más probable.

Tanto en la deliberación del hombre prudente aristotélico, como en la toma de decisiones a partir de la teoría de la elección racional, se intentan elaborar las hipótesis de acción más apropiadas en relación a la situación objetiva real del agente. Sin embargo, sólo en casos de información completa el agente conoce todas las características relevantes de su situación real. Por el contrario, en caso de información incompleta, el individuo delibera "objetivamente" (a partir de criterio objetivo de racionalidad) acerca de una situación construida de manera subjetiva. Resulta muy importante subrayar la naturaleza subjetiva de la situación de elección, ya que el hecho de que ciertas opciones se encuentren objetivamente disponibles al agente no puede ser parte de la explicación de su comportamiento si dicho agente no tiene bases racionales para creer que se encuentran efectivamente disponibles, así como tampoco puede hacerlo el hecho de que ciertas alternativas conduzcan objetivamente a ciertos resultados si el agente no tiene razones para pensar que lo harán.

Por lo tanto, es en los casos de información incompleta, especialmente en los de incertidumbre, que adquiere relevancia y sentido la distinción entre la situación subjetiva Ss a la que se refiere el agente y su situación real objetiva So que conoce sólo parcialmente. Es precisamente esta clase de casos, por lo general dejada de lado por la teoría clásica de juegos, la que aparece como más común, tanto en la acción cotidiana de los individuos como en la de los estados, y a la que voy a prestar especial atención en mi análisis sucesivo.

2) Deliberación y deducción de una acción. 
En la vida cotidiana no sucede que estemos elaborando permanentemente nuevas hipótesis de acción, sino que comunmente aplicamos las mismas hipótesis a situaciones más o menos similares. $\mathrm{Si}$, por ejemplo, deseo tomar un té a mi gusto, sé a partir de innumerables experiencias anteriores, que la acción apropiada es agregar tres cucharaditas de azúcar, sin necesidad de especular sobre otras acciones posibles (agregar más o menos azúcar). En ese caso, al elegir una acción el agente examina si las condiciones de su situación particular subjetiva se corresponden con las tenidas en cuenta en el antecedente de cierta hipótesis de acción ya deliberada contenida en su conjunto de creencias. Es decir, el agente asocia su situación subjetiva a cierta situación previamente considerada en la deliberación de una hipótesis de acción que después pasó a constituirse en una creencia asentada, para entonces "deducir" la acción que le permita lograr sus propósitos. El agente, en otro ejemplo, puede tener asimilada, en su conjunto de creencias una hipótesis que diga que aquellos días de sol en los que se goce de tiempo y salud y se disponga de espacio, es "bueno" (correcto, adecuado, apropiado) para todo hombre caminar. Incluso puede estar esperando un día en el que se cumplan dichas condiciones. En la deducción de su acción, el agente se reconoce como un individuo en esas circunstancias, advirtiendo que cierto día particular es un día soleado, que tiene tiempo, que no posee ninguna enfermedad que le impida caminar, y que, por ejemplo, no se encuentra frente a un precipicio. Una vez hecho esto, deduce que es "bueno" salir a caminar ese día.

Por lo tanto, en la elección de una acción pueden darse dos casos:

1) Cuando el agente se enfrenta a una situación nueva, se ve obligado a llevar a cabo la deliberación de la acción correcta en base a algún criterio de racionalidad.

2) Cuando el agente se enfrenta a una situación conocida, puede asimilar su situación subjetiva con alguna situación ya considerada en alguna hipótesis de acción previamente deliberada y que forma parte de sus creencias, para así deducir de manera directa (sin deliberar) la acción eventualmente correcta en su situación objetiva.

Mientras la deliberación, el caso 1, conlleva un examen racional "objetivo" de la acción a efectuar en cierta situación subjetiva, en la deducción no se delibera sino que se examina si cierta hipótesis ya deliberada resulta aplicable a la situación Ss dada.

Se tiene que, según sea el caso, es posible distinguir hasta tres perspectivas diferentes en la apreciación de la situación del agente. En la deliberación, el individuo se encuentra en una situación subjetiva Ss, consistente en el estado de cosas que juzga más probable, cuyos factores característicos, junto con algún criterio de racionalidad, serán los elementos a tener en cuenta al procurar encontrar una acción adecuada a su desconocida situación objetiva real So. En cambio, en la deducción de una acción, si bien el individuo también parte de una Ss particular, la asocia a una situación considerada Sc tenida en cuenta de manera más o menos general en una creencia, a partir de la cual infiere la acción.

Se dijo ya que todo individuo es siempre un individuo en situación. Todo individuo en situación dispone de una batería de hipótesis de acción previamente aceptadas, de creencias latentes en su memoria, a las que recurre cuando considera que su situación actual (Ss) encaja en la situación ( $\mathrm{Sc}$ ) tenida en cuenta en alguna de ellas (es decir, cuando Ss pertenece a cierta clase de situaciones abarcadas por Sc). Puede ocurrir también que la hipótesis de acción sea sostenida de manera manifiesta y presente por el agente de manera previa, y que sea conducido por ella a buscar cierto tipo de situaciones o a considerar cierta acción en una situación dada. Cuando, en cambio, se da una situación para la que no cuenta con ninguna hipótesis previamente elaborada, el agente la construye con los elementos y criterios a su alcance. Cualquiera sea el caso, luego de efectuada la acción, el agente pasa inmediatamente a encontrarse en una nueva situación, con nuevos deseos (preferencias) y circunstancias que requieren nuevas acciones.

Tómese el ejemplo de un sujeto común que elabora una hipótesis de acción que cree adecuada a su situación. Este individuo no se guía por ningún tipo de criterio de racionalidad estratégica, ni moral sino por intuición o generalización inductiva. Una vez ejecutada la acción, se tiene que ésta puede 
ser adecuada o bien inadecuada a la situación real, objetiva del agente (So). Supóngase que la acción resulta de hecho adecuada a la situación del agente. ¿Puede decirse que sea racional? La respuesta es que no. Como se señaló junto con Elster en 2.2.3, no basta que una acción sea adecuada o correcta para que sea racional ya que a partir de una deliberación irracional pueden llegar a deducirse acciones providencialmente correctas. Un vidente puede predecir lluvia al mismo tiempo que el Servicio Meteorológico pronostica sol. El hecho de que después llueva no alcanza, sin embargo, para afirmar que el vidente sea más racional que el Servicio Meteorológico.

Para que una acción pueda considerarse estratégicamente racional, su deliberación debe cumplir algún criterio de racionalidad estratégica. La apropiada aplicación de la teoría de la elección racional asegura, en los casos de información completa, la obtención de una acción estratégicamente correcta para la situación $\mathrm{Ss}=$ So. Sin embargo, en los casos de información incompleta, en los que el criterio de racionalidad de la teoría se aplica a preferencias con una probabilidad subjetivamente asignada, la acción elegida (subjetivamente racional) puede aún resultar objetivamente incorrecta en So. En general, diré que la hipótesis de acción de la que se derive una acción que en la práctica resulte adecuada a la situación So del agente quedará corroborada. ¿Qué sucede en cambio cuando la acción no responde en los hechos a las expectativas del agente, es decir, cuando no se ajusta a la situación a la que se suponía debía hacerlo? En este caso, en el que se produce una contradicción entre lo previsto por la hipótesis y sus resultados, el agente podrá refutar su hipótesis de acción y considerar una nueva. La refutación incrementará la experiencia, es decir la información del agente que, de tener una nueva posibilidad, efectuará una redefinición de la situación y referirá su acción a una nueva Ss más de acuerdo con la real So.

3) La acción y la ciencia.

Las apreciaciones anteriores constituyen el inicio de una analogía entre mi perspectiva de la acción (y la explicación) intencional y la racionalidad del discurso científico. En este punto comenzaré la continuación de tal analogía comparando dos ejemplos. En primer término, supóngase una persona cualquiera (incluyendo al conjunto de científicos) que, luego de observar y "experimentar" con distintas puertas, incorpora la hipótesis de acción "Si quiero abrir una puerta, debo bajar el picaporte", hipótesis será mantenida como creencia mientras las puertas que encuentre se abran al bajar el picaporte (en el caso de que esto no ocurra quizás la persona intente con una hipótesis nueva). En segundo lugar, tómese a un científico que observa que varios metales se dilatan con el calor e induce la hipótesis general "Todos los metales se dilatan con el calor" ("Si algo es metal, entonces se dilata con el calor"), que mantendrá dentro de su conjunto de creencias mientras no encuentre algún metal que efectivamente no se dilate con el calor. Se trata, como puede verse, de dos conductas análogas. En ambos casos, el hecho de que la realidad no se compadezca con la hipótesis supuesta como correcta, lleva a la refutación de tal hipótesis. Es decir, una hipótesis de acción se deja de lado de manera análoga a la forma en que, según el método hipotético-deductivo de Popper, se refuta una hipótesis científica si no se cumplen sus consecuencias observacionales (Popper 1935, 1972).

Llegado este punto, debe dejarse en claro que una cosa es la acción del científico (la racionalidad de la acción del científico) y otra el desarrollo de la ciencia (la racionalidad de la evolución del conocimiento científico). En cuanto a la acción del científico, ésta no se diferencia estructuralmente de la acción cotidiana. La acción instrumental correcta del científico en una situación experimental consiste en sostener o actuar conforme a una hipótesis (por ejemplo evitando diseñar con metal ciertos dispositivos expuestos al calor) mientras maximice su función de utilidad, que deberá tener como preferencia más alta el logro de explicaciones científicas (no sólo en base a relaciones causales, sino también a relaciones intencionales en el caso de las ciencias sociales). Cuando, partiendo de una creencia en una hipótesis científica y actuando en consideración a ella, el científico obtiene consecuencias inesperadas para una cierta situación experimental, éste podrá culpar a la creencia tenida en cuenta de la inadecuación de la acción, ya que la acción se deriva de la hipótesis de acción de la que dicha creencia (hipótesis científica) formaba parte. En lo que respecta al desarrollo de la ciencia, se ha visto en la comparación de los ejemplos con los que se comenzó este 
párrafo que éste presenta una estructura análoga a la de la evolución de la conducta a partir de los datos aportados por la experiencia (no se cuenta con espacio para ello, pero la analogía entre mi modelo y el método científico puede extenderse a otras interpretaciones más complejas de la ciencia tales como las de Kuhn o Lakatos).

Se tiene que el individuo actúa suponiendo que su acción, en tanto elegida de manera racional, ha de ser correcta, inclusive en los casos en que dicha elección racional es llevada a cabo en base a probabilidades objetivas o subjetivas (es decir bajo riesgo o incertidumbre). Esto está de acuerdo en general con la respuesta kantiana al problema de la causalidad en Hume y la popperiana al criterio inductivista del positivismo lógico: nada nos asegura que mañana exista el sol, los metales se dilaten con el calor o que las puertas se abran al bajar el picaporte, sólo suponemos (acción equivalente a la del científico) estos estados de cosas como probablemente ciertos, llevando a cabo nuestras demás acciones en consecuencia con esa suposición, hasta tanto no surjan indicios en contrario que nos lleven a considerar otros estados de cosas alternativos que maximicen nuestra utilidad individual. Por lo tanto, en caso de que se refute cierta hipótesis de acción, el individuo aprenderá de su error y procederá, cuando le sea posible, a elaborar otra hipótesis más rica, reflejo de la evolución de su conducta a partir de su experiencia personal (de manera análoga a la evolución científica).

Habiendo observado la similitud existente en el proceso de aceptación y rechazo de hipótesis de acción y el relativo a las hipótesis científicas, hay que hacer notar la diferencia esencial que distigue a ambas clases de hipótesis: mientras que en una hipótesis de acción la relación causal es establecida de manera pragmática por un agente guiado por su sentido común o en obediencia a criterios de elección racional, en una hipótesis científica la relación causal se establece en atención a una necesidad lógica (ciencias formales) o fáctica- experimental (ciencias fácticas). La hipótesis científica tiene además pretensiones de validez universal, y no se refiere a acciones del individuo particular que la formula, sino a "acciones" de entidades generales, abstractas o inanimadas (los electrones, los metales, la sociedad).

Sin embargo, a pesar de estas diferencias, creo que, dado que la acción humana es previa a la ciencia, la racionalidad del método científico no es sino una consecuencia más, lógica y natural del modo racional de actuar propio del hombre, es decir, de la racionalidad de la acción. No coincido con quienes afirman que la racionalidad se expresa fundamentalmente en la ciencia para entonces extenderse a otros campos de las actividades humanas, sino que, por lo contrario, sostengo que la racionalidad básica es la racionalidad de la acción, que naturalmente comprende a todas las actividades racionalizables, entre ellas la ciencia.

Mi perspectiva de la acción y de la ciencia coincide con la planteada por el pragmatismo y adoptada en la compilación de Eco y Sebeok (1992), quienes toman a Peirce para establecer una comparación entre la investigación científica y la detectivesca. Peirce caracteriza al modo de actuar del científico como una mezcla de tres tipos de razonamiento, inducción, "abducción" y deducción. Así, de acuerdo al "modo holmesiano de actuar" (por Sherlock Holmes), según Eco, el agente induce primero, a partir de datos limitados, la existencia de ciertos hechos, para después adelantar una hipótesis que explique o interprete esos hechos (esta es la abducción, nunca exenta de riesgo ni de cierta adivinación). Tal hipótesis pasa a constituir una creencia general (a la que se le asocia la máxima probabilidad subjetiva, es decir a la que se supone verdadera), para luego, a partir de ella, deducir sus consecuencias y probar si se corrobora o refuta. Para Peirce el entrelazamiento triádico inducción- abducción- deducción constituye una constante en la vida cotidiana y en la investigación científica. La ciencia resulta entonces una respuesta de entre las posibles, interesada, condicionada por el contexto y nunca gratuita, a la curiosidad explicativa del científico.

Un individuo cualquiera en situación sostiene de por sí un conjunto de creencias que juzga correctas, de la misma manera en que un científico procede a partir de supuestos corroborados. La suposición de creencias previas a cualquier tipo de acción, conecta mi punto de vista con el del convencionalismo. De hecho, mi modelo lleva asociadas una ontología y una teoría de la verdad 
convencionalistas. Somos lo que suponemos que somos, tomamos como verdadero lo que suponemos que es verdadero.

\subsection{5- Acción inadecuada, acción racional y acción irracional.}

En lo que sigue, se hará una enumeración de las circunstancias que pueden llevar a un agente a efectuar una acción incorrecta o inadecuada en su situación objetiva. Puede decirse, en principio, que dichas circunstancias habrán de referirse a una mala deliberación (de la que se derivan acciones irracionales y en consecuencia sólo providencialmente adecuadas), o bien a una deficiente definición subjetiva de los elementos de la situación (de la que se pueden derivar acciones inadecuadas pero no por ello irracionales). Así como se señaló que corrección no equivalía a racionalidad, incorrección no equivale a irracionalidad. Mientras la racionalidad tiene relación con el uso o no uso de un criterio en la elección de la acción, la corrección o incorrección se refieren a si la acción elegida racionalmente resulta o no resulta objetivamente correcta. Veamos los distintos casos en que una acción puede resultar incorrecta o inadecuada.

I) Inadecuación debida a una deliberación deficiente.

Es el caso que se da cuando una hipótesis de acción es establecida sin referencia al criterio estratégico de racionalidad o sin respetar las condiciones que lo complementan y que en 2.2.2 se enumeraron del 1 al 9. Pueden hacerse dos subclasificaciones:

I.1) Cuando el criterio no se aplica pudiéndose haber aplicado. Es decir, cuando no se ejecuta la acción marcada por el criterio estratégico dentro de las opciones posibles habiéndose dado las condiciones 1- 9. Según Elster (1986), las violaciones de la racionalidad de esta clase pueden tener su origen en distintos eslabones de la cadena explicativa: en la acción misma, en la formación de creencias, en la formación de deseos o preferencias y en la acumulación de evidencia. Esto da lugar a una serie de casos que se pasan a enumerar:

A) Irracionalidad en la acción misma.

a) Debilidad de la voluntad: se trata del conocido caso de la akrasia aristotélica a la que ya se hizo referencia en 2.2.3. El agente conoce cuál es la acción racional en su situación (por ejemplo que no debe comer dulces), pero no puede resistirse a actuar de otra manera (come un dulce cuando éste se le presenta). Es también el caso de Ulises, analizado en Elster (1979), quien se ata previamente al mástil de su barco para evitar ser sojuzgado por el canto de las sirenas, creándose constricciones por anticipado para evitarse de actuar en forma irracional.

b) Fenómeno de la utilidad no esperada: en numerosos casos de decisión bajo riesgo, el agente no recurre a la maximización de la utilidad esperada, sino que tiende por ejemplo a sobreenfatizar las bajas probabilidades objetivas y a menospreciar las altas, lo que lo puede llevar a una oposición irracional a planes con muy bajo riesgo de un gran accidente.

c) Calvinismo cotidiano: forma de pensamiento mágico ligado a la paradoja de la predestinación, por la cual el agente supone que el llevar a cabo cierta acción implica que uno ha sido ya predestinado.

d) Formas autodestructivas de la acción racional: existen algunos objetivos como la espontaneidad, el olvido o el sueño para los que intentar llevarlos a cabo a través de la acción instrumental equivale a interferirlos o evitarlos.

B) Irracionalidad en las preferencias.

Resulta controvertido hablar de deseos racionales, sin embargo se encuentran algunos ejemplos claros de irracionalidad en la modificación y formación de deseos. Tal es el caso, por ejemplo, del 
agente con "preferencias contraadaptativas", que es aquél que prefiere lo que no tiene y que deja de preferirlo cuando lo obtiene.

C) Irracionalidad en la formación de creencias.

a) Creencias de irracionalidad "caliente": aquí se incluyen las paradojas de la autodecepción y del deseo ansioso. Un ejemplo es la tendencia de sujetos normales de sobreestimar sus propias habilidades.

b) Creencias de irracionalidad "fría": este tipo de irracionalidad puede tomar, entre otras, la forma de generalizaciones a partir de pruebas escasas o de un tratamiento de la probabilidad de eventos compuestos como si fuera la suma y no el producto de la probabilidad de cada evento.

D) Irracionalidad en la recolección de evidencia.

Teniendo en cuenta que las evidencias pasan a formar parte de las creencias puede decirse que se trata de un caso particular de irracionalidad de las creencias. Se trata del procedimiento muy común consistente en detener la recolección de evidencia cuando la creencia está racionalmente justificada por la evidencia recogida, que es a su vez la única que se quiere que sea verdadera. Si la cantidad de información recolectada está por debajo de la banda de información necesaria, el comportamiento es irracional. Resulta interesante tomar este tipo particular de acción desde la perspectiva de los juegos repetidos. En ese sentido, puede decirse que el individuo se empeña en usar hipótesis de acción ya refutadas, es decir, se resiste a considerar los nuevos elementos de juicio (informaciones) aportadas por sus fallidas experiencias. Dichos elementos deberían modificar su situación subjetiva $\mathrm{y}$ en consecuencia su modo de actuar. No obstante el individuo achaca sus fracasos a factores accesorios, de manera de poder conservar cierta hipótesis sin refutarla, cayendo en el dogmatismo, que es como pretendo llamar a este tipo de acción del que volveré a ocuparme más adelante.

I.2) Cuando por falta de información resulta imposible aplicar un criterio de racionalidad estratégica.

Se trata básicamente de lo que Elster (1986) plantea como "problema de la no unicidad" de la acción racional. Ese problema surge cuando, permaneciendo fijos los deseos y creencias del agente, la elección racional prescribe más de una acción como posible, es decir, como igualmente maximizadoras de la utilidad esperada. Cuando la diferencia entre ambas alternativas es escasa (la opción entre tomar dos tipos diferentes de sopa, por ejemplo), el problema no es tal, ya que si bien el agente puede apelar a algún tipo de decisionismo, cualquiera de las opciones elegidas puede tomarse como racional. Las dificultades surgen cuando las acciones a optar son contradictorias entre sí, cuando el agente no puede establecer comparaciones fundadas acerca de la utilidad de las alternativas ya que son muy diferentes las unas de las otras y no conoce sus consecuencias. La no unicidad se transforma así en no existencia de la conducta racional. Se dice aquí que el ranking de preferencias está incompleto o desconectado. El déficit informativo se encuentra en las propias preferencias, el agente no sabe lo que quiere. Al respecto, tómese el paramétrico y cinematográfico ejemplo del policía que descubre una bomba en un edificio y al desarmarla encuentra dos cables (uno azul y otro rojo), de modo tal que cortar uno de ellos permite desactivar la bomba, mientras que cortar el otro la hace explotar. Como en toda esta clase de películas, el policía dispone de unos pocos segundos para desactivar la bomba y así salvar su vida. El policía se encuentra en una situación Ss en la que sólo tiene dos opciones posibles, cortar el cable rojo o cortar el cable azul. Sin embargo, carece de elementos de juicio que le permitan discernir la acción apropiada, ya que no conoce ni puede establecer las utilidades relativas a cada opción. Una misma alternativa puede representar la salvación o la destrucción. Al policía no le servirá de mucho adjudicar probabilidades subjetivas a los dos estados de cosas posibles (que el desactivador sea el cable rojo o que sea el cable azul), ya que necesariamente deberá atribuir la misma $(0,5)$ a ambos. El criterio de racionalidad puede ser aplicado para obtener dos respuestas racionales pero contradictorias. Por lo tanto el agente puede también apelar, en el momento de decidir su acción, a criterios irracionales supletorios como la intuición o el gusto personal por cierto color. Supongamos que decide cortar el 
cable azul. Si el cable azul resulta de hecho el desactivador, la acción del policía resultará providencialmente adecuada a su situación objetiva real So, pero en el caso contrario no tendrá oportunidad de refutar su hipótesis para tomar la otra sobre la que había deliberado.

II) Inadecuación resultante de una deficiente caracterización de los elementos de la situación.

Se trata de la circunstancia que se da cuando el estado de cosas esperado por el agente (Ss) resulta contradictorio con el estado de cosas objetivo (So) que hubiera sostenido el mismo individuo en posesión de información completa. En particular, habría aquí que señalar al menos dos subcasos:

1) El caso del individuo con información incompleta que asocia equivocadamente su situación subjetiva Ss con una situación considerada Sc (presente en una creencia aceptada) en la deducción de una acción.

2) El caso del individuo con información incompleta, que él mismo transforma en completa haciendo una mala distribución de probabilidades sobre los posibles estados de cosas.

En los dos subcasos, el individuo que cree tener información completa cuando esa información es en realidad equivocada. A su vez, ese déficit informativo redunda en una mala caracterización de los parámetros que definen la situación Ss $\mathrm{y}$, en consecuencia, en una acción posiblemente inadecuada a la real situación So del agente.

El error no está ahora en la deliberación de la hipótesis de acción, sino en la caracterización subjetiva Ss que el agente hace de su situación objetiva So. Al convertirse Ss en la situación tenida en cuenta a la hora de la aplicación del criterio de racionalidad, la acción deducida resulta adecuada para tal Ss, pero puede no serlo para So distinta de Ss.

Respecto del subcaso 1, puede ocurrir que por distintos motivos pero especialmente por la necesidad o tendencia de acotar el problema a abordar, el individuo asocie su situación Ss con una situación Sc equivocada. Como se dijo, el agente, en su vida cotidiana, responde de la misma manera ante situaciones similares pero no estrictamente idénticas. No guarda en su memoria una hipótesis distinta para cada una de las situaciones que enfrenta, lo que supondría una capacidad de retención muy grande, sino que, al corroborar una hipótesis relativa a cierta situación, lo está haciendo también respecto a cierta clase de situaciones. Lo que hace el individuo es distinguir las características relevantes de su situación de las características accesorias y, merced a la capacidad que le confieren los mecanismos de transferencia de su memoria, pasar a considerar luego, como antecedente de la hipótesis de acción, una situación que no es exactamente igual a la considerada en el momento de la corroboración de la premisa mayor, sino sólo en sus características relevantes. Así, una clase de situaciones puede ser definida como un conjunto de situaciones con las mismas características relevantes (abstraídas y generalizadas por el agente) pero con distintas características accesorias.

Resulta claro que una misma hipótesis de acción puede ser válida para situaciones con características accesorias distintas. En el paramétrico y ya anticipado ejemplo de la preparación del té, yo no necesitaría elaborar nuevas hipótesis de acción si estuviera en una cocina distinta a la de mi casa. Una creencia contemplará entonces un tipo de situaciones similares:

$\mathrm{Sc} \mathrm{a}=(\mathrm{Sc} 1 \mathrm{v} \operatorname{Sc} 2$ v Sc3 v ... v Scn $) \mathrm{a}$

$\mathrm{Sc1}=$ situación normal de mi casa.

$\mathrm{Sc} 2=$ situación idéntica a $\mathrm{Sc} 1$ pero con cucharas doradas en vez de plateadas.

$\mathrm{Sc} 3=\mathrm{Sc} 1$ con cucharas plateadas y tazas de otra forma y color.

$\mathrm{v}=$ disyunción.

Así, el agente puede reconocerse en alguna de estas situaciones de una misma clase, y proceder a elegir su acción a partir de ella. 
Supóngase, entonces, que después de escribir estas líneas, deseo tomar un té a mi gusto, es decir con tres cucharaditas de azúcar. Poseo todos los medios materiales necesarios excepto cucharitas. Como dispongo en cambio de cucharas grandes, apelo a una creencia de mi conjunto $\mathrm{C}$ que dice que una cuchara grande equivale a tres chicas y que, en consecuencia, para tomar un "buen" té debo agregar una cucharada grande de azúcar. Los conjuntos que definen la situación son los siguientes:

$\mathrm{C}=\{$ Creencias relevantes, incluida la de que si quiero tomar un

té a mi gusto debo agregarle una cuchara grande de azúcar \}

$\mathrm{P}=\{\mathrm{fu}(3)=4, \mathrm{fu}(2)=3, \mathrm{fu}(1)=2, \mathrm{fu}(0)=1, \mathrm{fu}(\mathrm{x}>3)=1\}$

$\mathrm{x}=$ número de cucharas chicas.

$\mathrm{M}=\{$ todos los medios necesarios excepto cucharas chicas $\}$

$\mathrm{A}=\{$ agregar $\mathrm{x}$ cantidad de cucharas grandes $\} 0<\mathrm{x}<10$

Asimilando mi situación Ss con aquélla ya deliberada en la creencia referida, deduzco la acción:

$\mathrm{CE}$

(1) Sc (C.P.M.A) a ----> A1 a

(2) $\mathrm{Ss} 1=\operatorname{Sc1}($ C1.P.M.A) a

(3) A1 a

A1 = "agregar una cucharada grande".

$\mathrm{C} 1=$ conjunto de creencias 1 .

Sin embargo, pruebo el té y lo encuentro amargo, es decir A1 no resulta adecuada a So. Resulta entonces que la información completa que creía tener no era tal, ya que incluía una creencia equivocada. Nótese que desde el punto de vista subjetivo el razonamiento es correcto, pero desde el punto de vista objetivo de un observador informado es falaz. La falacia objetiva proviene de identificar Sc1 con Ss1 y a esta última con So, y de extender las conclusiones extraídas para Sc a Ss y a So, cuando en realidad Sc y So se contradicen.

Refuto entonces la hipótesis de acción y paso a tener una nueva descripción de la situación de la acción, pudiendo considerar ahora como más probable el estado de cosas en que tres cucharas chicas equivalen a una y media de las grandes. Tengo entonces una nueva Ss2 de la que se infiere una nueva acción, distinta a la anterior:

$\mathrm{CE}$

Ss2 (C2.P.M.A) a ----> A2 a

A2 = "agregar una cucharada grande y media" (en realidad sólo media más ya que ya tiene una de la acción anterior).

$\mathrm{C} 2=$ conjunto de creencias 2.

Nuevamente encuentro al té falto de azúcar (Ss2 y So se contradicen). La diferencia es que ahora la deficiente caracterización de la situación subjetiva, que provoca la elección de una acción inadecuada, no proviene de una asociación equivocada con una creencia sino de una mala atribución de probabilidades subjetivas. Mientras en el paso anterior la asociación equivocada afectaba a una deducción, en este paso queda afectada una deliberación. Por lo tanto, refuto otra vez la hipótesis de acción y vuelvo a asignar probabilidades subjetivas, dándole la mayor al estado de cosas según el cual tres cucharas chicas equivalen a dos grandes. De nuevo, tengo otra situación (Ss3) de la que se deduce una acción diferente a las anteriores:

$\mathrm{CE}$

Ss3 (C3.P.M.A) a ----> A3 a 
A3 = "agregar dos cucharadas grandes" (es decir media más).

$\mathrm{C} 3=$ conjunto de creencias 3 .

Esta vez el té está a mi gusto, la acción resulta adecuada y la hipótesis respectiva corroborada, por lo que la próxima vez que me falten cucharas chicas, ya sabré a qué hipótesis recurrir.*

Puede decirse que, en general, el tipo II de inadecuación es el que subsume todos los casos a los que el agente puede aplicar la frase "Si hubiera sabido que las cosas eran así, hubiera actuado de otra manera". En ese sentido, se puede incluir dentro del subcaso 2 visto anteriormente al individuo "embromado", ya que el mecanismo de la broma, como el del engaño, consiste en dar cierta información falsa al agente para que éste construya una situación subjetiva Ss distinta a la real So, de manera de hacerlo deducir una acción torpe o ridícula para su situación So (conocida de antemano por los bromistas).

Además, una acción incorrecta puede ser el resultado de una de las falsas generalizaciones tan comunes en la vida cotidiana. Las falsas generalizaciones se producen cuando tomamos como pertenecientes a una misma clase a dos situaciones con características relevantes distintas. En el ejemplo anterior, la capacidad de las tazas y cucharas es una característica relevante de la situación (no es lo mismo diluir dos cucharas de azúcar en $250 \mathrm{cc}$ que en $300 \mathrm{cc}$ ), que si es tomada como accesoria puede conducir al agente a una acción inadecuada a su situación objetiva.

Una vez analizadas las distintas maneras en que puede ser producida una acción incorrecta o inadecuada, me gustaría hacer unas reflexiones generales adicionales al respecto.

En primer lugar, vale hacer referencia a la amplia gama de situaciones en las que, a pesar de la completitud del ranking de preferencias, la incertidumbre acerca de otras variables impide la aplicación del criterio de la teoría de la elección racional pero no de otro menos complejo. Al respecto, se hizo ya referencia a las dificultades que ha encontrado la teoría de la elección racional para dar cuenta de los juegos de información incompleta y a la compensación que ella hace de tal carencia al asimilar las incertidumbres de cada jugador como probabilidades subjetivas. Puede ocurrir, sin embargo, que sea imposible transformar el juego de información incompleta en uno de información completa, que el agente no pueda calcular de ninguna forma las probabilidades subjetivas que contrarresten su déficit de información. Tal imposibilidad se pone de manifiesto cuando no se tiene ningún dato sobre el cual apoyar dichas probabilidades, cuando se da el caso de jugadores con expectativas mutuamente inconsistentes, o bien cuando un gran número de jugadores o variables desconocidas entran en la deliberación. En estas circunstancias, el agente podrá tomar una decisión, pero no una decisión basada en el criterio de racionalidad estratégica de la teoría de la elección racional. No obstante, el individuo es libre de guiarse por algún criterio menos abarcativo y sofisticado que el de la teoría considerada, por ejemplo dejando de lado la situación de juego y adoptando el criterio de racionalidad paramétrica, o bien adhiriendo a criterios como el de la racionalidad limitada o a la simple racionalidad medios- fines del sentido común. Se ha dicho que la relación entre antecedente y consecuente de la hipótesis de acción puede llevarse a cabo por criterios más simples de racionalidad y no necesariamente a través del complicado criterio estratégico de la teoría de la elección racional, que aunque siendo el más refinado no siempre se puede aplicar. Sin embargo, la diferencia entre tomar el criterio de la teoría o tomar algún otro es que el primero, al ser más elaborado y abarcativo, ofrece al agente subjetivo mayores garantías de obtención de una acción correcta en la situación objetiva.

En segundo lugar, se dijo que el caso I1D merece especial atención. En ese sentido, la acción dogmática puede comenzar como una acción subjetivamente racional pero objetivamente inadecuada, del tipo II. Sin embargo, la persistencia del agente en no refutar la hipótesis de la que se deriva, en negarse a aceptar información probada disponible que modifique alguno de los parámetros de su situación objetiva (la aceptación de nuevas creencias, la admisión de nuevos medios y en consecuencia de nuevas acciones posibles, y hasta incluso un cambio de preferencias) determina que lo que era subjetivamente racional pase a ser subjetivamente irracional. La diferencia 
con el tipo II de acción incorrecta es que ahora el agente deja de lado conciente y voluntariamente la evidencia veraz obtenida de su propia experiencia que puede contribuir a completar su información. $\mathrm{Si}$, luego de varios juegos repetidos insatisfactorios, el agente se niega a modificar su hipótesis de acción, insistiendo en aplicar el criterio estratégico a la primitiva situación como si nada hubiera pasado, la incorrección se transforma en irracionalidad. Es el caso del dogmático de cualquier tipo que se adhiere a un conjunto rígido de creencias que se niega a modificar.

En tercer lugar, vale la pena hacer notar que si bien al nivel del discurso la racionalidad implica necesariamente corrección, esto no ocurre en el terreno de la acción, cuya dimensión empírica determina que racionalidad y corrección (adecuación) de una acción sean equivalentes sólo en casos con información completa. En los casos con información incompleta, puede darse, como se dijo, que de una hipótesis de acción considerada racional desde la perspectiva subjetiva del agente se deduzca una acción objetivamente incorrecta. Además, mientras el bien del discurso es único (el respeto de las leyes de la lógica), la acción puede ser buena en sentido estratégico o bien en sentido moral. En el punto 2.2.6 se profundizará esta observación ya adelantada en el capítulo 1.

En cuarto lugar, y a partir de los comentarios anteriores, me voy a permitir llevar a cabo una clasificación de las acciones según su grado de racionalidad de la manera que sigue:

1- Acciones racionales perfectas: son aquellas acciones subjetivamente racionales, a la vez que objetivamente correctas.

2- Acciones racionales imperfectas: aquéllas que siendo subjetivamente racionales, resultan ser objetivamente incorrectas. Es el caso de las acciones incorrectas correspondientes al tipo II, en el que la falta de información puede llevar a la paradoja de la elección racional de acciones incorrectas.

3- Acciones irracionales: son las subjetivamente irracionales (el agente no aplica un criterio de racionalidad, pudiéndolo haber aplicado, caso I1, o por imposibilidad efectiva, caso I2) sean objetivamente correctas o incorrectas.

Hay que aclarar que en I1 tanto el agente como su acción son susceptibles de ser declarados irracionales, mientras que en I 2 tal calificación parece sólo válida para la acción, ya que en este último caso el agente puede conocer todos los requisitos de una acción racional pero encontrarse impedido de aplicar ese conocimiento. Además, el hecho de no tener en cuenta que la falta de información en la elección racional puede conducir a un comportamiento incorrecto, puede llevar al agente a una forma de comportamiento irracional que Elster denomina hiperracionalidad, sustentada en la creencia irracional en la omnipotencia de la razón.

Terminaré este punto interrogándome acerca del tipo de explicación derivada de mi concepción de la racionalidad y la acción. En general, estoy de acuerdo con el punto de vista de Davidson y Elster respecto de la explicación intencional (en la que motivos e intenciones se reconocen a la vez como razones y causas de la acción). Así, coincidiendo con lo que Guariglia (1993) sostiene que debe constituir el carácter de la explicación práctica y con mis apreciaciones sobre la relación entre acción y ciencia, puede decirse que mi explicación es causal en tanto la situación Ss opera como causa de las acciones, pero no en el sentido de la explicación nomológico-deductiva de las ciencias naturales. La diferencia radica como se dijo en que la relación condicional establecida en la formulación lógica de la hipótesis de acción, al contrario que la de una hipótesis científica, constituye una relación pragmática entre acción y situación, una hipótesis particular y sin pretensión de validez universal.

De la misma manera que Elster (1990), concluyo que la explicación propia de las ciencias sociales debe combinar la explicación en términos de la situación subjetiva de los agentes con la explicación causal objetiva de sus interacciones. Primero se debe "comprender" endopáticamente, de la manera planteada por Weber (1904), por qué razones los agentes hacen lo que hacen, para después "explicar", desde una perspectiva objetiva, por qué comportándose como lo hacen dichos agentes provocan lo que provocan. En ese sentido, según Elster, una teoría social debe incluir: 
1) Explicaciones de cómo son conformados los deseos y creencias por socialización.

2) Explicaciones de acciones individuales en términos de deseos y creencias individuales.

3) Explicaciones de macroestados en términos de acciones individuales.

En particular y por consiguiente, un estudio científico de las relaciones internacionales debería contar con:

1) Explicaciones de cómo son conformados los intereses y ambiciones de los estados y demás actores internacionales

2) Explicaciones de las acciones de los estados y demás actores internacionales en términos de intereses nacionales y organizacionales.

3) Explicaciones de diversas situaciones de la sociedad internacional en términos de las acciones de los estados y demás actores internacionales.

Esta será pues la tarea a desarrollar a partir de la segunda parte.

\subsection{6- El modelo y la acción en base a principios morales.}

En el punto 1.2.3, al estudiarse las bases de la teoría de la elección racional, se admitieron sus bondades para analizar la racionalidad estratégica, pero se negó a aceptar los intentos de extensión de su criterio a la evaluación de la racionalidad moral. Habida cuenta de tal insuficiencia, se sugirió que había que complementar el criterio de la teoría de la elección racional con algún tipo de criterio moral. Por otro lado, se señaló que, para Aristóteles, lo bueno en una situación dada (la acción correcta, adecuada), es establecido por la recta razón del hombre prudente, tomada como criterio normativo de racionalidad tanto a nivel estratégico como moral (el phrónimos constituye la guía para la deliberación de la buena acción estratégica y de la buena acción moral).

No tomaré partido por el criterio aristotélico, ni siquiera por el de sus continuadores contemporáneos, los comunitaristas, sino por algún tipo de criterio de la línea universalista. Sin embargo, la alusión a Aristóteles sirve para volver a poner de manifiesto la carencia ética de la teoría de la elección racional y como introducción a mi perspectiva respecto a la acción gobernada por principios morales. En ese sentido, mi modelo tendrá en cuenta la posibilidad del agente de obedecer a un criterio estratégico (de buscar una acción estratégica "buena"), a un criterio moral (de buscar una acción moralmente "buena"), o bien a ambos (de buscar una acción no sólo estratégica sino moralmente buena). Cabría tener en cuenta otro tipo de acción y de racionalidad, el de la acción expresiva, apuntada entre otros por Habermas y Guariglia, cuyo criterio de racionalidad sería el de la maximización del contenido expresivo fijado por el propio agente. La acción expresiva, a diferencia de la moral, podría considerarse, a la luz de la teoría de la elección racional, como un caso particular de acción instrumental- estratégica, tomando como preferencia máxima de la función de utilidades al logro de la mayor expresividad posible. Desde ya, la atribución de racionalidad a la acción expresiva resulta bastante discutible, por lo que me limito a dejar planteada la anterior interpretación sólo como una posibilidad, sin adentrarme en una cuestión que, aunque relevante, no está directamente relacionada con las preocupaciones principales de este trabajo. Agréguese solamente que para Guariglia (1993), el interés estético eudemonista de afirmación que guía a la acción puramente expresiva, no sólo puede sino que debería acompañar al interés estratégico y a la preocupación moral, de manera de evitar la reducción y la separación entre los tipos de racionalidad estratégica y moral.

Recuérdese entonces que, hasta el momento, mi modelo se ha referido al análisis del aspecto estratégico de la acción dejando de lado premeditadamente las referencias a la racionalidad moral. Casi todo lo dicho es aplicable, sin embargo, para el análisis de la racionalidad y de la corrección o incorrección de las acciones morales. Sólo basta, en la deliberación de la premisa mayor, complementar el criterio de racionalidad estratégica con un criterio de racionalidad moral. 
Analicemos en primera instancia el que sería el esquema silogístico de un agente moral puro, es decir de un agente que guiara su acción sólo por respeto a un criterio moral, independientemente de las consecuencias estratégicas:

\section{$\mathrm{CM}$}

Ss (C.P.M.A) a ----> A1 a

CM: criterio normativo moral.

La hipótesis de acción se lee de la siguiente manera: "Si a es un agente en una situación $\mathrm{S}$, definida por los parámetros $\mathrm{C}, \mathrm{P}, \mathrm{M}$ y A, entonces, según el criterio moral $\mathrm{CM}$, resulta correcto que a efectúe la acción A1".

La aplicación de un criterio de racionalidad moral permite al agente deducir una acción A1 éticamente correcta en su situación subjetiva, según dicho criterio. No obstante, y por las mismas razones expuestas para la acción estratégica, la acción puede resultar moralmente incorrecta en la situación objetiva So. La clasificación de las acciones morales de acuerdo a su grado de racionalidad también resulta análoga a la de las acciones estratégicas, si se reemplaza al agente estratégico por el agente moral. En cuanto al tipo I de incorrección, el de la acción irracional, la incorrección provendrá del incumplimiento de las pautas del criterio normativo moral considerado.

Antes de seguir debe advertirse que para el caso de la acción moral, la formulación condicional de la hipótesis de acción no debe llevar a la confusión de creer que los elementos de la situación condicionan el respeto del criterio. Por el contrario, en la aplicación de criterios morales no utilitaristas tales elementos no condicionan la elección de la acción sino simplemente definen las circunstancias particulares que dan contenido a la mencionada aplicación. Sólo en este último sentido debe entenderse la formulación condicional de una hipótesis de acción moral.

Se tiene entonces que para un completo análisis de la racionalidad de la acción el agente debe ser considerado estratégica y moralmente racional. Sólo de esta manera se obtiene la forma más compleja de mi hipótesis de acción, que es la que sigue:

$\mathrm{CE}+\mathrm{CM}$

Ss (C.P.M.A) a -----> A1 a

Léase: "Si a es un agente en una situación $\mathrm{S}$, definida por los parámetros $\mathrm{C}, \mathrm{P}, \mathrm{M}$ y A, entonces, según el criterio estratégico $\mathrm{CE}$ y el criterio moral $\mathrm{CM}$, resulta correcto que a efectúe la acción A1".

Por las razones vistas en mi tipificación de las acciones inadecuadas, la acción bajo incertidumbre de un agente estratégica y moralmente racional puede resultar incorrecta en los hechos, desde el punto de vista estratégico, moral o desde ambos. En particular, una vez efectuada la acción, existen cuatro resultados posibles:

1) La acción resulta estratégica y moralmente adecuada.

2) La acción resulta moralmente adecuada pero estratégicamente inadecuada.

3) La acción resulta estratégicamente adecuada pero moralmente inadecuada.

4) La acción resulta estratégica y moralmente inadecuada.

En el caso 1 el agente corroborará su hipótesis de acción, mientras que en el 4 deberá refutarla totalmente. Con respecto a las ocurrencias 2 y 3 , puede pasar que de los criterios estratégico y moral no se deduzcan necesariamente acciones contradictorias entre sí para la situación tenida en cuenta, de manera de permitir una reconsideración de la acción que conduzca al estado de cosas 1 . Los inconvenientes surgen cuando de los dos criterios se infieren acciones contradictorias mutuamente excluyentes y el agente se ve obligado a optar entre 2 y 3 . ¿Cuál de estas alternativas es la más correcta, si hay una? Este es el problema que desde Maquiavelo ha tratado de zanjar toda la filosofía 
política. En ese sentido, revisaré en otro capítulo el a mi entender fallido intento de la ética política de incluir la estrategia en una ética de la responsabilidad o de las consecuencias.

\section{3- Las hipótesis del modelo.}

Tomando en consideración las reflexiones llevadas a cabo en el transcurso de este capítulo, paso ahora a definir el conjunto de hipótesis que sintetizan mi modelo interpretativo de la acción y su racionalidad.

1) Todo individuo (a) es un individuo en situación (S).

2) La situación de un individuo queda caracterizada a partir de una serie de elementos que la componen a saber, un conjunto $\mathrm{C}$ de creencias, un conjunto $\mathrm{P}$ de preferencias, un conjunto $\mathrm{M}$ de medios materiales disponibles, y un conjunto A de acciones alternativas posibles (S (C.P.M.A.)).

3) Todo individuo (a) en una situación $\mathrm{S}$ definida por ciertos parámetros $\mathrm{C}, \mathrm{P}, \mathrm{M}$ y A, delibera acerca de la acción más adecuada, correcta, apropiada a esa situación. En ese sentido, elabora permanentemente hipótesis de acción que vinculan condicionalmente su situación con las acciones elegidas como adecuadas a ella.

4) La deliberación y elección de la acción adecuada a la situación del agente, es decir, la conformación de su hipótesis de acción, se efectúan en relación a un criterio normativo de racionalidad, tanto en el terreno estratégico como en el moral.

5) La forma lógica que permite describir la variante más compleja de una hipótesis de acción es la que sigue:

$\mathrm{CE}+\mathrm{CM}$

Ss (C.P.M.A) a -----> A1 a

Léase: "Si a es un agente en una situación subjetiva de elección Ss, definida por los parámetros C, $\mathrm{P}, \mathrm{M}$ y A, entonces, según el criterio estratégico $\mathrm{CE}$ y el criterio moral $\mathrm{CM}$, resulta correcto que a efectúe la acción A1".

6) En el terreno estratégico, el criterio de maximización de la utilidad esperada propuesto por la teoría de la elección racional es el más refinado y abarcativo, pero diversas circunstancias conducen al agente a adoptar otros criterios menos amplios, pero más inseguros, como el de racionalidad limitada.

7) La elección de la acción de un agente en una dada situación se puede dar de dos maneras:

a) Si el agente cuenta con información completa, éste simplemente delibera a partir de algún criterio estratégico, moral o de ambos y obtiene la acción adecuada según el o los criterios adoptados.

b) Si la información del agente es incompleta, éste la completa de manera subjetiva mediante la asignación de probabilidades objetivas (riesgo) o subjetivas (incertidumbre) a los estados de cosas de los que se carece de información. Una vez hecho esto, pueden darse dos circunstancias:

b1) Si la situación subjetivamente considerada por el agente ( $\mathrm{Ss}$ ) es nueva, el individuo delibera racionalmente a partir de sus criterios normativos estratégico y moral y obtiene una acción adecuada a su Ss (distinta de su real situación objetiva So desconocida por el agente).

b2) Si Ss no es nueva, sino que puede asimilarse a una situación Sc considerada en el pasado, incluida en una hipótesis de acción ya deliberada y que forma parte del conjunto de creencias del agente, el individuo simplemente deduce directamente su acción a partir de tal asimilación (sin volver a deliberar). 
8) En cualquiera de los casos incluidos en 7b), una vez efectuada la acción por el agente puede ocurrir que ésta sea de hecho adecuada o inadecuada a su situación objetiva So, en el terreno moral, en el estratégico o en ambos. En particular pueden darse cuatro circunstancias:

a) La acción resulta estratégica y moralmente adecuada.

b) La acción resulta moralmente adecuada pero estratégicamente inadecuada.

c) La acción resulta estratégicamente adecuada pero moralmente inadecuada.

d) La acción resulta estratégica y moralmente inadecuada.

9) Si en cierto terreno (estratégico o moral), la acción es adecuada, entonces la hipótesis queda corroborada en ese terreno y pasa a formar parte del conjunto de creencias del agente.

10) Si en cierto terreno (estratégico o moral), la acción es inadecuada, entonces el individuo puede revisar y eventualmente refutar su acción en ese terreno de la misma manera que en ciencia se refutan aquellas hipótesis que no resisten la contrastación empírica.

11) La incorrección o inadecuación de una acción puede provenir de una mala deliberación (cuando no se aplica algún criterio de racionalidad pudiéndose aplicar o bien por falta de información) o de una deficiente caracterización de los elementos de la situación (los conjuntos C, P, M y A).

12) En base a premisa anterior pueden definirse tres tipos de acciones: irracionales (subjetivamente incorrectas), racionales imperfectas (subjetivamente correctas pero objetivamente incorrectas) y racionales perfectas (subjetiva y objetivamente correctas).

13) La explicación de una acción puede hacerse suponiendo heurísticamente que el individuo actúa de acuerdo a este modelo, examinando los criterios y la situación subjetiva de elección que lo condujeron a esa acción. Dicho procedimiento sirve para interpretar no sólo la acción racional sino también la irracional.

Una formalización más completa del modelo se halla desarrollada en el Apéndice.

\section{4- Principales aportes del modelo.}

Pasaré a enumerar aquí los que creo que constituyen los principales aportes de mi modelo a la teoría de la elección racional y a la interpretación de la acción en general:

- El modelo descripto en este capítulo permite una visión más amplia, natural y flexible sobre la racionalidad de la acción. El individuo propone o apela a hipótesis de acción que juzga racionales desde su perspectiva, corroborándolas o refutándolas según el caso, tanto en la más elemental situación instrumental, como en la más compleja situación estratégica. El modelo ilustra cómo el nivel de la acción estratégica, si bien subsume el concepto de fines en el de preferencias y considera la situación de juego, conserva la estructura condicional medios-fines del nivel del sentido común. En ese sentido, mi interpretación constituye, al igual que la teoría de la elección racional, una sofisticación filosófica de la racionalidad del sentido común basada en el hábito. Es por medio de la racionalidad medios- fines del sentido común que el agente, en la vida cotidiana, elige de manera intuitiva y directa la acción que estima más conveniente, sin detenerse de manera conciente a atribuir probabilidades ni a maximizar funciones de utilidad. La teorización sirve, no obstante, para la descripción, explicación y predicción de decisiones complejas, en las que la estructura de la acción tanto estratégica como moral resulta más manifiesta, quedando por extensión establecidas las características formales de dicho sentido común. Como se ha dicho, la relación entre el antecedente y el consecuente de una hipótesis de acción puede hacerse por el criterio de la teoría de la elección racional o bien por otros menos sutiles y complicados como los de la racionalidad limitada, adaptativa, paramétrica o el de la del sentido común. La diferencia radica en que cuanto más refinado es el criterio de racionalidad adoptado, mayores garantías hay de efectuar una acción no sólo subjetivamente racional sino también objetivamente correcta. En suma, el modelo presentado 
permite abarcar tanto las acciones y decisiones simples y de sentido común, como las acciones estratégica o moralmente complejas.

- Mi modelo hipotético- deductivo provee una descripción acerca de la relación (la aplicación alternativa o conjunta) entre los criterios normativos estratégico y moral de la racionalidad de la acción, introduciendo, en la decisión de la acción, la consideración de su racionalidad ética sin recurrir al controvertido utilitarismo moral.

- Las distinciones teóricas entre situación subjetiva y situación objetiva, entre deliberación y deducción y entre racionalidad y corrección permiten un mejor análisis de la acción con información incompleta (bajo riesgo e incertidumbre). Por esta razón resultará útil para el análisis de la acción de los agentes de la sociedad internacional, en la que la incertidumbre es la regla y no la excepción. En ese sentido, mi enfoque permite interpretar la justificada resistencia de parte de los estudiosos de las relaciones internacionales a aceptar algunas simplificaciones de la teoría de juegos, a la vez que explica su preferencia por la noción de "hipótesis de conflicto", es decir por el establecimiento en condiciones de incertidumbre de conexiones hipotéticas entre distintas situaciones conflictivas y sus posibles respuestas.

- En las conclusiones de Elster (1985) se señalan dos limitaciones de la teoría de la elección racional a tener en cuenta: el hecho de no poder predecir el comportamiento en aquellas situaciones en que la información es incompleta o en las que las personas actúan irracionalmente, y el hecho de no poder explicar el cambio de preferencias. Al respecto, mi punto de vista, merced a la introducción del concepto de refutación de una hipótesis de acción, así como de la consideración de la subjetividad y del tiempo, aporta una contribución a la descripción, explicación y predicción de la acción irracional y de la que he llamado racional imperfecta. En particular, permite un interesante estudio de la irracionalidad en la recolección de evidencia (aquí se la ha llamado dogmatismo), que constituye una de las clases más difundidas de acción irracional, tanto a nivel individual como en el de la acción de los estados. Para describir y explicar una acción incorrecta habrá que establecer primero si se trató de una acción racional imperfecta o irracional. En el primer caso, se podrá investigar la situación subjetiva Ss a la que el agente aplicó el criterio estratégico de racionalidad de la teoría de la elección racional o algún otro, en el segundo caso, se debería observar si el agente pudo o no aplicar un criterio y, en caso afirmativo, proceder a encontrar el tipo de acción irracional involucrado. Además, el modelo, en base al análisis de los componentes de las situaciones de los actores (conjuntos C, P, M, A), puede ayudar a predecir acciones racionales imperfectas e irracionales (objetivamente incorrectas), y a influir en ellas con el aporte de nueva información.

El esquema resulta también compatible con las observaciones que atribuyen al tiempo un papel fundamental en la acción irracional por debilidad de voluntad (akrasia). Asimismo, la sucesión temporal de refutaciones sucesivas ayuda a la comprensión de los cambios de preferencias de los agentes, en la misma dirección en que intenta hacerlo la teoría de la elección racional por medio de los juegos repetidos.

- Mi modelo permite numerosas conexiones con distintas teorías y áreas temáticas. Sería muy largo y excedería los objetivos de este trabajo, el desarrollo completo de tales conexiones (las principales se hallan brevemente citadas en el apéndice). Prefiero dejar esa tarea para otra oportunidad y concentrarme en la segunda parte en mi tema específico, el de la acción de los estados en la sociedad internacional.

Resumen de conclusiones de la primera parte.

1) La racionalidad se predica del discurso y de la acción. Hablar de racionalidad, del discurso o de la acción racionales, supone contar con un criterio de racionalidad, normativo, a partir del cual distinguir el discurso y la acción "buenos", fundados, correctos, adecuados, de la acción o el discurso "malos", infundados, incorrectos, inadecuados. 
2) En el terreno del discurso, el criterio normativo de racionalidad está dado por el respeto de las leyes de la lógica. En el terreno de la acción resulta más complicado establecer un criterio, por lo que la filosofía de la acción se ha ocupado de elaborar distintas teorías al respecto.

3) La teoría de la elección racional ha propuesto un criterio, la maximización de la utilidad esperada por el agente, que sintetiza distintas perspectivas constituyéndose en la interpretación más sofisticada y abarcativa de la acción racional.

4) Los enfoques más actualizados de la teoría de las relaciones internacionales suelen tomar de manera acrítica a la teoría de la elección racional. Sin embargo, ésta es susceptible de recibir al menos dos críticas principales:

a) En el plano estratégico: en la vida cotidiana, en situaciones de incertidumbre en las que el agente no puede cuantificar utilidades o probabilidades, o bien en problemas de gran complejidad de cálculos, el agente procede según criterios de racionalidad más simples.

b) En el plano moral: rechazo a la extensión del criterio de la teoría a la interpretación de la acción moral.

5) En base a los aportes de la teoría de la elección racional, a las críticas a ésta y a distintos elementos tomados tanto del método hipotético- deductivo popperiano como del silogismo práctico aristotélico, es posible construir el siguiente modelo interpretativo de la acción y su racionalidad:

(1) Todo individuo (a) es un individuo en situación (S).

(2) La situación de un individuo queda caracterizada a partir de una serie de elementos que la componen a saber, un conjunto $\mathrm{C}$ de creencias, un conjunto $\mathrm{P}$ de preferencias, un conjunto $\mathrm{M}$ de medios materiales disponibles, y un conjunto A de acciones alternativas posibles (S (C.P.M.A.)).

(3) Todo individuo (a) en una situación $\mathrm{S}$ definida por ciertos parámetros C, P, M y A, delibera acerca de la acción más adecuada, correcta, apropiada a esa situación. En ese sentido, elabora permanentemente hipótesis de acción que vinculan condicionalmente su situación con las acciones elegidas como adecuadas a ella.

(4) La deliberación y elección de la acción adecuada a la situación del agente, es decir, la conformación de su hipótesis de acción, se efectúan en relación a un criterio normativo de racionalidad, tanto en el terreno estratégico como en el moral.

(5) La forma lógica que permite describir la variante más compleja de una hipótesis de acción es la que sigue:

$\mathrm{CE}+\mathrm{CM}$

Ss (C.P.M.A) a -----> A1 a

Léase: "Si a es un agente en una situación subjetiva de elección Ss, definida por los parámetros C, $\mathrm{P}, \mathrm{M}$ y A, entonces, según el criterio estratégico $\mathrm{CE}$ y el criterio moral $\mathrm{CM}$, resulta correcto que a efectúe la acción A1".

(6) En el terreno estratégico, el criterio de maximización de la utilidad esperada propuesto por la teoría de la elección racional es el más refinado y abarcativo, pero diversas circunstancias conducen al agente a adoptar otros criterios menos amplios, pero más inseguros, como el de racionalidad limitada.

(7) La elección de la acción de un agente en una dada situación se puede dar de dos maneras:

a) Si el agente cuenta con información completa, éste simplemente delibera a partir de algún criterio estratégico, moral o de ambos y obtiene la acción adecuada según el o los criterios adoptados.

b) Si la información del agente es incompleta, éste la completa de manera subjetiva mediante la asignación de probabilidades objetivas (riesgo) o subjetivas (incertidumbre) a los estados de cosas de los que se carece de información. Una vez hecho esto, pueden darse dos circunstancias: 
b1) Si la situación subjetivamente considerada por el agente (Ss) es nueva, el individuo delibera racionalmente a partir de sus criterios normativos estratégico y moral y obtiene una acción adecuada a su Ss (distinta de su real situación objetiva So desconocida por el agente).

b2) Si Ss no es nueva, sino que puede asimilarse a una situación Sc considerada en el pasado, incluida en una hipótesis de acción ya deliberada y que forma parte del conjunto de creencias del agente, el individuo simplemente deduce directamente su acción a partir de tal asimilación (sin volver a deliberar).

(8) En cualquiera de los casos incluidos en 7b), una vez efectuada la acción por el agente puede ocurrir que ésta sea de hecho adecuada o inadecuada a su situación objetiva So, en el terreno moral, en el estratégico o en ambos. En particular pueden darse cuatro circunstancias:

a) La acción resulta estratégica y moralmente adecuada.

b) La acción resulta moralmente adecuada pero estratégicamente inadecuada.

c) La acción resulta estratégicamente adecuada pero moralmente inadecuada.

d) La acción resulta estratégica y moralmente inadecuada.

(9) Si en cierto terreno (estratégico o moral), la acción es adecuada, entonces la hipótesis queda corroborada en ese terreno y pasa a formar parte del conjunto de creencias del agente.

(10) Si en cierto terreno (estratégico o moral), la acción es inadecuada, entonces el individuo puede revisar y eventualmente refutar su acción en ese terreno de la misma manera que en ciencia se refutan aquellas hipótesis que no resisten la contrastación empírica.

(11) La incorrección o inadecuación de una acción puede provenir de una mala deliberación (cuando no se aplica algún criterio de racionalidad pudiéndose aplicar o bien por falta de información) o de una deficiente caracterización de los elementos de la situación (los conjuntos $\mathrm{C}$, $\mathrm{P}, \mathrm{M}$ y A).

(12) En base a premisa anterior pueden definirse tres tipos de acciones: irracionales (subjetivamente incorrectas), racionales imperfectas (subjetivamente correctas pero objetivamente incorrectas) y racionales perfectas (subjetiva y objetivamente correctas).

(13) La explicación de una acción puede hacerse suponiendo heurísticamente que el individuo actúa de acuerdo a este modelo, examinando los criterios y la situación subjetiva de elección que lo condujeron a esa acción.

7) Ni el modelo presentado en este trabajo ni el de la teoría de la elección racional afirman que el individuo se comporta o debe comportarse permanentemente de manera racional. Se trata de simples modelos heurísticos de la acción intencional conciente y racionalizable, a partir de los cuales se procura también interpretar la acción irracional. 


\section{Resumen de conclusiones de la primera parte}

1) La racionalidad se predica del discurso y de la acción. Hablar de racionalidad, del discurso o de la acción racionales, supone contar con un criterio de racionalidad, normativo, a partir del cual distinguir el discurso y la acción "buenos", fundados, correctos, adecuados, de la acción o el discurso "malos", infundados, incorrectos, inadecuados.

2) En el terreno del discurso, el criterio normativo de racionalidad está dado por el respeto de las leyes de la lógica. En el terreno de la acción resulta más complicado establecer un criterio, por lo que la filosofía de la acción se ha ocupado de elaborar distintas teorías al respecto.

3) La teoría de la elección racional ha propuesto un criterio, la maximización de la utilidad esperada por el agente, que sintetiza distintas perspectivas constituyéndose en la interpretación más sofisticada y abarcativa de la acción racional.

4) Los enfoques más actualizados de la teoría de las relaciones internacionales suelen tomar de manera acrítica a la teoría de la elección racional. Sin embargo, ésta es susceptible de recibir al menos dos críticas principales:

a) En el plano estratégico: en la vida cotidiana, en situaciones de incertidumbre en las que el agente no puede cuantificar utilidades o probabilidades, o bien en problemas de gran complejidad de cálculos, el agente procede según criterios de racionalidad más simples.

b) En el plano moral: rechazo a la extensión del criterio de la teoría a la interpretación de la acción moral.

5) En base a los aportes de la teoría de la elección racional, a las críticas a ésta y a distintos elementos tomados tanto del método hipotético- deductivo popperiano como del silogismo práctico aristotélico, es posible construir el siguiente modelo interpretativo de la acción y su racionalidad:

(1) Todo individuo (a) es un individuo en situación (S).

(2) La situación de un individuo queda caracterizada a partir de una serie de elementos que la componen a saber, un conjunto $\mathrm{C}$ de creencias, un conjunto $\mathrm{P}$ de preferencias, un conjunto $\mathrm{M}$ de medios materiales disponibles, y un conjunto A de acciones alternativas posibles (S (C.P.M.A.)).

(3) Todo individuo (a) en una situación $\mathrm{S}$ definida por ciertos parámetros C, P, M y A, delibera acerca de la acción más adecuada, correcta, apropiada a esa situación. En ese sentido, elabora permanentemente hipótesis de acción que vinculan condicionalmente su situación con las acciones elegidas como adecuadas a ella.

(4) La deliberación y elección de la acción adecuada a la situación del agente, es decir, la conformación de su hipótesis de acción, se efectúan en relación a un criterio normativo de racionalidad, tanto en el terreno estratégico como en el moral.

(5) La forma lógica que permite describir la variante más compleja de una hipótesis de acción es la que sigue:

$\mathrm{CE}+\mathrm{CM}$

Ss (C.P.M.A) a -----> A1 a

Léase: "Si a es un agente en una situación subjetiva de elección Ss, definida por los parámetros C, $\mathrm{P}, \mathrm{M}$ y A, entonces, según el criterio estratégico CE y el criterio moral $\mathrm{CM}$, resulta correcto que a efectúe la acción A1".

(6) En el terreno estratégico, el criterio de maximización de la utilidad esperada propuesto por la teoría de la elección racional es el más refinado y abarcativo, pero diversas circunstancias conducen al agente a adoptar otros criterios menos amplios, pero más inseguros, como el de racionalidad limitada. 
(7) La elección de la acción de un agente en una dada situación se puede dar de dos maneras:

a) Si el agente cuenta con información completa, éste simplemente delibera a partir de algún criterio estratégico, moral o de ambos y obtiene la acción adecuada según el o los criterios adoptados.

b) Si la información del agente es incompleta, éste la completa de manera subjetiva mediante la asignación de probabilidades objetivas (riesgo) o subjetivas (incertidumbre) a los estados de cosas de los que se carece de información. Una vez hecho esto, pueden darse dos circunstancias:

b1) Si la situación subjetivamente considerada por el agente (Ss) es nueva, el individuo delibera racionalmente a partir de sus criterios normativos estratégico y moral y obtiene una acción adecuada a su Ss (distinta de su real situación objetiva So desconocida por el agente).

b2) Si Ss no es nueva, sino que puede asimilarse a una situación Sc considerada en el pasado, incluida en una hipótesis de acción ya deliberada y que forma parte del conjunto de creencias del agente, el individuo simplemente deduce directamente su acción a partir de tal asimilación (sin volver a deliberar).

(8) En cualquiera de los casos incluidos en 7b), una vez efectuada la acción por el agente puede ocurrir que ésta sea de hecho adecuada o inadecuada a su situación objetiva So, en el terreno moral, en el estratégico o en ambos. En particular pueden darse cuatro circunstancias:

a) La acción resulta estratégica y moralmente adecuada.

b) La acción resulta moralmente adecuada pero estratégicamente inadecuada.

c) La acción resulta estratégicamente adecuada pero moralmente inadecuada.

d) La acción resulta estratégica y moralmente inadecuada.

(9) Si en cierto terreno (estratégico o moral), la acción es adecuada, entonces la hipótesis queda corroborada en ese terreno y pasa a formar parte del conjunto de creencias del agente.

(10) Si en cierto terreno (estratégico o moral), la acción es inadecuada, entonces el individuo puede revisar y eventualmente refutar su acción en ese terreno de la misma manera que en ciencia se refutan aquellas hipótesis que no resisten la contrastación empírica.

(11) La incorrección o inadecuación de una acción puede provenir de una mala deliberación (cuando no se aplica algún criterio de racionalidad pudiéndose aplicar o bien por falta de información) o de una deficiente caracterización de los elementos de la situación (los conjuntos $\mathrm{C}$, P, M y A).

(12) En base a premisa anterior pueden definirse tres tipos de acciones: irracionales (subjetivamente incorrectas), racionales imperfectas (subjetivamente correctas pero objetivamente incorrectas) y racionales perfectas (subjetiva y objetivamente correctas).

(13) La explicación de una acción puede hacerse suponiendo heurísticamente que el individuo actúa de acuerdo a este modelo, examinando los criterios y la situación subjetiva de elección que lo condujeron a esa acción.

7) Ni el modelo presentado en este trabajo ni el de la teoría de la elección racional afirman que el individuo se comporta o debe comportarse permanentemente de manera racional. Se trata de simples modelos heurísticos de la acción intencional conciente y racionalizable, a partir de los cuales se procura también interpretar la acción irracional. 


\section{LA RACIONALIDAD DE LA ACCION DE LOS ACTORES INTERNACIONALES}

\section{3- Posibilidad de la traslación del modelo interpretativo de la acción del individuo a la acción exterior de los Estados y demás actores internacionales.}

¿Puede aplicarse el modelo interpretativo de la acción individual visto en la primera parte a la descripción, explicación y predicción de las acciones de política exterior de los estados? En tal caso, ¿cuáles son las advertencias a tener en cuenta?

Antes de intentar responder a estas preguntas, vale la pena primero pasar revista a la manera en que es considerada la acción de los estados por algunos de los padres de la filosofía y la ciencia políticas.

Maquiavelo identifica en El Príncipe (1532) la acción del Estado con la del soberano individual. Esta visión aparece suavizada en los Discursos sobre la primera década de Tito Livio (1531), en los que se afirma que los gobernantes de las repúblicas mixtas pueden ser influidos por los "tumultos" o por los consejos del Senado, aunque en definitiva, en los asuntos relativos a la acción exterior del Estado, son los gobernantes quienes deciden.

Por su parte, en Hobbes (1651:122), el Estado es definido como "una persona (artificial) de cuyos actos una gran multitud, por pactos mutuos, realizados entre sí, ha sido instituida por cada uno como autor, al objeto de que pueda utilizar la fortaleza y medios de todos, como lo juzgue oportuno, para asegurar la paz y defensa común". Esta afirmación, junto con aquéllas en que este autor se refiere a las amenazas constantes entre los estados, a un "estado de naturaleza" de la sociedad internacional de su tiempo (en el que las decisiones de política exterior dependían de la voluntad del rey), permiten establecer que sus conclusiones relativas a la acción de los individuos son extendidas a la de los estados.

En lo que respecta a Kant, el siguiente párrafo de La paz perpetua (1795) aparece bastante claro, en relación a las presentes reflexiones: "Los pueblos pueden considerarse, en cuanto estados, como individuos que en su estado de naturaleza (es decir, independientes de leyes externas) se perjudican unos a otros por su mera coexistencia y cada uno, en aras de su seguridad, puede y debe exigir del otro que entre con él en una Constitución semejante a la Constitución civil, en la que se pueda garantizar a cada uno su derecho" (Kant 1795:21). La Constitución civil a la que se refiere Kant es la de una forma de gobierno republicana, que opone al despotismo. En una forma de gobierno republicana (en la que existe división de poderes), tanto el ejecutivo como la cancillería del Estado, deben tener en cuenta el "espíritu" del pueblo en la toma de decisiones de sus acciones de política exterior. Esto no ocurre, sin embargo, en un gobierno despótico, "gobierno bajo el cual el soberano trata al pueblo como si fuera de su propiedad", en el que la voluntad pública se identifica directamente con la voluntad del gobernante.

Max Weber, aunque adhiriendo a la posición que luego tomará el nombre de individualismo metodológico, señala la utilidad práctica de considerar al Estado como a un individuo: "Para otros fines de conocimiento [distintos de la sociología] (por ejemplo jurídicos o por finalidades prácticas) puede ser conveniente y hasta sencillamente inevitable tratar a determinadas formaciones sociales (estado, cooperativas, compañía anónima, fundación) como si fueran individuos (por ejemplo como sujetos de derechos y deberes o de determinadas acciones de alcance jurídico)" (Weber 1922). En todo caso, y en especial en el de la sociología comprensiva, siempre deberá tenerse en cuenta y no 
perderse de vista el hecho de que la accion de esas formas sociales se deriva de las acciones de los individuos que lo forman.

Pasando ahora al ámbito específico de la teoría de las relaciones internacionales, se observó en la Introducción cómo la mayoría de sus enfoques, análogamente a los autores comentados más arriba, han suscripto en líneas generales y con distintos matices la idea del Estado como agente unificado racional y protagonista principal de la escena internacional. En particular, los enfoques más actualizados y ahora en debate, el neorrealismo y el institucionalismo, han trasladado a los estados las conclusiones de la teoría de la elección racional (de los individuos) de una manera bastante acrítica. En la primera parte se vieron, sin embargo, algunas de las críticas de las que es susceptible dicha teoría, a partir de las cuales se elaboró un modelo aún más completo. No obstante, la consideración de tales críticas tampoco alcanza para justificar el traspaso directo de un modelo racionalista de la acción individual a la acción de los estados, ya que para ello mi modelo, el de la teoría de la elección racional o el de cualquier perspectiva que adjudique a los estados el papel de agentes racionales, deben hacer algunas advertencias. En ese sentido, vale prestar atención al argumento conocido como Teorema de Arrow, para lo cual me basaré en Naishtat (1992b) y en Shubik (1982).

El problema que investiga el Teorema de Arrow es el de la composición de las preferencias individuales en una preferencia social, problema que subyace en el discurso político en expresiones como "Estados Unidos invadió Panamá" o "el Pueblo israelí quiere la paz", en las que se oculta, tras los sujetos gramaticales "Estados Unidos" o "Pueblo", un presupuesto ontológico antropomórfico, que traslada a los colectivos atributos referidos a individuos. Como señala Naishtat, el problema que plantea Arrow consiste en que para ser expresables antropomórficamente, los colectivos y las instituciones deben sortear una doble prueba: "una prueba lógica en el sentido de que no exista una quiebra de la racionalidad en el pasaje de las preferencias individuales a la preferencia social, y una prueba política, en el sentido de que la preferencia social sea genuinamente una preferencia social y no el mero disfraz institucional de una preferencia individual".

El resultado del "teorema de imposibilidad de Arrow" establece la inconsistencia de la conjunción de ambos condicionamientos (lógico y político), lo que según Naishtat "significa que toda regla de preferencia social que no quiebre la racionalidad individual es una regla manipulada por un individuo, o viceversa, que toda regla de preferencia social no manipulada por un individuo es una regla que quiebra la racionalidad individual". Esta conclusión arroja un manto de duda sobre la adecuación de las metáforas antropomórficas del discurso político y obliga a reflexionar sobre la validez de la teoría democrática de la representación cuando las opciones electorales son más de dos, allí dónde se empieza a percibir el llamado "efecto Condorcet" (relativo a la no transitividad de las preferencias sociales). Al respecto, el Teorema de Arrow no pone en crisis el sistema democrático sino la continuidad entre la racionalidad individual y la racionalidad del sujeto colectivo, lo que se quiebra no es el procedimiento democrático en sí mismo sino la homogeneidad entre las preferencias individuales y la preferencia social. Esta falta de homogeneidad invalidaría la "metáfora antropomórfica" en la referencia a sujetos colectivos.

Sin embargo, para el caso particular de la asunción del colectivo Estado como actor racional unificado dentro de la sociedad internacional, las conclusiones del teorema de Arrow pueden ser obviadas a partir de la consideración de las características del proceso de toma de decisiones previo a la acción de política exterior. La acción de política exterior de un estado es siempre una acción manipulada por un individuo o grupo de individuos, entre los que se pueden encontrar los miembros del poder ejecutivo y de la cancillería, así como los distintos grupos de presión que intenten imponer sus propias hipótesis de acción. Pero, en definitiva, la acción del Estado, en tanto órgano burocrático con una política exterior coordinada, será la decidida por los tomadores de decisiones responsables, de acuerdo a lo que desde su perspectiva resulte más beneficioso para el Estado en su conjunto (y según distintos niveles de racionalidad). Los representantes del Estado actúan en nombre del Estado y con la autoridad del Estado. En ese sentido, cuanto más centralizado es el proceso de toma de decisiones, más se asemeja la estructura de la acción de los estados a la de los 
individuos. El límite de este acercamiento es la identificación individuo- Estado, a la manera de Luis XIV, "El Estado soy yo" (decido yo). Sin embargo, no sólo en los regímenes monárquicos, dictatoriales o autoritarios puede tomarse al Estado como un actor antropomórfico, sino también en el Estado democrático moderno, ya que será el grupo "manipulador" de la política exterior del que se hablaba, el que en representación del Estado deliberará organizada y racionalmente la acción a llevar a cabo a partir de las distintas alternativas posibles. La expresión "Estados Unidos invadió Panamá" significa que el Departamento de Estado, con la aprobación del Presidente, decidió de manera racional estratégica la invasión de Panamá en representación del pueblo norteamericano, que puede aprobar o no tal decisión política desde el punto de vista estratégico o moral.

Puede ocurrir que ciertas decisiones de un mismo Estado no sean coherentes con otras anteriores (especialmente cuando se trata de gobiernos distintos), pero esto no invalida los intentos de asimilar la conducta de los estados a la de los individuos, en este caso, el de traspolar mi modelo interpretativo de la acción de los individuos a la acción de los estados.

Si bien el Estado es considerado ampliamente como el agente preponderante de las relaciones internacionales, se señaló en la Introducción, el cada vez mayor énfasis puesto en la aparición de nuevos actores tales como los organismos internacionales, las empresas transnacionales y los propios individuos. En ese sentido, las reflexiones de este punto valen para cualquiera de los grupos mencionados, que habrán de ser considerados actores internacionales en tanto sus acciones tengan consecuencias en el ámbito internacional y en cuanto constituyan lo que Aron (1962) denomina "unidades políticas", es decir, en tanto dispongan de un mecanismo centralizado y racional de toma de decisiones en el que los representantes de sus miembros puedan decidir las acciones adecuadas a los intereses del grupo. Por supuesto que, en el caso de los individuos, su acción internacional podrá ser interpretada directamente según el modelo propuesto. En consecuencia, resulta correcto definir a las relaciones internacionales como al conjunto de interacciones que se dan entre los distintos actores que constituyen la sociedad internacional y a la ciencia de las relaciones internacionales como al estudio de esas interacciones. 


\section{4- Traslación del modelo interpretativo de la acción del individuo a la acción de los Estados y demás actores internacionales.}

\section{1- Un modelo interpretativo de la acción de los estados y demás actores internacionales.}

Teniendo en cuenta las advertencias del capítulo anterior paso ahora a trasladar el modelo desarrollado en la primera parte a la acción de los estados:

1) Todo estado (e) es un estado en situación (S) en el marco de la sociedad internacional.

2) La situación de un estado queda caracterizada a partir de la combinación de los elementos que componen las situaciones subjetivas (Ss) de los tomadores de decisiones, de sus conjuntos $\mathrm{C}$ de creencias, $\mathrm{P}$ de preferencias, $\mathrm{M}$ de medios materiales disponibles y $\mathrm{A}$ de acciones alternativas posibles (S (C.P.M.A.)). Mientras los conjuntos C y $\mathrm{P}$ pueden variar según el decisor de que se trate, M y A permanecen constantes, es decir, los decisores pueden disentir acerca de la historia y los intereses del estado, pero la información acerca de los medios materiales disponibles y de las acciones posibles es compartida por todos.

3) En todo estado (e) en una situación $\mathrm{S}$, la acción de política exterior se define a partir de un proceso de toma de decisiones en el que los responsables de esa política deliberan acerca de la acción más adecuada, correcta, apropiada a esa situación. En ese sentido, elaboran hipótesis de acción alternativas en las que se vincula condicionalmente la situación del estado con las acciones elegidas como adecuadas a ella. Dado que la situación del estado es subjetivamente interpretada por los decisores, la situación tenida en cuenta en la elección será aquélla que los decisores establezcan de manera consensuada o bien la sostenida por el individuo o grupo de presión que logre imponer su perspectiva.

4) En el proceso de toma de decisiones, la deliberación de la acción adecuada a la situación del estado, es decir, la conformación de una hipótesis de acción de política exterior, se efectúa en relación a cierto criterio normativo de racionalidad, tanto en el terreno estratégico como en el ético.

5) En el terreno estratégico, el criterio de maximización de la utilidad esperada propuesto por la teoría de la elección racional es el más refinado y abarcativo, pero diversas circunstancias conducen a los estados a adoptar otros criterios menos amplios, pero más inseguros, como el de racionalidad limitada. En el terreno ético, cuesta hacer referencia a un criterio sostenible por entidades colectivas como los estados. En este caso puede decirse que los principios éticos a ser tenidos en cuenta por ellos se hallan resumidos en el derecho internacional, de manera que el peso del criterio moral en la elección de la acción de un individuo, puede equipararse, a nivel de los estados, al simple respeto del derecho internacional. En el ámbito de las relaciones internacionales la moralidad se reduce a la legalidad. El respeto al derecho internacional es un criterio legal pero también moral en tanto que las normas internacionales son orientadas por principios morales.

6) La forma lógica que describe la variante más compleja de una hipótesis de acción de política exterior de un estado es la que sigue:

$\operatorname{PTD}(\mathrm{CE}+\mathrm{DI})$

Ss (C.P.M.A) e -------> A1 e

$\mathrm{e}=$ estado.

Ss = situación subjetiva del estado en la sociedad internacional.

$\mathrm{C}=$ conjunto de creencias e informaciones manejadas por los decisores o bien conjunto de preferencias del individuo o grupo de presión que logre imponer su perspectiva.

$\mathrm{P}=$ conjunto de preferencias adoptada por consenso por los decisores o bien perteneciente al individuo o grupo de presión que logre imponer su perspectiva. 
$\mathrm{M}=$ conjunto de medios materiales disponibles por el estado (fuerza militar, económica).

$\mathrm{A}=$ conjunto de acciones posibles del estado en virtud de los medios disponibles.

$\mathrm{PTD}=$ proceso racional de toma de decisiones.

$\mathrm{CE}=$ criterio estratégico de racionalidad.

$\mathrm{DI}=$ respeto del derecho internacional (criterio legal- moral de racionalidad).

Léase: "Si e es un estado en una situación dada Ss, subjetivamente considerada por los decisores y definida por por los parámetros $\mathrm{C}, \mathrm{P}, \mathrm{M}$ y A, entonces, según el criterio estratégico CE y el criterio legal- moral DI, resulta correcto que a efectúe la acción A1".

7) La elección de la acción de un estado en una dada situación se puede dar de dos maneras:

a) Si los decisores cuentan con información completa, estos simplemente deliberan a partir de algún criterio estratégico, del legal- moral o de ambos y obtienen la acción adecuada según el o los criterios adoptados.

b) Si la información de los decisores es incompleta, estos la completan de manera subjetiva mediante la asignación de probabilidades objetivas (riesgo) o subjetivas (incertidumbre) a los estados de cosas de los que se carece de información. Una vez hecho esto, pueden darse dos circunstancias:

b1) Si la situación subjetivamente considerada por los decisores (Ss) es nueva, estos deliberan racionalmente a partir de sus criterios normativos estratégico y legal- moral y obtienen una acción adecuada a su Ss (distinta de su real situación objetiva So desconocida por ellos).

b2) Si Ss no es nueva, sino que puede asimilarse a una situación Sc considerada en el pasado, incluida en una hipótesis de acción ya deliberada y que forma parte del conjunto de creencias de los decisores, estos simplemente deducen directamente su acción a partir de tal asimilación (sin volver a deliberar).

8) En cualquiera de los casos incluidos en 7b), una vez efectuada la acción por el estado puede ocurrir que ésta sea de hecho adecuada o inadecuada a su situación objetiva So, en el terreno estratégico, en el del respeto al derecho internacional, o en ambos. En particular pueden darse cuatro circunstancias:

a) La acción resulta estratégica y legalmente adecuada.

b) La acción resulta legalmente adecuada pero

estratégicamente inadecuada.

c) La acción resulta estratégicamente adecuada pero

legalmente inadecuada.

d) La acción resulta estratégica y legalmente

inadecuada.

9) Si en cierto terreno (estratégico o legal- moral), la acción es adecuada, entonces la hipótesis queda corroborada en ese terreno y pasa a formar parte del conjunto de creencias de los decisores.

10) Si en cierto terreno (estratégico o legal- moral), la acción es inadecuada, entonces los decisores pueden revisar y eventualmente refutar su acción en ese terreno de la misma manera que en ciencia se refutan aquellas hipótesis que no resisten la contrastación empírica.

11) La incorrección o inadecuación de una acción puede provenir de una mala deliberación (cuando no se aplica algún criterio de racionalidad pudiéndose aplicar o bien por falta de información) o de una deficiente caracterización de los elementos de la situación (los conjuntos C, P, M y A). 
12) En base a premisa anterior pueden definirse tres tipos de acciones: irracionales (subjetivamente incorrectas), racionales imperfectas (subjetivamente correctas pero objetivamente incorrectas) y racionales perfectas (subjetiva y objetivamente correctas).

13) La explicación de una acción de cierto estado puede hacerse suponiendo heurísticamente que ese estado actúa de acuerdo a este modelo, examinando los criterios y la situación subjetiva de elección que lo condujeron a esa acción. Dicho procedimiento sirve para interpretar no sólo la acción racional sino también la irracional.

Una formalización más completa del modelo trasladado a los estados se halla desarrollada en el Apéndice. Por otro lado, cabe hacer aquí una serie de observaciones adicionales:

I) Me he referido a los estados en tanto constituyen los actores preponderantes de las relaciones internacionales, sin embargo, como se adelantó, el modelo es generalizable a cualquiera de los nuevos actores internacionales:

$\operatorname{PTD}(\mathrm{CE}+\mathrm{DI})$

Ss (C.P.M.A) ai -------> A1 ai

ai $=$ actor internacional (estado, organismo internacional, organización no gubernamental, empresa multinacional, individuo).

II) En los casos particulares en que los propios individuos son considerados actores internacionales, la forma de su "acción internacional" es la misma que se ha descripto para la acción individual general en los capítulos 1 y 2 .

III) Respecto al criterio a considerar en el proceso de toma de decisiones, el modelo trasladado enfatiza que no necesariamente tiene que ser el de la teoría de la elección racional (aunque por supuesto contempla la maximización de la utilidad esperada, tomada en sentido "absoluto" o "relativo"). Tal criterio constituye un ideal heurístico que incluye de la manera más compleja a todos los demás niveles de racionalidad, lo que no descarta que en la práctica de la política exterior, donde predomina la incertidumbre, los tomadores de decisiones recurran a niveles de racionalidad menos abarcativos y seguros (con menos garantías de obtención de una acción objetivamente correcta), pero más manejables, como la racionalidad medios-fines del sentido común o la racionalidad limitada de Simon. Según Allison (1971), por ejemplo, el modelo del agente estrictamente racional, debe ser complementado por un modelo de proceso organizativo que involucre la influencia de las organizaciones gubernamentales (guiadas por un comportamiento adaptativo del tipo de la racionalidad limitada de Simon) en la toma de decisiones, y por un modelo de política burocrática que explique las soluciones mixtas a las que pueden llegar decisores enfrentados. Steinbruner (1974), por su parte, sostiene que los encargados de tomar decisiones minimizan los cálculos a desempeñar, limitándose a controlar un pequeño conjunto de variables críticas simples y manteniéndolas dentro de gamas tolerables. Por otro lado, muchos autores coinciden en que las decisiones de política exterior por lo general "no son el resultado de un estudio desapasionado de todos los hechos pertinentes -que, por lo demás, casi nunca se conocen en el momento de la elección- sino la consecuencia de un intento de análisis razonado, combinado con los prejuicios, las emociones intensas y presiones políticas internas del estado en cuestión, y, a veces, con una evaluación muy parcial de los intereses y metas de otros estados, todo lo cual contribuye a distorsionarlo". "Para todos los fines prácticos, la política exterior de cualquier estado puede considerarse como una formulación subjetiva que se aproxima, en mayor o menor grado, a su interés nacional objetivo" (Hartmann 1983:285).

IV) Recuérdese la analogía establecida con la visión de las ciencias sociales de Elster (1990), de la que se dedujo que un estudio científico de las relaciones internacionales debería combinar la explicación de la acción de los actores internacionales en términos de su situación objetiva (intereses nacionales, intereses institucionales, creencias, cultura, medios materiales) con la explicación causal objetiva de sus interacciones. Primero se deberá "comprender" la manera en que 
los actores internacionales elaboran, prueban y refutan sus hipótesis de acción pragmáticosubjetivas, para después "explicar" objetivamente por qué comportándose como lo hacen, los actores internacionales provocan lo que provocan, es decir cómo la interacción de los distintos comportamientos de los actores internacionales, da lugar a distintas coyunturas en la sociedad internacional. En cuanto a la predicción, habrá que tener en cuenta tanto la racionalidad como los distintos elementos de la situación subjetiva del actor internacional, de manera de poder predeterminar sus posibles cursos de acción.

V) En todo caso, se insiste en el cuidado a tener en la aplicación de la teoría de juegos, teoría que en el ámbito de las relaciones internacionales ha conducido tanto a simplificar y falsear problemas (es muy conocido el caso del erróneo análisis de la guerra de Vietnam a la manera de un juego de suma cero llevado a cabo por la Escuela de Pensamiento Estratégico norteamericana), como también a aportes interesantes entre los que merece destacarse el de Niou, Ordeshook y Rose (1989). Respecto del presente trabajo, habré de utilizar la mencionada teoría en un terreno en el que se ha demostrado particularmente adecuada, el del análisis del conflicto y la cooperación.

VI) En relación al conjunto de preferencias, resulta relevante referirse al discutido concepto de "interés nacional". Hartmann (1983) define a los intereses nacionales como a aquello que los estados procuran, o podrían, proteger o lograr frente a otros estados, a la vez que, siguiendo una interpretación aceptada entre los realistas clásicos, distingue entre intereses nacionales vitales (aquéllos por los que un estado está dispuesto a luchar, como la protección de su territorio o el resguardo de su prestigio), y secundarios (aquéllos por los que no vale la pena librar una guerra). Otra distinción, la establecida entre intereses nacionales comunes (compatibles o similares), e intereses nacionales opuestos (divergentes o antagónicos) de los estados, sirve a Hartmann para apoyar la aplicación práctica de su "teoría tridimensional". Las dimensiones de esa teoría se refieren al enfoque en términos de intereses nacionales de las relaciones entre los estados, a la estructura de las cinco respuestas organizativas posibles al "problema de poder" de los estados en la sociedad internacional (a las que habremos de prestar especial atención en la tercera parte) y al "contexto", término con el que engloba los "cuatro principios cardinales de las relaciones internacionales":

1) Las influencias de terceros: una interacción entre dos estados nunca es tan bilateral como parece, sino que siempre se tiene en cuenta la reacción potencial de otras naciones.

2) Los nexos entre el pasado y el futuro: el sentido del tiempo y las expectativas de las partes son decisivos en sus relaciones. Dos naciones que encaran un mismo problema con una experiencia histórica diferente no contemplan, de hecho, la misma cuestión ni prevén las mismas consecuencias.

3) El contrabalance de los intereses nacionales: los países elaboran un cálculo de los costos y beneficios de las distintas alternativas de acción exterior.

4) La conservación de los enemigos: los estados prudentes no tratan de acumular más enemigos de los que pueden combatir o manejar simultánea y efectivamente.

Así, la aludida distinción entre intereses nacionales comunes y opuestos, junto a la consideración de los "principios cardinales", que desde el esquema presentado aquí pueden ser vistos como principios de prudencia incluidos en las creencias (el conjunto $\mathrm{C}$ ) de los decisores de un estado, permiten a Hartmann desarrollar un modelo, de interesante utilidad predictiva, acerca de la manera en que los estados evalúan, revalúan, sustituyen, adoptan o rechazan guiarse de acuerdo a ciertos intereses dados, según sus circunstancias específicas (las relaciones buenas, malas o regulares con otros estados). En ese sentido, el modelo de Hartmann, inclusive sus diagramas sistémicos, puede ser tomado desde mi punto de vista como una herramienta a tener en cuenta a la hora de ordenar las preferencias de los decisores y de aclarar las alternativas de acción susceptibles de ser elegidas.

Sin embargo, sin desmerecer esa perspectiva, pero apuntando a su enriquecimiento, se debe traer a colación la posición de aquéllos que como Mena (1989:51) sostienen que el interés nacional "se ha convertido en un concepto elástico y ambiguo, por lo que su rol en cuanto orientador de la política 
externa resulta problemático y controversial". Según el autor citado, el interés nacional debe ser entendido como "interés nacional irreductible" término que involucra tres valores fundamentales:

a) La supervivencia física del país y de sus ciudadanos y no sólo la preservación de la integridad territorial, de la independencia y de la soberanía del Estado.

b) La libertad de un país de elegir su forma de gobierno y de los ciudadanos dentro del Estado.

c) La subsistencia económica del Estado.

Las implicancias de estos "intereses nacionales irreductibles" para la política exterior no resultan evidentes por sí mismas, según advierte Mena. Esto es así porque:

1) Una opción forzada entre estos tres tipos de intereses es difícil ya que los decisores políticos coinciden por lo general en sostener que ninguno de estos intereses debe quedar subordinado a otro.

2) El interés nacional es una meta no operacional, que no provee los mecanismos para medir y comparar políticas alternativas, medición que queda a juicio de los decisores.

3) Como consecuencia de lo anterior, los decisores tienden a ver los problemas desde su propia perspectiva o desde la de su grupo de presión.

A pesar de esto, la noción de "interés nacional irreductible" ayudaría a introducir cierta disciplina en las preferencias de los decisores, cuya función de utilidad debería priorizar la satisfacción de dicho interés. Sin olvidar que se trata de un concepto incompleto y en muchos casos inaplicable, el "interés nacional irreductible" constituiría al menos una pauta, un criterio orientativo para la elaboración de la función de utilidades de parte de los tomadores de decisiones.

Tomassini (1991) va un poco más lejos en su crítica al uso de la expresión "interés nacional" al hacer lo que podría definirse como una deconstrucción o desideologización de esa noción. Según este autor, frente al carácter no operativo y sujeto a manipulaciones del concepto de interés nacional, se impone su operacionalización mediante su reemplazo por la más amplia noción de agenda internacional. Dicha noción se refiere a la desagregación del concepto abstracto de interés nacional en un repertorio de temas más complejos, específicos y diversificados, susceptibles de ser operacionalizados. En ese sentido, el proceso de operacionalización de la agenda internacional planteado por Tomassini incluye tres pasos:

1) El establecimiento de la agenda, que incluye a su vez la identificación de los temas que podrían integrarla, la selección y jerarquización de los más relevantes y la definición específica de los mismos.

2) La fijación de los objetivos del estado en relación con los temas establecidos.

3) La determinación de los cursos alternativos de acción apropiados para alcanzar los objetivos planteados.

De esta manera, el planteo de Tomassini respecto al interés nacional (pero no en lo relativo a otros temas como el proceso de toma de decisiones) se articula con mi modelo, echando luz sobre la forma en que los decisores de acciones internacionales deberían constituir los conjuntos $\mathrm{C}, \mathrm{P}$ y $\mathrm{A}$ de la situación subjetiva de elección para incrementar su grado de adecuación objetiva a la realidad.

VII) Se dijo que, de la misma manera que en el caso de los individuos, una acción externa de un estado puede resultar estratégicamente racional pero éticamente repudiable, de modo que aquí tampoco vale extender el criterio estratégico de la teoría de la elección racional al juzgamiento ético de las acciones de los estados. Al trasladar el modelo se señaló que cuesta, sin embargo, hacer referencia a un criterio moral sostenible por entidades colectivas como los estados, por lo que se equiparó el peso del criterio moral en la elección individual con el respeto del derecho internacional en las elecciones de los estados. Subsiste el problema de encontrar un criterio moral inequívoco sobre el cual fundar objetivamente dicho derecho, cuestión a la que me referiré en la cuarta parte. 


\section{2- Un ejemplo.}

Paso ahora a efectuar una aplicación del modelo, a modo de ejemplo, a la interpretación de la decisión argentina de invadir las Malvinas en 1982.

Primero, ensayaré la reconstrucción de la situación subjetiva Ss (C.P.M.A) considerada en la deliberación de los militares argentinos. Respecto de las preferencias (P), debe tenerse en cuenta que dado que el mantenimiento del territorio constituye inequívocamente un interés nacional vital para un Estado, la recuperación del archipiélago de las Malvinas se desprende como uno de los principales temas de la agenda internacional argentina. La definición de tal tema permite, en principio, establecer dos preferencias de valor opuesto:

$\mathrm{P} 1=$ recuperar las Malvinas. Utilidad 1.

$\mathrm{P} 2=$ no recuperar las Malvinas. Utilidad -1 .

$\mathrm{P}=(\mathrm{P} 1, \mathrm{P} 2)$.

Tanto en la época de la guerra como en la actualidad, existen dos acciones posibles para satisfacer $\mathrm{P} 1$, el uso de la fuerza (el ataque armado) o la negociación (bilateral o a través de los organismos internacionales), es decir, el conjunto A cuenta con dos elementos:

$\mathrm{A} 1=$ atacar.

$\mathrm{A} 2=$ negociar (no atacar).

A $2 \mathrm{a}=$ negociar bilateralmente.

$\mathrm{A} 2 \mathrm{~b}=$ negociar multilateralmente.

¿Por qué los militares argentinos, en 1982, decidieron A1?

Si se supone que la decisión de invadir el archipiélago obedeció a una deliberación racional de la Argentina (de los decisores del gobierno militar de turno), la inadecuación de la acción debe buscarse en la deficiente caracterización de los elementos definitorios de la situación. En efecto, planteado sólo en términos estratégicos (los decisores no tomaron en cuenta el respeto al derecho internacional, aunque esto pueda justificarse como respuesta a una usurpación anterior y a la imposibilidad de hacer valer los legítimos derechos de la Argentina en un mundo sin un mecanismo global efectivo de dictaminación e imposición de justicia), el proceso de toma de decisiones estuvo fuertemente influenciado por la consideración de ciertas creencias y la evaluación de los recursos militares (los conjuntos $\mathrm{C}$ y $\mathrm{M}$ de Ss que faltaba analizar). En particular, pueden citarse cuatro creencias fundamentales en la decisión de la acción A1:

C1: la negociación (A2) no se había mostrado como una acción adecuada para la recuperación de las Malvinas.

C2: necesidad de un golpe de efecto que permitiera tapar los conflictos y reclamos internos, y perpetuar a la junta militar en el poder.

C3: Gran Bretaña no respondería en caso de una invasión argentina.

C4: Estados Unidos se mantendría neutral.

Respecto de los medios materiales disponibles (M), se disponía de fuerzas suficientes como para tomar el control del archipiélago, pero no había certeza en que éstas alcanzaran para defenderlo en caso de una reacción británica.

Todos estos elementos, pero especialmente las creencias referidas, derivadas de un pésimo análisis político de la situación, llevaron a la elección de A1 como acción adecuada para la recuperación del archipiélago:

PTD (CE)

Ss(C.P.M.A) e -----> A1 e 
$\mathrm{C}$ incluye a $\mathrm{C} 1, \mathrm{C} 2, \mathrm{C} 3$ y $\mathrm{C} 4$.

$\mathrm{P}$ incluye a P1 y $\mathrm{P} 2$.

A incluye a A1 y A2.

$\mathrm{e}=$ estado argentino.

PTD se refiere sólo a un criterio estratégico.

Aunque cargada de elementos de irracionalidad emotiva, puede decirse que en principio se trató de una acción racional imperfecta (subjetivamente correcta pero, en los hechos, objetivamente inapropiada). Sin embargo, con el transcurrir de los acontecimientos, y ante la evidencia de la incorrección de la acción adoptada, el mantenimiento de la decisión original hizo que ésta se transformara en irracional (dogmática). La incapacidad política para reconocer el error cometido y elaborar nuevas respuestas que permitieran enmendarlo, sumada a la adopción de una nueva creencia equivocada, la subestimación del poderío militar rival, y a la obstinación irracional e irresponsable de los conductores argentinos de la guerra, se pusieron de manifiesto con la decisión de "resistir hasta la última gota de sangre", en lugar de intentar alguna clase de negociación. Descartada A2a luego de la infructuosa mediación de Haig, quedaba aún margen para A2b. En ese sentido, la aceptación de las resoluciones de Naciones Unidas y del "plan de las tres banderas", que proponía un condominio transitorio del archipiélago hasta tanto se hallara una solución negociada, hubiera constituido una salida no sólo respetuosa de las normas internacionales, sino también estratégicamente racional.

El desastroso resultado de la guerra condujo necesariamente a la refutación de la hipótesis de acción adoptada, a la reconsideración del conjunto de creencias y, en consecuencia, a la revalorización de la negociación como camino estratégica y éticamente adecuado para lograr el reconocimiento efectivo de nuestros derechos soberanos.

\section{3- Los aportes teóricos del modelo al estudio de las relaciones internacionales. Hacia un realismo idealista.}

Dentro de la vasta red de enfoques presentadas brevemente en el punto b de la Introducción (punto que recomiendo ahora releer a quienes no lo tengan claramente presente), ¿cómo se inserta el modelo descripto en estas páginas?, ¿cuáles son sus aportes a la interpretación de las relaciones internacionales?

- Se tiene en primer lugar que el modelo constituye una teoría de la acción de los estados y demás actores internacionales, inducida a partir del estudio de la lógica de la acción individual cotidiana, de la que se puede deducir una interpretación original de las relaciones internacionales.

- En tanto toma al Estado como agente unificado racional y como actor fundamental de las relaciones internacionales, el modelo se adapta perfectamente a los supuestos esenciales del enfoque clásico- realista. De esta manera, resulta compatible con la mayoría de los supuestos fundacionales de Morgenthau ("es la comprobación de esta hipótesis racional (la formulada subjetivamente por el estadista que debe confrontar ciertos problemas de política exterior bajo ciertas circunstancias y contando con diferentes alternativas), en contrastación con los hechos reales y frente a sus consecuencias, lo que da sentido a los hechos de la política internacional y hace posible una teoría de la política" (Morgenthau 1948:15)), así como con diferentes líneas de ese enfoque. En particular, dado que además de resaltar la importancia de la ética destaca el lugar de la historia en la conformación subjetiva de las situaciones de decisión y en la inducción de alternativas de acción, se halla emparentado con la línea de la sociología histórica.

- La perspectiva analizada aquí incorpora, en consonancia con la síntesis teórica posterior a los debates entre los enfoques realista y científico, toda la problemática behaviorista de la mano de su 
teoría más desarrollada y depurada, la teoría de la elección racional, a la vez que se muestra compatible con la corriente sistémica, la otra línea del enfoque científico.

- Al tomar el análisis de la teoría de la elección racional, el modelo se emparenta con los enfoques más actualizados en el estudio de las relaciones internacionales, el neorrealista y el institucional. Pero como además incluye una crítica a dicha teoría, brinda nuevos elementos de análisis.

- Al admitir y explicar la posible utilización de distintos criterios de racionalidad estratégica y la participación de distintos sujetos o grupos internos de influencia en el proceso de toma de decisiones, la teoría permite incorporar análisis basados en el criterio de racionalidad limitada como el de Allison o bien en el criterio de racionalidad cibernética de Steinbruner.

- La consideración en el proceso decisorio del respeto al derecho internacional marcha en la dirección marcada por el idealismo. De hecho, el modelo presentado es un intento de elaborar, desde el behavorismo depurado, una teoría que sintetice elementos de los enfoques liberales (más influenciados por el idealismo) y conservadores (realistas), y que vaya en dirección de la línea de estudios conocida como "investigaciones sobre la paz".

- Al analizar la situación de decisión y la racionalidad del proceso de toma de decisiones desde el punto de vista subjetivo de los decisores el modelo enfatiza la importancia de la información y de la comunicación en la sociedad internacional puesta de manifiesto por el enfoque de la interdependencia y resaltada por los nuevos enfoques.

- El modelo descripto permite analizar de manera análoga la forma en que se dan las decisiones, acciones e interacciones de los actores de las relaciones internacionales, sean estados, individuos, organismos, empresas o grupos, integrándolas de modo natural y armónico en el marco de la nueva, interdependiente y compleja sociedad internacional.

- La interpretación propuesta rechaza, en cambio, la consideración de las clases sociales como actores unificados, racionales y coherentes de las relaciones internacionales que hace el paradigma de la dependencia, en atención del individualismo metodológico y de las conclusiones del teorema de Arrow. Sin embargo no excluye la existencia de situaciones de dependencia política, económica y tecnológica, ni el hecho de que ciertas acciones y relaciones de los estados puedan ser de dominación, explotación, inequidad o injusticia.

Se tiene, por lo tanto, que el modelo expuesto no sólo se comparece con el realismo, sino que cuenta además con elementos para superar sus limitaciones y desafíos heredados al neorrealismo. En particular, la interpretación de la acción de los estados y demás actores internacionales llevada a cabo hasta aquí apunta a fundar las bases de un enfoque que de una manera un tanto ambiciosa y arriesgada llamaré "realismo idealista". La expresión "realismo idealista" aparenta constituir un oxymoron, es decir, una frase del tipo de "la seca humedad" o "la negrura blanca" en las que el adjetivo contradice al sustantivo. Sin embargo, se observó en la Introducción que el idealismo no cuestiona los fundamentos esenciales del enfoque clásico- realista, sino que constituye una línea interpretativa derivada de aquél. Realismo e idealismo no resultan opciones absolutamente contradictorias, sino dos caras de una misma moneda, el enfoque clásico del Estado como actor racional. De hecho, el actual intento institucionalista de integrar su perspectiva con la neorrealista representa una nueva instancia en procura de dar solución a la vieja discusión entre conservadores (realistas) y liberales (más influidos por el idealismo), entre quienes enfatizan las dificultades para la cooperación internacional y quienes defienden esa posibilidad. De ahí que el referido intento integrador del institucionalismo tome elementos tanto del realismo como del liberalismo, y que por eso se lo catalogue también de "realismo liberal". Como señala Keohane (1992:297) la síntesis paradigmática buscada por el institucionalismo no resulta contradictoria, "dado que las aproximaciones racionalistas a las instituciones internacionales se apoyan en el realismo tratando de especificar las condiciones bajo las cuales las instituciones tienen un papel significativo". En ese sentido, mi perspectiva compartirá con el institucionalismo tanto la referencia al realismo como el énfasis en el rol de las instituciones internacionales para el logro de la cooperación. Pero a 
diferencia de tal enfoque, que al igual que el neorrealismo se preocupa por estudiar el ser concreto de las relaciones internacionales, no renunciará a la reflexión acerca del deber ser de la sociedad global, incorporando la reflexión ético- jurídica. Por lo tanto, mi perspectiva de las relaciones internacionales será más idealista que la del "realismo liberal", diferencia que precisamente permitirá distinguir al "realismo idealista" del institucionalismo. En ese sentido, y en tanto que al igual que el institucionalismo partirá de supuestos realistas, el realismo idealista evitará la ingenuidad del idealismo primitivo, afirmando que la cooperación no es necesaria sino sólo posible cuando existen ganancias mutuas y que el respeto del derecho internacional resulta difícil en una sociedad internacional anárquica.

En definitiva, de lo que se trata es de fundar las bases de un enfoque científico comprensivo de las relaciones internacionales que, en línea con el enfoque institucionalista, integre los supuestos básicos del realismo con otros tomados de los enfoques idealista y de la interdependencia, avance en la superación de las críticas del enfoque clásico- realista $\mathrm{y}$, en consecuencia, contribuya a una mejor interpretación de una realidad internacional cada vez más compleja en la que entran a la vez el conflicto y la cooperación, la interdependencia y la dependencia, la continuidad y el cambio.

Habiendo ya ubicado mi perspectiva en el marco de estudio de las relaciones internacionales, el resto del trabajo, intentará completar las mencionadas bases para un realismo idealista que cumpla con las metas aún pendientes de las ya planteadas en el final de la Introducción, y que ahora vale la pena repetir:

- No sólo admitir sino resaltar la importancia de las relaciones cooperativas entre los estados y demás actores internacionales, y no sólo de las conflictivas, considerando al ámbito de las relaciones internacionales en una situación mixta alejada de los extremos de conflicto y cooperación total.

- Apuntar a la superación dialéctica de la antagonía entre realistas e idealistas y entre neorrealistas e institucionalistas mediante la explicación de la cooperación (acción cooperativa) a partir del análisis lógico del conflicto.

- No limitarse a describir las condiciones para la cooperación en estado de anarquía, sino que ataque las causas de dicho estado inhibidor de la cooperación intentando establecer las condiciones para la instauración de un auténtico mecanismo de seguridad colectiva que permita un paso ordenado y con justicia desde la actual estructura anárquica del sistema internacional a una estructura de tipo jerárquico que, sin llegar a constituir un gobierno mundial, alcance al menos para garantizar que las acciones estratégicas de los estados sigan un camino conforme al derecho internacional.

- Considerar las circunstancias especiales ofrecidas por la distensión post guerra fría para la consolidación de un auténtico organismo de seguridad colectiva internacional, así como los peligros y oportunidades abiertos en esa dirección por la posmodernidad en general.

- Permitir estudiar, a partir de la discusión filosófica analítica acerca de la racionalidad, la decisión y la acción, fenómenos como el fundamentalismo, el nacionalismo extremo o la persistencia en el uso de la fuerza en las relaciones internacionales.

- Sostener junto con el idealismo que la paz, la libertad y la justicia son valores cuya concreción no puede ser dejada en manos de los caprichos y vaivenes del balance de poder y que, en el marco de las nuevas características de la sociedad mundial, constituye un deber de la teoría de las relaciones internacionales el intentar al menos (contando con las nuevas herramientas teóricas, teniendo en cuenta las enseñanzas del enfoque clásico- realista y sin caer en una posición ingenua) el estudio de las fórmulas que conduzcan a la solución del problema de la guerra. 


\section{Resumen de conclusiones de la segunda parte}

1) La aplicación del modelo interpretativo de la acción individual visto en la primera parte (así como la de cualquier otro modelo que contemple la idea de tomar actores colectivos como agentes internacionales unificados y racionales) a la descripción, explicación y predicción de las acciones de política exterior de los estados y demás actores de la sociedad internacional debe contemplar algunas advertencias:

(1) Para el caso particular de la asunción del colectivo Estado como actor racional unificado, las conclusiones del teorema de Arrow sobre la invalidez de la antropomorfización de los colectivos sólo pueden ser obviadas a partir de la consideración de las características del proceso de toma de decisiones previo a la acción de política exterior, acción que es siempre una acción manipulada por un individuo o grupo de individuos (miembros del poder ejecutivo y de la cancillería, grupos de presión).

(2) La acción del Estado, en tanto órgano burocrático con una política exterior coordinada, será la elegida por los decisores responsables, de acuerdo a lo que desde su perspectiva resulte más beneficioso para el Estado. Los representantes del Estado actúan en nombre del Estado y con la autoridad del Estado.

(3) Las advertencias anteriores son extensibles a aquellas entidades colectivas que puedan ser consideradas actores internacionales, es decir a aquéllas cuyas acciones tengan consecuencias en el ámbito internacional y que dispongan de un mecanismo centralizado y racional de toma de decisiones.

2) Teniendo en cuenta las advertencias señaladas, es posible trasladar el modelo desarrollado en la primera parte a la acción de los estados de la manera que sigue:

(1) Todo estado (e) es un estado en situación (S) en el marco de la sociedad internacional.

(2) La situación de un estado queda caracterizada a partir de la combinación de los elementos que componen las situaciones subjetivas ( $\mathrm{Ss}$ ) de los tomadores de decisiones, de sus conjuntos $\mathrm{C}$ de creencias, $\mathrm{P}$ de preferencias, $\mathrm{M}$ de medios materiales disponibles y $\mathrm{A}$ de acciones alternativas posibles (S (C.P.M.A.)). Mientras los conjuntos $\mathrm{C}$ y $\mathrm{P}$ pueden variar según el decisor de que se trate, $\mathrm{M}$ y A permanecen constantes, es decir, los decisores pueden disentir acerca de la historia y los intereses del estado, pero la información acerca de los medios materiales disponibles y de las acciones posibles es compartida por todos.

(3) En todo estado (e) en una situación S, la acción de política exterior se define a partir de un proceso de toma de decisiones en el que los responsables de esa política deliberan acerca de la acción más adecuada, correcta, apropiada a esa situación. En ese sentido, elaboran hipótesis de acción alternativas en las que se vincula condicionalmente la situación del estado con las acciones elegidas como adecuadas a ella. Dado que la situación del estado es subjetivamente interpretada por los decisores, la situación tenida en cuenta en la elección será aquélla que los decisores establezcan de manera consensuada o bien la sostenida por el individuo o grupo de presión que logre imponer su perspectiva.

(4) En el proceso de toma de decisiones, la deliberación de la acción adecuada a la situación del estado, es decir, la conformación de una hipótesis de acción de política exterior, se efectúa en relación a cierto criterio normativo de racionalidad, tanto en el terreno estratégico como en el ético.

(5) En el terreno estratégico, el criterio de maximización de la utilidad esperada propuesto por la teoría de la elección racional es el más refinado y abarcativo, pero diversas circunstancias conducen a los estados a adoptar otros criterios menos amplios, pero más inseguros, como el de racionalidad limitada. En el terreno ético, cuesta hacer referencia a un criterio sostenible por entidades colectivas como los estados. En este caso puede decirse que los principios éticos a ser tenidos en cuenta por ellos se hallan resumidos en el derecho internacional, de manera que el peso del criterio moral en la 
elección de la acción de un individuo, puede equipararse, a nivel de los estados, al simple respeto del derecho internacional. En el ámbito de las relaciones internacionales la moralidad se reduce a la legalidad. El respeto al derecho internacional es un criterio legal pero también moral en tanto que las normas internacionales son orientadas por principios morales.

(6) La forma lógica que describe la variante más compleja de una hipótesis de acción de política exterior de un estado es la que sigue:

$\operatorname{PTD}(\mathrm{CE}+\mathrm{DI})$

Ss (C.P.M.A) e -------> A1 e

$\mathrm{e}=$ estado.

Ss = situación subjetiva del estado en la sociedad internacional.

$\mathrm{C}=$ conjunto de creencias e informaciones manejadas por los decisores o bien conjunto de preferencias del individuo o grupo de presión que logre imponer su perspectiva.

$\mathrm{P}=$ conjunto de preferencias adoptada por consenso por los decisores o bien perteneciente al individuo o grupo de presión que logre imponer su perspectiva.

$\mathrm{M}=$ conjunto de medios materiales disponibles por el estado (fuerza militar, económica).

$\mathrm{A}=$ conjunto de acciones posibles del estado en virtud de los medios disponibles.

$\mathrm{PTD}=$ proceso racional de toma de decisiones.

$\mathrm{CE}=$ criterio estratégico de racionalidad.

$\mathrm{DI}=$ respeto del derecho internacional (criterio legal- moral de racionalidad).

Léase: "Si e es un estado en una situación dada Ss, subjetivamente considerada por los decisores y definida por por los parámetros $\mathrm{C}, \mathrm{P}, \mathrm{M}$ y A, entonces, según el criterio estratégico CE y el criterio legal- moral DI, resulta correcto que a efectúe la acción A1".

(7) La elección de la acción de un estado en una dada situación se puede dar de dos maneras:

a) Si los decisores cuentan con información completa, estos simplemente deliberan a partir de algún criterio estratégico, del legal- moral o de ambos y obtienen la acción adecuada según el o los criterios adoptados.

b) Si la información de los decisores es incompleta, estos la completan de manera subjetiva mediante la asignación de probabilidades objetivas (riesgo) o subjetivas (incertidumbre) a los estados de cosas de los que se carece de información. Una vez hecho esto, pueden darse dos circunstancias:

b1) Si la situación subjetivamente considerada por los decisores (Ss) es nueva, estos deliberan racionalmente a partir de sus criterios normativos estratégico y legal- moral y obtienen una acción adecuada a su Ss (distinta de su real situación objetiva So desconocida por ellos).

b2) Si Ss no es nueva, sino que puede asimilarse a una situación Sc considerada en el pasado, incluida en una hipótesis de acción ya deliberada y que forma parte del conjunto de creencias de los decisores, estos simplemente deducen directamente su acción a partir de tal asimilación (sin volver a deliberar).

(8) En cualquiera de los casos incluidos en 7b), una vez efectuada la acción por el estado puede ocurrir que ésta sea de hecho adecuada o inadecuada a su situación objetiva So, en el terreno estratégico, en el del respeto al derecho internacional, o en ambos. En particular pueden darse cuatro circunstancias:

a) La acción resulta estratégica y legalmente adecuada.

b) La acción resulta legalmente adecuada pero estratégicamente inadecuada. 
c) La acción resulta estratégicamente adecuada pero legalmente inadecuada.

d) La acción resulta estratégica y legalmente inadecuada.

(9) Si en cierto terreno (estratégico o legal- moral), la acción es adecuada, entonces la hipótesis queda corroborada en ese terreno y pasa a formar parte del conjunto de creencias de los decisores.

(10) Si en cierto terreno (estratégico o legal- moral), la acción es inadecuada, entonces los decisores pueden revisar y eventualmente refutar su acción en ese terreno de la misma manera que en ciencia se refutan aquellas hipótesis que no resisten la contrastación empírica.

(11) La incorrección o inadecuación de una acción puede provenir de una mala deliberación (cuando no se aplica algún criterio de racionalidad pudiéndose aplicar o bien por falta de información) o de una deficiente caracterización de los elementos de la situación (los conjuntos C, P, M y A).

(12) En base a premisa anterior pueden definirse tres tipos de acciones: irracionales (subjetivamente incorrectas), racionales imperfectas (subjetivamente correctas pero objetivamente incorrectas) y racionales perfectas (subjetiva y objetivamente correctas).

(13) La explicación de una acción de cierto estado puede hacerse suponiendo heurísticamente que ese estado actúa de acuerdo a este modelo, examinando los criterios y la situación subjetiva de elección que lo condujeron a esa acción. Dicho procedimiento sirve para interpretar no sólo la acción racional sino también la irracional.

3) El modelo anterior es generalizable a cualquiera de los nuevos actores internacionales.

4) Para el caso de los estados, el ambiguo y en muchos casos inaplicable concepto de interés nacional constituiría sólo una pauta, un criterio orientativo para la elaboración de la función de utilidades de parte de los tomadores de decisiones. En ese sentido, frente al carácter no operativo y sujeto a manipulaciones de dicho concepto, se impone su operacionalización mediante su reemplazo por la más amplia noción de agenda internacional.

5) El modelo presentado aporta elementos para el desarrollo de un enfoque científico comprensivo de las relaciones internacionales que, en línea con el enfoque institucionalista, integre los supuestos básicos del realismo con otros tomados de los enfoques idealista y de la interdependencia, avance en la superación de las críticas del enfoque clásico- realista y, en consecuencia, contribuya a una mejor interpretación de una realidad internacional cada vez más compleja en la que entran a la vez el conflicto y la cooperación, la interdependencia y la dependencia, la continuidad y el cambio. 


\title{
DE LA RACIONALIDAD ESTRATEGICA AL CONFLICTO, DEL CONFLICTO A LA COOPERACION Y DE LA COOPERACION A LA RACIONALIDAD MORAL
}

\author{
5- La lógica de la cooperación. El Estado como garantía de la acción legal y moral.
}

\section{1- Introducción.}

Las primeras dos partes de este trabajo se ocupan respectivamente de cumplir con los primeros dos objetivos planteados en la Introducción, es decir, el establecimiento de un modelo interpretativo de la acción racional individual y su traslado al análisis de la acción de los estados y demás actores internacionales. Una vez trasladado el modelo, las partes tres a cinco se ocuparán de su aplicación al desarrollo de un enfoque comprensivo de las relaciones internacionales. En particular, la tercera parte constituirá un estudio personal de la lógica del conflicto y la cooperación internacional, una aplicación de mi perspectiva a la investigación de la relación entre racionalidad estratégica y conflicto, al análisis del pasaje del conflicto a la cooperación y al estudio de la vinculación entre cooperación estratégica y racionalidad moral. En ese sentido, el quinto capítulo iniciará el camino llevando a cabo, a partir de una interpretación original del pensamiento de Maquiavelo y Hobbes, un análisis de la relación entre la racionalidad estratégica de los individuos y la formación del Estado como garante de la acción moral y legal. Dicho análisis se basará inicialmente en un trabajo ya publicado (Daló 1994) y obedecerá a distintos intereses, por un lado efectuar una interpretación nueva de Maquiavelo y Hobbes, por otro, introducir mi punto de vista acerca de la lógica de la cooperación, y en tercer lugar, obtener elementos a ser utilizados en el capítulo 6, en el que se trasladarán las conclusiones de esta sección al análisis de la posibilidad de instauración de un auténtico régimen de seguridad colectiva internacional.

\section{2- Maquiavelo: la necesidad del Príncipe.}

En una carta dirigida a su amigo Vettori, Maquiavelo señala que su obra maestra, El Príncipe (1532), constituye el resultado de sus estudios "entrando en las cortes de los antepasados" a fin de "conversar con ellos y preguntarles las razones de sus actos". A su vez, en el mismo inicio del libro, le ofrece a Lorenzo de Médicis aquello que tiene más valor de lo que posee, "el conocimiento de las acciones de los grandes hombres". Maquiavelo (1469-1527) resulta así uno de los primeros pensadores en marcar una tendencia que se hará patente en el siglo XVII, consistente en el paso del modelo de conocimiento clásico, el cual suponía que conocer un objeto era equivalente a poder clasificarlo según géneros y especies, a un nuevo modelo, moderno, según el cual conocer algo equivale a poder calcular sus movimientos. En otras palabras, mientras el primer modelo intentaba responder a la pregunta ¿qué es X? (¿qué es el bien?, ¿cuál es el fin último del hombre?), el segundo procurará dar una solución a la pregunta ¿cómo actúa $X$ ?

¿Cómo actúan entonces los príncipes de su época? Para Maquiavelo su conducta se rige según la virtud (virtú). En ese sentido, la esencial noción maquiaveliana de virtú constituye el factor interno de la acción política, en contraposición a la fortuna, que es vista como un factor externo, circunstancial, azaroso. La virtú es la capacidad mediante la cual un príncipe organiza y orienta su acción hacia fines deseados. Virtud es capacidad de adaptación a las circunstancias. Maquiavelo afirma que un príncipe virtuoso será aquel capaz de actuar de una manera que le permita conseguir gloria y mantener el poder (que sólo cuenta a su vez cuando es el medio para alcanzar la gloria). 
Desde la perspectiva de mi modelo interpretativo de la acción puede decirse en principio que Maquiavelo describe una racionalidad estratégica cuyo criterio sería la maximización de la gloria y el mantenimiento del poder. Es decir, los valores máximos de las funciones de utilidad subjetiva de los príncipes serían atribuidos a la gloria y al mantenimiento del poder. La manera de maximizar la función de utilidades sería a través de la virtú, a partir de un cálculo estratégico (se tienen en cuenta las posibles acciones de otros príncipes) que permitiera establecer los medios (las acciones) correctos para el logro de los fines buscados. Dicho cálculo estratégico debería apoyarse en las circunstancias, en la oportunidad (disponibilidad de los medios materiales) y necesidad (limitaciones externas), que dan marco a la situación del príncipe, a la vez que no podría estar exento de riesgo, incertidumbre, ni de cierto componente azaroso, atribuidos a los caprichos de la diosa Fortuna (el príncipe nunca tiene información completa). La acción social y política surgiría así de una tensión dialéctica entre las condiciones objetivas (condicionantes pero no determinantes de la acción) y los factores subjetivos (la voluntad transformadora de los hombres). Se puede interpretar así a la virtud, como a la capacidad estratégica de establecer y elegir la hipótesis de acción medios- fines adecuada en determinadas circunstancias. Téngase en cuenta también que el sentido maquiaveliano de virtud está estrechamente ligado a su concepto de prudencia, entendida aquí como sentido de la anticipación, capacidad de prever riesgos. En el capítulo XIV de El Príncipe se señala que "Los historiadores alaban a Filipómenes, príncipe de los aqueos, que en la paz pensaba constantemente en el arte de la guerra y cuando se hallaba acampando con sus amigos se detenía a menudo a discutir con ellos:"si el enemigo ocupase aquella colina y nosotros nos encontráramos aquí con nuestro ejército ¿de quién sería la ventaja? ¿Cómo podríamos salir a su encuentro observando las reglas oportunas? ¿Qué deberíamos hacer si deseáramos retirarnos? Y si fueran ellos quienes se retirasen ¿de qué modo los perseguiríamos?". Y durante el camino iba pensando en cuantas cosas pueden presentársele a un ejército. Escuchaba la opinión de sus amigos y expresaba la suya corroborándola con las razones apropiadas y merced a este continuo ejercicio hacía imposible que luego, dirigiendo sus tropas, tropezase de dificultades para las que careciese de oportuno remedio". En esta cita de fundamental importancia desde mi enfoque de la acción, se evidencia el mecanismo de la deliberación de la premisa mayor (de la hipótesis de acción adecuada) que he tratado de describir en el capítulo 2 con ayuda de la teoría de la elección racional.

Maquiavelo pretende en El Príncipe examinar las acciones de los hombres insignes, para transmitir sus enseñanzas a los príncipes contemporáneos a manera de consejos, de imperativos hipotéticos de prudencia (expresados a través de un deber ser sin sentido moral o absoluto, sino meramente estratégico), que los nuevos príncipes deberán tener en mente, como Filipómenes tenía en cuenta las soluciones para los posibles problemas, si desean la gloria y el mantenimiento del poder. Así, en tanto útiles a los fines del príncipe, las acciones decididas como medios para su consecución podrán ser catalogadas de virtuosas (estratégicamente racionales) o de "irracionalidades políticas".

Maquiavelo es el primero en separar los dos campos de la racionalidad de la acción, el de la racionalidad estratégica y el de la racionalidad moral, el de la acción política y el de la acción moral, al admitir que una acción moralmente racional no siempre es estratégicamente racional y viceversa. En ese sentido, se aparta tanto de la perspectiva de los moralistas clásicos como de la de los humanistas del Renacimiento. Los moralistas romanos, señala Madanes (artículo inédito 1), describían al hombre virtuoso como dotado de distintas cualidades, entre ellas la prudencia, la justicia, la fortaleza y la templanza, además de "la honestidad". En De los deberes de Cicerón se observaba que muchos piensan que "una cosa puede ser moralmente recta sin ser conveniente, y conveniente sin ser moralmente recta", pero se concluía que esto es un engaño, pues sólo por métodos morales se puede esperar alcanzar los objetos de nuestros deseos ya que "la conveniencia nunca puede entrar en conflicto con la rectitud moral". Este análisis fue adoptado de nuevo en su integridad por los escritores de libros de consejos para príncipes del Renacimiento, quienes respaldaban sin vacilar la postura de que el rumbo racional de la actuación del príncipe debía ser únicamente el moral, argumentando en favor de ello con tal fuerza que al fin lograron que se convirtiera en proverbio la expresión "la honradez es la mejor política". Insistían con una específica 
objeción cristiana según la cual las aparentes ventajas conseguidas a través de injusticias son anuladas con el justo castigo divino en la vida futura. Frente a ellos, la crítica que hace Maquiavelo del humanismo clásico y del de su época es simple pero devastadora. Al respecto, argumenta que si un gobernante quiere alcanzar sus más altos propósitos, es decir la gloria y el mantenimiento del poder, no siempre debe considerar racional (aquí se dirá estratégicamente racional), el ser moral. Por el contrario, hallará que cualquier intento serio de "practicar todas aquellas cosas por las que los hombres se consideran buenos", acabará en una ruinosa e irracional política.

Estas observaciones acerca del pensamiento de un maestro de la acción, resultan interesante para el análisis de la teoría de la elección racional, a la que se ha acusado de cometer el error inverso, es decir, de extender su criterio utilitarista estratégico a la interpretación de las acciones morales. En ese sentido, podrá parecer contradictorio, a primera vista, el hecho de que se ayude a fundamentar mi crítica a la extensión del criterio de dicha teoría al terreno de las acciones morales a partir de un autor como Maquiavelo, al que se etiqueta comunmente como inmoralista. Quien haya leído con atención su obra habrá comprobado, sin embargo, la superficialidad de esa caracterización.

Maquiavelo es también el primero que fundamenta y legitima el Estado moderno apelando a una reflexión de la política como ciencia libre de la subordinación clásica de la moral. Toda la filosofía política clásica a partir de la República de Platón, que es la filosofía tanto de los moralistas romanos que analizamos antes, como de los escritores de "espejos de príncipes" del Renacimiento a los que Maquiavelo se opone, está basada en un análisis teleológico de la acción social que liga a la racionalidad de la acción con el fin propio del hombre y la sociedad. ¿Cuál es el fin propio del hombre? (Recuérdese la pregunta propia del modelo clásico de conocimiento, es decir ¿qué es X?). Platón dirá que, dependiendo de la clase a la que pertenezca cada hombre, éste será el de llevar a cabo de manera virtuosa su función propia. La virtud propia de la clase gobernante es la prudencia (acompañada del ejercicio de las virtudes morales), la de los guardianes la valentía y la de los artesanos el hacer bien su arte. La virtud propia de la sociedad es la justicia, que no es la virtud propia de una clase, sino que constituye el resultado que se logra en una sociedad en la que cada clase cumple adecuadamente su función propia. Así, el criterio de racionalidad de la acción quedaba ligado a las virtudes morales (el fin de los príncipes) y a la justicia (el fin de la sociedad). Todas las acciones que condujeran a dichos fines eran racionales, las demás irracionales. Racionalidad y moralidad quedaban unidas por el criterio de racionalidad adoptado. Maquiavelo será, como se dijo, el primero en separarlas al desplazar a la sabiduría y a la virtud moral como fines supremos del príncipe, por la gloria y el mantenimiento del poder. Resulta interesante al respecto extraer del capítulo XV de El Príncipe el siguiente párrafo: "Muchos han imaginado repúblicas y principados que ni vieron nunca ni existieron en realidad (Maquiavelo se refiere a la República de Platón). Hay, en efecto, tanta distancia entre cómo se vive y cómo se debería vivir que aquél que abandona lo real centrándose en lo "ideal" camina más hacia su ruina que hacia su preservación, pues el hombre que pretenda hacer en todos los sentidos profesión de bondad fracasará necesariamente entre tanto bellaco. Es, por ello, necesario que un príncipe, si desea mantenerse como tal, aprenda a poder no ser bueno y a usar o no semejante capacidad en función de las necesidades y circunstancias".

Maquiavelo no es un inmoralista, sino que simplemente da cuenta de las auténticas "relaciones de producción de la acción". Como observador agudo de su realidad y de la de sus antepasados, se limita a describir lo que ve: la racionalidad estratégica y la moral no coinciden, sobre todo en el ámbito de los príncipes "contra los cuales no hay tribunal al que recurrir". En ese sentido será el primero en insinuar la necesidad de la existencia de un poder soberano como condición previa, como garantía de la acción moral.

¿Cuál es el objetivo que mueve a Maquiavelo a su reflexión sobre el Estado? Puede decirse en principio que, además del deseo de mejorar su precaria situación personal, la idea obsesiva que guía su trabajo es la de la unidad nacional italiana. El medio que Maquiavelo considera como necesario para tal fin es la constitución de un Estado grande y poderoso, capaz del esfuerzo requerido para arrojar fuera de Italia a los invasores extranjeros. En su opinión, dicho Estado puede tomar la forma o bien de un principado o bien de una república (Maquiavelo se muestra aprensivo hacia las formas 
de gobierno intermedias). Así, mientras en El Príncipe se dedica al análisis del principado, en los Discursos se aboca más específicamente a la república. La diferencia esencial que encuentra entre estos dos tipos de Estado es de orden cuantitativo: los estados están regidos por uno (principados) o por varios (que pueden ser pocos o muchos según sean las repúblicas aristocráticas o democráticas). La otra diferencia es que además las repúblicas permiten asegurar la libertad individual de los ciudadanos.

Maquiavelo sostiene en sus Discursos que el mejor Estado es el Estado de hombres libres, a la vez que asegura que la manera de lograrlo es a través de una república, más precisamente de una república mixta (con la participación de la nobleza y el pueblo) como la de los romanos. Un principado, en cambio, es incompatible con la libertad de los ciudadanos, cuyos fines son impuestos por los príncipes. Ahora bien, en el caso de la república, ¿cómo se establece y mantiene un Estado libre sin que la libertad individual degenere en la anarquía? Maquiavelo dice que es a través de la virtud. Sin embargo, si bien la distinción entre gobernantes y gobernados parece ser sólo convencional, Maquiavelo parece hablar de virtud en dos sentidos distintos, según se refiera a "los que mandan" (los jefes de la república o bien el príncipe) o a los gobernados. En el caso de los gobernantes la virtud es la virtú maquiavélica. La libertad de todos los integrantes de una república se defiende con la virtú de los gobernantes, que asegura la independencia del Estado de otros que pretendan conquistarlo y así arrebatarle la libertad a sus ciudadanos, de la misma manera que un príncipe virtuoso defiende a su pueblo de ser sojuzgado. En el caso de los gobernados, en cambio, Maquiavelo parece referirse a las virtudes ciceronianas de los humanistas clásicos. Para evitar la servidumbre y asegurar su libertad individual, los ciudadanos de una república deberán cultivar las virtudes políticas y ser devotos de una vida al servicio público. Caso contrario (observar la semejanza de este argumento con el de los moralistas romanos), la opción por los propios fines privados en lugar del bien público, será vista como una inhabilidad para reconocer que la propia libertad depende del compromiso hacia una vida de virtud y servicio público.

Se tiene entonces que las acciones de los gobernantes y las de los gobernados, tanto en el principado como en la república, son juzgadas de distinta manera. Mientras las de los príncipes son susceptibles de ser evaluadas a la luz de un criterio estratégico que permite establecer si resultan o no virtuosas, nada se dice del modo de evaluar la corrección o no de las acciones de los integrantes del pueblo. En rigor de verdad, al definir a la virtú en términos de gloria y de mantenimiento del poder, Maquiavelo queda condicionado a hablar de acciones estratégicas únicamente en relación a las acciones de los gobernantes. ¿Cómo podría un integrante del pueblo tener como objetivos a la gloria y al mantenimiento del poder?

Ahora bien, según Colonna d'Istria y Frapet (1980), todo el problema del arte político en Maquiavelo, consiste no en limitar el deseo de gloria, sino en llevarlo por la buena dirección, de manera que pueda coincidir con el bien común. El bien común es un objetivo estratégico compartido por gobernantes y gobernados, que incluye entre otras cosas el mantenimiento del Estado y de la libertad, y la obtención de riquezas (incluso con el sometimiento de otros pueblos). En ese sentido, todos participan en su concreción: es alcanzado y resguardado en el exterior a través de la virtú estratégica de los gobernantes, mientras que en el orden interno se mantiene con la virtud moral de los gobernados. No obstante, si bien los príncipes se encuentran justificados en la utilización de distintas argucias estratégicas para llevar a cabo sus fines, no todo les estaría permitido. Maquiavelo hace una alusión al tirano Agatócles en la que se aclara que "no se puede considerar virtud al asesinato de los ciudadanos, la traición a los amigos, ni a la carencia de palabra, humanidad y religión. Tales medios pueden proporcionar poder, pero no gloria". La crueldad de Agatócles no es un medio estratégico adecuado para mantener el Estado y en consecuencia para el bien común. Existiría entonces, para Maquiavelo, cierta base moral difusa, reconocida por el pueblo, que debería ser en general respetada por todos, incluso por los príncipes que busquen llevar a cabo sus fines. Así y todo, sin llegar al exceso de transgredir esa mínima base, los príncipes son libres de contradecir la rígida moral ciceroniana en virtud de las consecuencias que para el Estado tienen sus acciones. Queda claro que en todo momento el gobernante no actúa de manera moral sino 
estratégico - política. Sin embargo, a partir del ejemplo de Agatócles y de otras pocas citas podría interpretarse que Maquiavelo sostiene un punto de vista ambiguo en lo relativo a la moral: por un lado, para los gobernantes, sería partidario de una ética consecuencialista del tipo que Weber (1919) llama "ética de la responsabilidad", mientras que al pueblo se le exigiría una "ética de la convicción", independiente de las consecuencias. Creo al respecto que esta interpretación contradice precisamente el punto esencial de la obra de Maquiavelo: la separación neta y clara entre racionalidad estratégica (política) y racionalidad moral (ética). Insisto en que la ambigüedad consiste en reconocer la virtú de los gobernantes ignorando el carácter estratégico de la acción de los gobernados, a quienes en cambio se les reclama "convicción" en el respeto no sólo de la base moral mínima sino también de las virtudes ciceronianas en general. Eso sí, Maquiavelo no dice que los príncipes estén aplicando ningún tipo de ética sino estrategia política.

Desde una perspectiva crítica contemporánea, la extensión del cálculo estratégico a los gobernados permite abarcar no sólo las acciones de los gobernantes de las que se ocupa Maquiavelo (aquéllas que buscan la gloria y el mantenimiento del poder), sino también las acciones del pueblo (Hobbes da un paso significativo al hablar del mantenimiento de la vida como fin de las acciones de los hombres). Los hombres del "vulgo", desde ya, no son malos por definición como afirma Maquiavelo, sino que sus acciones estratégicas no son necesariamente morales. Es más, si el Estado no está fundado, si no hay "tribunal al que recurrir", como en el caso de las relaciones entre príncipes, aquél que actúe moralmente podrá también "sucumbir ante tanto bellaco". La extensión del cálculo estratégico a los gobernados resulta además más coherente con las propias afirmaciones de Maquiavelo sobre la libertad individual.

Mi interpretación de Maquiavelo surge también como más consistente con su predilección por la república mixta, en la que reconoce la conflictividad como base de la preservación de ese tipo de Estado (a diferencia de los griegos, para quienes el conflicto era sinónimo de degradación social). Puede decirse que dicha conflictividad no es debida sino a la existencia de intereses estratégicos contrapuestos entre las clases sociales, incluso al sentido que cada clase da al bien común. Según Bobbio (1987), para Maquiavelo "los "tumultos" que muchos condenan no son la causa de la ruina de los Estados sino la condición para que se promulguen buenas leyes en defensa de la libertad,..., tal aseveración expresa claramente una nueva visión de la historia, que podríamos llamar justamente "moderna", de acuerdo con la cual el desorden, no el orden, el conflicto entre las partes contrapuestas, no la paz social impuesta desde arriba, la desarmonía, no la armonía, los "tumultos, no la tranquilidad derivada de un dominio irresistible, son el precio que se debe pagar por el mantenimiento de la libertad".

En una república mixta, la libertad permite la búsqueda de los intereses estratégicos particulares (y de clase), esto lleva al conflicto (los "tumultos"), del que surgen buenas leyes que permiten la conservación del Estado. En un principado, en cambio, no se permite la libertad de los gobernados, en consecuencia no hay conflicto y las buenas leyes son en este caso las impuestas desde arriba por el príncipe. Esto no significa, claro está, que el pueblo de los principados no conozca sus intereses ni que sea incapaz de diseñar estrategias para defenderlos. Parece aquí haber un doble juego en lo relativo al papel del conflicto: no se acepta en un principado pero se considera positivo en una república mixta.

Antes de terminar, será bueno hacer un resumen que integre los distintos aspectos tomados separadamente en esta interpretación. El objetivo principal al que Maquiavelo pretende contribuir es a la unión de Italia, a "mantener la unidad en un pueblo corrompido y salvarle de la anarquía". Para tal fin sostiene como necesaria la formación de un Estado poderoso (una república o un principado). El concepto de necesidad aparece aquí como condición limitadora de la acción en las circunstancias de su producción, que conduce a la virtú (capacidad estratégica de adaptación a las circunstancias) del fundante del Estado a llevar a cabo la acción adecuada en dichas circunstancias (necesaria en tanto acotada por la situación). Pero, a su vez, un Estado no se puede mantener si la necesidad no hace que los hombres naturalmente malos se tornen buenos. La manera de hacerlo es a través de las leyes. Extendiendo la virtú a todos los integrantes de la sociedad, se encuentra que lo anterior 
equivale a decir que para el mantenimiento del Estado necesario para la unidad se necesita de leyes que orienten el cálculo estratégico individual hacia el bien común. Más precisamente puede decirse que la función del Estado en Maquiavelo, y a la vez la condición misma de su existencia, es elaborar leyes que trasladen el cálculo estratégico individual del interés privado al interés público.

Se ha visto cómo de las dos formas de Estado aceptadas por Maquiavelo, éste se inclina por la república, en particular por la república mixta de tipo romano, a la que le atribuye mayor estabilidad (mantenimiento del poder, utilidad). Sin embargo, y aquí es donde se inserta El Príncipe (escrito por Maquiavelo en una pausa de sus Discursos), no descarta al principado como otro medio posible para lograr la unidad y la gloria de Italia. En ese sentido, Maquiavelo sostiene la necesidad de un príncipe virtuoso que funde el Estado instaurando las instituciones republicanas y las leyes que conduzcan a una forma de gobierno más útil, en la que predomine el interés público sobre el privado y en la que se garantice la libertad individual (de maximizar su propia utilidad) a la que aspira todo hombre. El Príncipe constituiría entonces una guía para que el príncipe fundante siente una estructura básica de dominación. Así, el principado en el que se le niega la libertad a los gobernados, puede aparecer como una transición a la instauración de las instituciones republicanas. Maquiavelo piensa en Rómulo, que fundó Roma por medio de acciones inmorales pero estratégicas (mata a su hermano), para dotarla luego de sus instituciones republicanas, y a quien "los hechos acusan pero las consecuencias excusan". El príncipe fundante, virtuoso, es conciente en cierta medida de la corrección (racionalidad) moral (toda la sociedad civil, desde su nacimiento, "comienza por conocer qué es bueno y honesto y a distinguirlo de aquello que es vicioso y malo" (Discursos, I, 2)), de que la racionalidad estratégica precede a la moral ("los guerreros nacen antes que los filósofos") y también de que para instaurar la moral (las leyes), es necesario a veces contradecirla.

Sobre la base de un crimen, de la acción inmoral pero virtuosa de un príncipe, puede fundarse una república mixta asentada en un derecho que garantice la justicia, la libertad individual (entendida no sólo en sentido negativo, sino orientada también al bien común) y en consecuencia las acciones con arreglo a valores.

Se dijo anteriormente que Maquiavelo acepta la libertad y el conflicto en la república mixta, mientras que los rechazaba para el principado. Por consiguiente, puede interpretarse que en virtud de la necesidad de la unión, para imponer el Estado, el "pecador original" debe eliminar la posibilidad de conflictos que enturbien su acción, sin embargo, una vez instaurada las instituciones y constituida la república mixta, la discusión interna redundará en "buenas leyes" y en la propia conservación de dicho Estado (el conflicto sólo aparece como constructivo en el marco de un Estado sólidamente constituido). Es decir, el príncipe necesitaría imponer el Estado para evitar los conflictos derivados de la acción estratégica de los gobernados, orientando la cooperación a partir de la cual resulta posible la acción legal y moral.

Se vuelve a comprobar que resulta injusto tildar a Maquiavelo de inmoralista, como lo hacen aquellos que presentan aisladamente y como máximas de moral las que son de política y dependen de determinados supuestos, cuando en realidad no es más que el primero en insinuar, invirtiendo la relación clásica, la existencia de un poder soberano como condición previa de la moral, fundamentando además su constitución, en el miedo recíproco de los ciudadanos, en el deseo (preferencia) de seguridad propio de los gobernados. A partir de Maquiavelo comienza a tomar cuerpo la línea de pensamiento que fundamenta su reflexión política en la suposición de la existencia de un estado de conflicto (de intereses contrapuestos) universal. Este conflicto es entre los Estados y entre los ciudadanos dentro de cada Estado. El Estado se origina en esta situación de conflicto, en la que la política constituye el arte de dominar las diferentes estrategias existentes para afirmarse en el poder. A diferencia de los clásicos, para los que la organización de la sociedad era consecuencia de un orden, de un equilibrio estático (en el que cada individuo cumplía su función sin salirse de ella), Maquiavelo va a ser el primero en basar el origen y la sustentación del Estado (los "tumultos" no son la causa de la ruina de la república mixta, sino la condición para que se promulguen buenas leyes en defensa de la libertad) en la conflictualidad. Interpretándolo desde esta 
corriente, El Príncipe es un manual que enseña cómo mantenerse en el poder (cómo maximizar la utilidad de un gobernante, y en consecuencia de un Estado) en ausencia de un poder soberano con la fuerza suficiente para instaurar leyes que permitan garantizar la acción moral (o conforme a la moral), tanto entre diferentes estados como a nivel interno. El principal representante de dicha línea de pensamiento será Thomas Hobbes.

\section{3- Hobbes: la necesidad del Estado.}

Hobbes, a diferencia de Maquiavelo, no divide a la sociedad en gobernantes y gobernados sino que, como la mayoría de los pensadores del siglo XVII, sostiene claramente la igualdad de todos los hombres. Más precisamente, entiende que si bien los hombres pueden o no ser iguales por naturaleza, de todas maneras ningún hombre acepta ser tratado como si no fuera igual al resto, de lo que se deriva que los hombres suponen que son todos iguales entre sí. Además, siguiendo la línea de los pensadores modernos, afirma que a pesar de dicha igualdad, es imposible ponerse de acuerdo acerca del bien común supremo de todos ellos ("no existe el finis ultimus ni el summun bonum"). No obstante, sí se puede determinar el mal mayor que todo hombre quiere evitar: la muerte violenta. El miedo a la muerte violenta constituye así la pasión que iguala a los hombres y que permite un análisis general de sus acciones (a diferencia de Maquiavelo, para quien gobernantes y gobernados tienen diferentes motivos para actuar).

El temor a la muerte como punto de partida del análisis hobbesiano de la acción de los individuos, puede encuadrarse dentro de las dos interpretaciones más extendidas que se han hecho de su visión de la naturaleza humana. Una de ellas, la interpretación clásica, se basa en la descripción marcadamente negativa del hombre presente en su obra. "El hombre es el lobo del hombre", naturalmente malo (en este aspecto sigue a Maquiavelo), por lo que librado a sus instintos, es decir en ausencia de un poder soberano que ponga límites a esta inclinación, se encuentra en estado de guerra de todos contra todos, tal es el "estado de naturaleza".

La interpretación liberal, en cambio, asocia el planteo de Hobbes con el estudiado juego del "dilema del prisionero", permitiendo una interpretación desde la teoría de la elección racional. Desde este punto de vista, la posición de Hobbes puede sostenerse sin recurrir a la "maldad natural" del hombre ni al pecado original, sino tomando al hombre estratégicamente racional.

Puede partirse, pues, de esta segunda interpretación y reconstruir, desde mi propia perspectiva, el análisis de Hobbes en los capítulos 12 al 20 del Leviatán (1651). Se dijo que para Hobbes todos los hombres son iguales y se interpretó que, como tales, se comportan de manera racional estratégica. "De esta igualdad en cuanto a la capacidad se deriva la igualdad de esperanza respecto a la consecución de nuestros fines" (Hobbes 1651:101). Pero a su vez, los hombres tienen intereses contrapuestos, lo que genera un estado de temor y de desconfianza recíproca. Sucede entonces que, en ausencia de un poder soberano que garantice la cooperación, sin garantía ni conocimiento de las acciones de los otros, la misma racionalidad estratégica de los agentes los arrastra a un resultado irracional, a un estado de conflicto de una utilidad menor a la que se obtendría de la cooperación. Así, es paradójicamente el temor a la muerte el que conduce a la muerte. Hobbes concluye que "durante el tiempo en que los hombres viven sin un poder común que los atemorice a todos, se hallan en la condición o estado que se denomina guerra, una guerra tal que es de todos contra todos" (Hobbes 1651:102). La búsqueda estratégica individual lleva, en ausencia de un Estado que monopolice la fuerza en defensa del derecho, a un estado de guerra. Sin embargo, aclara que no se trata de una guerra permanente en el sentido de una batalla, sino de una conflictualidad latente, de una disposición manifiesta a la lucha durante el tiempo en el que no hay seguridad de lo contrario. En esa situación, en la que los hombres viven sin otra seguridad que la de su propia fuerza, "existe continuo temor y peligro de muerte violenta, y la vida del hombre es solitaria, pobre, tosca, embrutecida y breve" (Hobbes 1651:103). 
Más adelante Hobbes señala que "En esta guerra de todos contra todos, se da una consecuencia: que nada puede ser injusto. Las nociones de derecho e ilegalidad, justicia e injusticia están fuera de lugar. Donde no hay poder común, la ley no existe: donde no hay ley no hay justicia. En la guerra, la fuerza y el fraude son las dos virtudes cardinales" (Hobbes 1651:104). Es decir, en ausencia de un Estado son imposibles la moral y un derecho basado en ella. Como se ve esto está íntimamente ligado a las conclusiones de Maquiavelo respecto a la manera de actuar de los príncipes que en ausencia de una instancia superior de poder, deben apelar a la virtú estratégica y no a la virtud moral para lograr sus objetivos "entre tanto bellaco". Tanto en Maquiavelo como en Hobbes, el actuar moralmente en una situación de las descriptas como de estado de naturaleza no tiene sentido, ya que no están dadas las condiciones que garanticen las relaciones morales. A su vez, desde el punto de vista estratégico tal manera de actuar resulta irracional y atenta contra el derecho de cada individuo de defender su propia existencia.

¿Cómo salir del estado de naturaleza y de este modo asegurar nuestra vida? Hobbes dice que los hombres pueden hacerlo "en parte por sus pasiones, en parte por su razón" (Hobbes 1651:104). Respecto de las pasiones que llevan a los hombres a superar el estado de guerra la fundamental es el temor a la muerte, aunque también menciona al "deseo de las cosas que son necesarias para una vida confortable y la esperanza de obtenerlas por medio del trabajo" (Hobbes 1651:105). Sostiene entonces que los objetivos que buscan todos los hombres son la paz y la seguridad, pero no como bienes supremos, teleológicos, sino en oposición al mal mayor que representa la muerte violenta. En otras palabras, la paz y la seguridad constituyen las máximas prioridades (preferencias) del hombre frente al costo máximo que supone la muerte violenta.

En lo que concierne a la razón, ésta "sugiere adecuadas normas de paz, a las cuales pueden llegar los hombres por mutuo consenso" (Hobbes 1651:105). Tales normas de paz son llamadas "leyes de naturaleza" y definidas como preceptos generales que prohiben al hombre hacer algo que vaya en contra de la preservación de su vida. Más precisamente, puede decirse que se trata de imperativos hipotéticos de acción, imperativos de prudencia que sugieren acciones adecuadas para lograr el fin de evitar la muerte. Las leyes de naturaleza se inscriben dentro del "derecho de naturaleza" que "es la libertad que cada hombre tiene de usar su propio poder como quiera, para la conservación de su propia naturaleza, es decir de su propia vida, y por consiguiente, para hacer todo aquello que su propio juicio y razón considere como los medios más aptos para lograr ese fin" (Hobbes 1651:106). A su vez, la libertad se entiende, acorde con el mecanicismo del siglo XVII, como "libertad para", es decir, de la misma forma que en Maquiavelo, como ausencia de impedimentos externos que reduzcan el poder del hombre de hacer lo que quiera.

Ordénense estas últimas consideraciones desde mi modelo interpretativo. Se puede salir del estado de naturaleza en base a las pasiones y a la razón. Las pasiones son los estados afectivos que determinan nuestros intereses e intenciones, es decir nuestras preferencias. Por lo tanto, y apartándose del barroquismo hobbesiano, pueden dejarse de lado las pasiones y hablar en su lugar de intereses, intenciones, fines estratégicos (evitar la muerte violenta, obtener cosas necesarias para una vida confortable) o simplemente de preferencias subjetivas.

La razón proporciona en cambio, reglas de prudencia que indican los medios "más aptos para lograr" esos fines estratégicos. El hombre tiene libertad para elegir los medios (las acciones) más adecuadas (más virtuosas diría Maquiavelo) para el logro de dichos fines. Todo el Leviatán está lleno de citas que demuestran el carácter condicional que para Hobbes tenía la acción. Evidentemente, la razón de la que habla Hobbes es la razón estratégica, por lo que el criterio de racionalidad estratégica de la teoría de la elección racional (la maximización de la utilidad esperada) puede extrapolarse a su teoría a partir de las numerosas frases que hablan de acciones correctas como "medios más aptos para el logro de los fines".

Sigamos ahora con el argumento de Hobbes. ¿Qué dicen las leyes de la naturaleza? La primera ley aconseja a todo hombre buscar la paz y seguirla mientras sea posible, pero defenderse por todos los medios y utilizar las ventajas de la guerra en caso contrario. Sin embargo es la segunda la que 
resulta clave para la continuación del razonamiento: "que uno acceda, si los demás consienten también, y mientras se considere necesario para la paz y defensa de sí mismo, a renunciar este derecho a todas las cosas y a satisfacerse con la misma libertad, frente a los demás hombres, que les sea concedida a los demás con respecto a él mismo" (Hobbes 1651:107). Así, la salida del estado de naturaleza es posible mediante un pacto en virtud del cual los hombres renuncian a ciertos derechos transfiriéndolos a un poder soberano por encima de ellos. Las leyes de naturaleza marcan, por lo tanto, el camino de salida del dilema del prisionero a través de la cooperación, marcando el paso entre la racionalidad estratégica individual y la colectiva.

Se trata pues de un pacto estratégico por el cual se pasa de un juego no cooperativo a uno cooperativo (en el que las reglas de acción recíproca están garantizadas). En ese sentido, Hobbes introduce la regla de oro en el campo estratégico, señalando que la medida de la renuncia de los derechos de un hombre estará en relación con los derechos que no desee que los demás utilicen en su contra.

El pacto tiene además carácter condicional, como se adelantó al considerar a las leyes de naturaleza como imperativos hipotéticos. "Doy para que me den", sería la estrategia individual de la cooperación, es decir "Si me dan entonces doy" ("Si no me dan, no doy"). Al respecto, cuando se refiere a la nulidad de los pactos que obliguen a alguien a no defenderse a sí mismo con la fuerza contra la fuerza, dice que "aunque un hombre pueda pactar lo siguiente: Si no hago esto o aquello, matadme, no puede pactar esto otro: Si no hago esto o aquello, no resistiré cuando vengan a matarme" (Hobbes 1651:115).

El pacto es por lo tanto condicional y estratégico, y convierte la estrategia (utilidad) individual en colectiva. En el estado de naturaleza, cuando las partes hacen un pacto confiando una en otra, cualquier sospecha razonable es motivo de nulidad. "En efecto, quien cumple primero no tiene seguridad de que el otro cumplirá después". "Pero cuando existe un poder común sobre ambos contratantes, con derecho y fuerza suficiente para obligar al cumplimiento", es decir, "en un Estado civil donde existe un poder apto para constreñir a quienes, de otro modo violarían su palabra", dicho temor ya no es razonable ni el pacto nulo.

De tal modo, el Estado se constituye en el poder coercitivo que garantiza el cumplimiento de los pactos y, en consecuencia de la justicia (definida como la observancia de los pactos). Así, el juego cooperativo que constituye al Estado, permite garantizar los demás juegos cooperativos que se den en su seno, es decir asegurar el cumplimiento de las reglas de dichos juegos, la justicia, sin la cual los participantes no están dispuestos a ceder derechos. A su vez, así como en la república de Maquiavelo la justicia era necesaria para la libertad y el mantenimiento del Estado, en Hobbes será la condición para evitar la disolución del Estado y la vuelta al conflicto.

Hobbes no plantea la situación del estado de naturaleza de manera histórica, sino teórica, como una hipótesis de lo que pasaría en caso de disolución total del Estado. De tal modo, la justificación hobbesiana del Estado tendría una prueba empírica a posteriori que desnudaría sus características intrínsecas, consistente en la observación de las consecuencias de la destrucción de los pactos (los conflictos internos en el seno de estados fragmentados políticamente), así como también una corroboración parcial en el terreno de las relaciones de fuerza entre los estados, sin un poder soberano que los englobe. Puede decirse que una vez instituido el Estado, éste se autoconstituye permanentemente en el mantenimiento de la cooperación de sus integrantes, afirmándose en la sucesión de cada nuevo gobierno, sin pasar por el estado de naturaleza. En ciertas circunstancias, sin embargo, los ciudadanos pueden llegar a salirse del pacto, no sólo colectiva sino también individualmente. Mientras el abandono colectivo del pacto supone su destrucción y su reemplazo por la anarquía (disociación rayana con el estado de naturaleza) o bien por una o más nuevas formas asociativas (nuevos pactos), el abandono individual tiende a minar las bases del pacto, en tanto pueda inducir nuevos abandonos o como simple expresión de oposición al sistema.

Cabe aquí preguntar: ¿qué es lo que garantiza el primer pacto, el de la constitución del Estado? 
En primer instancia puede decirse que nada, sino que sólo cabría que sea impuesto gracias al poder de uno o más de los contratantes, de la manera en que Rómulo sentó las bases de Roma según Maquiavelo. Hobbes no dice nada al respecto, pero parece difícil que el estado de naturaleza pueda superarse de manera espontánea. Mas bien aparece como necesario un "pecador original" que disponga del poder suficiente como para instaurar las instituciones del Estado (recuérdese que Maquiavelo aspiraba a un príncipe que impusiera la unidad y las instituciones republicanas). Según Hobbes, el soberano no pacta sino que recibe su poder de manera incondicional, por el temor de sus súbditos, aunque "es cierto que una vez instituida o adquirida una soberanía, las promesas que proceden del miedo a la muerte o a la violencia no son pactos ni obligan cuando la cosa prometida es contraria a las leyes" (Hobbes 1651:162).

Hobbes escribe en el marco de las guerras civiles inglesas. En ese sentido afirma que en definitiva, incluso el poder ilimitado de un soberano es preferible (más útil) al estado de naturaleza ya que "lo más grave que en cualquier forma de gobierno puede suceder, posiblemente al pueblo en general, apenas es sensible si se compara con las miserias y horribles calamidades que acompañan a una guerra civil" (Hobbes 1651:150).

Esa situación, la necesidad de un soberano fuerte que ponga fin a la anarquía, junto a una visión excesivamente (desde el punto de vista teórico) pesimista de la naturaleza humana, conducen su teoría del Estado al absolutismo. La idea de un soberano más allá de la ley, al que el ciudadano cede todos los derechos menos uno (el de defender su propia vida), lleva a que todo elemento de crítica o disidencia sea visto como atentatorio del pacto, y en consecuencia de la sociedad, y le otorga tal rigidez a su teoría que la hace desembocar en el absolutismo. Así como en Maquiavelo los hombres iguales otorgaban poder a un príncipe, desigual a ellos en virtud de ese acto, en Hobbes los hombres iguales crean un Estado soberano distinto a ellos en tanto que dicta las leyes pero no está obligado a cumplirlas. El absolutismo del Estado de Hobbes radica en que, si bien se origina en un pacto condicional entre individuos que dan para recibir, el soberano no pacta, y una vez instituido su poder, éste resulta incondicional, y anula para su mantenimiento toda manifestación de los intereses de los contratantes ("los mandatos de quien tiene derecho a mandar no deben ser censurados ni discutidos por sus súbditos" (Hobbes 1651:169)). Sin embargo, debilitando alguno de sus supuestos y modificando otros, como he estado haciendo en parte, su teoría se ha mostrado adecuada, no sólo para la fundamentación del estado autoritario, sino también para la del Estado democrático moderno.

Se observó antes que las leyes de la naturaleza eran imperativos estratégicos de prudencia que la razón nos daba para salir del estado de conflicto. Hobbes sostiene sin embargo, que del aprendizaje de esas leyes, "cuando se confrontan las acciones de otros hombres con las de uno mismo" (Hobbes 1651:129), surge como resultado la regla de oro: No hagas a otro lo que no querrías que te hicieran a ti. De este modo, así como la segunda ley introducía a la regla de oro como criterio estratégico a tener en cuenta, el conjunto total de las leyes la introduce como criterio moral. Personalmente creo que tal criterio se deriva en particular de las leyes novena (que reconoce la igualdad entre los hombres) y décima (que establece que al iniciarse las condiciones de paz, nadie debe exigir reservarse algún derecho que él mismo no se avendría a ver reservado por cualquier otro). Tales leyes llevan implícito el criterio moral que ordena no ponerse en excepción a la hora de decidir una acción con repercusiones morales, criterio formulable análogamente con la regla de oro.

Hobbes afirma que tal criterio obliga in foro interno (en la conciencia), pero sólo in foro externo (en cuanto a su aplicación), cuando "hay seguridad bastante". Por el contrario, en ciertas situaciones límite, y particularmente ante el riesgo de muerte violenta, el individuo deja de tener en cuenta el bien de los demás y suspende su juicio moral. Se tiene entonces que, si bien los hombres son siempre concientes de la racionalidad moral de sus acciones, sólo un poder que garantice nuestra seguridad, podrá garantizar a su vez las relaciones basadas en ese tipo de racionalidad (para Hobbes, el Estado, representante de Dios, garantiza la moral cristiana con el derecho). 
Puede efectuarse ahora un resumen de lo analizado hasta aquí, a partir de mi punto de vista. Todos los hombres buscan la paz y la seguridad como principales utilidades, no como fines en sí mismos sino en oposición al máximo costo de la muerte violenta. En ausencia de un poder soberano, son arrastrados en virtud de su propia racionalidad estratégica a la situación irracional del conflicto permanente, inestable, imprevisible y de mayores costos que los de una eventual cooperación. En tal situación, los individuos son concientes de la moralidad o inmoralidad de sus acciones, sin embargo, se ven desincentivados a actuar moralmente (de acuerdo a la virtud), cuando todos lo hacen estratégicamente (de acuerdo a la virtú) para no ser grave y reiteradamente perjudicados. El medio que constituye la solución a esa situación de estado de naturaleza, y que permite alcanzar la paz es un pacto colectivo mediante el cual cada individuo renuncia a un cierto número de derechos (en igual medida que todos los demás) en favor de un Estado. Hobbes no aclara cómo se garantiza esta cooperación, pero extrapolando a Maquiavelo se concluye que bien puede ser a través de la fuerza de uno o más de los contratantes. Una vez constituido, el Estado se dota de leyes. En un Estado democrático las leyes estarán de acuerdo a aquellos principios morales que los individuos reconocían aún en su estado de naturaleza, pero que se veían inhibidos de aplicar. Como consecuencia de la traslación de derechos de los individuos, el Estado adquiere el poder visible suficiente para garantizar esas leyes. Por lo tanto, la función del Estado será la de respaldar con la fuerza pública a las leyes (y en consecuencia a la parte de las relaciones éticas contempladas por esas leyes), actuando como elemento disuasivo que permita la cooperación al hacer coincidir el interés estratégico privado del individuo con el interés colectivo, público (aumentando los costos eventuales de una acción individual que afecte a las mencionadas leyes).

\section{4- La lógica de la cooperación.}

\subsection{1- Acción colectiva, lógica de la cooperación y teoría de juegos.}

El análisis del pensamiento de Maquiavelo y Hobbes ha puesto de manifiesto las características esenciales de la cuádruple relación entre racionalidad estratégica, conflicto, cooperación y racionalidad moral. Dicho análisis me permite introducirme de lleno en lo que a partir de Olson (1965) se ha dado en llamar "el problema de la acción colectiva". El problema de la acción colectiva o del francotirador hace referencia al fracaso de los individuos egoístas y racionales en obtener un bien común, y debe ser distinguido de la lógica de la acción colectiva o lógica de la cooperación, consistente en el análisis formal, por medio de la teoría de juegos, de dicho problema así como de sus posibles soluciones. Es entonces a través de la lógica de la cooperación, en particular de los artículos de Elster (1982) y Aguiar (1991), que intentaré enriquecer mi punto de vista acerca de la justificación maquiavélico- hobbesiana del Estado, todo lo cual estará orientado a desarrollar, en el siguiente capítulo, una teoría propia acerca de la necesidad y la forma de un auténtico organismo internacional de seguridad colectiva.

Se dijo que la teoría de juegos constituía una herramienta útil para el análisis del conflicto y la cooperación. Dado que a su vez dicha teoría es absolutamente compatible con mi modelo interpretativo de la acción y su racionalidad, comenzaré mi análisis de la lógica de la cooperación presentando directamente la situación en la que dos jugadores pueden elegir entre dos cursos de acción o estrategias: cooperar (C) o no cooperar (NC). Transformando artificialmente el juego de dos personas a uno entre "yo" y "cualquier otro", con el fin de introducir mayor realismo en el modelo, se pueden distinguir cuatro posibilidades de solución del juego:

$\mathrm{U})$ Cooperación universal (CC): todos eligen $\mathrm{C}$.

E) Egoísmo universal (NC NC): todos eligen NC.

F) El francotirador (NC C): "yo" elijo NC, "cualquier otro" elige C.

P) El primo (C NC): "yo" elijo C, "cualquier otro" elige NC. 
Así, cada individuo de la sociedad colocará estas alternativas en un determinado orden, de acuerdo con sus preferencias en el papel de "yo". En todos los casos, la forma abstracta de la matriz será la siguiente:

Cualquier otro

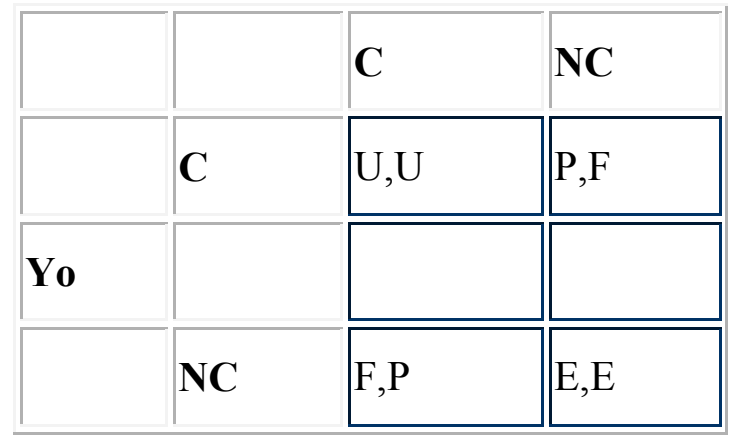

La situación puede también ser reflejada según la forma de la llamada notación extensiva, es decir según el diagrama de árbol siguiente:

\begin{tabular}{|c|c|c|c|c|c|c|}
\hline $\mathbf{U}, \mathbf{U}$ & & $\mathbf{P}, \mathbf{F}$ & & $\mathbf{F}, \mathbf{P}$ & & $\mathbf{E}, \mathbf{E}$ \\
\hline \multirow[t]{4}{*}{ C } & & $\mathbf{N C}$ & & C & & NC \\
\hline & Otro & & & & Otro & \\
\hline & C & & & & $\mathbf{N C}$ & \\
\hline & & & Yo & & & \\
\hline
\end{tabular}

En este diagrama el primero en jugar soy "Yo", que puedo optar entre cooperar (C) o no cooperar (NC). Si elijo C, entonces "cualquier otro" estará parado a la izquierda del diagrama y podrá optar entre cooperar $(\mathrm{C} \mathrm{C})$, lo que lo conducirá al estado de cosas descripto como cooperación universal $(\mathrm{U}, \mathrm{U})$, o bien por no cooperar (C NC), lo que me llevará al estado del primo (P,F). En cambio, si elijo NC, "cualquier otro" puede cooperar transformando mi estado en la situación de francotirador (F,P), o bien no cooperar y determinar una situación de mutuo egoísmo universal (E,E).

Las características de cada juego, y en consecuencia su resultado o solución, dependerá del orden de preferencias de los jugadores, es decir, del orden de prioridades que otorguen a las cuatro posibilidades citadas. Es decir, el valor que los jugadores den a las variables U, E, F y P determinará la estructura del juego, estructura que a su vez determinará el nivel de cooperación de los jugadores.

\subsection{2- De la racionalidad estratégica al conflicto.}

En las últimas tres décadas el problema de la acción colectiva ha sido planteado, estudiado y asimilado al juego ampliamente conocido como el dilema del prisionero, definido por el orden de preferencias $\mathrm{F}>\mathrm{U}>\mathrm{E}>\mathrm{P}$. Asignando por ejemplo los valores $\mathrm{F}=4, \mathrm{U}=3, \mathrm{E}=2, \mathrm{P}=1 \quad(\mathrm{~F}>\mathrm{U}>\mathrm{E}>\mathrm{P}=(\mathrm{NC}$ C) $>($ C C $)>(\mathrm{NC} \mathrm{NC})>(\mathrm{C} \mathrm{NC})$ ), es ese orden de preferencias el que determina que la matriz respectiva quede como sigue:

\section{Cualquier otro}




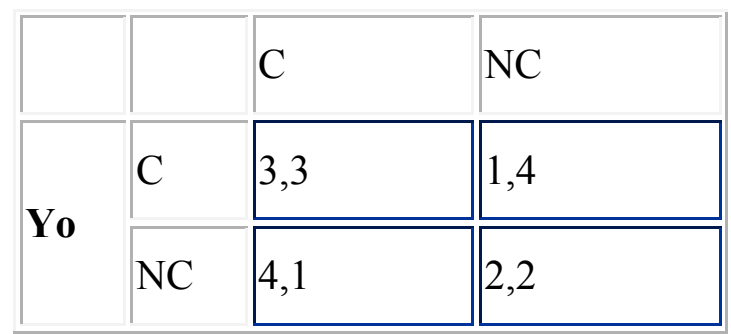

\section{Dilema del prisionero}

Se tiene que:

1) La estrategia $\mathrm{NC}$ es dominante, es decir, constituye la mejor elección para cada actor, independientemente de lo que hagan los otros. A cada uno le interesa comportarse como un francotirador y dejar que el otro coopere, de manera de obtener el mayor beneficio sin costo alguno (a partir de $(3,3)$ los individuos tienden a beneficiarse corriéndose a $(4,1)$ ).

2) Como consecuencia del dominio de la estrategia no cooperativa, la solución al juego es el conflictivo egoísmo universal $(2,2)$, que todos individualmente sitúan por debajo de la cooperación universal $(3,3)$.

3) La cooperación universal no es individualmente estable ni individualmente accesible: todos darán el primer paso para alejarse de ella y nadie dará el primer paso para acercarse a ella.

Así, el dilema muestra de manera muy sencilla la esencia del problema de la acción colectiva: el hecho de que la racionalidad individual puede conducir a la irracionalidad colectiva, a un resultado global no deseado por nadie. Como señala Aguiar, puede preguntarse por qué los jugadores no cooperan si saben que así obtendrían un resultado aceptable para todos. Puede ocurrir que los jugadores no tengan comunicación entre sí y no sepan qué van a hacer los demás, caso en el que cooperar entrañaría un gran riesgo individual. Pero aún suponiendo la existencia de comunicación entre los actores y la posibilidad de un pacto cooperativo, nada les asegura el cumplimiento de ese acuerdo.

\subsection{3- Del conflicto a la cooperación.}

¿Cómo salir, entonces, de la situación del dilema del prisionero?, ¿qué solución tiene el problema de la acción colectiva? Los teóricos de la lógica de la cooperación han elaborado una serie de salidas que quedan abarcadas por las tres clases de soluciones siguientes:

1) Las "soluciones internas": son aquéllas en las que los jugadores conservan su orden de preferencias $\mathrm{F}>\mathrm{U}>\mathrm{E}>\mathrm{P}$, aquéllas que según Taylor (1987) "ni implican ni presuponen cambios en el "juego", es decir, en las posibilidades abiertas al individuo,... en las preferencias individuales,... y en sus creencias".

Las soluciones internas son posibles cuando el dilema del prisionero se juega más de una vez, a partir de lo que se ha llamado dilema del prisionero repetido o iterado. En efecto, puede ocurrir que "al repetirse una y otra vez la situación que origina el dilema, los miembros de un grupo de interesados en algún bien colectivo puedan aprender a colaborar" (Aguiar, 1991:14). Esto es lo que ha demostrado Axelrod (1984), quien señala que la reciprocidad inherente a la cooperación de individuos egoístas depende de que los jugadores puedan identificar a los no cooperadores, de que se puedan tomar represalias sobre ellos y de que se tenga incentivos para tomar esas represalias, para lo cual es necesario que exista una gran probabilidad de que los jugadores vuelvan a encontrarse, de manera que tengan algo que ganar en una futura interacción. Si esto se cumple, podrá surgir la cooperación condicional a partir de estrategias como la de "toma y daca" (tit for tat), que consiste en comenzar cooperando para continuar tal como lo haga el oponente, cooperando si coopera, no cooperando si no coopera. De esta forma, las estrategias de cooperación condicional conducen a la propagación de los acuerdos cooperativos en un contexto en el que sigue privando el 
interés egoísta del orden de preferencias del dilema del prisionero (el cambio de hipótesis de acción se debe a un cambio en el conjunto de creencias, no en el de las preferencias). Hay que aclarar que, como lo señalan Olson (1965) y Taylor (1987), la cooperación condicional voluntaria se da más fácilmente en grupos pequeños, ya que en esos casos resulta más sencillo identificar a los no cooperadores de la anterior jugada.

2) Las "soluciones externas": son aquéllas en las que por medio de la coacción o el incentivo externo se provoca un reordenamiento de las preferencias individuales que transforma el dilema del prisionero en un juego distinto. La solución externa clásica consiste en establecer mecanismos de coacción que conduzcan a los individuos a un cambio del orden de las preferencias del dilema del prisionero, por uno del juego de la seguridad, en el que la cooperación universal es preferida a la no cooperación individual. El orden de preferencias del juego de la seguridad es $\mathrm{U}>\mathrm{F}>\mathrm{E}>\mathrm{P}$ (por ejemplo $\mathrm{U}=4, \mathrm{~F}=3, \mathrm{E}=2, \mathrm{P}=1$ ) de manera que la matriz queda como sigue:

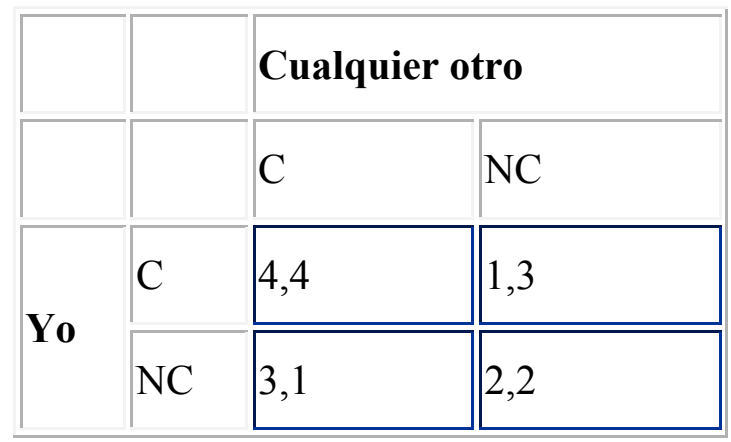

\section{Juego de seguridad}

Respecto de este juego, Elster (1982:47) observa que:

1) El egoísmo es la mejor respuesta al egoísmo, la solidaridad la mejor respuesta a la solidaridad.

2) El óptimo de la cooperación universal es individualmente estable, pero no individualmente accesible.

3) El egoísmo universal y la solidaridad universal son, ambos, puntos de equilibrio. Dado que la cooperación universal es preferible por todos al egoísmo universal, la primera se plantea como la solución al juego.

4) Dado que no hay una estrategia dominante la solución sólo será alcanzada si hay una información completa y perfecta. Una información incompleta (acerca de las preferencias o de la información disponible) lleva fácilmente a la incertidumbre, a la sospecha y a la conducta consistente en jugar sobre seguro (es decir a optar por la solución egoísta).

En el dilema del prisionero se prefería no cooperar si los demás cooperaban. Ahora, se prefiere cooperar si cooperan todos, pero es necesario tener la seguridad de que esto ocurrirá, es decir, de que nadie actuará con las preferencias del dilema del prisionero. Se debe estar seguro de que no ocurrirá lo siguiente:

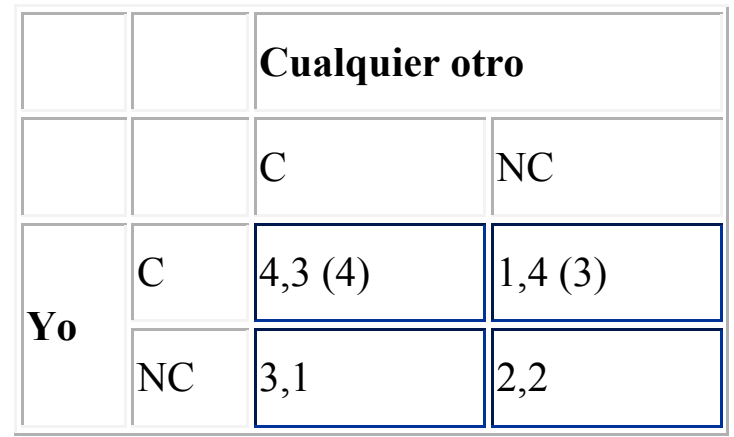


Aquí, los números entre paréntesis indican las preferencias que "yo" creo que tiene "cualquier otro" (las del juego de la seguridad), distintas de las que realmente tiene el otro jugador (las del dilema del prisionero). Se observa que mi desconocimiento de esta circunstancia me lleva a cooperar y a ser defraudado por "cualquier otro", que privilegia NC (4) frente a C (3) (dejándome con 1 en lugar de 4), cuando yo creía que haría lo contrario. Si "yo" hubiera sabido la forma real del juego (la situación objetiva So de mi esquema de la acción individual), la solución hubiera sido el punto de no cooperación 2,2 .

Por lo tanto, la cooperación del juego de la seguridad es en cierta medida condicional, pero a diferencia de la solución interna, la condición aquí no consiste sólo en que los demás jugadores cooperen una vez que se ha cooperado, sino también en que exista la seguridad de que actúen según un orden de preferencias ACBD.

3) Internalización de un nuevo orden de preferencias: esta alternativa, planteada por Elster (1982) y (1983), puede verse como una combinación de las anteriores soluciones. Aquí también, como en la solución interna, se puede partir de la consideración de la situación planteada por el dilema del prisionero. Sin embargo, la diferencia es que en este caso, como resultado de su interacción, los agentes llegan a interesarse unos por otros de manera que surge una interdependencia positiva en las estructuras de recompensa. Mediante dicha interacción continuada, los agentes terminan por estar más preocupados por los demás y más informados acerca de ellos. La preocupación por los demás provoca un cambio en el orden de preferencias y en consecuencia la transformación del juego del dilema del prisionero en un juego de seguridad, en el que la conducta cooperativa se plantea como posible solución. Por lo tanto, la cooperación surge como consecuencia de la internalización de un orden de preferencias distinto al del dilema del prisionero, no como producto de la coacción externa, sino a partir de un cambio de actitud voluntario y no condicionado.

Paso entonces a enriquecer mi interpretación de la justificación hobbesiana del Estado, a la luz de la lógica de la cooperación. Partiendo de las conclusiones del punto anterior, supongo una situación inicial de estado de naturaleza en la que el orden de preferencias del dilema del prisionero conduce a los agentes al egoísmo universal, situación subóptima respecto de la cooperación universal que no puede alcanzarse en forma individual. No se descarta que existan sujetos con otras preferencias (cooperadores condicionales, "kantianos" (cooperadores incondicionales)), sino que la consideración metodológica de la situación del dilema del prisionero, al tomar el caso menos cooperativo de entre aquéllos en los que existen intereses comunes (es decir en los que $U>E$ ), resulta la suposición que permite encarar de manera más abarcadora y realista la aplicación del problema de la acción colectiva a la constitución del Estado. Mi análisis de la cooperación parte del conflicto que, como se ha visto, no equivale a la irracionalidad.

En la situación del dilema del prisionero, Hobbes propone como salida el pacto y la cesión de derechos a un poder soberano con poder de coacción. Es decir, una solución de tipo externo, según se ha analizado. Sin embargo, como ya se señaló, Hobbes no describe los mecanismos de formación y garantía del pacto primigenio, tarea en la que se puede avanzar aplicando mi estudio de la lógica de la cooperación.

En principio, la cooperación inicial entre los individuos del futuro Estado debe darse necesariamente a partir de una solución interna o de la internalización voluntaria de un nuevo orden de preferencias, ya que, como se ha visto, no existe un poder de coacción que garantice el primer pacto. Entre las dos alternativas restantes, piénsese en la menos cooperativa pero más abarcadora y realista solución interna. Resulta difícil imaginar una solución interna simultánea, espontánea y coordinada entre todos los individuos de la sociedad, sino que, como ya se adelantó en el punto anterior, parece más natural y acorde con la historia de la formación de los Estados suponer un grupo fundador, un "pecador original" maquiaveliano. Es decir, resulta más adecuado interpretar que sea un grupo pequeño (requisito favorable a una eficaz solución interna), integrado por individuos egoístas pero interesados en un bien colectivo, el que puede aprender a cooperar condicionalmente a partir de una situación de dilema del prisionero repetido (previsible en una 
sociedad anárquica) y decidir colaborar en la instalación de un Estado. En ese sentido, el "pecador original" deberá reunir el poder necesario para conseguir lo que Granovetter (1978) ha denominado umbral de participación, es decir, el número de personas que tendrían que unirse al grupo para que un individuo concreto se animara a secundarlos. Obtenido ese poder, dicho grupo será el encargado de organizar inicialmente el Estado imponiendo las leyes a través de la coacción, provocando de esa manera una solución externa al dilema del prisionero de los restantes miembros de la sociedad.

Una vez instituido el Estado, éste deberá dotarse de los instrumentos adecuados que le permitan mantener la cooperación y evitar su disolución. Así, puede decirse que también para el caso del Estado, el problema de la acción colectiva presenta dos aspectos, el logro de la cooperación de individuos racionales con preferencias egoístas del orden del dilema del prisionero y, una vez conseguido esto, el mantenimiento de dicha cooperación. Se distinguen entonces dos momentos o instancias de cooperación, antes y después de la constitución del Estado:

1) En un primer momento, el "pecador original" asegura el umbral de participación y consigue que cada individuo ceda los mismos derechos a un poder común transformando la incertidumbre inicial, natural (el temor a la muerte hobbesiano), en miedo hacia el castigo subsecuente al quebrantamiento de la ley instaurada por dicho "pecador original", es decir, transformando el egoísmo universal en cooperación universal merced a la inducción de un cambio de preferencias del orden del dilema del prisionero al orden del juego de la seguridad (se pasa a privilegiar la cooperación universal, el bien común). Sucede que, al orientar la acción con las leyes (respaldadas por la fuerza), el grupo fundador (y el Estado después) transforma la información incompleta de los agentes en completa o cuasi completa, reduciendo la incertidumbre y la sospecha que, tanto para los individuos que actúan de acuerdo al orden del dilema del prisionero como para los que lo hacen en base al del juego de seguridad, conduce al egoísmo universal. En ausencia de un poder soberano, en cambio, el agente se ve desalentado a aplicar su criterio estratégico a un orden de preferencias del juego de seguridad o bien a actuar de acuerdo a un criterio moral, aunque lo prefiera "in foro interno" (reconocer algo como justo no implica actuar de manera justa). La falta de garantías (de información) conduce al agente a suspender la aplicación de su criterio de racionalidad moral y a guiarse según el orden del dilema del prisionero. Dicho agente no puede arriesgarse a elegir $\mathrm{C}$ sin estar seguro de que los demás también van a elegir $\mathrm{C}$ (por propia elección o inducidos por la ley), ya que si elige $\mathrm{C}$ y los demás eligen NC está en la peor situación, la del "primo". Por otro lado, los agentes éticos puros que "sigan en sus trece" habrán de enfrentarse a la muerte violenta y, según Hobbes, tenderán a la desaparición (aquí se dirá que su número tenderá a reducirse al ser permanentemente defraudados). Nótese que la inhibición moral planteada aquí tiene un carácter inverso al de la suspensión de la racionalidad estratégica a la que aludía el utilitarismo ético para justificar la acción en base a principios morales.

2) Una vez constituido el Estado, éste hereda y conserva del grupo fundador la autoridad y el poder de coacción que le permite enfrentar el desafío de la segunda instancia: el mantenimiento de la cooperación conseguida. En un Estado establecido habrá individuos con distintos órdenes de preferencias, estarán los puramente egoístas que conservarán el orden del dilema del prisionero, otros priorizarán la cooperación universal inestable y en cierto sentido condicionada del juego de seguridad, mientras que otros podrán ser agentes morales puros o cooperadores incondicionales. Incluso estarán aquéllos que actuarán según uno u otro orden de acuerdo a la situación de que se trate (la actitud de estos agentes con preferencias mixtas, de órdenes distintos para juegos distintos, parece ser la más natural). En todo caso, el Estado deberá estar atento a los "francotiradores" egoístas que tratarán de eludir las leyes en su propio beneficio, de manera de garantizar no sólo la cooperación estratégica básica e inestable de los individuos que actúan de acuerdo al orden del juego de seguridad, sino también la "supervivencia" de los agentes morales puros. Resulta evidente que en un Estado débil (no confundir fuerza con autoritarismo ni con amplitud), con leyes inadecuadas o sin el poder suficiente para hacerlas respetar, los "francotiradores" serán los beneficiados, y su bando se irá incrementando paulatinamente a expensas de los otros dos, al mismo tiempo que la corrupción y la anarquía. El proceso no se revierte sino hasta tanto se logra una nueva 
cooperación estratégica inicial, que según el caso y el grado de deterioro alcanzado, podrá contar o no con un nuevo "pecador original". Estas reflexiones se me ocurren interesantes para su aplicación práctica en la explicación de ciertos casos históricos en que a períodos mas bien anárquicos o laxos han sucedido gobiernos fuertes o dictatoriales. Entre estos casos podríamos ubicar el surgimiento del rosismo y de la última dictadura militar en la Argentina, y el bonapartismo de Napoleón III en Francia, en los que autoproclamados "restauradores de las leyes", apoyados tácita o explícitamente por individuos con "temor a la muerte", impusieron su fuerza cayendo en el exceso. Por otra parte, me cuesta realmente encontrar casos de estados en disolución que no hayan terminado de la anterior manera. Pareciera que la recomposición del Estado, luego de su aproximación a la situación de estado de naturaleza, exigiera la reconstrucción lenta del poder civil y democrático, de la misma manera en que la democracia no fue posible sino luego de una larga lucha de los individuos comunes contra las monarquías absolutistas (éticamente irracionales). Suavizando su contenido, la anterior interpretación sería potente también para explicar la alternancia gobiernos conservadoresgobiernos liberales, observable en las democracias avanzadas y en los modos político-económicos en general. Así, a gobiernos permisivos con los "francotiradores" (los agentes económicos capitalistas en general), le seguirían gobiernos más estatizadores, controladores de dichos agentes. La sociedad oscilaría en torno a un punto de equilibrio entre bienes privados y bienes públicos (mayor demanda de bienes privados derivaría en gobiernos conservadores, mayor demanda de bienes públicos en liberales o socialdemócratas). En la cuarta parte, al analizar la teoría del Public Choice, se volverá a hacer referencia a este tema.

Para terminar con este punto puede traerse a colación a Elster (1989), quien discute las condiciones del orden en el mundo social, pretendiendo dar una respuesta a la pregunta acerca de "qué es lo que mantiene unidas a las sociedades y les impide desintegrarse en el caos y la guerra". Elster considera dos conceptos de desorden: a) el desorden entendido como imposibilidad de predecir, ya sea por falta de información o de racionalidad del agente, del que se ocupa como vimos la teoría de la elección racional y sobre el que hemos aportado algunas conclusiones; b) el desorden concebido como falta de cooperación. En relación a este segundo concepto, distingue entre cooperación centralizada y descentralizada. Si bien destaca la importancia de la cooperación centralizada, reconociendo que para salvar la situación de desastre colectivo "las personas pueden abdicar su poder en favor del Estado, y entonces tenemos el Leviatán de Hobbes", centra su atención en lo que considera las distintas formas de cooperación descentralizada: la basada en circunstancias exteriores creadas por la acción individual, la de asistencia y ayuda, la de las convenciones, la de las empresas colectivas y la de los convenios. Elster lleva a cabo un detallado estudio de las motivaciones desencadenantes de la cooperación descentralizada, a partir del cual concluye que ésta obedece a una mezcla de motivaciones racionales e irracionales (entre las que ubica a las "normas sociales") que se interrelacionan y combinan de distinta manera en distintas sociedades, determinando el grado de cooperación y constituyendo lo que dicho autor denomina el "cemento de la sociedad", es decir aquello que da una respuesta a su pregunta acerca del factor que une a las sociedades e impide su desintegración. Desde mi perspectiva, puede decirse que tal tipo de cooperación no coercitiva y descentralizada sólo podrá ser factible en el marco de un Estado organizado, una vez alcanzada la primera instancia estratégica de cooperación. La constitución de un Estado con poder coercitivo para aplicar las leyes establece la condición de posibilidad de los dos conceptos de orden social de los que habla Elster: el de la conducta predecible (la estabilidad) y el de la conducta cooperativa (la cooperación). Permite además la confianza necesaria para las distintas formas de cooperación según las metodologías propuestas por el referido autor. Creo, por lo tanto, que el "cemento" de la sociedad pasa más por la constitución y preservación de las instituciones del Estado, es decir por el mantenimiento de la cooperación estratégica básica, que por el sostenimiento de las formas no centralizadas y no coercitivas, ya que sin el primero no se da el segundo. Aunque puede admitirse que la destrucción del segundo tipo de cooperación lleve a la destrucción del primero, sí es seguro en cambio que si se destruye el primer tipo se destruye automáticamente el segundo. 


\subsection{4- De la cooperación a la racionalidad moral.}

Establecido el Estado, es decir, una vez superada la primera instancia de cooperación, la función del derecho será la de crear las condiciones para que los francotiradores cambien su orden de preferencias del dilema del prisionero por uno del juego de seguridad, de manera que la acción estratégica que se deduzca, aunque maximizadora de la utilidad individual, sea al menos conforme a los principios morales orientadores de las leyes. En otras palabras, el derecho interno, garantizado por la fuerza legítima, procurará inducir un cambio de preferencias tal que la aplicación del criterio estratégico sea equivalente a la del criterio moral en el que se inspiran las leyes del Estado.

La institución del Estado no sólo provoca un cambio coaccionado del juego, sino que también da pie para que de la interacción continuada y el conocimiento mutuo de los agentes, se produzca en algunos de ellos una internalización voluntaria de un nuevo orden de preferencias. Así, un francotirador puede llegar a reconocer las ventajas de la adopción de un orden de preferencias del juego de la seguridad o incluso de un orden "kantiano" que pudo haber abandonado por "temor a la muerte". Por su parte, los individuos adherentes al orden del juego de la seguridad podrán pasar también a ser cooperadores incondicionales o bien afirmar sus propias preferencias, ya no por temor al castigo externo sino como producto del propio autoconvencimiento. En el estado de naturaleza, la suspensión de la racionalidad moral lleva a que la cooperación pueda darse sólo por referencia a utilidades individuales egoístas, sin embargo, restaurado el juicio moral, dicha cooperación podrá ocurrir también de manera espontánea y por referencia exclusiva a un principio moral. Así, la aplicación concreta de cierto principio moral, la crítica a la corrupción por ejemplo, podrá ser el eje de referencia a partir del cual distintas acciones individuales podrán derivar en una acción colectiva espontánea (una manifestación contra la corrupción, en el caso citado). Se tiene entonces que la solución interna del estado de naturaleza, llevada a cabo por el grupo fundador, lleva a la imposición de una solución externa a partir de la cual es posible la internalización de ordenes de preferencias cooperativos o bien el seguimiento de criterios morales derivado del levantamiento de la inhibición de la racionalidad moral.

En cuanto a los "kantianos", éstos tendrán asegurada su existencia, dato que aunque poco pueda importarle a los "kantianos puros", resulta relevante para la más extensa y realista categoría de los "kantianos cotidianos". Elster (1989), define a los kantianos cotidianos como a aquéllos que cooperan sólo si la cooperación universal es mejor para todo el mundo que la defección universal. A diferencia de los kantianos puros o verdaderos, estos sujetos generalmente no son insensibles al resultado en lo tocante a los costos: "En términos generales proceden en dos pasos. Primero emplean algo semejante al imperativo categórico para decidir cuál es su deber. Luego, antes de actuar, consideran si los costos son prohibitivos, los cuales, en ciertas ocasiones, pueden realmente serlo" (por ejemplo en el estado de naturaleza hobbesiano)..."Además en la práctica el kantiano cotidiano es de alguna manera sensible a los beneficios" (Elster 1989:222), ya que si bien no considera el impacto de su cooperación, sí considera el de la cooperación universal, de manera que cuanto más pequeña es la diferencia entre cooperación universal y no cooperación universal, más baja será la voz de la conciencia del deber y más probable será que sea acallada por consideraciones de costo. Los kantianos cotidianos condicionan entonces su "cooperación incondicional" a ciertos costos y beneficios, por lo que su acción puede compararse con la de los seguidores de la "norma de la honestidad", aquéllos que cooperan sólo si los demás, o al menos un número sustancial de ellos, coopera. La diferencia radica en que mientras el seguidor de la norma de honestidad basa su cooperación condicional en la cooperación actual de los demás, el kantiano cotidiano lo hace sobre la cooperación prevista del resto de los actores. Más precisamente, el kantismo cotidiano se funda en una forma de pensamiento mágico que Elster denomina "calvinismo cotidiano" y que consiste en la confusión entre eficacia causal y eficacia diagnóstica, en la creencia de que al obrar sobre los síntomas uno puede también cambiar la causa. "En la acción colectiva interpersonal, el pensamiento mágico equivale a creer (o a obrar como si se creyera) que mi cooperación puede hacer que otros cooperen" (Elster 1989:230). La calificación de esta forma de actuar como "pensamiento mágico" no debe ser, sin embargo, un obstáculo para admitir, como lo han demostrado distintos autores, que 
es una manera en que las personas realmente piensan. De hecho, es en esta forma de pensamiento en la que se basa la cooperación condicional propia de la solución interna al dilema del prisionero. El que "yo" coopere primero a fin de que "cualquier otro" coopere después, constituye una conducta diagnóstica de la otra persona que se elige como si pudiera tener eficacia causal. El hecho de que no exista esa relación lógica causal no implica, sin embargo, que yo no pueda obtener, a partir de esa estrategia, los resultados buscados. Tanto los seguidores de la norma de la honestidad como los kantianos cotidianos no son personajes heroicos, sino hombres comunes que bajo ciertas circunstancias de riesgo extremo y falta de reciprocidad, se niegan a actuar moralmente, a ser tomados como ingenuos, prefiriendo defenderse con las mismas armas estratégicas que el resto de los actores con los que interactúan.

El kantiano cotidiano actúa como francotirador en las situaciones del dilema del prisionero, pero como kantiano puro en las del juego de seguridad. La conducta de los demás, a diferencia del verdadero kantiano, constituye la causa de su posición y no un elemento de ella. Así, en circunstancias "no prohibitivas" como la generada a partir de la imposición del Estado, su accionar adquiere importancia, junto con el de los seguidores de la norma de honestidad, al incrementar sustancialmente el número de cooperadores y al funcionar como multiplicadores de la cooperación de personas más inestables (las del orden del juego de la seguridad) o más reacias a la colaboración (los francotiradores).

Por lo tanto, al asegurar ciertas condiciones de viabilidad y el logro de cierto umbral de participación, el paso del dilema del prisionero al juego de la seguridad, vía coacción del Estado, puede desencadenar la cooperación voluntaria de kantianos cotidianos inhibidos (que pasan de francotiradores a kantianos puros) y de seguidores de la norma de la honestidad (que pasan de francotiradores al orden del juego de la seguridad).

Se tiene entonces que es en la segunda instancia donde se facilita la cooperación y el juzgamiento de la acción no sólo desde el criterio estratégico, sino también a partir de criterios de racionalidad moral (cuyo respeto pudo ser dejado de lado en el estado de naturaleza por temor a la muerte violenta), garantizados ahora por la ley a la cual inspiran. En ese sentido, y coincidiendo con mis reflexiones sobre Maquiavelo, el papel de gobernante (del Estado) consistirá en principio en asegurar al menos la obediencia estratégica de los gobernados, de manera que a partir de la seguridad, la libertad adquiera un sentido positivo en la realización de acciones de bien público, en la configuración de una auténtica sociedad civil y en la participación constructiva de una comunidad más justa.

En último término, el equilibrio cooperativo del Estado está respaldado en el uso de la violencia legítima, como castigo a la deserción. En este sentido, mi interpretación coincide con la teoría weberiana, en tanto que ésta muestra al Estado como una burocracia organizada que se reserva el monopolio del uso de la fuerza legítima. Por otro lado, este esquema también puede examinarse desde las categorías freudianas de "represión necesaria" y "represión excedente". Desde esta perspectiva, el Estado sería el encargado de garantizar, a nivel social, la "represión necesaria" fundante de la sociabilidad, de la cooperación y de la cultura en general, sin recaer en la "represión excedente", en el absolutismo.

Sin embargo, se dijo antes que en el caso de Hobbes, distintos elementos de su pensamiento lo conducían a la defensa abierta de la soberanía absoluta del Estado sobre el pueblo. Se advirtió, no obstante, que una interpretación liberal como la mía de su justificación del Estado podía valer también para el Estado democrático. Desde la perspectiva de dicha interpretación, puede suponerse que la diferencia entre un Estado democrático y uno absolutista radicará en:

1) La amplitud de los derechos cedidos por los ciudadanos al Estado (la medida material del Estado).

2) El criterio de elaboración de las leyes y su cumplimiento de parte del Estado (la medida o patrón moral del Estado). 
En lo que concierne a la amplitud de los derechos cedidos (Hobbes llega a decir que la libertad de un súbdito radica solamente "en aquellas cosas que en la regulación de sus acciones ha predeterminado el soberano" (Hobbes 1651:173), será válida la crítica al absolutismo de Hobbes de parte de los filósofos posteriores, crítica que no afecta la aplicación de su justificación del Estado al Estado democrático y en la que habré de detenerme en el capítulo 8. Previamente a esto y en relación con esta cuestión, se examinará en el capítulo 7 una visión contemporánea que intenta explicar las dimensiones de los dominios público y privado (la mencionada teoría del Public Choice).

Respecto al criterio de elaboración de las leyes y su cumplimiento por el Estado, hay que decir aquí lo siguiente.

Se observó antes que aún en la situación previa a la institución del Estado, los individuos son en general concientes "in foro interno" de lo moral (aunque de hecho se vean inhibidos a actuar moralmente), de las "leyes de la naturaleza" de las que hablaba Hobbes, de la base moral que el príncipe maquiaveliano no debe contradecir si quiere lograr sus fines estratégicos. En esta situación, los fundadores del Estado imponen sus leyes, que no podrán ser cualquier cosa, sino que deberán disponer de cierto consenso, de una mínima aceptación social, sólo posible si se respeta la mencionada base moral difusa, que dichos fundadores deberán tener en cuenta si desean imponer su estrategia (recuérdese que en El Príncipe la crueldad de Agatócles no es impugnada por inmoral sino por mala estrategia). Si, además de respetar esa base moral, los fundadores establecen o se comprometen a establecer mecanismos de participación democrática para el perfeccionamiento gradual de las leyes y del sistema, de manera de garantizar una conflictualidad positiva generadora de "buenas leyes", el nuevo Estado transitará el camino de la democracia. Si, por el contrario, la base moral es respetada sólo en la medida de la estrategia egoísta de los fundadores, sin dar lugar a la libertad ni a la expresión del disenso a través de mecanismos de participación y de mejoramiento de las normas, se marchará hacia el absolutismo dictatorial.

Se tiene entonces que una vez instituido el Estado, éste sostendrá un conjunto de leyes o Constitución impuesta por los fundadores. Un Estado democrático orientará su Constitución en principios morales de los que se deduzca y en los que se consagre la igualdad de los individuos (definitoria de la democracia y punto de partida de la justificación de Hobbes), estableciendo mecanismos que permitan a los ciudadanos discutir estratégicamente las diferentes opciones legales posibles dentro de ese marco moral. Un Estado absolutista, en cambio, aunque deberá también respetar cierta base moral necesaria para su subsistencia, inspirará sus leyes en principios inmorales ( clase social, por ejemplo), o bien en principios morales, pero apartándose en este caso del alcance y del respeto de las leyes que él mismo dicte. Al contrario del Estado democrático, que fija como se ha señalado los mecanismos de participación y control de sus acciones internas que lo involucran a él mismo en el pacto, propiciando su evolución y preservación como entidad cooperativa, la dictadura se autoexcluye del pacto, anulando o negándose a establecer los mencionados mecanismos. En este sentido, puede decirse que en el caso de la imposición de una dictadura (bonapartista o de otro tipo), la segunda instancia del proceso de cooperación resulta más traumática y sólo parcial, ya que si bien un dictador permite que los ciudadanos establezcan relaciones morales entre sí, que cambien su orden de preferencias egoísta al del juego de seguridad o al del imperativo categórico, él mismo se excluye del juego moral, continuando con su orden egoísta y constituyéndose (junto con su entorno) en un francotirador del propio sistema que ha instaurado. Tal situación podrá ser mantenida con puño de hierro, pero tarde o temprano el cuestionamiento moral de un régimen absolutista (su irracionalidad moral) habrá de llevarlo hacia la democratización o hacia la disolución.

Resta considerar cómo se fundamentan de manera éticamente objetiva las leyes de un sistema democrático, asunto al que habré de referirme en la cuarta parte. Dejando este tema pendiente, paso entonces a extender las conclusiones de este capítulo al ámbito internacional. 


\section{6- La cooperación internacional. Hacia una auténtica seguridad colectiva}

\section{1- El problema de poder.}

Todos los estados, como los individuos hobbesianos, aspiran a la paz. Basta, sin embargo, una mirada a la historia y a nuestra realidad cotidiana para dar cuenta de una interminable lista de guerras y conflictos, con sus consecuencias de miseria, hambre, destrucción y muerte. ¿Cómo se explica esta paradoja? Puede decirse, en primera instancia, que si bien es cierto que los estados desean la paz, también lo es el hecho de que antes que a ella privilegian a la seguridad, definida como la suma de sus intereses vitales. La preferencia de los estados por la paz no resulta entonces incondicional, sino que queda en segundo término respecto de su seguridad. Por ello, a pesar de que los estados se sientan más seguros en tiempos de paz, ninguno vacila en ir a la guerra cuando se ponen en juego intereses vitales como la integridad de su territorio o la vida de sus habitantes. Así como el individuo hobbesiano era arrastrado al conflicto por la necesidad de defender su vida amenazada, los estados van a la guerra cuando juzgan en peligro los intereses vitales que determinan su existencia como tales. Ningún estado se conforma con una paz de cementerios, ni con una paz que considera indigna, impuesta por otro estado, o en condiciones inmerecidas, injustas o no equitativas. En todo caso, como señala Hartmann (1983), la paz constituye más bien un subproducto de la seguridad.

Debido a que a nivel internacional no existe un organismo imparcial de justicia con la fuerza suficiente para imponer sus decisiones, cada estado juzga sus humillaciones y ambiciones según sus propios intereses, por lo que resulta inevitable la conformación de un sistema esencialmente conflictivo. La ausencia de un poder soberano por encima del de los estados da pie al llamado "problema de poder" de la sociedad internacional: Todo estado existe en un mundo de estados soberanos, en el que cada uno dispone de poder capaz de ser utilizado con fines hostiles. La incertidumbre conduce a la sospecha y a la situación subóptima de no cooperación. Al no existir una instancia superior de justicia y coacción, los estados se niegan a desarmarse y a renunciar a la fuerza, renuncia que en estas circunstancias puede costarle caro a aquel que la efectúe en forma individual.

Mientras las doctrinas legalistas- idealistas pretenden seguir sosteniendo que la paz y la seguridad pueden deducirse del respeto al derecho, resulta evidente que en la práctica ocurre todo lo contrario, es decir, que la paz y el respeto del derecho resultan subproductos de la seguridad. La comprobación fáctica de este hecho en la sociedad internacional contemporánea hace que valga la pena plantear el problema de poder desde la perspectiva de los filósofos del siglo XVII. En ese sentido, la realidad internacional ha sido tomada como uno de los ejemplos más claros y clásicos de estado de naturaleza y de situación de dilema del prisionero (a partir de la cual se caracterizó en el capítulo anterior al problema de la acción colectiva). Ya el mismo Hobbes (1651:104) afirmaba que "aunque nunca existió un tiempo en que los hombres particulares se hallaran en una situación de guerra de uno contra otro, en todas las épocas, los reyes y personas revestidas con autoridad soberana, se hallan en estado de continua enemistad, en la situación y postura de los gladiadores, con las armas asestadas y los ojos fijos uno en otro". Con algunas diferencias conceptuales, la misma situación es reconocida entre otros por Spinoza, Locke y Kant, y ya en nuestros días por un gran número de estudiosos de las relaciones internacionales, que como Aron (1962:842) sostienen que para el logro definitivo de la paz y la seguridad internacionales "no hay que preocuparse primordialmente de los objetos de los litigios ni de los actores, sino del fundamento de la situación hobbesiana: la reivindicación por los estados del derecho a hacerse justicia a sí mismos y, por lo tanto, el reservarse la última ratio del recurso de las armas".

En esa dirección, los institucionalistas, a partir de trabajos como los de Axelrod (1984), Keohane (1984), Axelrod y Keohane (1986), Lipson (1984) y Stein (1983), definen al estado de anarquía internacional como a la falta de un gobierno común, tomando a la sociedad internacional como esencialmente descripta por el juego del dilema del prisionero, en el que la cooperación es posible 
pero no necesaria ni individualmente accesible en ausencia de una autoridad central. Si bien el dilema del prisionero no es tomado como la única situación de juego presente en la sociedad internacional, los institucionalistas aceptan su coexistencia con juegos más cooperativos (juegos de armonía, de seguridad y otros) o menos cooperativos (juego de estancamiento ("deadlock")), éste es tomado como el más característico pero sobre todo como aquel que describe la esencia del problema de poder. Reconocida la existencia de intereses comunes (la preferencia U se supone mayor a la preferencia E, contrariamente al juego de estancamiento) el dilema del prisionero constituye la perspectiva menos cooperativa, ya que si bien permite la posibilidad de cooperación ésta no resulta individualmente accesible (en el juego de estancamiento el hecho de que la defección mutua sea preferida a la cooperación mutua anula toda posibilidad de cooperación). En base a este diagnóstico, los institucionalistas han puesto énfasis en el papel facilitador de la cooperación atribuido a las instituciones, a la vez que se han lanzado a la descripción de la cooperación internacional bajo anarquía y al estudio de estrategias como la cooperación condicional o el logro de acuerdos institucionalizados en procura de desincentivar a los francotiradores.

Las conclusiones del institucionalismo han sido sin embargo impugnadas por neorrealistas como Grieco $(1988,1992)$, quienes ven una posibilidad muy limitada para la cooperación entre los estados. Según estos autores, la inseguridad general de la anarquía internacional conduce a los estados a preocuparse no sólo por cómo les va a ellos mismos sino también por cómo les va a los demás, es decir, a considerar no sólo sus ganancias (utilidades) absolutas (absolute gains) sino sus ganancias relativas (relative gains). En palabras de Waltz (1979:105) citadas tanto por Baldwin (1993) como por Snidal (1991), "cuando enfrentan la posibilidad de cooperar por un bien común, los estados, inseguros, se preguntan cómo el bien será dividido. Ellos no son compelidos a preguntarse "¿Ganaremos los dos?" sino "¿Quién ganará más?" Si una ganancia esperada se divide, digamos, en una proporción de dos a uno, un estado puede usar esta desigual ganancia para implementar una política tendiente a dañar o a destruir al otro". Así, la anarquía llevaría a la búsqueda de la utilidad relativa, lo que inhibiría la cooperación al conducir a los estados a situaciones de juego menos cooperativas que las descriptas por el dilema del prisionero.

Lejos de amedrentarse, el institucionalismo ha sabido responder a las críticas neorrealistas incorporando a su propio enfoque las observaciones acerca de la utilidad relativa. En general los autores de esa línea se muestran dispuestos a aceptar el hecho de que un estado, al evaluar los resultados de una posible cooperación no se limita a evaluar las ganancias absolutas a obtener, sino que también toma en cuenta la influencia de las ganancias mutuas en las intenciones futuras de los demás cooperadores. De manera que en el cálculo de utilidades de los cooperadores ya estaría incluido el "costo" asociado al temor a lo que los demás hagan a partir de las ganancias mutuas futuras. Es decir se produciría un "linkage" entre el juego presente y un juego futuro, de modo que la deliberación sobre un hipotético juego futuro llevaría a un cambio de preferencias en el presente.

Por otro lado, los institucionalistas han demostrado que la consideración de la utilidad relativa adquiere importancia en los casos en que ella conduce a la transformación de los dilemas del prisionero de dos jugadores en juegos de estancamiento o en juegos de suma cero (en los que la ganancia de un jugador es tomada como pérdida por el otro), es decir en juegos de dos jugadores totalmente enfrentados, sin intereses comunes. Dado que también se ha probado que el impacto de la utilidad relativa decrece a medida que aumenta el número de actores, los institucionalistas concluyen que el a su entender excesivo pesimismo de los neorrealistas respecto de las posibilidades para la cooperación internacional se debe a una equivocada extensión de las conclusiones obtenidas en base a juegos de dos actores al conjunto de una sociedad internacional de múltiples jugadores, en la que la ausencia de intereses comunes no es el caso general, sino una situación más bien difícil de encontrar. De manera que al llevar a cabo la referida generalización, el neorrealismo se mostraría, paradójicamente, poco realista.

En suma, el institucionalismo acepta las suposiciones realistas acerca de la anarquía consecuente de la falta de gobierno común y de la consideración de la utilidad relativa, pero argumenta que cuando existen intereses comunes, el neorrealismo es demasiado pesimista respecto a las perspectivas para 
la cooperación y acerca del rol de las instituciones. Al respecto, el institucionalismo no predice la cooperación ni la formación de instituciones internacionales, simplemente dice que ante la evidencia de ganancias mutuas tales fenómenos son posibles.

Es entonces que de la mano del institucionalismo, a partir de mi modelo interpretativo de la acción de los actores internacionales y de mis reflexiones sobre la lógica de la cooperación obtenidas en base al análisis de Maquiavelo y Hobbes, que en el siguiente punto comenzaré mi indagación sobre la posibilidad de instituir un auténtico organismo de seguridad colectiva internacional que permita una mayor cooperación política y militar. Es decir, se no tratará de analizar la posibilidad de un organismo que se limite simplemente a favorecer la cooperación en el marco de anarquía internacional, sino la de uno que consiga eliminar el estado de anarquía mismo y con él la referencia a utilidad relativa, optimizando así la cooperación mundial en todos los terrenos y posibilitando la acción conforme al derecho internacional. En ese sentido, el desafío consistirá en mostrar, a partir de la aplicación de la lógica de la cooperación al ámbito internacional, la factibilidad de un auténtico organismo de seguridad colectiva que no constituya una carga sino un elemento útil para los países, de manera que la consideración de los intereses comunes y de las ganancias mutuas a obtener de la inhibición de la utilidad relativa y del aumento de la cooperación, lleven a los estados a una toma de conciencia de las bondades de tal organismo.

Vale aclarar que en tanto involucraría la cooperación de todos los estados, la eliminación de la utilidad relativa no estaría en sí misma afectada por consideraciones de utilidad relativa, dado que el número de cooperadores evitaría que tales consideraciones influyeran en la construcción de la seguridad colectiva. Es decir, la eliminación de la utilidad relativa sería posible a través de un proceso en el que ésta careciera de relevancia debido al elevado número de participantes.

Resultará de sumo interés, por lo tanto, aplicar aquí las conclusiones que en el capítulo anterior se obtuvieron, a partir de la lógica de la cooperación individual, para la descripción y explicación de la constitución del Estado. En este sentido, se investigarán las consecuencias que se desprenden de la implementación de dicha lógica al estudio de la acción colectiva de los estados, con el objeto de analizar las bases lógicas de un auténtico sistema interestatal de seguridad colectiva. Además, a medida que se vaya avanzando en esta tarea, se irán comparando sus resultados teóricos con los intentos prácticos de seguridad colectiva llevados a cabo en el presente siglo, fundamentalmente el de las Naciones Unidas, de manera de obtener nuevas conclusiones. Nótese que mi fundamentación de la seguridad colectiva, a diferencia de las perspectivas idealistas-juridicistas, partirá del ser de las relaciones internacionales, el conflicto, para avanzar en el entendimiento de la cooperación necesaria para el logro del deber ser, el respeto del derecho internacional. Más precisamente, se irá del ser práctico del conflicto al deber ser teórico de las formas cooperativas, para desde allí volver al ser y reflexionar acerca del fracaso en el establecimiento de una auténtica seguridad colectiva.

\subsection{La seguridad colectiva, alternativa de solución al problema de poder.}

Identificando a la anarquía internacional con la falta de un gobierno común por sobre el de las naciones, desde las relaciones internacionales se plantean cinco respuestas organizativas posibles al problema de poder de los estados en la sociedad internacional:

1) El unilateralismo: consiste en "arreglárselas solo", independientemente de toda alianza o disposición de seguridad colectiva. El aislacionismo y la neutralidad son sus expresiones más conocidas, aunque también pueda tomar la forma del intervencionismo individual.

2) El balance de poder: constituye, como se ha visto, la forma más tradicional de las relaciones entre estados. Consiste en la cooperación estratégica de un estado con otros con intereses comunes, ya sea mediante alianzas o entendimientos menos formales.

3) La seguridad colectiva: modelo surgido luego de la Primera Guerra Mundial con el objeto de resolver el problema de poder de manera más eficaz que el unilateralismo y el balance de poder. La 
idea consiste, básicamente, en un plan de seguro mutuo con participación lo más universal posible, según el cual todos los miembros de la organización de seguridad deben auxiliar a cualquier miembro atacado, ya fuese por otro (otros) miembro (miembros) o por un país ajeno a la organización. Este modelo es el que ha sido auspiciado por Sociedad de Naciones y, después de la Segunda Guerra Mundial, por las Naciones Unidas.

Según Hartmann (1983:16), estos tres modelos de poder "son las estrategias alternativas estructurales u organizativas de que disponen los estados para hacer frente al problema de poder, suponiendo que el sistema de naciones-estados continuara existiendo, bajo cualquier forma parecida a la actual". Existen, sin embargo, otras dos posibles soluciones teóricas:

4) El imperio mundial: sería posible si un estado lograra poder destruir o someter a su poder a todos los demás mediante la conquista del mundo.

5) La federación mundial: la resolución del problema de poder mediante la eliminación de los estados nacionales podría también ocurrir, si todos ellos se uniesen, entregando voluntariamente la soberanía a un gobierno mundial.

¿Cuál de estas cinco soluciones aparece como la mejor o más deseable? Desde mi interpretación del problema de poder a la luz del dilema del prisionero puede decirse que tanto el unilateralismo como el balance de poder conducen, ya sea en la relación entre países, alianzas, o entre países y alianzas, a un equilibrio no cooperativo y por lo tanto subóptimo. En particular, el unilateralismo, al considerar a la sociedad internacional como un juego de estancamiento en el que la defección mutua se prefiere a la cooperación mutua, se ha tornado reconocidamente impracticable en el ámbito de una comunidad internacional cada vez más interdependiente. Por su parte, reconocida la existencia de intereses comunes y en consecuencia de la posibilidad de identificar al problema de poder con el dilema del prisionero, el balance de poder se ha mostrado como una solución ineficaz, inestable y peligrosa, a consecuencia de las rigideces en las que suelen derivar los cambios de sistemas de poder y que han llevado las más de las veces a distintas guerras (la duración de un balance de poder se define comunmente entre el fin de una guerra y el inicio de otra). En ese sentido, las opciones 3, 4 y 5 representan otras soluciones posibles al dilema del prisionero (problema de poder). Entre ellas, las alternativas teóricas posibles a partir de la disolución del sistema de estados nacionales no parecen muy alentadoras. Un imperio mundial, en realidad una dictadura mundial, resulta moralmente inaceptable. Pero además, en tanto el estado hegemónico constituiría un francotirador del propio sistema al autoexcluirse del cumplimiento de las reglas que él mismo impondría a los demás, el imperio vería amenazada su estabilidad. Inmoralidad e inestabilidad serían así dos razones que permitirían calificar de subóptimo al imperio frente a una federación mundial voluntaria. Sin embargo, este último modelo de poder tampoco parece el ideal. En primer lugar, resulta difícil imaginar, en un tiempo en el que las soberanías nacionales y el nacionalismo se hallan fuertemente arraigados, que una mayoría de estados se avengan a renunciar totalmente a su soberanía en favor de un único poder mundial. Pero si esto ocurriera, aún así no quedaría superado el problema de poder, ya que algunas unidades podrían decidir no adherirse, o separarse de la federación, e incluso enfrentarla en forma individual o colectiva. Por otro lado, queda claro que al igual que el imperio, la federación no eliminaría las luchas de poder entre grupos rivales por los intereses en el control del estado mundial.

Parece ser, entonces, que la solución más adecuada al problema de poder pasa por el establecimiento de un auténtico mecanismo de seguridad colectiva que oriente un cambio de preferencias de los estados, de manera que sus relaciones abandonen el marco del juego del dilema del prisionero por el del juego de la seguridad. A partir de dicha seguridad, la paz y la aplicación del derecho internacional serían posibles subproductos derivados de ella.

¿Cómo debería constituirse este auténtico mecanismo de seguridad colectiva? Mi respuesta a esta pregunta comenzará, como ya se adelantó, con una aplicación de mi interpretación maquiavélicohobbesiana de la lógica de la cooperación al análisis del deber ser de la cooperación internacional, para pasar luego a una comparación con la realidad de la referida cooperación. Finalmente, a la luz 
de esa investigación, intentaré dar las pautas que permitirían pasar del actual intento de seguridad colectiva propiciado por las Naciones Unidas a una seguridad colectiva real y efectiva. Comenzaré entonces afirmando que en una sociedad internacional anárquica pura, el establecimiento de la seguridad colectiva debería darse teóricamente del modo siguiente:

1) Necesariamente, en ausencia de un garante inicial, el primer paso debería surgir a partir de una solución interna de algunos estados que, reconociendo intereses comunes, se decidieran a superar la situación subóptima del dilema del prisionero y a constituirse en los fundadores de un organismo de seguridad colectiva que optimice la cooperación.

2) Tales estados, cooperando condicionalmente entre sí, deberían ponerse de acuerdo en establecer las instituciones y fundar las leyes del mencionado organismo. Pero sobre todo, y al mismo tiempo, para asegurar la seguridad colectiva, deberían reunir un poder disuasivo capaz de inducir en el resto de los países un cambio en el orden de sus preferencias que los condujera a una solución externa del dilema del prisionero (de su problema de poder), es decir, que transformara el sistema anárquico internacional en un juego de seguridad. La existencia de dicho poder debería también contribuir a que se lograra una internalización voluntaria más allá de la coacción.

3) Para conseguir una cooperación rápida, honesta y sostenible en el tiempo, las leyes instauradas por los fundadores deberían cumplir ciertos requisitos morales mínimos, por ejemplo, la aceptación al menos de la igualdad de derechos y deberes de sus miembros. En ese sentido una vez superado el proceso fundacional, fijadas las leyes iniciales y los mecanismos del nuevo organismo, los "pecadores originales" deberían integrarse a éste como miembros normales e iguales, favoreciendo el control "público" de sus actos y la participación equitativa y democrática de sus integrantes.

4) Una vez logrado el umbral de participación y establecido el organismo de seguridad colectiva, la cooperación condicional de los jugadores del juego de la seguridad (francotiradores corregidos, kantianos cotidianos, seguidores de la norma de la honestidad) debería quedar asegurada a partir de la atribución del monopolio del uso de la violencia legítima a dicho organismo, de manera que se castigara a los francotiradores que no cumplieran con las leyes establecidas.

5) La calificación de las violaciones al derecho internacional, así como el juzgamiento de los litigios, deberían quedar a cargo de organismos imparciales internacionales creados a tal fin.

Se tiene entonces que, de acuerdo a mi interpretación de la lógica de la cooperación, el logro del deber ser de la cooperación internacional llevaría también implicado el estudiado pasaje de la racionalidad estratégica al conflicto, del conflicto a la cooperación y de la cooperación al respeto del derecho. En particular, la reciprocidad estratégica propia de la cooperación condicional inicial sería el inicio del camino a la reciprocidad legal y moral. En ese sentido, el hecho de partir de la asociación de la anarquía internacional con el dilema del prisionero y de sostener que tanto la cooperación espontánea como el respeto del derecho internacional (racionalidad moral) son posibles sólo en una segunda instancia, una vez lograda la cooperación estratégica, marcará la dirección "realista idealista" de mi enfoque.

\section{3- Los intentos prácticos de seguridad colectiva: la Liga de las Naciones y la Organización de las Naciones Unidas.}

El deber ser de la lógica de la cooperación dirigida contrasta con la historia y la realidad de los organismos que han procurado imponer el modelo de la seguridad colectiva, la Liga de las Naciones y la Organización de las Naciones Unidas.

Antes de hacer referencia a los mencionados organismos, debe decirse que el tratado de Kant sobre La paz perpetua (1795) constituye la primera justificación seria de organización mundial tendiente a la superación del estado de naturaleza internacional, dentro de una serie de proyectos aparecidos desde la Baja Edad Media hasta la actualidad, y entre los que se destacan, con anterioridad a Kant, los de Sully y Emeric Crucé, Will Penn, el abate de Saint-Pierre y Bentham. Culminación de la 
literatura anterior sobre el tema, que en algunos autores se identifica con el género de la utopía, dicha obra se sitúa en el marco de los escritos kantianos, constituyendo su propia filosofía de la sociedad internacional. Para Kant (1795:21), "los estados con relaciones recíprocas entre sí no tienen otro medio, según la razón, para salir de la situación sin leyes, que conduce a la guerra (cuya eliminación es un deber moral), que el de consentir leyes públicas coactivas, de la misma manera que los individuos entregan su libertad salvaje (sin leyes), y formar un Estado de pueblos (civitas gentium) que (siempre, por supuesto, en aumento) abarcaría finalmente a todos los pueblos de la tierra". Como acota Truyol y Serra en su presentación a Kant (1795), es la misma exigencia racional del imperativo categórico que obliga a los individuos a asociarse en el Estado, la que los obliga también a superar el estado de naturaleza que impera entre los estados y a constituir una unión de estados. Mientras no se llegue al Estado mundial, cosmopolita, el derecho de gentes (internacional) no pasará de ser un sucedáneo "provisional" carente de eficacia. Es precisamente la idea de que la precariedad del derecho internacional sólo puede ser superada por la vía de la organización internacional, y de que la paz, éticamente necesaria, va vinculada a tal clase de organización, la que ejerció gran inflluencia a lo largo de los siglos XIX y XX, especialmente en la creación de la Liga de las Naciones. Sin embargo, al considerar el establecimiento de una institución supranacional desde una perspectiva puramente moral, independientemente de la consideración de los intereses estratégicos de los estados, Kant peca de ingenuidad. Ese idealismo ingenuo, tomado por la Liga de las Naciones, es el que le impedirá ver sus problemas estructurales y la conducirá a la disolución.

La Liga de las Naciones surge tras el fuerte impacto producido, después de un siglo de paz general, por la Primera Guerra Mundial. Así, inspirados en el idealismo del presidente norteamericano Woodrow Wilson, los estados vencedores de dicha contienda reconocen sus intereses comunes y la suboptimalidad de la no cooperación, dan una "solución interna" a sus problemas de poder y se avienen a cooperar en la creación del primer organismo de seguridad colectiva. La aplicación de la seguridad colectiva exigía mayores responsabilidades para los estados que la incorporación a una alianza de balance de poderes, ya que suponía extender la obligación de la defensa ante la agresión de intereses vitales a todos los estados (y no sólo a los amigos), sin importar cuál fuera atacado y por qué. Como señala Hartmann (1983:407), desde la incorporación de este principio al Pacto de la Liga, el mundo nunca volvió a ser el mismo."Estuvieran o no dispuestos a cumplir con el espíritu y la letra de sus obligaciones de seguridad colectiva, las naciones ya no pudieron actuar como lo habían hecho antes de la Primera Guerra Mundial", apartándose o manteniéndose neutrales ante una agresión flagrante que no afectara sus intereses específicos,"cada guerra local se convirtió - al menos en teoría y en cuanto a presión moral - en una responsabilidad de toda la "familia de naciones""'.

A la estructura de la seguridad colectiva de la Liga se agrega en 1928 la firma del Pacto BriandKellog, en el que por primera vez los estados "condenan el recurso a la guerra para resolver controversias internacionales y renuncian a él, como instrumento de política nacional, en sus relaciones recíprocas" (artículo 1) y convienen que "el arreglo o solución a todas las disputas o conflictos que pudieran surgir entre ellas, sea cual fuera su naturaleza $u$ origen, nunca serán buscados por otros medios que no sean los pacíficos" (artículo 2). Sin embargo, tanto el Pacto de la Liga de las Naciones como el Briand-Kellog, contenían lagunas y excepciones contradictorias con la lógica de la cooperación que los condujeron al fracaso.

En primer lugar, ninguno de los dos hacía ilegales todas las guerras. La guerra seguía siendo legal si se hacía contra un estado no signatario del Pacto de la Liga, o contra un estado signatario que lo hubiera violado (cada estado podía interpretar con amplitud las disposiciones al respecto). Por otro lado, el artículo 16 de ese Pacto, que introducía la seguridad colectiva, consideraba que un estado cometía un acto de guerra contra los otros miembros de la Liga si a) recurría a la guerra antes de pasados los tres meses siguientes a la decisión arbitral o judicial de su reclamo, b) entraba en guerra con un estado parte que hubiese aceptado el juicio de un árbitro o el veredicto de un tribunal, c) entraba en guerra con un estado que hubiese aceptado las recomendaciones de un informe votado por unanimidad (excluidos los estados parte del conflicto) por el Consejo de la Liga de Naciones. 
No obstante, si bien los estados se comprometían a someter sus disputas al arbitraje, a la decisión de un tribunal o al Consejo de la Liga, no se obligaban a ello, continuando libres de decidir su recurrencia a tales mecanismos de solución de conflictos. Así, la única manera que existía de aplicar la seguridad colectiva a un conflicto no llevado a arbitraje o juicio por las partes (o en que éstas hubieran rechazado la solución dispuesta) era mediante una recomendación unánime del Consejo. Demás está decir que no era difícil que esta unanimidad no fuera conseguida, caso en el que "los miembros de la Liga se reservaban el derecho a actuar como creyeran necesario para el mantenimiento del derecho y de la justicia" (artículo 15). Pero aún si la unanimidad era conseguida, el Consejo no podía sino formular recomendaciones acerca de la participación de los distintos estados en las sanciones militares.

Por otra parte, los signatarios se habían reservado dos vías de evasión por las que se filtraban las prácticas tradicionales: el derecho a la legítima defensa propia y la posibilidad de emplear la fuerza sin declarar la guerra. El derecho a la defensa propia fue también reconocido por el pacto BriandKellog e introducía una excepción tan importante que prácticamente dejaba sin sentido todo lo demás. Dado que no se preveía ningún organismo que limitara este derecho, así como por consecuencia de la vaguedad y globalidad del término "defensa propia", cualquier estado podía argumentar que se limitaba a ejercerla (así lo hicieron Japón en referencia a Manchuria e Italia respecto de Etiopía).

De todos modos y a pesar de las numerosas lagunas y excepciones citadas, el Pacto de la Liga, con algunas modificaciones como la supresión del requisito de la unanimidad para las recomendaciones del Consejo, podría haber sido suficiente para preservar la seguridad colectiva si no fuera por la imperfección esencial que constituía el estar formada por estados que no habían enajenado su soberanía militar, que no deseaban respetarlo ni se sentían obligados por sus recomendaciones y contra los cuales la Liga no contaba con la fuerza de sanción suficiente para imponer sus decisiones. He ahí la causa profunda del fracaso de la tentativa de obligar a Italia a renunciar a la conquista de Etiopía (las potencias europeas se negaban, a pesar de la resolución unánime del Consejo, a entrar en una guerra de segundo orden con Italia teniendo la amenaza alemana a sus espaldas).

Puede concluirse que el sistema que intentó imponer la Liga de las Naciones contradecía al menos los puntos 2, 4 y 5 de la lista en la que sinteticé las condiciones básicas para el establecimiento de la seguridad colectiva:

- Los estados fundadores no alcanzaron a reunir un poder disuasivo tal que orientara un cambio en las preferencias egoístas y no cooperativas de los demás países, sobre todo de los revisionistas (Alemania, Italia, Japón).

- A pesar de la instauración de un Tribunal Internacional de Justicia, se otorgó excesiva libertad de interpretación a los estados en cuestiones relativas a la necesidad de someterse a los tribunales, a la legítima defensa y al juzgamiento acerca de si una determinada guerra violaba o no el Pacto (al permitírsele alterar la unanimidad, cada estado podía boicotear la aplicación de la seguridad colectiva en un conflicto en el que no estuviera directamente involucrado).

- Los distintos equívocos, falencias y lagunas que se han observado en el sistema favorecían la aparición de francotiradores que violaban sus reglas sin ser castigados y que lo hacían tender inevitablemente hacia su disolución. De hecho, el modelo de seguridad colectiva nunca llegó a darse de manera pura sino que siempre, como consecuencia de la inseguridad original del sistema propuesto, continuaron subsistiendo las alianzas estratégicas propias del balance de poder.

La Organización de las Naciones Unidas nace en 1945, promovida por los triunfadores de la Segunda Guerra Mundial e inspirada en la misma filosofía legalista y pacifista que su predecesora. No es casual que el preámbulo de la Carta comience haciendo referencia a la resolución de los miembros de "preservar a las generaciones venideras del flagelo de la guerra que dos veces durante nuestra vida ha infligido a la humanidad sufrimientos indecibles", ni que el artículo 1 señale como principales propósitos el de "mantener la paz y la seguridad internacionales" tomando "medidas 
colectivas eficaces para prevenir y eliminar amenazas a la paz" y el de "realizar la cooperación internacional en la solución de problemas internacionales de carácter económico, social, cultural o humanitario". Puede interpretarse a partir de estas citas que los estados vencedores de la guerra, luego de una larga interacción continua y de los terribles costos de las dos guerras mundiales, toman conciencia de la ineficacia del sistema de balance de poderes para la consecución de sus intereses comunes y deciden cooperar para evitar que la desgracia se repita. Esta "solución interna" del problema de poder se plasma en la creación de un nuevo organismo de seguridad colectiva que permitiría sustentar y canalizar la cooperación induciendo a una "solución externa" a todos los estados. Así, con el fin de cumplir con sus propósitos, la Carta establece, en el artículo 2, los principales principios que deberán seguir los estados en la resolución de sus conflictos internacionales:

-"La Organización está basada en el principio de la igualdad soberana de todos sus miembros" (Principio de la igualdad soberana, artículo 2.1).

-"Los miembros de la Organización arreglarán sus controversias internacionales por medios pacíficos, de tal manera que no se pongan en peligro ni la paz y la seguridad internacionales ni la justicia" (Principio de reglamento pacífico de las controversias, artículo 2.3).

-"Los miembros de la Organización, en sus relaciones internacionales, se abstendrán de recurrir a la amenaza o al uso de la fuerza contra la integridad territorial o la independencia política de cualquier estado o en cualquier otra forma incompatible con los Propósitos de las Naciones Unidas". (Principio de no uso de la fuerza, artículo 2.4).

Como señala Aron (1962), puede decirse que estos principios constituyen fórmulas vagas (de hecho han sido frecuente e inevitablemente retorcidos e ignorados por los estados) que expresan ideales más que obligaciones precisas o que no imponen obligaciones legales a los estados más que en la medida en que vienen precisadas en los capítulos VI y VII, es decir los relativos al arreglo pacífico de las controversias y a la acción en caso de amenazas a la paz o actos de agresión.

El capítulo VII de la Carta constituye el núcleo del sistema de seguridad colectiva de las Naciones Unidas, resultando en ese sentido análogo a los artículos 10 a 16 del Pacto. Sus artículos son más precisos, claros y detallados, lo que permite corregir muchas de las lagunas de aquél, aunque dejando sin resolver sus principales falencias. En primer lugar, es ahora el Consejo de Seguridad el que determina la existencia de una amenaza a la paz, quebrantamiento de la paz o acto de agresión y el que cuenta con la autoridad de decidir las medidas, militares o no, tendientes a imponer su respeto y restablecer la paz. Es decir que el Consejo puede decidir el uso de la fuerza, para lo cual los miembros se comprometen (pero no se obligan) a poner a su disposición las fuerzas armadas necesarias para el cumplimiento de su tarea. No obstante, según el capítulo $\mathrm{V}$, si bien no se requiere unanimidad, las medidas del Consejo relativas al uso de la fuerza deben contar con el voto afirmativo de los cinco miembros permanentes (Estados Unidos, Rusia, Reino Unido, Francia, China). Es decir, los miembros permanentes disponen de derecho de veto de las decisiones del Consejo, incluso sobre aquellas cuestiones que los afectan directamente. Por su parte, la Asamblea puede por una mayoría de dos tercios votar recomendaciones sobre cualquier tema, pero no actuar para imponer su respeto.

El capítulo VII recoge también, en el artículo 51, la expresión de la legítima defensa individual o colectiva empleada en el Pacto Briand-Kellog. Su inclusión ha sido vista como una de las cláusulas de evasión más importantes del tratado, ya que permitió la proliferación de alianzas estratégicas "de defensa" y la formación de bloques hostiles durante la guerra fría, en contradicción con lo que se propusieron los creadores de la Carta. Sin embargo, se admite que el mantenimiento de las políticas de balance de poder resultó no una consecuencia de este único artículo sino de las fallas esenciales del sistema de seguridad colectiva, fallas que le impidieron suprimir los motivos de inseguridad y de conducta no cooperativa de los estados. Como señala Aron (1962), la defensa colectiva es un sustituto impuesto por la inacción del Consejo derivada del derecho de veto, no una consecuencia de la seguridad colectiva sino de su inexistencia. 
Hay que agregar que la recurrencia al artículo 51 como justificación de distintas agresiones resultó producto de la mala fe y de las estrategias egoístas de los estados que así lo hicieron, y no de su redacción, ya que ésta limita expresamente el derecho a la legítima defensa individual y colectiva al "caso de un ataque armado" contra un miembro, impidiendo por ejemplo los ataques preventivos o las represalias armadas.

Comparando ahora el sistema de Naciones Unidas con mi síntesis de la lógica de la cooperación dirigida pueden hacerse las siguientes observaciones.

- Las Naciones Unidas surgen como consecuencia de la "solución interna" al problema de poder y la subsiguiente cooperación condicional de ciertos estados fundadores (los vencedores de la Segunda Guerra Mundial) decididos a evitar la reiteración del conflicto y la no cooperación.*

- Dichos estados consiguen aglutinar una gran cantidad de naciones, superando el umbral de participación que los autoriza a instaurar las instituciones y las leyes de la nueva organización. Pero, si bien establecen un organismo destinado a determinar los casos en que se amenaza a la paz o se incurre en una agresión, no se obligan ni obligan a los demás estados a aportar los recursos militares necesarios para hacer respetar sus decisiones.

- Es más, al arrogarse el derecho de veto, los estados fundadores se autoexcluyen del cumplimiento de la Carta, convirtiéndose en los principales francotiradores impunes del sistema de cooperación colectiva que ellos mismos intentan imponer. El derecho de veto, inmoral y antidemocrático, introduce una deliberada inequidad en el sistema. Este instrumento permite que dichos estados continuen con la inercia de la "solución interna" (en la que no hay un cambio de preferencias sino una cooperación condicional que mantiene las del dilema del prisionero), negándose a internalizar el orden del juego de la seguridad que ellos mismos pretenden imponer a los demás. Es decir, los "pecadores originales" mantienen su reciprocidad estratégica pero impiden la reciprocidad legalmoral.

- La inexistencia de una fuerza disponible suficiente para desalentar toda agresión, producto de la escasa disposición de los estados a colaborar militarmente allí donde no se encuentren afectados sus intereses (actitud alimentada por la no obligatoriedad de tales compromisos), a lo que se suma la incertidumbre sobre una agresión de alguno de los miembros permanentes (no sancionables de manera colectiva), conducen a los estados a adoptar estrategias no cooperativas, a jugar sobre seguro en un mundo colectivamente inseguro y a la preservación de las condiciones esenciales del estado de naturaleza. Es decir, el mismo sistema hace imposible que los estados puedan resolver su problema de poder adoptando las preferencias del juego de la seguridad, ya que desde el vamos están dadas las circunstancias que hacen factible la posibilidad de ser defraudados en caso de prestarse a la cooperación. En todo caso, al no existir una solución externa, los estados cooperarán sólo de manera condicional, la mayoría de las veces como seguidores de la norma de la honestidad. Debe conseguirse entonces una solución externa que asegure el cumplimiento de los requisitos que a falta de ella son necesarios para la cooperación del seguidor de la mencionada norma de la honestidad.

- La Carta es netamente juridicista, habla de paz pero no establece los mecanismos adecuados para fundar una auténtica seguridad colectiva. Así, los estados siguen buscando la seguridad por su cuenta poniendo en peligro la paz, que como se ha visto constituye un subproducto de ella.

- En cuanto al arbitraje y juzgamiento de los litigios, al no ser obligatoria la recurrencia a la Corte Internacional de Justicia, los estados se muestran renuentes a presentarse ante ella, prefiriendo otros métodos de resolución de diferendos como la negociación o la conciliación, en las cuales no existe una sentencia de cumplimiento obligatorio (aunque la Corte, la mayoría de las veces, no cuente con la fuerza para hacer cumplir las sentencias).

Inexistencia de fuerza coactiva y derecho de veto constituyen los dos elementos estructurales que hacen posible el fracaso de la seguridad colectiva propugnada por las Naciones Unidas y determinan la continuación del juego clásico de la política de poder. 
Si bien el Consejo puede tomar e imponer una decisión colectiva por las armas, esto raramente ha ocurrido por la imposición del veto. Por otro lado, como señala Aron, cuando las grandes potencias están de acuerdo, con o sin seguridad colectiva, no tiene lugar una gran guerra. En ese sentido la Carta estaba más orientada a evitar el resurgimiento de las potencias del Eje (contra quiénes sino era más factible obtener el voto de los miembros permanentes del Consejo) que a conformar un auténtico y estable sistema de seguridad colectiva, lo que resultaba comprensible si se tiene en cuenta la cercanía de las dos guerras mundiales por ellas provocadas.

\section{4- Algunas enseñanzas aportadas por las experiencias en seguridad colectiva.}

Antes de pasar a investigar los requisitos a ser cumplidos para la consecución de una auténtica seguridad colectiva, vale la pena tener en cuenta algunas conclusiones obtenidas de la experiencia de los distintos intentos en ese sentido.

- El caso ítalo-etíope, más precisamente la decisión de levantar las sanciones a Italia, interpretado como uno de los fracasos más notorios de la Liga, resultó una consecuencia directa de la falta de capacidad coercitiva de esa organización. En ese sentido, la determinación de Gran Bretaña y Francia de evitar una guerra con Italia fue acertada, teniendo en cuenta la presencia de Hitler, agazapado a sus espaldas y a la espera de beneficios. Coincido entonces con Hartmann (1983:413), en que las normas éticas y jurídicas sustentadas en el Pacto, además de distar de ser universalmente aceptadas, excedían la capacidad de la Liga para cumplirlas, lo que ocasionó efectos desastrosos en las relaciones internacionales anteriores a la Segunda Guerra Mundial.

- La intervención de la ONU en la guerra de Corea, inicialmente exitosa, se vio alterada radicalmente con el ingreso de China Popular en la contienda, que transformó la superioridad absoluta de las fuerzas internacionales en una lucha entre fuerzas relativamente parejas y determinó que el final de la contienda se diera a través de un armisticio conciliado que, si bien no castigaba la agresión norcoreana, satisfacía el más limitado y realista objetivo de reinstaurar el statu quo ante bellum. De esta manera, el conflicto coreano puso sobre el tapete el problema que se le presenta a las Naciones Unidas cuando se ven en la necesidad de coaccionar por la fuerza a una gran potencia (problema que el derecho de veto ha evitado al costo de conservar las prácticas de balance de poderes entre las potencias y en desmedro de la seguridad colectiva), así como evidenció las dificultades que, salvo un pequeño puñado de países, afrontan las naciones para aportar, equipar y sostener un número significativo de fuerzas para la defensa colectiva sin dejar descubiertas sus defensas nacionales. A su vez, la experiencia de Corea dejó un precedente según el cual, a falta de consenso y de normas aceptadas mundialmente, el castigo a una agresión no debe ir más allá de negarle al agresor el botín deseado.

- Resulta muy difícil que se dé en la práctica el caso teórico clásico de seguridad colectiva en el que un estado agresor es condenado y resistido por todas las demás naciones en favor del agredido. Aún después de la clara agresión de Irak a Kuwait algunos estados árabes respaldaron a Saddam Hussein. Sin embargo, la experiencia ha demostrado que los resultados y potencialidades de la seguridad colectiva no dependen del estricto cumplimiento de la situación clásica, sino de que el grupo antiagresor quiera y pueda comprometer fuerzas conjuntas muy superiores a las involucradas por el agresor y sus eventuales aliados.

- Se dice que, así como hasta 1914 era concebible un sistema de poder mixto en el que mientras algunos países optaban por la neutralidad era posible que otros estuvieran enmarcados en un balance de poder, desde 1945 existe un régimen mixto de balance de poder y seguridad colectiva. Sin embargo, la seguridad colectiva, como los modelos de la federación y el imperio, es teóricamente contradictoria con el balance de poderes que intenta desterrar. La mencionada "coexistencia" no marca otra cosa que la sostenida vigencia del balance de poderes en desmedro de la seguridad colectiva, desvirtuada y reducida su aplicación a los casos en que hay acuerdo entre las potencias, es decir, cuando no modifica el balance de poderes existente. 
- De la teoría y también de la práctica de la acción colectiva se deduce también que mientras los estados conserven la posibilidad de defender con armas aquellos intereses que consideren vitales, ningún organismo de seguridad colectiva será capaz de eliminar las guerras, así como las leyes o el poder de policía de un estado sobre su territorio no pueden de por sí eliminar el crimen. No obstante, pueden concebirse mecanismos que permitan minimizar en número y magnitud los delitos internacionales. Del mismo modo, aunque la seguridad colectiva tampoco va a hacer desaparecer las guerras civiles (la guerra en Chechenia, por ejemplo, fue reconocida como un problema interno ruso que no justificaba un conflicto entre las Naciones Unidas y Rusia), permitiría ejercer controles efectivos y efectuar recomendaciones a ser cumplidas bajo amenaza de sanciones económicas.

- El funcionamiento de los distintos intentos de seguridad colectiva ha confirmado la frase que dice que "no hay mayor injusticia que tratar a los desiguales como si fueran iguales". Mientras un país grande o de alta población, con significativos aportes e intereses en la buena marcha del organismo no ve bien su ausencia en la toma de decisiones importantes, un país pequeño no puede ser sometido a las mismas exigencias que uno grande. Así, sobre la base democrática de la igualdad de trato ante los tribunales y en las votaciones (un país, un voto), quedan justificadas tanto la proporcionalidad de los aportes y obligaciones como la desigualdad en las asignaciones de ayuda económica y la desigualdad de responsabilidades que implica la existencia de miembros permanentes en el Consejo de Seguridad. Este argumento no alcanza, sin embargo, para justificar el derecho de veto que, como vimos, constituye un abuso de poder que atenta contra todo el sistema.

- Pese a todos sus defectos, las Naciones Unidas han logrado constituirse en un foro de acercamiento de los pueblos, generador y coordinador de conductas cooperativas de todo tipo en los terrenos económico, humanitario y cultural. Es de esperar que estas formas de compromiso colectivo estimulen a esos pueblos a encontrar las soluciones institucionales necesarias a nivel de la seguridad colectiva que permitan asegurar también la cooperación política y militar.

- Si bien ha constituido una gran contribución al entendimiento y al desarrollo de los pueblos, no puede decirse que el sistema de seguridad colectiva propiciado por las Naciones Unidas haya sido el responsable de los cincuenta años sin conflictos generales que han seguido a su conformación en 1945. De hecho, salvo casos aislados, la aplicación del derecho de veto privó al organismo de un papel importante en los acontecimientos internacionales. Así, al haber sido dejado intacto el esquema de preferencias del dilema del prisionero, en lo relativo a las grandes potencias, las causas de la ausencia de guerras generales deben más bien ser rastreadas en las consideraciones estratégicas de dichas potencias basadas en la posibilidad de la destrucción mutua. En ese sentido, la relación entre las dos superpotencias de la guerra fría, los Estados Unidos y la Unión Soviética, se caracterizó por la desconfianza y la falta de cooperación recíproca en todos los niveles. Sin embargo, la mencionada capacidad de respuesta a las armas de destrucción masiva, al asegurar la mutua destrucción consecuente a un ataque de cualquiera de las superpotencias, al identificar la no cooperación en materia nuclear como un suicidio, advirtió sobre la existencia de intereses comunes que debían ser conciliados y evitó que la falta de cooperación en todos los niveles se transformara, en el terreno militar, en una conflagración nuclear. La evidencia contrafáctica de un colapso nuclear supo conducir a las superpotencias a una solución interna que dio pie a una cooperación condicional en temas militares bilaterales. De esta manera, si bien las superpotencias conservaron sus preferencias del dilema del prisionero, durante la guerra fría trasladaron su falta de cooperación y antagonismo militar a los conflictos internos de países pequeños como Vietnam, Nicaragua o Afganistán, con el objetivo de integrarlos a uno o a otro de los bloques rivales.

- Inmediatamente concluida la guerra fría, la exitosa operación de las Naciones Unidas en Irak, el caso histórico más cercano al ideal de la seguridad colectiva, pareció abrir un nuevo y auspicioso horizonte para el modelo de poder auspiciado por dicho organismo. Sin embargo, el fracaso de la intervención en Somalía, así como la ineficacia y las complicaciones surgidas durante la guerra de Bosnia, han resucitado el escepticismo así como han hecho patente la dificultad que representa, en el marco desideologizado y economicista de la posguerra fría, organizar y mantener una 
intervención en aquellos lugares en los que, a diferencia de las ricas arenas kuwaitíes, las potencias carecen de intereses relevantes afectados.

Por lo tanto, es ahora, y sobre todo a partir del descrédito adquirido por las Naciones Unidas luego de las mencionadas participaciones en Somalía y Bosnia, aparentemente ya superados los recelos de la guerra fría y de cara a las oportunidades de la posguerra fría, que se impone una reformulación del sistema de ese organismo de manera que, teniendo en cuenta la nueva configuración de la sociedad internacional, acierte en la consecución de una auténtica y efectivamente útil seguridad colectiva que permita asegurar la vigencia del derecho internacional. Es decir, se hace necesario el paso de la actual estructura anárquica del sistema internacional (en la que el uso de la fuerza entre los Estados no es constante pero permanece como "última ratio") a una estructura jerárquica que termine con la incertidumbre inhibitoria de la cooperación y de la racionalidad moral.

\section{5- Los requisitos para una auténtica seguridad colectiva.}

¿Qué requisitos deberían agregarse al actual marco de las Naciones Unidas para que éstas pudieran cumplir auténticamente con su rol de seguridad colectiva?

$\mathrm{Al}$ respecto, se han elaborado numerosas sugerencias, entre las que merece destacarse el completo y detallado plan de revisión de la Carta de las Naciones Unidas llevado a cabo por Clark y Sohn (1958). Este proyecto, al que resulta muy interesante rescatar a la luz de la posguerra fría, parte de mi punto de llegada respecto de la lógica de la acción colectiva (la necesidad de un conjunto de normas emanadas de una autoridad mundial y susceptibles de ser aplicables de manera efectiva), pero debido a su carácter juridicista deja casi sin explicar las causas por las que los estados habrían de delegar poder a una organización mundial, más allá de apelar a la superación de los atavismos tradicionales y culturales. Mi esquema argumentativo, en cambio, resulta más persuasivo ya que ataca la irracionalidad estratégica y moral inherentes al mantenimiento del balance de poder a partir de la forma en que ésta es determinada por la lógica de la acción colectiva. Al final de este punto se volverá a tratar este tema.

Sin pretender ser tan minucioso como Clark y Sohn en la descripción de los cambios jurídicos a introducir para el logro de una institución eficaz para la prevención de la guerra, de acuerdo a las conclusiones alcanzadas en mi estudio de la lógica de la cooperación, a su comparación con los intentos prácticos de seguridad colectiva y a las enseñanzas dejadas por ellos, me atreveré a formular algunas sugerencias.

En primer lugar, el funcionamiento de la seguridad colectiva no debe quedar librado a la buena voluntad de cooperación de los estados miembros, sino que debe ser respaldado por una fuerza permanente de sanción, no condicionada a lealtades nacionales, que a partir de contribuciones proporcionales directas y obligatorias de todos los estados miembros, adquiera una dimensión y potencial irresistible que disuada a los eventuales agresores. Una fuerza de policía mundial con la potencialidad y el armamento que le permitan prevenir o suprimir rápida y certeramente cualquier violencia internacional resulta indispensable, a pesar del riesgo que supone que esa fuerza pueda ser usada indebidamente. En todo caso, como señalan Clark y Sohn, ese riesgo, que debería ser controlado por medio de límites y vigilancias estrictos a la fuerza de policía, sería el precio inevitable de la paz. En la misma dirección apuntan las sugerencias de Boutros Ghali (1992) respecto de la creación de "unidades de resguardo de la paz" a disposición permanente del Consejo de Seguridad cuya fácil disponibilidad podría servir, por sí misma, para disuadir a los agresores potenciales. Aunque la fuerza militar debería utilizarse sólo si han fracasado todos los medios pacíficos, "la posibilidad de recurrir a ella es esencial para que se pueda dar crédito a las Naciones Unidas como garantes de la seguridad internacional" (Boutros Ghali 1992:128). El Secretario General añade que para que haya confianza es indispensable que se pueda tener fe en que las Naciones Unidas reaccionarán con rapidez, firmeza e imparcialidad y que no será debilitada por el oportunismo político ni por las deficiencias administrativas o financieras. Ello presupone "una 
administración pública internacional vigorosa, eficiente e independiente, y de una integridad intachable, así como una administración financiera segura que rescate a la organización, de una vez por todas, de su actual estado de mendicidad" (Boutros Ghali 1992:131).

Por ejemplo, podría establecerse que las naciones se avinieran a utilizar un porcentaje (digamos un $3 \%$ ) de sus gastos de defensa en la preparación de una fuerza a permanente disposición, so pena de castigos económicos (quizá a través de las instituciones de crédito dependientes del organismo), de las Naciones Unidas y para los propósitos que ésta estimare necesario. Hay otras ideas, como la del Premio Nobel de Economía James Tobin de aplicar un impuesto del 0,05\% a las transferencias monetarias internacionales, que permitiría recaudar unos 150 mil millones de dólares al año para el financiamiento de la organización mundial (téngase en cuenta que actualmente se dedican sólo 3 mil millones para financiar todas las misiones de paz y 3600 para los programas y fondos para el desarrollo). Como señala Boutros Ghali (1992:129), "el contraste entre el costo de las actividades de mantenimiento de la paz por las Naciones Unidas y el costo de la alternativa, la guerra, al igual que el contraste entre lo que se pide a la Organización que haga y los medios que se le proporcionan para ello, serían risibles si las consecuencias no fueran tan perniciosas para la estabilidad mundial y para el prestigio de la Organización".

En cuanto a las armas de destrucción masiva, debería acelerarse el actual proceso de control y reducción coordinada de los arsenales y de los riesgos propiciada en el marco del Tratado de No Proliferación Nuclear, conservando la mínima proporción que asegure la destrucción mutua (y la consecuente cooperación militar) entre las superpotencias hasta tanto estén dadas las condiciones para un adecuado funcionamiento de la seguridad colectiva, momento en el que las Naciones Unidas podrán conservar un escaso número de ellas como poder disuasivo y disponer la eliminación del resto, prohibiendo totalmente su uso, fabricación, comercio y almacenamiento. Incluso, los recursos a obtenerse podrían ser destinados a la construcción de un sistema tecnológico de seguridad, del tipo de la Iniciativa de Defensa Estratégica norteamericana (Star War), que asegure la disuación a nivel global. Como señala el quizás más descarnado defensor del realismo y el balance de poder, Morgenthau (1948:752), "sólo cuando las naciones hayan sometido a una autoridad superior los medios de destrucción que la tecnología moderna ha puesto en sus manos (...) podrá la paz internacional ser tan segura como la paz doméstica". La pérdida de capacidad de defensa de cada país se vería compensada con la disminución de la amenaza y la desaparición de hipótesis de conflicto consecuentes de la nueva y real seguridad colectiva, además de lograrse un nivel mayor de transferencia y cooperación tecnológica como consecuencia de la eliminación de los temores respecto a los fines de su utilización. El ideal a alcanzar aquí sería lograr una progresiva y paralela disminución de los presupuestos de defensa, que iría acompañada de un aumento del porcentaje de la proporción destinada a la fuerza multinacional, hasta lograr la desaparición de los ejércitos nacionales a cambio de la contribución por cada país de un porcentaje de su presupuesto (que desde ya sería proporcionalmente mucho menor a las actuales partidas de defensa) destinado a la fuerza de seguridad multinacional. Aún sin llegar a este ideal, sino desde el punto de partida del 3\% de los gastos actuales de defensa, el nuevo sistema impediría que la cooperación de los miembros en las distintas situaciones se vea afectada por cálculos de costos y beneficios, especulaciones que como señalamos han llevado por ejemplo a Estados Unidos a comandar una gigantesca operación de Naciones Unidas en Irak (allí donde se afectaban sus intereses nacionales), pero también a abstenerse de enviar tropas antes del cese de hostilidades en el terreno de Bosnia, donde evidentemente no tenía nada por ganar. Con el nuevo sistema será el Consejo el que decidirá la cantidad y procedencia de tropas y recursos a movilizar para la solución de determinado conflicto, mientras los estados se limitarán a contribuir con su parte obligatoria de apoyo, que deberán dar de manera constante, independientemente de la existencia de un conflicto y, de haberlo, del tipo de conflicto. En situaciones de paz internacional o de no utilización plena, los recursos comunes podrán ser destinados a otras necesidades tales como ayuda humanitaria.

El segundo elemento a tener en cuenta para el logro de una auténtica seguridad colectiva pasa por la composición y atribuciones del Consejo de Seguridad. En principio coincido con Brzezinsky (1994) 
en la necesidad de aumentar el número de miembros permanentes del Consejo, entre los que se podrían incluir, teniendo en cuenta la nueva realidad internacional, países representativos de los cinco continentes como Alemania, Japón, Australia, India, Egipto, Nigeria, Sudáfrica, México, Brasil y Argentina. Desde ya que el derecho de veto, fuente de inequidad y de incertidumbre internacional (como quedó nueva y trágicamente demostrado en el conflicto de Bosnia), sería suprimido.

Se tiene, que si bien las dos únicas disposiciones analizadas aquí, la formación de una fuerza multinacional irresistible y permanente y el cambio de la composición y atribuciones del Consejo de Seguridad, bastarían para hacer funcionar el mecanismo de seguridad colectiva, una tercera sería deseable: el que los estados se obligaran, una vez agotados todos los métodos no formales de solución de controversias, a dirimir sus conflictos por canales formales como el arbitraje o el recurso a la Corte Internacional de Justicia. Respecto a la elaboración y aplicación del derecho internacional, la cuarta parte hará referencia a los criterios éticos que a mi juicio deberían guiarlas.

Puede preguntarse por último por qué los estados, y en particular las grandes potencias, habrían de avenirse a someter su conducta exterior al derecho internacional y a aceptar la constitución de un organismo capaz de coaccionarlas. Se dijo que ya han sido elaborados planes de "constituciones internacionales" que como el de Clark y Sohn (1958), contaban con un poder ejecutivo (el Consejo de Seguridad), un poder legislativo (la Asamblea de las Naciones Unidas), un tribunal (la Corte Internacional de Justicia) y una policía (fuerzas armadas obedientes al ejecutivo). La creación de una "policía internacional" sugerida ya en 1946 por el húngaro Emery Reves en su libro Anatomía de la paz, figura como ha visto entre las ambiciones del actual Secretario General Boutros Ghali, para quien el actual período constituye una etapa de transición hacia la aplicación de una auténtica seguridad colectiva. Hasta el momento, las rivalidades de poder, las contradicciones de intereses y las incompatibilidades ideológicas se han impuesto a tales proyectos. Sin embargo, creo que a partir del fin de la guerra fría, las circunstancias de la sociedad internacional han cambiado de forma tal que podría permitirse pensar lo que hasta hace poco parecía una utopía, la internalización de parte de las potencias del orden de preferencias del juego de la seguridad y la puesta en marcha de un sistema de cooperación basado en una real seguridad colectiva, en contemplación de los elementos que he marcado. El punto consiste en demostrar a las potencias, como pretende hacer este trabajo, que dicho sistema no sólo implica una mayor racionalidad ética, sino que también resulta de conveniencia estratégica. Este optimismo se verá mayormente justificado en la quinta parte, en la que se analizarán las oportunidades y perspectivas abiertas a la seguridad colectiva por la situación originada a partir de la posguerra fría. 


\section{Resumen de conclusiones de la tercera parte}

1) A partir del modelo interpretativo de la acción presentado en la primera parte, una interpretación original del pensamiento de Maquiavelo y Hobbes permite:

a) Introducir, a partir del análisis de la relación entre la racionalidad estratégica de los individuos y la formación del Estado como garante de la acción moral y legal, mi punto de vista acerca de la lógica de la cooperación.

b) Obtener elementos a ser utilizados en la aplicación de la mencionada lógica de la cooperación al análisis de la posibilidad de instauración de un auténtico régimen de seguridad colectiva internacional.

2) Es posible distinguir tres pasos en la lógica de la cooperación dirigida de individuos con intereses comunes:

a) De la racionalidad estratégica al conflicto.

b) Del conflicto a la cooperación.

c) De la cooperación a la racionalidad moral.

3) Definiendo a la anarquía internacional como a la ausencia de un poder soberano por encima del de los estados e identificando sus características esenciales con la situacion de juego del dilema del prisionero, la solución organizativa posible al problema de poder de los estados en la sociedad internacional (es decir, al hecho de que todo estado existe en un mundo de estados soberanos, en el que cada uno dispone de poder capaz de ser utilizado con fines hostiles) pasa por el establecimiento de un auténtico mecanismo de seguridad colectiva que oriente un cambio de preferencias de los estados, de manera que sus relaciones abandonen el marco del juego del dilema del prisionero por el del juego de la seguridad. A partir de dicha seguridad, la paz y la aplicación del derecho internacional serían posibles subproductos derivados de ella.

4) De la mano del enfoque institucionalista, a partir de mi modelo interpretativo de la acción de los actores internacionales y de mis reflexiones sobre la lógica de la cooperación obtenidas en base al análisis de Maquiavelo y Hobbes, el establecimiento de un auténtico mecanismo de seguridad colectiva en una sociedad internacional anárquica debería darse teóricamente del modo siguiente:

(1) Necesariamente, en ausencia de un garante inicial, el primer paso debería surgir a partir de una solución interna de algunos estados que, reconociendo intereses comunes, se decidieran a superar la situación subóptima del dilema del prisionero y a constituirse en los fundadores de un organismo de seguridad colectiva que optimice la cooperación.

(2) Tales estados, cooperando condicionalmente entre sí, deberían ponerse de acuerdo en establecer las instituciones y fundar las leyes del mencionado organismo. Pero sobre todo, y al mismo tiempo, para asegurar la seguridad colectiva, deberían reunir un poder disuasivo capaz de inducir en el resto de los países un cambio en el orden de sus preferencias que los condujera a una solución externa del dilema del prisionero (de su problema de poder), es decir, que transformara el sistema anárquico internacional en un juego de seguridad. La existencia de dicho poder debería también contribuir a que se lograra una internalización voluntaria más allá de la coacción.

(3) Para conseguir una cooperación rápida, honesta y sostenible en el tiempo, las leyes instauradas por los fundadores deberían cumplir ciertos requisitos morales mínimos, por ejemplo, la aceptación al menos de la igualdad de derechos y deberes de sus miembros. En ese sentido una vez superado el proceso fundacional, fijadas las leyes iniciales y los mecanismos del nuevo organismo, los "pecadores originales" deberían integrarse a éste como miembros normales e iguales, favoreciendo el control "público" de sus actos y la participación equitativa y democrática de sus integrantes. 
(4) Una vez logrado el umbral de participación y establecido el organismo de seguridad colectiva, la cooperación condicional de los jugadores del juego de la seguridad (francotiradores corregidos, kantianos cotidianos, seguidores de la norma de la honestidad) debería quedar asegurada a partir de la atribución del monopolio del uso de la violencia legítima a dicho organismo, de manera que se castigara a los francotiradores que no cumplieran con las leyes establecidas.

(5) La calificación de las violaciones al derecho internacional, así como el juzgamiento de los litigios, deberían quedar a cargo de organismos imparciales internacionales creados a tal fin.

5) El deber ser de la lógica de la cooperación dirigida contrasta con la historia y la realidad de los organismos que han procurado imponer el modelo de la seguridad colectiva:

a) En el caso de la Liga de las Naciones, las cláusulas del Pacto contradecían al menos los puntos (2), (4) y (5) de la lista anterior, aunque su imperfección esencial la constituía el hecho de estar formada por estados que no habían enajenado su soberanía militar, que no deseaban respetarlo ni se sentían obligados por sus recomendaciones y contra los cuales no se contaba con la fuerza de sanción suficiente para imponer las decisiones.

b) En el caso de las Naciones Unidas, existen dos elementos estructurales principales que han hecho posible el fracaso del sistema de seguridad colectiva propugnado y han determinado la continuación del juego clásico de la política de poder:

b1) La inexistencia de una fuerza disponible suficiente para desalentar toda agresión conduce a los estados a adoptar estrategias no cooperativas, a jugar sobre seguro en un mundo colectivamente inseguro.

b2) El derecho de veto de los cinco miembros permanentes del Consejo de Seguridad, mediante el cual los estados fundadores se autoexcluyen del cumplimiento de la Carta, convirtiéndose en los principales francotiradores impunes del sistema de cooperación colectiva que ellos mismos intentan imponer.

6) De acuerdo a las explicaciones y conclusiones alcanzadas en mi estudio de la lógica de la cooperación, a su comparación con los intentos prácticos de seguridad colectiva y a las enseñanzas dejadas por ellos, pueden formularse distintas sugerencias para el logro de un auténtico mecanismo de seguridad colectiva internacional:

a) En primer lugar, el funcionamiento de la seguridad colectiva no debe quedar librado a la buena voluntad de cooperación de los estados miembros, sino que debe ser respaldado por una fuerza permanentemente disponible de sanción, no condicionada a lealtades nacionales, que a partir de contribuciones proporcionales directas y obligatorias de todos los estados miembros, adquiera una dimensión y potencial irresistible que disuada a los eventuales agresores.

b) Para que se pueda tener fe en que las Naciones Unidas reaccionarán con rapidez, firmeza e imparcialidad y que no será debilitada por el oportunismo político ni por las deficiencias administrativas o financieras se requiere una administración financiera segura que rescate a la organización de su actual estado de mendicidad. En ese sentido se sugieren mecanismos posibles de financiación en el que los costos se reparten de manera automática y proporcional a la medida de cada estado miembro.

c) En cuanto a las armas de destrucción masiva, se sugieren distintas ideas que a partir de la institución de un auténtico organismo de seguridad colectiva facilitarían la reducción coordinada de los arsenales hasta llegar a su eliminación.

d) Se torna fundamental la supresión del derecho de veto así como el discutido aumento del número de miembros permanentes del Consejo de Seguridad.

e) Sería deseable que los estados se obligaran, una vez agotados todos los métodos no formales de solución de controversias, a dirimir sus conflictos por canales formales como el arbitraje o el recurso a la Corte Internacional de Justicia. 
7) A diferencia de las posiciones juridicistas, mi análisis argumentativo no se limita a enumerar los defectos del actual intento de seguridad colectiva sino que, a partir del análisis de la lógica de la cooperación, ataca el problema de la irracionalidad estratégica y moral inherentes al mantenimiento del balance de poder y asume el desafío de mostrar la factibilidad de un auténtico organismo de seguridad colectiva que no constituya una carga sino un elemento útil para los países, de manera que la consideración de los intereses comunes y de las ganancias mutuas a obtener de la inhibición de la utilidad relativa y del aumento de la cooperación, lleven a los estados a una toma de conciencia de las bondades de tal organismo. 


\section{CUARTA PARTE}

\section{LA MEDIDA MATERIAL Y MORAL DE LA SEGURIDAD COLECTIVA}

\section{7- La medida material}

\section{1- Introducción.}

En la última parte del capítulo 5, teniendo en cuenta el absolutismo en el que desembocaba Hobbes, se planteó la pregunta acerca del parámetro con el cual medir la amplitud de las incumbencias materiales del Estado y respecto del parámetro moral considerado en la elaboración de las leyes de tal Estado. De manera análoga y a partir de las conclusiones del capítulo anterior puede preguntarse acerca de la amplitud de las incumbencias y del parámetro moral apropiados para la constitución de un auténtico organismo de seguridad colectiva internacional que no degenere en un sistema autoritario. Tal es, en efecto el cuarto de los objetivos planteados en la Introducción general de este trabajo. Respecto de la medida material, como ya se adelantó, será interesante en este capítulo hacer referencia a la neoclásica teoría del Public Choice, teoría que voy a compartir y a partir de la cual pretenderé extraer, en el siguiente capítulo, conclusiones aplicables al análisis de la dimensión de un eventual mecanismo internacional de auténtica seguridad colectiva. Para tal fin me basaré en el libro de James Buchanan y Gordon Tullock, El Cálculo del Consenso, publicado en 1962, pero reconocido y estudiado desde mediados de los 70, con el afianzamiento del Public Choice como teoría concreta.

\section{2- La medida material del Estado.}

La teoría del Public Choice arranca de la acción y la toma de decisiones del individuo, en tanto participante de procesos a través de los cuales se organizan elecciones de grupo. Desde aquí, incorporando el análisis de la teoría de la elección racional y considerando el proceso de discusión llevado a cabo por individuos libres que intentan formular reglas aceptables a su propio interés a largo plazo, intenta proporcionar una explicación del nacimiento de las constituciones políticas. El enfoque toma entonces como punto de partida a una sociedad compuesta de individuos racionales e informados, definiendo a la acción ( $\mathrm{y}$ a la elección) racional como a aquella que tiende a maximizar la utilidad esperada del agente que la efectúa. El individuo elige en función de sus objetivos individuales, lo que no significa que otro sea perjudicado necesariamente (la racionalidad estratégica no implica de por sí juegos de suma cero). En ese sentido, el establecimiento de relaciones económicas y políticas entre los individuos supone el reconocimiento de intereses comunes entre ellos. Tanto el mercado como el Estado son mecanismos a través de los cuales la cooperación se hace posible. Los hombres cooperan a través del intercambio de bienes y servicios en mercados organizados, y tal cooperación implica beneficios recíprocos. Dos o más individuos encuentran mutuamente ventajoso unir sus fuerzas para lograr ciertos objetivos comunes, entrar en un "intercambio" político y dedicar algunos recursos para la construcción del bien común. Así, el individuo encarará una acción de manera colectiva cuando espere poder incrementar su utilidad individual a través de ella, ya sea a partir del logro de beneficios que no puedan asegurarse a partir del comportamiento individual o merced a la reducción de los costos. Al respecto, Buchanan y Tullock hacen una distinción entre dos tipos de costos esperados. En primer lugar los costos que el individuo espera soportar como resultado de las acciones privadas de los otros, sobre los que no tiene control directo, denominados convencionalmente costos externos. En segundo lugar, los costos en los que el individuo espera incurrir como resultado de su propia participación en una 
actividad organizada, denominados costos de la toma de decisiones. La suma de estos dos tipos de costos es denominada costo de interdependencia social. El individuo racional tratará de maximizar los beneficios de la cooperación colectiva y de minimizar el costo de interdependencia social, siendo éste el objetivo de la organización social o política. De esta manera, para el Public Choice los estados surgen en respuesta al interés del individuo por colectivizar ciertas actividades. La colectivización de una actividad será apoyada por el individuo maximizador de la utilidad cuando espere que los costos de interdependencia de esta actividad colectivamente organizada (beneficios de interdependencia), tal como él los percibe, se sitúen debajo (sitúen encima) a los relacionados con la organización individualista voluntaria de la actividad.

¿En qué medida, pues, el individuo elige bienes privados o bienes públicos? Si las hipótesis anteriores son válidas, el individuo representativo debería, al enfrentarse a alternativas relevantes, elegir más bienes públicos cuando el "precio" (los costos) de éstos bajen. El individuo votará más actividades colectivas cuando se reduzcan los impuestos que debe pagar, permaneciendo las otras invariables. Por el contrario si la cuota impositiva aumenta y se permite elegir al individuo, éste seleccionará un nivel más reducido de la actividad colectiva. De un modo paralelo, si la renta del individuo aumenta y su presión fiscal no, él tenderá a optar por tener más bienes públicos.

En el punto 5.3 se había propuesto ya una interpretación en este sentido de la sucesión gobiernos conservadores - gobiernos liberales que se observa en las democracias estables.

Otro aspecto relevante para este análisis es la afirmación de los autores según la cual los costos que una actividad organizada colectivamente imponen sobre el individuo dependen del modo en el cual vayan a tomarse las decisiones colectivas. La elección entre varias posibles reglas de la toma de decisiones no es independiente de la elección en cuanto al método de organización. Bajo ciertas reglas de la toma de decisión, el grupo puede tomar acciones contrarias al propio interés del individuo. En cualquier caso, la participación en la actividad colectiva es costosa para el individuo, y el agente estratégico tendrá en cuenta este hecho en el período de la elección constitucional. El análisis demuestra que la regla de la unanimidad posee ciertos atributos especiales, puesto que solamente a través de su adopción el individuo puede asegurarse a sí mismo contra el perjuicio externo que le puedan ocasionar las acciones de otros individuos, privada o colectivamente. Todas las demás reglas, incluso la de la mayoría, suponen mayores costos. Por lo tanto, el individuo elegirá cambiar más actividades al sector público a medida que sea más inclusiva la regla de la toma de decisiones, es decir a medida que las decisiones requieran un mayor consenso.

Buchanan y Tullock deducen también que los costos totales de la toma de decisiones serán más bajos en las comunidades con una población razonablemente homogénea que en las de población heterogénea. Parece razonable esperar que se invertirá más en la negociación en un grupo compuesto de miembros que tienen características externas diferentes que en un grupo compuesto de miembros más o menos homogéneos. Cuando conoce a sus compañeros mejor, el individuo seguramente será menos obstinado en su negociación.

Puede entonces decirse, en base al Public Choice, que no es necesario retroceder hasta el comienzo de los tiempos para comprender el origen contractualista y estratégico del Estado, sino que basta observar el nacimiento y evolución de las distintas asociaciones hoy. Tanto en agrupaciones económicas, políticas, culturales o deportivas, los individuos se juntan o separan por conveniencia estratégica, aportando cierto esfuerzo a una causa común en pos de beneficios superiores (no necesariamente económicos sino también espirituales). A todo esto, serán los ciudadanos los que al votar o exigir mayor cantidad de bienes públicos, pretenderán un mayor control del Estado que, en tanto garante ético de la comunidad, deberá imponer su presencia no sólo en sentido negativo, haciendo respetar el derecho, sino también en sentido positivo, estableciendo por ejemplo las reglas y márgenes de movimiento del capital privado, de manera que una conducta inmoral de una empresa privada (el despido sin previo aviso del personal), conlleve mayores costos que la acción moral alternativa. El Estado tendrá ingerencia directa allí donde los ciudadanos lo consideren necesario, fuera de este ámbito no tomará el lugar de los privados pero deberá seguir ejerciendo su 
papel de garante ético, haciendo respetar el derecho y orientando, en la medida de lo posible, el capital privado hacia los intereses públicos. Una forma de hacer esto último será hacer uso de lo que Elster (1982) llama "zona de indiferencia" de los individuos (campo de acciones en el que al individuo egoísta le resulta indiferente la opción entre un orden de preferencias egoísta y uno solidario, es decir la opción entre las preferencias E y U analizadas en el capítulo 5, persuadiendo a los empresarios individuales de que actúen de una forma que al menos no sea dañina desde su punto de vista privado, pero que produzca beneficios colectivos cuando sea adoptada por todos.

La solución del Public Choice a la cuestión de la medida material del Estado no es conferir a éste todos los derechos menos uno (absolutismo hobbesiano), ni solamente el de arbitraje entre terceros (Locke), sino adaptar la medida de los bienes públicos según las utilidades, la voluntad, de sus ciudadanos. La teoría de la elección pública, por lo tanto, no sólo se muestra compatible con una interpretación maquiavélico- hobbesiana de la cooperación, sino que también ayuda a complementarla y enriquecerla.

\section{3- La medida material de la seguridad colectiva.}

Para el Public Choice la acción del Estado en su relación con otros estados resulta básicamente análoga a la de los individuos. Por lo tanto, trasladando las conclusiones del punto anterior puede afirmarse que la amplitud de poderes e incumbencias de un eventual mecanismo auténtico de seguridad colectiva como el propuesto será aquélla que los estados en su conjunto quieran que tenga. Así como se observó que el Estado surge en respuesta al interés del individuo por colectivizar ciertas actividades y que toda colectivización de actividades es apoyada por el agente maximizador de utilidades cuando los costos de interdependencia esperados resultan menores que los relativos a la organización individualista voluntaria de tales actividades, puede afirmarse que un grupo de estados aceptará constituir una entidad en común sólo si los beneficios de esa acción colectiva superan a los de la acción individual. Es en base a esta interpretación y a otras consideraciones adicionales de la teoría del Public Choice, que en otro lugar (Daló 1993) he llevado a cabo un análisis del proceso de integración de la Unión Europea poniendo de relieve los pasos conducentes a la consolidación de un poder europeo capaz de regir en aquellos sectores en los que la acción común resulta más eficaz que la de los estados miembros por separado. Allí también he tratado de comprender la doble y aparentemente contradictoria tendencia observable en la actualidad, tanto en Europa como en el resto del mundo, hacia una fragmentación de estados en otros más pequeños a causa de razones políticas y culturales por un lado y, por el otro, hacia uniones o bloques económicos en respuesta a intereses económicos y comerciales. Desde mi perspectiva, la mencionada tendencia no apuntaría a la disolución del estado-nación como tal, sino a la de aquellos estados que aglutinan diversas naciones con intereses culturales contradictorios, aquellos cuyos ciudadanos consideran "costosa" la convivencia. Se trataría de auténticas naciones que quieren constituirse en nuevos estados, para luego sí buscar integrarse económicamente (conservando sus propios intereses), y quizás también políticamente (en condiciones análogas a las de los otros miembros que no se tenían antes de la independencia). Por eso, no sería raro que Croacia, Bosnia y Servia, luego de independizadas y con sus fronteras establecidas, llegaran algún día a pertenecer a la Unión Europea, a pesar de las luchas que hoy las enfrentan. Recuérdese que ya estuvieron unidas, y por momentos prósperamente, con el nombre de Yugoslavia (a pesar de siglos de rivalidades), y que la disolución de esa unión se debió al rechazo de la hegemonía servia de parte de las naciones más ricas del norte que se negaron a seguir sosteniéndola. Así como dentro de un país no tiene el mismo peso político una provincia (con su escudo y su relativa autonomía) que el departamento de una provincia, dentro de una comunidad económica o política de países tiene mayor importancia un estado miembro que una provincia de un estado miembro.

Se puede entonces interpretar que el establecimiento de un auténtico organismo de seguridad colectiva constituiría un bien público internacional cuya primera y fundamental manifestación de utilidad sería la garantía de paz y seguridad internacionales. La reducción de la posibilidad de 
conflictos derivaría en una reducción sustancial en los gastos de armamentos, mayor inversión para el desarrollo y una mayor cooperación en todos los campos que redundarían en un importante aumento del bienestar para todo el planeta. Sin embargo, como se dijo, una vez constituido el mecanismo de seguridad colectiva serían los propios estados los que decidirían la amplitud de atribuciones y responsabilidades, es decir el poder, del nuevo organismo, lo que dependería de distintas circunstancias. Aquí es donde toma realmente interés la perspectiva del Public Choice como aporte a mi análisis de la lógica de la cooperación y a lo que se refiere la "medida" a la que alude el título de este punto. En ese sentido, la relación entre la medida del bien público internacional encargado de mantener la seguridad colectiva y los "bienes privados" (atributos soberanos) conservados por los estados particulares dependería de la manera en que las circunstancias inclinaran a las naciones a ceder más o menos responsabilidades a la entidad común, pudiéndose prever desde ya que la cooperación habría de oscilar entre momentos más "conservadores" (con tendencia a achicar las incumbencias del bien público internacional) y más "liberales" (en los que los "bienes privados" de los estados se reducirían en favor del organismo de seguridad colectiva).

Entre las circunstancias que influirían en que los estados acuerden ceder derechos a una entidad colectiva se encuentra (análogamente a la cesión individual dentro del Estado) el modo en el que fueran a tomarse las decisiones. En ese sentido, el hecho de que cuando más inclusiva es la regla de toma de decisiones, menores son los costos, explica las discusiones respecto a la regla de la toma de decisiones de los distintos organismos de las Naciones Unidas. Así, mientras en la Asamblea General y en la mayoría de sus organismos dependientes se requiere de una amplia mayoría para la aprobación de las resoluciones, sin llegar a la impracticable unanimidad, el Consejo de Seguridad, aunque resuelve por mayoría calificada de sus quince miembros, reserva la posibilidad de veto a sus cinco miembros permanentes, lo que implica para ellos unanimidad en la toma de decisiones. Las grandes potencias se muestran recelosas a la hora de asumir los costos y riesgos de la cooperación internacional por lo que pese a las críticas y al cambio de la situación mundial se resisten a modificar la composición y el mecanismo de decisión del Consejo. Así, mientras dichas potencias participan en el organismo mundial aseguradas contra cualquier decisión opuesta a sus intereses, los demás Estados deben hacerlo sin ese seguro (sometiéndose a la mayoría) y en condiciones de inequidad. Esta situación alienta la desconfianza y desfavorece, como se ha visto en el capítulo anterior, la conformación de un auténtico mecanismo de seguridad colectiva con todo el poder y la legitimidad pertinente.

Por su parte, la observación del Public Choice respecto de que los costos totales de la toma de decisiones resultan más bajos en comunidades de población homogénea que en las de población heterogénea representa un gran desafío para la comunidad mundial compuesta de miles de culturas, religiones y modos de vida diferentes. Sin embargo, como se verá en la quinta parte, la creciente tendencia hacia la globalización y la interdependencia entre los pueblos permiten ser optimistas acerca de un aumento de su mutua comprensión y de que esto ayude a concretar más rápidamente una auténtica seguridad colectiva. En ese caso, y como se dijo al principio de este punto, serán los propios estados los que votarán mayor o menor cantidad de atribuciones para la entidad colectiva que, en tanto garante ético de la comunidad internacional, deberá imponer su presencia no sólo en sentido negativo, haciendo respetar el derecho internacional, sino también en sentido positivo, estableciendo reglas que determinen mayores costos para las conductas contrarias al derecho internacional que para las acciones legales alternativas, de manera de orientar los intereses de los estados particulares hacia los de la sociedad internacional en su conjunto. 


\section{8- La medida moral}

\section{1- Introducción.}

En la segunda parte, al desarrollar mi modelo interpretativo de la acción de los estados y demás actores internacionales, hice referencia al respeto del derecho internacional como criterio legal equivalente, en el ámbito de los actores internacionales, a la consideración de un criterio normativo de racionalidad moral en el ámbito de los individuos. Se dijo también que en tanto el derecho internacional se orientaba según principios morales mundialmente aceptados, implicaba el respeto del criterio de racionalidad moral supuesto por tales principios. En base a esto, en la tercera parte se construyó una perspectiva propia de la lógica de la cooperación que supuso al derecho interno y al internacional como dados, sin hacer referencia al criterio o a los criterios morales implicados en ellos. Sin embargo, tanto a nivel interno como en el internacional se está lejos de concordar acerca de cuál es el criterio moral más apropiado de los propuestos por las distintas éticas. Las disidencias han adquirido particular relevancia en lo referente al derecho internacional, sobre todo a partir de la agudización del debate entre universalistas y relativistas, ya que la diferencia de culturas y religiones impediría aceptar, como ocurre en la mayoría de las constituciones estatales, una determinada ética religiosa como marco de referencia universal. Será para comprender ése y otros debates que se analizará primero el tema tal cual ha sido planteado al nivel de los individuos y en relación al derecho interno, para después extender las conclusiones obtenidas al ámbito de las relaciones internacionales.

\section{2- La medida moral del Estado.}

\subsection{1- La carencia de la nueva ciencia política.}

Se señaló antes a Maquiavelo como al iniciador de la transformación de la doctrina política clásica en una ciencia de la política, es decir del paso de la tradición de pensamiento conocida como filosofía práctica a la nueva ciencia política, disciplina constituida hoy en día según el modelo de las ciencias experimentales contemporáneas. Ahora, siguiendo a Madanes (artículo inédito 2), vale hacer referencia a tres características que distinguen a la nueva ciencia política de la filosofía política clásica:

1- Aspira establecer, de una vez y para siempre, las condiciones para el correcto ordenamiento del Estado y de la sociedad.

2- Aspira a calcular, mecánicamente, las leyes generales, relaciones e instituciones que granticen la eficacia del Estado, independientemente de la prudencia de los ciudadanos.

3- El científico social deja de lado las cuestiones morales y se aboca a la construcción de un Estado en el que los hombres se comportan necesariamente de una manera predecible, tal como los otros objetos de la naturaleza. El orden social, que en la antigüedad clásica se entendió como una jerarquía de virtudes, pasa a ser aquél en el que se obedece la ley positiva, independientemente de la moralidad de los principios en los que se sustenta y de la de las intenciones de los individuos. La ciencia política suele presentarse como valorativamente neutra. Así, reflexiona sobre la funcionalidad estratégica de sus leyes y constructos, pero deja de lado el análisis de su racionalidad moral.

Junto con Madanes, coincido en destacar la carencia de la ciencia política de la que habla el título de este punto, la que puede sintetizarse en su falta de respuesta a las siguientes preguntas: ¿cómo se puede resguardar la reflexión moral (asegurada por la filosofía política clásica) sin renunciar al rigor de la ciencia política moderna? ¿Bajo qué criterio criticar el absolutismo de Estado de Hobbes como mejor o peor que la democracia moderna? ¿Cómo distinguir los principios morales sobre los que se orientan las leyes? ¿Cómo juzgar una acción como buena y justa en sus circunstancias? ¿Qué papel 
le queda a la libertad individual dentro del Estado? ¿Cómo juzgar la moralidad o la inmoralidad de una política?

Todos estos interrogantes quedan subsumidos en el siguiente: ¿Existe, y en tal caso, cuál es el criterio normativo de racionalidad moral (la medida o patrón moral) a partir del cual juzgar las acciones de los individuos y del Estado, así como fundamentar objetivamente la moralidad de sus leyes?

\subsection{2- Las dos líneas.}

Se dijo que los anteriores interrogantes, si bien han ido quedando fuera del terreno de la ciencia política, sin embargo, han subsistido en el de la filosofía en general y en el de la filosofía política moderna en particular (aunque por supuesto no en todos los filósofos de la política, ni en todos con la misma fuerza).

Se ha observado ya el carácter moral que asumía la libertad positiva en la república mixta maquiaveliana, así como la difusa noción de la regla de oro implicada por las leyes de naturaleza de Hobbes (que respalda al derecho y obliga a los individuos pero no al Estado). Sin embargo, para reflexionar acerca de las preguntas formuladas en el punto anterior, que como se habrá advertido coinciden con mis cuestionamientos a la teoría de la elección racional planteados en 1.2.3, será bueno examinar algunas posiciones y distinciones sostenidas por la crítica posterior a Hobbes, que han conducido a la fundamentación del Estado tal como es conocido hoy en día. En primer lugar téngase en cuenta que a partir de Hobbes comienzan a distinguirse dos líneas de pensamiento en la filosofía política liberal, que llegan hasta la actualidad. Por un lado una línea de autores más "hobbesianos", economicistas, más afines a la ciencia política dura de la que se hablaba, "conservadores", partidarios del derecho positivo (justo es aquéllo sancionado por el soberano), que van a hacer hincapié en la racionalidad estratégica del "homo economicus". Por el otro, una línea más "kantiana", humanista, universalista, "liberal"(en el sentido que esta palabra toma dentro de la propia tradición liberal moderna), sostenedora de la existencia de un derecho natural (de derechos superiores inherentes al ser humano con independencia de la voluntad del soberano), que procurará defender un concepto más amplio de racionalidad, no restringido a los intereses estratégicos sino sustantivo, orientando su atención a la racionalidad moral del individuo y de las normas ( $\mathrm{y}$ a su garantía de parte del Estado).

Como primer representante de la primera línea se puede citar a Baruch Spinoza (1632-1677), continuador y radicalizador de Hobbes, que a partir del esquema hobbesiano, pero en oposición al absolutismo, lleva a cabo una justificación del Estado democrático. El argumento de Spinoza es que si el soberano desea mantener el pacto (el poder), debe mantener el consenso de los gobernados. A su vez, el consenso se mantiene con la razón, común a todos los hombres, pero no con la satisfacción de deseos particulares. En ese sentido, el Estado democrático, el respeto de la tolerancia y la libertad, constituye para Spinoza la estrategia más racional para la conservación del poder, siendo ésta más ética pero fundamentalmente más útil que el abuso de poder. Otro autor que puede ubicarse en la primera línea es John Locke (1632-1704), quien recibe el esquema de Hobbes y lo transforma. Según Strauss (1970:65) el cambio introducido es en un solo punto: "Se da cuenta de que el hombre necesita fundamentalmente para su conservación los alimentos, o sea, la propiedad, más que la pistola. Entonces el instinto de conservación se transforma en deseo de prosperidad, deseo de adquirir, y el derecho de autoconservación se convierte en derecho a la adquisición ilimitada". Así, el ánimo de apropiación, pasión egoísta que no exige derramamiento de sangre y cuya puesta en práctica lleva consigo la mejora de la suerte de todos, sustituye el miedo a la muerte, en consecuencia, la propiedad reemplaza a la conservación de la vida como máxima utilidad. En ese sentido, la conflictualidad pierde terreno en la justificación del Estado de Locke, quien sosteniendo una concepción no conflictiva del estado de naturaleza, con individuos dispuestos a la cooperación, afirma la posibilidad de una convivencia social pacífica y armoniosa con un soberano al que se le delegue sólo un derecho, el de evitar que alguien sea juez en causa propia. Sin embargo esta crítica 
es asimilable desde la propia teoría de Hobbes y en particular desde la interpretación liberal. Cualquiera sea la sociedad pacífica de que se trate, siempre podrán surgir personas conflictivas o intereses contrapuestos que lleven al conflicto y a su resolución a través de la lucha. El papel del Estado será en ese caso no sólo el de aplicar imparcialmente el derecho sino el de garantizarlo. Como se dijo en el capítulo 5, suponer una sociedad de individuos con intereses comunes pero poco cooperativos (con un orden de preferencias del juego de seguridad) resulta más realista que tomar una de individuos altamente dispuestos a la cooperación (con un orden de preferencias kantiano o del juego de armonía). Al respecto Hobbes tiene una lógica liberal, según la cual el Estado se justifica para asegurar uno de los derechos (el de la conservación de la vida), de los que el individuo es portador previamente a la constitución del Estado. Puede coincidirse con Locke, en cambio, en que el individuo debe, en la medida que lo desee, conservar más derechos de los que se le atribuyen en el Estado absolutista hobbesiano (a esto me he referido en 7.1). Siguiendo con la enumeración de los exponentes de la primera línea, es Montesquieu (1689-1755) quien, en El espíritu de las leyes (1748), verá en la monarquía parlamentaria inglesa de su tiempo una nueva versión de la teoría del gobierno mixto, enunciada por Aristóteles, llevada a la práctica durante la República romana y reconocida siglos más tarde, como se ha visto, por Maquiavelo. Así, propondrá la división de poderes como alternativa a la monarquía absoluta de los Borbones. A partir de este momento los filósofos políticos considerarán la posibilidad de un equilibrio armónico pero tenso entre tres poderes, el ejecutivo (remanente de la monarquía absoluta), el judicial (remanente de la aristocracia, compuesto de hombres prudentes "que saben lo que está bien") y el legislativo (propiamente democrático). De la defensa de un poder incondicional se pasa a la de tres poderes que se condicionan mutuamente. El poder soberano se traslada del monarca al pueblo. En ese sentido, la separación dentro del Estado de las entidades encargadas de la ejecución, aplicación y elaboración de las normas legales surge entonces como límite al absolutismo hobbesiano y como medio más eficaz de conservación del mismo Estado. Montesquieu plantea, además, una oposición entre dos ideas político-sociales: la república romana, cuyo principio es la virtud, e Inglaterra, cuya expresión es la libertad política. Según Strauss (1970:66), "la supremacía de Inglaterra se basa, según él, en el hecho de que este país ha encontrado un elemento sucedáneo para la rígida virtud de la Roma republicana. Este sucedáneo es el comercio y las finanzas". El fundamento del orden social pasa ahora completamente al terreno estratégico.

De igual manera, tanto en Hume (1711-1776) como en Smith (1723-1790), la pasión que lleva al ordenamiento de la sociedad es el interés económico mediante el cual el mercado, del que participan individuos estratégicos (con el orden de preferencias de dilema del prisionero), ordena naturalmente la convivencia social. Según Smith en La riqueza de las naciones (1776), cada agente maximizador de la función costo-beneficio se especializa en producir el bien o el servicio que mejor sabe y lo intercambia por lo que otros ofrecen en un mercado libre de presiones. Si es ineficiente, otro operador lo desplazará. El resultado de la siguiente competencia (forma económica que asume el conflicto) es el desarrollo y la riqueza de las naciones.

Los continuadores contemporáneos de esta corriente, llamados neoclásicos, no han cuestionado en general sus supuestos esenciales, sino que han refinado sus argumentos de base economicista extendiéndolos a otros ámbitos, como el análisis de la acción y de las conductas sociales. Tal es el caso de la teoría de la elección racional (Rational Choice) y de la teoría de la elección pública (Public Choice). Se ha visto ya la gran contribución de esta línea en la interpretación de la acción individual y en lo relativo a la cuestión de la medida material del Estado (esto último en el punto 7.1). Más discutibles, desde mi punto de vista y como ya se adelantó en el capítulo 1, han sido sus soluciones respecto al parámetro moral según el cual las normas de derecho son elaboradas por el poder legislativo, aplicadas por el judicial y respaldadas por el ejecutivo, es decir respecto al parámetro moral sobre el que el Estado en general funda sus leyes, al que apuntan las preguntas que quedaron planteadas en 8.2.1.

Antes de pasar a la segunda línea debe decirse que la justificación del Estado de Hobbes puede aún ser sostenible y aplicable al Estado democrático moderno, a pesar de la andanada de críticas que le 
siguieron, si se lo enfoca desde el punto de vista de la interpretación liberal (es decir desde la perspectiva de la primera línea del pensamiento analizada antes), tal cual se ha venido haciendo. De tal forma el soberano de Hobbes no debe ser visto como un monstruo, sino como el intento de mostrar las características de la relación de obediencia: 1) todo poder soberano debe ser obedecido, en este sentido la democracia es tan absoluta como la dictadura (hay muchas maneras de organizar la soberanía, pero esta es absoluta independientemente de la forma de gobierno); 2) todo poder soberano es arbitrario, en última instancia la decisión discutida y aprobada por la mayoría de los representantes de los ciudadanos, en el marco de la división de poderes, se impone sobre la libertad individual. Es en este sentido en el que el uso de la violencia legítima es absoluto y arbitrario.

Sin embargo, la teoría de Hobbes, al excluir al Estado del pacto, y así de la obligación del cumplimiento de las leyes (como se analizó en la última parte del punto referido a este filósofo), deja anulada toda posible crítica moral al soberano. Al respecto, las críticas de Rousseau y Kant no pretenden restarle poder al soberano sino recuperar el espacio perdido de la crítica moral al Estado. En tal sentido, y de una manera que en sí no es contradictoria con la reformulación liberal de Hobbes, los filósofos de la segunda corriente argumentarán que la instancia moral no se agota una vez que el derecho ha hablado, sino que incluye al derecho, y que la justicia no depende sólo de la obediencia a cualquier dictamen del soberano. Si bien el Estado instaura la reciprocidad de derechos y deberes que permite la cooperación, él mismo no debe excluirse de esa relación.

J. J. Rousseau (1712-1778) se va a oponer a la eliminación del bien y del deber ser del pensamiento político haciendo la distinción entre voluntad general y voluntad de todos. Mientras la voluntad de todos constituye la suma de los intereses particulares de los ciudadanos, la voluntad general es la expresión del interés común. Como Maquiavelo, Rousseau pretende que a partir de la discusión de los intereses estratégicos particulares surja y se imponga el interés común, la cooperación, y con él, la recuperación de la instancia moral. Interpretando su posición según mi análisis de la lógica de la cooperación, Rousseau sostendría que la discusión de los intereses particulares conduce a los individuos a internalizar un nuevo conjunto de preferencias, a abandonar el orden del dilema del prisionero (expresado por la "voluntad de todos") por el del juego de seguridad (la "voluntad general"). Es decir, la interacción propiciaría un cambio desde una postura egoísta a una más solidaria de cooperación, que sería posible, claro está, sólo en la órbita de un Estado constituido.

Los ideales de Rousseau, y los de la Ilustración en general, culminarán en la Bill of Rights americana y en la Declaración de los Derechos del Hombre de 1789, declaraciones de principios que junto a la apelación a las leyes religiosas cristianas, servirán de base y de criterio moral sobre el cual elaborar las normas de derecho de los nuevos estados modernos.

Como señala Strauss (1970:66), "Rousseau abandona el mundo moderno de las finanzas, ese mundo que él fuera el primero en denominar el mundo del "bourgeois" para volver al mundo de la ciudad y de la virtud, al mundo del "citoyen"'. En ese sentido el beneficio general se obtiene no del mercado egoísta, sino anteponiendo el interés general al instinto de conservación particular, de manera hobbesiana. Sin embargo aparecen algunas dificultades. Si como sostiene Rousseau, la voluntad general no puede equivocarse en tanto en que participa en la ejecución de las leyes,"si es el criterio para determinar lo que es justo, el canibalismo es tan justo como una política cualquiera. Cualquier institución santificada por el consenso popular tendría que considerarse sagrada" (Strauss 1970:68).

Será Kant (1724-1804) quien más tarde tratará de rescatar de manera menos ingenua el punto de vista de Rousseau. Como señala Truyol en su presentación a Kant (1795), a diferencia de Rousseau, y en consonancia con Hobbes, Kant considera que la paz no es lo natural entre los hombres, sino una conquista de su voluntad conciente. "El estado de paz entre hombres que viven juntos no es un estado de naturaleza, que es más bien un estado de guerra, es decir, un estado en el que, si bien las hostilidades no se han declarado, sí existe una constante amenaza. El estado de paz debe, por tanto, ser instaurado." (Kant 1795:14). Salir del estado de naturaleza para constituir una sociedad civil mediante el "contrato originario" resulta un imperativo de la razón práctica, un deber moral. Si bien las conclusiones de Kant no contrarían esencialmente a las de Hobbes, el punto del cual parte es 
distinto. Para Kant los hombres son seres no sólo estratégicamente racionales sino moralmente racionales, y en tanto libres y autónomos (capaces de darse su propia ley moral), organizan el Estado de acuerdo a leyes que reflejan los principios morales (la racionalidad moral). El Estado se entiende como condición y garantía del derecho. El derecho, al limitar a los ciudadanos, es la garantía de la ética que lo funda, la condición bajo la cual la autodeterminación (libertad) de un individuo puede ser compatible con la de otros. El legislador debe legislar para todos según las leyes universales que no contradigan el imperativo categórico, es decir el criterio kantiano de la racionalidad moral: Actúa de manera tal que puedas querer que la máxima de tu acción se convierta en ley universal. Dicho criterio puede parafrasearse aproximadamente con la Regla de Oro (no hagas a los demás lo que no quieras que te hagan a ti), que como vimos se deduce según Hobbes de sus leyes de la naturaleza. Esta es la causa por la que puede afirmarse que el pensamiento de Hobbes no resulta incompatible con el de Kant, ya que Hobbes no desconoce la existencia de la racionalidad moral de los individuos, sino que sostiene, con una cuota mayor de realismo, la inhibición del juicio moral en ausencia de un poder soberano. Una vez instaurado este poder, los ciudadanos pueden, a su amparo, establecer relaciones legales y morales. Sin embargo, y aquí es donde sí pesa la crítica de Kant, el Estado absolutista hobbesiano no entra en el juego moral, no pacta, por lo que no puede ser impugnado moralmente por el ciudadano. En Kant, en cambio, la moral pone límites a la acción del soberano, ante el cual el ciudadano tiene derecho a decir: "esto es inmoral". El Estado no puede ser paternalista o despótico, sino que las leyes, basadas en el reconocimiento de la libertad y de la igualdad de todos los individuos, deben reflejar los intereses de todos (la voluntad general, que aquí sí cuenta con un criterio), y aplicarse universalmente (incluso sobre los funcionarios de los tres poderes del Estado). Para Kant, debe existir un uso público de la razón, mediante el cual el pueblo, no el legislador absoluto, debata y decida las leyes.

Se tiene entonces que, frente a la explicación de la primera línea, llevada a cabo en términos de estrategias individuales egoístas de los actores (en virtud del orden de preferencias del dilema del prisionero), la recuperación de la instancia moral a la que se había aludido asumirá en Rousseau la forma de un cambio de las preferencias (hacia el orden del juego de la seguridad), mientras que en Kant supondrá el respeto del imperativo categórico, que por encima de cualquier consideración de costos, asume el rol de criterio normativo moral.

En lo que concierne a los seguidores contemporáneos de esta segunda corriente, puede tomarse una amplia gama de pensadores y teorías, cuya característica común es el intento de balancear las estrategias económicas egoístas del mercado, por medio de una interacción positiva entre éste y el Estado. En este gran conjunto se pueden incluir entre otros a Weber y a todos los teóricos de la socialdemocracia y del "estado de bienestar", así como también a los filósofos partidarios de éticas universalistas, entre ellos Apel, Habermas y Rawls.

He distinguido, por lo tanto, las dos grandes líneas que, a partir de Hobbes, han marcado el pensamiento liberal moderno. Dichas líneas no se han mantenido independientes la una de la otra, sino que se han ido contrastando e influyendo mutuamente a través del tiempo. En la actualidad, y en especial a partir de la conservadora década del ochenta, es la primera corriente la que ha tomado renovado auge. Sin embargo, y como se ha visto al iniciar mi crítica a la elección racional, no resulta satisfactoria la respuesta de estos teóricos en el campo de la ética, ni las propuestas alternativas a algunos de los cuestionamientos relativos a las limitaciones del sistema capitalista.

El desafío consiste en lograr una síntesis entre estas dos corrientes, es decir en conciliar a los representantes contemporáneos de dichas líneas, buscando un criterio sobre el cual basar la crítica ética a las posturas neoclásicas (utilitaristas), sin perder el rigor científico ni la capacidad descriptiva, explicativa y predictiva de éstas. Tal constituye quizás el más importante de los aspectos de mi crítica a la teoría de la elección racional.

\section{3- Hacia una fundamentación objetiva de la ética.}




\subsection{1- Utilitarismo vs. Universalismo. El problema de una ética política.}

Vuelvo ahora a la pregunta dejada pendiente en 7.2 y vuelta a plantear en 8.2 .1 : ¿cuál es el criterio con el cual juzgar moralmente a los individuos? La solución a este interrogante puede buscarse desde las dos líneas en que se dividió a la filosofía política. En lo que respecta a la corriente "conservadora", se ha visto y criticado, en el capítulo 1, la forma en que la teoría de la elección racional reduce en general el estudio empírico de la acción al de la acción estratégica, introduciendo, en lo referente a las cuestiones éticas, el criterio utilitarista de la maximización de la utilidad colectiva. Parece más apropiado entonces rastrear la solución del interrogante desde la perspectiva "liberal", más rica en este tipo de reflexiones. Se dijo en el punto anterior que el desafío consiste en llevar a cabo una síntesis dialéctica entre las dos líneas: partir desde planteamientos "liberales" y oponerlos a los "conservadores", no de manera ingenua ni destructiva, sino tomando en cuenta sus aportes. En otras palabras, dicho desafío es el de conciliar a Hobbes con Kant (como ya lo ha hecho en parte Rawls (1971)), o bien a Elster-Buchanan con Apel-Habermas-Rawls. Hacia esta dirección apunta la crítica del punto 1.3.3 tanto como las presentes consideraciones.

Mi rechazo al utilitarismo derivado de las teorías "conservadoras" me ha conducido a sostener la necesidad de alguna otra clase de criterio moral para el análisis de la racionalidad moral de la acción. En particular me inclinaré, como he venido adelantando, por los criterios universalistas del tipo de los que se desprenden de las posturas de Rawls o Apel. Sin pretender hacer un análisis exhaustivo, con el fin de consolidar mi crítica a la teoría de la elección racional y de ir estableciendo mi posición acerca de lo que debe ser la base ética del derecho internacional, resultará interesante en lo que sigue exponer y discutir algunos aspectos básicos de las posturas universalistas tomando como punto de partida al artículo de Apel (1985), "Etica normativa y racionalidad estratégica: el problema filosófico de una ética política".

Como bien lo señala en el título, la cuestión a la que apunta Apel es a la de la ética política, más precisamente a la de si existe una ética que sea al mismo tiempo "filosóficamente satisfactoria y sugerible a un político". En este sentido, luego de presentar a Maquiavelo como el emancipador de la racionalidad valorativamente neutral (pero éticamente insatisfactoria), se pregunta acerca de si existe "algo como una razón ética, o para expresarlo en otras palabras, un tipo de racionalidad que sería valorativamente neutral pero fundamentaría una norma básica de acción moral o el valor de una vida buena". Por lo tanto admite que antes de estudiar la posibilidad de una ética política hay que analizar la de "un fundamento racional de la ética en general". Este camino lo inicia en la tercera parte de su artículo, "El error de un intento de fundamentación de la ética por medio de la razón estratégica- instrumental". Si bien coincido con el diagnóstico expresado en dicho título, no comparto del todo su argumentación. Según Apel, para Hobbes y sus sucesores (se está refiriendo a la línea "conservadora"), sobre la base de las leyes naturales hobbesianas es posible fundar moralmente y explicar el origen del contrato social. El hecho de que estas leyes naturales sean imperativos hipotéticos (estratégicos) basados en el autointerés no permitiría, para Apel, que tuvieran la validez intersubjetiva necesaria como para constituirse en los principios morales fundantes de un Estado. Sin embargo, cuando hice referencia a Hobbes, en el punto 5.3, me preocupé en dejar aclarado que dicho filósofo no se refiere en ningún momento a sus leyes naturales como principios morales, sino como reglas generales de cuyo conjunto se deriva la regla de oro. Por otra parte, se ha visto desde mi perspectiva una salida a los problemas que se plantean a tal posición: la racionalidad estratégica establece las bases para que en una segunda instancia se aplique la racionalidad moral. Es en este sentido que las leyes naturales permiten fundar moralmente el contrato social, lo que no tiene nada que ver con identificar ley natural con principio moral en Hobbes, ni con una fundamentación de la ética a partir de la racionalidad estratégica. Por eso, para negar los intentos de tal fundamentación, es decir para llegar al diagnóstico del título de la tercera parte del artículo de Apel, preferí hacerlo de la manera en que ya se ha discutido el tema en el punto 1.2.3.

Apel introduce dentro de esta tercera parte a Rawls, de quien dice que busca la fundamentación suficiente de la justicia en una combinación de la teoría de juegos y la "teoría contractual", es decir 
bajo los supuestos del autointerés y de la racionalidad valorativa neutral. Sintéticamente, el procedimiento constructivista ideado por Rawls (1971) consiste en imaginar metodológicamente una "situación original" en la que los contrayentes ignoran no sólo su posición económica y social, sino también características tales como el color de la piel, el sexo y el grado de desarrollo de sus talentos y dotes naturales. En estas condiciones de extrema restricción, bajo el "velo de la ignorancia" (manera en que Rawls designa a esta forma de abstracción), los contrayentes en la "situación original" están en condiciones de elegir sin coerciones e imparcialmente aquellos principios universalmente válidos bajo cuyo amparo desearán desarrollar sus vidas. Ahora bien , como señala Guariglia (1993:320), a diferencia de Kant, quien "se sitúa desde la perspectiva de la primera persona, que es la que eleva la máxima de su acción a ley universal y establece la comparación entre el mundo social posible así creado y el mundo actual, a fin de comprobar su carácter no contradictorio, la perspectiva elegida por Rawls evita el procedimiento de universalización de la máxima individualidad como test y propone, desde el comienzo, dos principios sustantivos de justicia, que serán aquéllos con respecto a los cuales habrá un acuerdo unánime de las partes con anterioridad a cualquier otra acción o decisión" (es decir, aquéllos con los que se estará de acuerdo en la situación original). Tales principios, en la formulación dada en Rawls (1985), son los siguientes:

1- "Cada persona tiene un derecho igual a un esquema completamente adecuado de iguales derechos básicos y libertades, el cual es compatible con un esquema igual para todos".

2- "Las desigualdades sociales y económicas deberán satisfacer dos condiciones: primero, deberán estar ligadas a oficios y posiciones abiertas a todos bajo condiciones de una equitativa igualdad de oportunidades, y segundo, deben ser para el mayor beneficio de los miembros menos aventajados de la sociedad".

Según Apel (1985:14), para mostrar que los seres humanos racionales elegirían un estado de justicia sobre la base de los supuestos de la racionalidad estratégica, (Rawls) imagina una situación artificial a la que también llama "situación original", en la cual el "punto de vista moral", es decir, el reconocimiento recíproco de los seres humanos como seres dotados de los mismos derechos, se identificaría con el punto de vista del autointerés de todos. Y tal situación es alcanzable bajo el supuesto del así llamado "velo de la ignorancia" en relación con la propia posición que uno tendría en la sociedad surgida en virtud del contrato social, porque en tal situación, según Rawls, todos calcularían sus riesgos y en consecuencia elegirían a partir de su propio interés un orden social orientado a la compensación de las desventajas individuales, en lugar de confirmar la desigualdad natural y social de justicia. Así, Rawls, trata de compatibilizar, por así decirlo, la postura de Hobbes y la de Kant con respecto al contrato social".

Apel termina su reflexión sobre Rawls concluyendo que éste no logra su objetivo, ya que en la "situación original" la razón no sería una facultad valorativa neutral destinada a calcular al servicio del autointerés, sino una "facultad de motivación y valoración transubjetiva". Sin embargo, no considero apropiada la inclusión que Apel hace de la teoría de Rawls dentro de la tercera parte de su artículo, es decir dentro de los intentos de fundamentar la ética por medio de la razón estratégica. Si bien Rawls toma en cuenta a la racionalidad estratégica para llegar a sus principios de justicia, la toma dentro de las condiciones particulares, experimentales e irreales de la "situación original", en la que se lleva a cabo una valoración transubjetiva.

Siguiendo con mi revisión de las posiciones universalistas a partir del artículo de Apel, se tiene que el segundo intento de fundamentación racional de la ética que este autor analiza es el kantiano. Kant es el primero en postular a la razón como una facultad de valoración transubjetiva, al describir a la razón práctica como una facultad legislativa autónoma de la voluntad, capaz de darse su propia ley moral independientemente de determinaciones heterónomas tales como los mandatos divinos de la ética cristiana o el autointerés efectivo del utilitarismo. El imperativo categórico es dicha ley moral y proporciona un criterio de transubjetividad. 
Sin embargo, según Apel, a pesar de que Kant fue el primero en plantear en forma adecuada el problema de la fundamentación de la ética, su concepción no brinda una solución satisfactoria a los problemas de la ética en general. Para Apel la causa de tal fracaso se encuentra en su metafísica dualista, que le impide elaborar una concepción basada en la unidad de la razón práctica y teórica. Al no concebir una intervención de la voluntad libre y por consiguiente de las acciones morales en el reino de la experiencia posible (para Kant en el mundo de la naturaleza no hay fenómenos posibles a partir de acciones intencionales sino sólo determinadas por causas naturales), no puede concebir la responsabilidad del hombre en relación con los efectos de sus acciones, lo que lo lleva a definir el bien moral haciendo abstracción explícita de la consideración de las consecuencias de las acciones del sujeto hacia otras personas.

Apel pone el ejemplo de Kant en relación con el problema de si se debe decir la verdad o mentir en el caso de que un asesino preguntara por el escondite de su víctima, y en el que Kant insiste en la prioridad del "deber perfecto" (el de decir la verdad), frente al "deber imperfecto" de salvar la vida a otro ser humano. Según Apel, la deficiencia de la solución kantiana se relaciona con el problema de la reciprocidad. No vivimos en un mundo donde la reciprocidad generalizada de los derechos y los deberes (tal como se postula en el imperativo categórico) sea reconocida y observada de manera general. Al político no se le permite dejar de lado las probables consecuencias de las acciones, ni que las considere desde la perspectiva kantiana de consecuencias buenas o malas para sí mismo, sino como consecuencias que afectan a las personas que dependen de él. De esta manera, el "rigorismo" de la ética kantiana, origen de la conocida distinción weberiana entre ética de la convicción y de la responsabilidad, coloca a Apel en posición para introducirse de lleno en la problemática acerca de la posibilidad de la ética política.

Apel plantea entonces "el problema específico de la ética política" en los siguientes términos: ¿Es posible tomar en cuenta el derecho y aún el deber de la autopreservación de los sistemas sociales en un mundo de probables conflictos entre sistemas, sin reducir la razón ética a una racionalidad estratégico-instrumental al servicio del autointerés?

Para contestar esta pregunta Apel debe resolver aún la cuestión pendiente acerca de una fundamentación satisfactoria de la ética en general. En este sentido el camino que toma es el de una reconstrucción de la ética kantiana en términos de una ética de la comunicación consensual.

Antes de precisar la posición de Apel, vale la pena hacer referencia a los puntos principales de la ética discursiva o argumentativa de Habermas con la que se emparenta, para lo cual me apoyaré en Guariglia (1993). De acuerdo a la teoría de la acción comunicativa planteada por Habermas (1981), el procedimiento para la fundamentación de la legitimidad normativa en un Estado postradicional está inscripto en las formas de comunicación intersubjetiva de acuerdo a reglas que son constitutivas de las estructuras de sentido, del "mundo de la vida", sobre las que se asienta la sociedad moderna. "La tematización de estas estructuras se produce cuando son cuestionadas ya sea las acciones o las normas bajo las que estas se amparan, dando lugar a la justificación argumentativa y discursiva de las mismas. El telos (fin) de esta argumentación está dado, intencionalmente, por la restauración basada en razones del consenso entre interlocutores, consenso que, en consecuencia, presupone la posibilidad de lograr tanto una comunicación libre de distorsiones como una aceptación no forzada de las coerciones impuestas por la razón argumentativamente desplegada". "El desarrollo, en efecto, de una argumentación en el campo ético no es más que un caso especial de las reglas argumentativas que rigen todo discurso, si éste ha de satisfacer el requisito de ser convincente y de no incurrir en contradicciones no solamente lógicas y semánticas, sino especialmente pragmáticas"(Guariglia 1993:325). De este modo, para forzar al escéptico a entrar en el juego moral basta con mostrarle lo que él mismo presupone cuando hace uso del lenguaje normativo, cuyo rechazo equivale a quedar reducido al silencio. En ese sentido, para Habermas la regla argumentativa implícitamente reconocida por todos los participantes de una discusión queda explicitada por su principio de universalización: 
U: "Toda norma válida debe satisfacer la condición siguiente: que los efectos colaterales y las consecuencias que (previsiblemente) se producirán a partir de su aplicación general en favor de la satisfacción de los intereses de cada uno, puedan ser aceptadas por todos los involucrados -y puedan ser preferidas a los efectos de las reglamentaciones posibles alternativas que se conozcan-".

Como señala Guariglia, para que este principio argumentativo de universalización se convierta en un principio moral, debe transformarse en el criterio de validez que toda norma ha de satisfacer para ser reconocida como tal, para lo cual debe añadírsele un principio complementario, el llamado fundamento D de la ética comunicativa, que dice lo siguiente:

D: "Solamente pueden reclamar validez las normas que han obtenido (o podrían obtener) la aceptación de todos los involucrados como participantes de un discurso práctico".

Al igual que el imperativo categórico kantiano, ambos principios establecen sólo requisitos formales, sin predeterminar un contenido, para la validez de normas que pretendan aspirar a los rasgos de universalidad, imparcialidad y equidad implícitos en los ideales de una ética universalista.

De manera análoga a la teoría de la acción comunicativa de Habermas, Apel basa su punto de vista en una reflexión sobre la situación del discurso argumentativo, en la que, si se quiere argumentar algo seriamente, se debe admitir a priori que en principio es posible compartir la validez intersubjetiva del significado y la verdad de todos los interlocutores de la "comunidad de argumentación". De la transubjetividad inherente a toda argumentación seria se implica la norma fundamental de la ética de Apel: el principio de reciprocidad generalizada de derechos y deberes. Esto es así, según Apel, porque en el discurso argumentativo se debe suponer una situación de habla ideal, y en consecuencia "adjudicar iguales derechos y deberes de preguntar y contestar toda clase de cuestiones relativas a cualquier tópico concebible a todos los miembros de una comunidad de argumentación". El principio de reciprocidad generalizada no constituye así una norma material, sino una meta-norma que prescribe el procedimiento ideal de fundamentación o legitimación de normas materiales que debe lograrse "buscando el consenso de todas aquellas personas afectadas por una mediación argumentativa de sus intereses".

Esta es pues, la transformación a la ética kantiana propuesta por Apel como fundamentación satisfactoria de la ética. A partir de dicha fundamentación pasa a reflexionar sobre la posibilidad de una ética política de la responsabilidad estratégica. En ese sentido, comienza sosteniendo que las limitaciones de Kant respecto de la ética política radican en que no consideró que el imperativo categórico debe implicar el principio de reciprocidad generalizada de derechos y deberes, y en consecuencia no debe aplicarse al hablar con un hombre que tiene la intención de asesinar. Como admite Apel, el problema del político de buena voluntad es el de hacer frente a una situación de reciprocidad insuficientemente realizada entre individuos, grupos o estados, ya que las situaciones reales de comunicación se caracterizan por una mezcla de interacción comunicativa consensual y estratégica. De esta manera, la solución de Apel no nos deja mejor parados que las alternativas anteriores en lo que concierne a la ética política. Sin embargo, admitiendo que "hasta ahora no hay una ética filosóficamente satisfactoria que al mismo tiempo pueda ayudar o servir realmente a un político", propone desde su perspectiva algunas interpretaciones en el ámbito de la política nacional e internacional. En lo que respecta a la política interna defiende la tesis de que los estados democráticos modernos han reconocido ya el principio de reciprocidad y la necesidad de ir realizando progresivamente los ideales de una ética de la comunicación consensual, proceso que sólo puede llevarse a cabo en la "segunda instancia" a las que me referí en mis reflexiones sobre el Estado a partir de Hobbes. En relación a la política exterior, observa síntomas de un desarrollo tendiente al respeto del principio de reciprocidad en las relaciones internacionales, sobre todo a la luz de la mediación consensuada de intereses que se trata de establecer tanto en las Naciones Unidas como en los demás organismos internacionales.

Para terminar su artículo, Apel (1985:26) postula una máxima para una ética de la responsabilidad política: "tratar de utilizar tantos recursos estratégicos (como por ejemplo amenazas militares) como 
sea necesario (a fin de garantizar la seguridad) y de proveer la mayor cantidad de medidas previas a fin de lograr una solución de los conflictos de manera consensual comunicativa".

Personalmente, creo que no tiene sentido plantearse el problema de una ética políticamente aceptable. La ética y la política constituyen disciplinas diferentes, cada una con sus criterios y leyes específicos tal como señalé en mi crítica al utilitarismo ético de la teoría de la elección racional y como se reafirmó en el análisis de Maquiavelo (cuya división entre moral y estrategia política sigue siendo resistida todavía). En particular una ética política o de la responsabilidad (como la defendida por Weber en El político y el científico), que incluya la evaluación de las consecuencias de la acción de un político en el juicio moral, se guiará siempre por consideraciones de utilidad estratégicopolítica antes que de valor moral. La política no siempre es ética, hay casos en que el político se ve obligado a ir en contra de la moral para defender a sus representados de consecuencias adversas a sus intereses. No se trata de condenar a toda estrategia política que utilice medios moralmente peligrosos, sino simplemente de señalar que tales casos no entran en el campo de la ética, por lo que sus responsables deberían asumir los eventuales costos derivados de esas acciones, que podrán ser aceptadas (si no son ilegales) o condenadas por la justicia (las ilegales), o por el voto (las meramente inmorales ya que no todas las inmoralidades políticas son ilegales, especialmente en la sociedad internacional). Sin embargo, resulta más fácil, y mucho más "político", escudarse y decir que se ha actuado conforme a una "ética de la responsabilidad", cuando en realidad se ha llevado a cabo una acción de estrategia política. La falta de reciprocidad no puede ser la excusa que permita el encubrimiento ideológico de acciones como el perdón de personas juzgadas y sentenciadas culpables de asesinatos y torturas, la distracción frente al aniquilamiento sistemático de un pueblo, o el arrojar una bomba atómica sobre una ciudad indefensa, sean tomadas como acciones de ética política. Porque, por más que las miremos desde todos los ángulos posibles no parece que tales acciones merezcan el adjetivo "éticas", sino solamente el de "políticas" o "estratégicas".

Por supuesto, el problema que intenta solucionar sin éxito la ética política no atañe a todas las acciones del político, sino a aquéllas que entran en contradicción con principios morales. En ese sentido, la máxima de comportamiento que sugiere Apel insta al político a que, en aquellas acciones en las que se contradice el bien estratégico con el bien moral, se juzgue cada vez más, en la medida de lo posible y en el marco del consenso democrático, en base a un criterio moral antes que a uno estratégico. En todo caso serán las leyes nacionales e internacionales las que, a la luz de principios éticos y contando con el necesario poder coercitivo que las respalde, deberán ir acotando el rango de acción de los políticos, de manera de evitar que les sea concebible una política inmoral (que podrán reservar para aquellas acciones que siendo inmorales no sean ilegales). En cuanto al papel del Estado y del eventual auténtico organismo de seguridad colectiva internacional como instituciones, expresadas a través de sus leyes y medidas y por medio de la acción de sus funcionarios, como garantes del derecho deberán ser quienes más lo respeten, ya que como expresé en mi estudio de la lógica de la acción cooperativa, un régimen corrupto genera las bases de su disolución al aumentar el número de "francotiradores". Es decir, que una falta moral o de derecho de una institución es una falta doble, una falta en sí y una falta atentatoria contra el sistema.

\subsubsection{Universalismo vs. Comunitarismo.}

En su disputa teórica acerca de la fundamentación objetiva del sistema de normas morales, el universalismo ha tenido que enfrentarse no sólo con las teorías utilitaristas, sino también con una corriente ética desarrollada durante los años ochenta y a la que se ha denominado comunitarismo, neoaristotelismo o particularismo. Los supuestos básicos de esta corriente, resultado de la confluencia entre la adaptación de la hermenéutica heideggeriana llevada a cabo por Ritter y Gadamer y la renovación de la moral de la virtud aristotélica efectuada por Anscombe, se sintetizan a continuación a partir de las consideraciones al respecto de Guariglia (1993): 
1) Férrea oposición al universalismo de Kant y demás filósofos herederos de la Ilustración, en particular a las nociones de deber, como obligación incondicional de la acción, y de la ley moral, como fundamento objetivo de la existencia de esa obligación.

2) El individuo es incapaz de acceder por sí mismo a una forma de norma moral universalmente válida para todos en toda circunstancia, dada la incapacidad de la razón para ofrecer una norma moral de ese tipo, independientemente de las circunstancias históricas y de las tradiciones culturales o religiosas dentro de las que se sitúa.

3) Dado que en la deliberación precedente a la elección de la acción se parte de la situación particular del agente, nadie que no haya sido educado previamente en los modos de conducta que permiten reconocer las situaciones particulares como casos que caen bajo el alcance de una determinada virtud, puede tener acceso a las premisas evaluativas que permiten extraer la conclusión correcta.

4) A la concepción moral propia de la modernidad oponen los comunitarios "la necesidad de una idea del bien ampliamente compartida por los miembros de una misma comunidad y expresada tanto en el lenguaje valorativo que acompaña la ponderación de las buenas acciones como en la participación de un mismo "ideal de la buena vida", como telos (finalidad) de las prácticas sociales" (Guariglia 1993:319).

Me voy a oponer al comunitarismo en favor del universalismo. Creo que, como el utilitarismo social, el comunitarismo conduce al relativismo y a la fundamentación de aberraciones morales como la castración, el autoritarismo o el asesinato en nombre de tradiciones culturales o religiosas. Al respecto, tendré bastante que decir en el siguiente punto, cuando me refiera a la disputa entre universalistas y relativistas en el ámbito del derecho internacional, más precisamente, en el de la Conferencia de las Naciones Unidas sobre los Derechos Humanos. Por otra parte, sus argumentos resultan insuficientes para anular la validez de los diversos intentos universalistas de fundamentación de una ética postmetafísica basada en la autonomía del individuo, es decir, de los intentos de construcción de un criterio de racionalidad a partir del cual deducir los principios morales orientadores de las leyes del Estado postradicional que, siendo en sí valorativamente neutro, permita la atribución de valor moral a las acciones dejando de lado a la utilidad, la tradición o la religión como referencias valorativas de los juicios éticos. Es más, sostendré que, de hecho, el compromiso con la argumentación discursiva ampliamente aceptado como consecuencia de la difusión global de la reflexividad moderna, implica criterios lógicos universales que superan las diferenciaciones culturales. Acerca de cuál es el criterio universalista específicamente adecuado, si el incluido en el paradigma de Rawls, Apel o Habermas, o bien una mezcla de algunos de ellos, la pregunta permanece abierta en el terreno de la ética $\mathrm{y}$, por supuesto, no tengo espacio aquí para siquiera arriesgar una respuesta.

\section{4- La medida moral objetiva del derecho internacional.}

Dentro del ámbito de la comunidad mundial, la búsqueda de un fundamento moral sobre el cual apoyar el derecho internacional se da en el marco de la lucha entre las posiciones universalistas y las particularistas o relativistas a la que se hizo referencia. Así, mientras las primeras defienden la adopción de criterios morales objetivos de aplicación universal del tipo de aquéllos a los que aludimos al comentar los puntos de vista de eticistas como Rawls, Habermas o Apel, las segundas hacen hincapié en el papel de la costumbre y la tradición en la justificación de la acción moral, cuestionando la capacidad del individuo de acceder por sí mismo a un criterio moral universalmente válido y poniendo en tela de juicio la capacidad de la razón para ofrecer un criterio de esta clase independientemente de las circunstancias históricas y de las tradiciones culturales dentro de las cuales se sitúa. Este debate quedó claramente manifestado durante el desarrollo de la Conferencia de Viena sobre los Derechos Humanos que con el auspicio de las Naciones Unidas tuvo lugar en junio de 1993. En esa ocasión se produjo un avance de las tendencias relativistas, auspiciado en 
particular por los representantes de países de religión musulmana, que llegó a cuestionar incluso algunos de los puntos incluidos en la Declaración de los Derechos del Hombre de 1948. Ese avance relativista no aparece en forma casual sino que se da en un marco de escepticismo moral internacional acerca de la posibilidad de acordar normas de alcance mundial y de que éstas sean respetadas. Según Cohen (1984), en la configuración de ese marco influyen no sólo la larga historia de egoísmo y brutalidad que ha caracterizado las relaciones entre las naciones, sino también el auge del paradigma realista y de un "escepticismo hobbesiano" en el que se podría ubicar a los pesimistas que sostienen la imposibilidad de la ética en un ámbito en el que la situación de estado de naturaleza sería esencial y definitoria. Respecto de esto último, se ha visto que el análisis lógico de la situación hobbesiana no conduce ineludiblemente al escepticismo o a la aceptación resignada de la política de balance de poder, sino que, por lo contrario, lleva a comprender la necesidad de principios morales universales (en esto coincide Cohen), de reciprocidad, y de un orden mundial colectivo.

Así, frente al escepticismo y contra el relativismo, vuelvo a tomar partido y a depositar mis esperanzas en las fundamentaciones universalistas de la ética, sosteniendo la necesidad, en un mundo plural, de un criterio de racionalidad moral objetivo, neutro y autónomo. Se ha visto ya, al hacer referencia a Kant, la definición de la autonomía como la capacidad del individuo de darse su propia ley moral universal con independencia de factores externos, culturales y religiosos, a los que se refieren los criterios heterónomos. La autonomía de la razón permite al individuo reflexionar lógicamente sobre criterios de aplicación general y universal (el imperativo categórico kantiano, el criterio de universalización habermasiano), la heteronomía, en cambio, implica la adhesión no cuestionada por la razón a algún criterio externo (la aceptación de los diez mandamientos o de alguna costumbre cultural). Al defender a los criterios heterónomos (la moral cristiana, la moral musulmana) frente a los autónomos (una única moral universal), el particularismo se enlaza con el relativismo y posibilita la justificación de la intolerancia religiosa o cultural. Desde ya, no tengo nada contra la práctica privada de la religión o de las tradiciones culturales, sino contra la pretensión de alguna de ellas de imponer públicamente su visión por sobre las de todas las minorías de la sociedad, nacional o internacional. En el caso de las religiones el riesgo de intolerancia está asociado a su naturaleza dogmática e intransigente. Como señala Vargas Llosa (1995),"todas ellas postulan una verdad, que tiene la abrumadora coartada de la trascendencia y el padrinazgo abracadabrante de un ser divino, contra los que se estrellan y pulverizan todos los argumentos de la razón, y se negarían a sí mismas, se suicidarían, si fueran tolerantes y retráctiles y estuvieran dispuestas a aceptar los principios elementales de la vida democrática", permitiendo el cuestionamiento de sus dogmas. En la base particular en la que descansan las distintas éticas religiosas, se cimenta el rechazo a lo diferente (algo moral para un cristiano puede ser inmoral para un musulmán y viceversa) y la explicación para los numerosos conflictos y guerras religiosas "contra los infieles" que han caracterizado la historia. La esencia dogmática e intolerante de las religiones se hace evidente en el caso del islamismo, porque las sociedades donde éste se ha asentado no han experimentado el proceso de secularización que en Occidente separó a la religión del Estado, convirtiéndola en un derecho individual en lugar de un deber público. Tómese como ejemplo a la Declaración de El Cairo sobre los derechos del Hombre en el Islam, preparatoria para la Conferencia de Viena. Según ese documento, sometido a la chari'a, la vida no puede quitarse "sin motivo legítimo", así como la libertad de expresión y la producción literaria, científica o artística deben ser garantizadas sólo si no se contradice la ley islámica (la diversidad cultural terminó constituyendo en Viena la moneda de cambio para los países islámicos, los que condicionaron la firma del documento final, afirmando la universalidad de los derechos humanos, a la adopción de una resolución sobre la situación de Bosnia). Pero también la Iglesia Católica, como señala Vargas Llosa (1995), en aquellas sociedades tercermundistas donde todavía tiene influencia decisiva en la redacción de las leyes y en el gobierno de la sociedad, no vacila en imponer sus verdades sobre la censura, el divorcio o el control de la natalidad a como dé lugar, y no sólo a sus fieles, sino también a todos los infieles que se le pongan a su alcance. Por eso, una sociedad internacional pluralista debe impedir que cualquier iglesia imponga sus particulares convicciones en el derecho internacional, algo que sólo puede hacer atropellando la libertad de los no creyentes. 
En lo que respecta a las tradiciones culturales, son muchos y conocidos los ejemplos de intolerancia y discriminación en los que ellas pueden desembocar. La aceptación de la diversidad cultural no implica ni justifica la complacencia con aberraciones morales como la corrupción política o la castración femenina.

En suma, como no hay manera de respetar todas las creencias religiosas y culturales a la vez, el derecho internacional no puede ser otra cosa que neutral. Está claro que en una sociedad internacional de innumerables minorías, la autonomía a la que apelan los criterios morales universalistas es la única garantía de la neutralidad valorativa a la hora de diseñar las normas legales de alcance mundial. En ese sentido, se verá en la quinta parte que el compromiso con la argumentación discursiva ampliamente aceptado como consecuencia de la difusión global de la reflexividad moderna implica la aceptación de criterios lógicos y morales universales más allá de las diferencias culturales. El reconocimiento de tales diferencias culturales no determina el triunfo del relativismo, sino que constituye un desafío a la razón: la búsqueda de criterios morales y derechos universales en un universo marcado por la diversidad cultural. En todo caso, el respeto completo del derecho internacional y la no suspensión de la racionalidad moral que lo inspire será posible en el marco de un mecanismo de seguridad colectiva con la fuerza suficiente para castigar a los infractores. 


\section{Resumen de conclusiones de la cuarta parte}

1) Puede establecerse una analogía entre la reflexion acerca de la medida material y el patrón moral del Estado y las relativas a la amplitud de las incumbencias y al parámetro moral apropiados para la constitución de un auténtico organismo de seguridad colectiva internacional que no degenere en un sistema autoritario.

2) En lo que respecta a la medida material, la extensión de la teoría del Public Choice a las relaciones internacionales permite deducir las conclusiones siguientes:

a) La amplitud de poderes e incumbencias de un eventual auténtico mecanismo auténtico de seguridad colectiva será aquélla que los estados en su conjunto quieran que tenga. Un grupo de estados aceptará constituir una entidad en común sólo si los beneficios de esa acción colectiva superan a los de la acción individual.

b) El establecimiento de un auténtico organismo de seguridad colectiva constituiría un bien público internacional cuya primera y fundamental manifestación de utilidad sería la garantía de paz y seguridad interna diferentes.

3) En lo relativo a la medida moral, tanto a nivel interno como en el internacional se está lejos de concordar acerca de cuál es el criterio moral más apropiado. En particular, se observa una notable carencia en la ciencia política contemporánea que puede sintetizarse en su falta de respuesta a la siguiente pregunta: ¿Existe, y en tal caso, cuál es el criterio normativo de racionalidad moral (la medida o patrón moral) a partir del cual juzgar las acciones de los individuos y del Estado, así como fundamentar objetivamente la moralidad de sus leyes?

4) De mi análisis de las propuestas de distintas corrientes de la ética, en particular de los debates entre utilitaristas y universalistas $\mathrm{y}$ entre estos últimos y los relativistas, se obtienen las conclusiones siguientes:

a) La pregunta planteada en la hipótesis 3 ha sido respondida por dos líneas de autores:

a1) Una línea de autores más "hobbesianos", economicistas, más afines a la ciencia política dura de la que se hablaba, "conservadores", partidarios del derecho positivo (justo es aquéllo sancionado por el soberano), que van a hacer hincapié en la racionalidad estratégica del "homo economicus".

a2) Una línea más "kantiana", humanista, universalista, "liberal"(en el sentido que esta palabra toma dentro de la propia tradición liberal moderna), sostenedora de la existencia de un derecho natural (de derechos superiores inherentes al ser humano con independencia de la voluntad del soberano), que procurará defender un concepto más amplio de racionalidad, no restringido a los intereses estratégicos sino sustantivo, orientando su atención a la racionalidad moral del individuo y de las normas (y a su garantía de parte del Estado).

b) El desafío consiste en lograr una síntesis entre las corrientes a1 y a2, es decir, en conciliar a los representantes contemporáneos de dichas líneas buscando un criterio sobre el cual basar la crítica ética a las posturas neoclásicas (utilitaristas), sin perder el rigor científico ni la capacidad descriptiva, explicativa y predictiva de éstas.

c) En relación a la disputa entre utilitaristas y universalistas me inclino, en base a mi crítica a la teoría de la elección racional desarrollada en la primera parte, por el universalismo.

d) Por otro lado, frente al relativismo, vuelvo a tomar partido por las fundamentaciones universalistas de la ética, sosteniendo la necesidad, en un mundo plural, de un criterio de racionalidad moral objetivo, neutro y autónomo. Como no hay manera de respetar todas las creencias religiosas y culturales a la vez, el derecho internacional no puede ser otra cosa que neutral. 
e) En una sociedad internacional de innumerables minorías, la autonomía a la que apelan los criterios morales universalistas es la única garantía de la neutralidad valorativa a la hora de diseñar las normas legales de alcance mundial. El compromiso con la argumentación discursiva ampliamente aceptado como consecuencia de la difusión global de la reflexividad moderna implica la aceptación de criterios lógicos y morales universales más allá de las diferencias culturales.

f) En todo caso, el respeto completo del derecho internacional y la no suspensión de la racionalidad moral que lo inspire será posible en el marco de un mecanismo de seguridad colectiva con la fuerza suficiente para castigar a los infractores. 


\title{
QUINTA PARTE
}

\section{LA RACIONALIDAD DE LA ACCION DE LOS ACTORES INTERNACIONALES EN LA SOCIEDAD INTERNACIONAL DE LA POSGUERRA FRIA}

\author{
9- Modernidad, posmodernidad y realismo utópico.
}

\section{1- Introducción.}

Las primeras dos partes de este trabajo están orientadas al desarrollo de un modelo interpretativo de la acción de los actores internacionales y su racionalidad. Por su lado, la tercera y cuarta partes constituyen una aplicación del modelo a la investigación de los objetivos tercero y cuarto. Dicha aplicación me ha permitido desarrollar un punto de vista original acerca de la lógica de la cooperación que reconoce tres fases, la que va de la racionalidad estratégica al conflicto, la que va del conflicto a la cooperación y la que va de la cooperación a la racionalidad moral. Es decir, en la tercera y cuarta partes se traza un camino que parte del ser del conflicto para tratar de describir el deber ser de la cooperación. Falta resolver, sin embargo, un último interrogante: ¿Por qué, habiéndose negado hasta ahora, las potencias habrían de avenirse a dejar de lado el ser conflictivo del balance de poderes para pasar al deber ser cooperativo de la seguridad colectiva? En esta quinta parte, a la luz tanto de mi modelo como de las conclusiones obtenidas en la tercera y la cuarta, se intentará mostrar que ello es posible merced a las características propias de la posmodernidad en general y de la posguerra fría en particular. Por lo tanto, se empezará con una caracterización de la posmodernidad y de la posguerra fría a partir de la cual se pasarán a deducir las oportunidades ofrecidas y también los peligros que de ellas se deducen para la seguridad colectiva y en dirección a una sociedad internacional más racional.

\section{2- Modernidad y posmodernidad.}

Existen dos maneras básicas de definir a la posmodernidad: como negación o como recuperación de los valores de la modernidad, como punto final o como punto de inflexión, como quiebre o como prolongación, como proceso separado o como consecuencia interna de la modernidad. Ambos enfoques, a pesar de sus diferencias, tienen en común el hecho de apoyarse sobre un conjunto de postulados compartidos por toda la "reacción posmoderna", entre los cuales resaltan los siguientes:

- Crítica a la razón moderna, especialmente a sus formas dogmáticas y a sus exacerbaciones totalizantes y uniformadoras.

- Rechazo al discurso logocéntrico, a la capacidad de los grandes paradigmas, ideologías o metarrelatos para la explicación de la historia.

- Cuestionamiento de la idea de progreso y de la posibilidad de vanguardias ilustradas.

- Fragmentación de la sociedad ideológica, uniformizadora, dirigista y tecnocrática a través de un proceso de personalización en el que predominan la expresión individual, la libertad de elección y la diferenciación.

- Reivindicación del sujeto como agente privado que se afirma a través de la expresión de sus preferencias y la materialización de sus opciones. Prioridad de la esfera privada sobre la pública.

- Búsqueda de un mayor equilibrio entre idea y experiencia, entre la razón y la práctica. Revalorización de la filosofía práctica en general y de la hermenéutica (el "arte de la interpretación") en particular. 
- Primacía de lo cualitativo sobre la aspiración a tener "más de lo mismo", legitimación de las diferencias y valorización de lo personal, específico o local.

- La cultura posmoderna "rechaza los textos, programas y códigos conclusos y omnicomprensivos: representa la crisis del relato y la liberación del sujeto. Es heterogénea, multidireccional y policéntrica. Por ser personalista es también contradictoria: es a la vez vanguardista y nostálgica, indiferente y selectiva, insatisfecha y saciada, solidaria y anárquica, ecológica y consumista, materialista y psicológica, sofisticada y espontánea, seductora y discreta, aficionada a la cultura a la carta pero también a los grandes espectáculos" (Tomassini 1991:30).

Sobre la base de este diagnóstico, la caracterización particular de cada perspectiva, así como la de los enfoques que toman elementos de las dos, dependerá tanto de la visión de la modernidad a la que cada una se refiera como de los valores y dominio de especialización de cada autor. En el terreno de las relaciones internacionales, la corriente que ve a la posmodernidad como quiebre con la modernidad puede ser ejemplificada a partir del análisis de Tomassini (1991). Este autor, tomando como punto de partida la anterior descripción de la posmodernidad y coincidiendo con aspectos del enfoque de la interdependencia, lleva a cabo una crítica a la escuela clásica-realista de las relaciones internacionales a partir de la cual sostiene la necesidad de una nueva perspectiva que:

1) No considere al sistema internacional a partir del modelo de Estado como actor racional, sino como fruto de una constante interacción entre diferentes prácticas y fuerzas.

2) Cuestione la subordinación de la práctica a la teoría y valorice la interacción entre ambos términos.

3) Amplíe la descripción del sistema internacional permitiendo enriquecer su agenda y reconocer su dinámica, desdibujando las fronteras entre el ámbito interno y el internacional, entre la "alta" y la "baja" política exterior, y entre lo público y lo privado.

4) Permita no sólo comprender los procesos de cambio y de crisis del sistema internacional, sino hacer de ellos un elemento central de ese sistema.

5) Rechace la pretendida necesidad de una presencia hegemónica global como garantía de funcionamiento del sistema.

Para llevar a cabo este programa "es necesario reestructurar el sistema cognitivo heredado por los clásicos y reformulado por los neorrealistas", recurriendo a la epistemología postestructuralista. A partir de esta toma de posición, sumada a su rechazo total al paradigma clásico, al modelo de Estado como actor racional y al "iluminismo" racionalista de la modernidad, Tomassini se ubica en la referida línea de autores que, como Lyotard y Vattimo, ven a la posmodernidad como un quiebre con la modernidad.

La aproximación postestructuralista al conocimiento de la realidad se basa en la deconstrucción y la hermenéutica. La deconstrucción supone que nuestra perspectiva de la realidad depende de imágenes previas y prejuiciosas de las cosas, seleccionadas mediante un proceso ideológico de desplazamiento o subordinación de otras imágenes que podrían haber servido para construir una visión alternativa. En ese sentido, el proceso de deconstrucción busca revelar cómo se seleccionan esas imágenes, lo que equivale a desideologizarlas, restando validez a los grandes relatos y valorizando los elementos fragmentarios, transitorios y contingentes de que la trama social está hecha realmente. Por su parte, la hermenéutica (el "arte de la interpretación") centra su atención en lo nuevo, singular, fragmentario y efímero como expresión de lo universal y permanente, en la intuición del sentido del todo a través del significado de sus partes, intentando constituirse en una alternativa válida para acceder al conocimiento de las cosas, las ideas, los valores, las instituciones y las acciones que definen el mundo y la sociedad contemporáneos. Según Tomassini, la crisis de los grandes relatos hace necesario reivindicar el significado de espacios considerados marginales desde una óptica convencional y que reflejan una creciente fragmentación de la realidad internacional, incluyendo "agendas y actores mucho más diferenciados que los que predominaron 
en el pasado, así como una visión más amplia, más pluralista y ecléctica del universo de prácticas a través de las cuales se desarrolla la vida internacional, y una concepción de poder mucho más diferenciada" (Tomassini 1991:61). En ese sentido, las perspectivas epistemológicas de la posmodernidad (la deconstrucción y la hermenéutica) comenzarían a ejercer su influencia en los estudios internacionales tendiendo "a disolver las categorías racionalistas, universales y unívocas en que se basan sus análisis, y a relativizarlos y fragmentarlos en una pluralidad de fenómenos en que todo es válido o, como dice Paul Feyerabend, "cualquier cosa funciona"" (Tomassini 1991:63).

Así, la epistemología posmoderna, privilegiando lo particular, lo específico, lo efímero, lo fortuito o lo propio de los agentes por sobre el sistema en su conjunto, poniendo de relieve la historicidad de las relaciones internacionales, la pluralidad de situaciones que éstas presentan, su sujeción al cambio y la relevancia de los temas emergentes, y subrayando la diversidad de actores, problemas y elementos que intervienen en la escena internacional, permitiría iluminar mejor y en forma más flexible la realidad internacional que los modelos globales, sistémicos y conclusos adoptados por los enfoques basados en la soberanía del agente racional. Tomassini (1991:81) concluye que la "tendencia hacia la fragmentación de la política mundial, la diversificación de la agenda internacional y la incorporación a ella de numerosos temas dotados de una gravitación propia, que antes no formaban parte de la "alta política", implican el fin del mundo jerarquizado de Estados monolíticos exclusivamente ocupados de garantizar su seguridad mediante la acumulación y el uso de recursos de poder que defendió la teoría clásica".

¿Qué debe decirse, desde mi perspectiva, acerca de lo tratado en todo este punto?

En primera instancia, no tengo nada en contra de los planteos fundamentales de la reacción posmoderna planteados al principio. También reconoceré los elementos que a juicio de ese autor deben ser tenidos en cuenta en una nueva perspectiva de las relaciones internacionales y que he numerado de 1 a 5 .

Sin embargo, y como podría ya suponerse, me opondré a su crítica al realismo, a su rechazo al modelo de Estado como actor racional y a su apresurado e injustificado reemplazo por la epistemología postestructuralista. Creo que si bien sus intenciones y críticas al realismo clásico son dignas de ser tenidas en cuenta, éstas no alcanzan para refutar al modelo de Estado como actor racional ni para desplazar al realismo, que puede ser criticado y mejorado sin renunciar a la racionalidad y sin falsear a la realidad. En ese sentido, tanto la deconstrucción como la hermenéutica resultan elementos útiles a la crítica mientras no conduzcan al relativismo, a la irracionalidad y a la justificación de que todo es válido o de que "cualquier cosa funciona". Una cosa es la justificación del "vale todo" en el arte, allí donde la pura subjetividad y la relatividad moldean la acción expresiva con independencia de la racionalidad, otra cosa es deducir un comportamiento no racional de los actores internacionales o la aceptación, por ejemplo, de violaciones de los derechos humanos llevadas a cabo en nombre de costumbres particulares o de factores histórico-culturales. La deconstrucción y la hermenéutica no son incompatibles con la racionalidad, de hecho mi enfoque constituye una deconstrucción y una interpretación hermenéutica (una filosofía práctica) de los elementos y conceptos inherentes a la acción racional. Se puede criticar al realismo, incluso desde la epistemología posmoderna, sin renunciar al fructífero modelo que supone que el Estado y a los demás actores internacionales actúan pretendiendo ser racionales, modelo que a pesar de sus críticas y correcciones ha sabido resistir a sus refutadores a raíz de su capacidad explicativa. Tomassini no ofrece una alternativa a su rechazo del modelo de Estado como actor racional, ya que su apelación a la epistemología postestructuralista no alcanza por sí sola para llevar a cabo su objetivo de explicar la compleja dinámica de la sociedad internacional a partir de la interpretación fragmentada de la práctica. Así, mientras este autor señala tres características del neorrealismo (el modelo del Estado como actor racional, el utilitarismo racionalista en desmedro de lo colectivo y lo histórico, y el positivismo) como a las culpables de su fracaso interpretativo y de su consecuente refutación, mi esquema, manteniendo el supuesto de racionalidad y considerando la cuantificación estratégica de manera metodológica (y sólo en el terreno estratégico), permite una interpretación de los fenómenos colectivos que toma en cuenta las circunstancias históricas de la 
acción colectiva sin caer en una posición positivista sino tomando a la teoría como a una serie de conjeturas sujetas a refutación práctica.

El poner de manifiesto el surgimiento de nuevos actores y factores no analizados por los clásicos y que caracterizan a la sociedad internacional de la posguerra fría no resulta suficiente para refutar el modelo del Estado (actor internacional) como agente, ya que la práctica muestra que dichos nuevos agentes (económicos, sociales, intelectuales) no se desempeñan de manera irracional o emotiva, sino de la manera descripta por mi modelo, tratando de modificar racionalmente su situación subjetiva, procurando llevar a cabo acciones e interacciones objetivamente correctas. Sin renunciar al supuesto de racionalidad, mi modelo permite explicar el cambio, la conducta de los nuevos y tradicionales actores internacionales, las tensiones internas inherentes al proceso de toma de decisiones, así como la importancia de la historia en la definición de la situación de elección y en la refutación en la práctica de conjeturas equivocadas. Como se dijo, si bien a menudo los agentes se conducen de manera irracional y emocional, el presupuesto de racionalidad resulta provechoso para cualquier teoría acerca de los fenómenos sociales. El mismo Tomassini define a la política exterior de un Estado como a la elección del curso de acción más "apropiado". Un simple análisis del término "apropiado" lleva a preguntarse su significado para el o los agentes decisores de la política exterior, lo que conduce directamente al tratamiento de la racionalidad.

En virtud de las anteriores críticas a la postura expresada por Tomassini, extensibles en general a la consideración de la modernidad como punto de quiebre con la modernidad, preferiré tomar partido por la segunda de las líneas mencionadas al principio de este punto, aquélla que considera a la posmodernidad como un proceso interno y consecuente con la modernidad, como una prolongación de la crítica a la razón presente en la mayoría de los autores modernos desde Kant hasta Nietzsche. La reacción posmoderna adquiere relevancia no como rechazo a la razón o de la ética, sino como cuestionamiento a los elementos ideológicos o dogmáticos que suelen escudarse tras de ella. Así, tanto la teoría de la elección racional como mi modelo apelan a un racionalismo crítico moderado que intenta, con la ayuda incluso de la epistemología posmoderna, interpretar las formas de la acción irracional, entre ellas la que precisamente he denominado dogmatismo.

Se trata por lo tanto de hacer una crítica constructiva de la razón y la racionalidad, dirección por la que ha avanzado mi trabajo. En ese sentido y llegado este punto, resultará de sumo interés considerar los aspectos centrales analizados por Giddens (1990), autor que al igual que Habermas (aunque con fuertes discrepancias), pertenece a la línea que entiende a la posmodernidad como consecuencia de la modernidad (de ahí el título de su libro al que se refiere el siguiente punto).

\section{3- Las consecuencias de la modernidad.}

Se ha visto en el punto anterior cómo los autores de la "línea" de Lyotard y Vattimo ven en la crisis de los grandes relatos el origen de una pluralidad de heterogéneas pretensiones al conocimiento, entre las cuales la ciencia no tiene un lugar privilegiado. Tales pretensiones, en particular las de la epistemología postestructuralista, tenderían a disolver las categorías racionalistas, universales y unívocas en que se basan los análisis modernos, y a relativizarlos y fragmentarlos en una pluralidad de fenómenos. Frente a esta posición, la respuesta standard de Habermas (1985) y otros consiste en procurar demostrar que es posible una epistemología coherente y que se puede lograr un conocimiento generalizable de la vida social. Sin polemizar con dicho intento, Giddens (1990) toma otro camino, el del análisis de la naturaleza de las instituciones modernas, edificando su visión de la posmodernidad sobre la manera en que éstas son conceptualizadas. Giddens destaca cuatro dimensiones fundamentales características de la modernidad, a la que define inicial y provisoriamente como el conjunto de modos de vida y organización social surgidos en Europa a partir del siglo XVII y extendidos más tarde a nivel global:

I) El capitalismo, entendido como el sistema de producción de mercancías centrado en la relación entre el capital privado y la mano de obra asalariada, que implica la acumulación de capital en el 
contexto de mercados competitivos de trabajo y productos, y el aislamiento de lo económico de lo político.

II) El industrialismo, caracterizado por el uso de la maquinaria y de fuentes inanimadas de energía material en el proceso de producción y de transformación de la naturaleza.

III) El estado nacional, en tanto sistema administrativo que ejerce la vigilancia territorial y el control coordinado de los recursos sociales y económicos. "Los estados nacionales concentraron el poder administrativo mucho más eficazmente que los estados tradicionales y, consecuentemente, hasta estados muy pequeños fueron capaces de movilizar recursos sociales y económicos más allá de los disponibles por los sistemas premodernos"(Giddens 1990: 66).

IV) El poder militar, definido como el control monopólico de los medios de violencia dentro de precisas fronteras nacionales ejercido por el estado moderno (a diferencia de los premodernos) en el contexto de la industrialización de la guerra.

Detrás de estas dimensiones institucionales se encuentran las que Giddens caracteriza como las tres fuentes del dinamismo de la modernidad, sin las cuales el desprendimiento de los órdenes tradicionales premodernos no habría sucedido de manera tan radical y rápida a nivel mundial:

a) La separación entre tiempo y espacio. Según Giddens, la estimación del tiempo que configuraba la base de la vida cotidiana de las culturas premodernas, vinculaba siempre el tiempo con el espacio y era normalmente imprecisa y variable. El "cuando" estuvo casi universalmente conectado al "donde" hasta que la popularización de la invención del reloj mecánico determinó la uniformidad de la medida y, en consecuencia, de la organización social del tiempo.

b) El desanclaje. La separación entre tiempo y espacio fue la condición que permitió el proceso de desanclaje, es decir el "despegar" de las relaciones sociales de sus contextos localizados de interacción y su reestructuración a través de enormes distancias entre tiempo y espacio, es decir, en intervalos espacio-temporales indefinidos. Giddens distingue dos tipos de mecanismos de desanclaje intrínsecamente implicados en el desarrollo de las instituciones sociales modernas: la creación de "señales simbólicas" (medios de intercambio interpersonales independientes de los individuos que los manejan, por ejemplo el dinero) y el establecimiento de "sistemas expertos" (sistemas de logros técnicos o de experiencia profesional organizadores de grandes áreas del entorno material y social). Los mecanismos de desanclaje descansan sobre la noción de "fiabilidad". Por fiabilidad Giddens entiende una forma de confianza en una persona o sistema, por lo que respecta a un conjunto de resultados o acontecimientos, expresando en esa confianza cierta fe en la probidad de otra persona o en la corrección de principios abstractos (conocimiento técnico). Aunque desconoce la forma en que se elaboran y funcionan, el hombre moderno confía en las señales simbólicas (en el valor de uso conferido al dinero por ejemplo) y en los innumerables sistemas expertos con los que interactúa (automóviles, sistemas de telecomunicaciones). "La naturaleza de las instituciones modernas está profundamente ligada con los mecanismos de fiabilidad en los sistemas abstractos, especialmente en lo que respecta a la fiabilidad en los sistemas expertos" (Giddens 1990:84).

c) La índole reflexiva de la modernidad. El carácter tomado por la reflexión en la modernidad constituye su aspecto más influyente. "La reflexión es una característica definitoria de la acción humana. Todos los seres humanos se mantienen rutinariamente en contacto con los fundamentos de lo que hacen, como elemento esencial del mismo hacer" (Giddens 1990:45). Este "control reflexivo de la acción" no es sino un control consistente, "que nunca descansa", de la conducta y sus contextos. Con el advenimiento de la modernidad, la reflexión es introducida en la misma base del sistema de manera que pensamiento y acción pasan a ser constantemente refractados el uno sobre el otro. La rutina de la vida cotidiana y la tradición quedan a salvo sólo si pueden ser defendidas a la luz de los nuevos conocimientos. En todas las culturas las prácticas sociales son alteradas en virtud de los nuevos conocimientos de que se nutren, "pero sólo en la era de la modernidad se radicaliza la revisión de la convención para (en principio) aplicarla a todos los aspectos de la vida humana, 
incluyendo la intervención tecnológica en el mundo material" (Giddens 1990:46). Lo característico de la modernidad es la presunción de reflexión general, que incluye la reflexión sobre la naturaleza de la misma reflexión. "Cuando las pretensiones de la razón reemplazaron a aquéllas de la tradición, parecían ofrecer una sensación de certidumbre mayor que la que proporcionaba el dogma preexistente. Pero esta idea sólo logra ser convincente si no reconocemos que la reflexión de la modernidad, de hecho, derriba la razón, siempre que se entienda por razón la obtención de un conocimiento cierto. (...) Nos encontramos en un mundo totalmente constituido a través del conocimiento aplicado reflexivamente, pero en donde al mismo tiempo nunca podemos estar seguros de que no será revisado algún elemento dado de ese conocimiento" (Giddens 1990:47). La idea de la razón providencial coincidió con el auge del dominio europeo y de su pretensión de sentar bases que proporcionaran seguridad ofreciendo la emancipación del dogma de la tradición. Sin embargo, las semillas del nihilismo, sostiene Giddens, estuvieron desde un principio en el pensamiento ilustrado, ya que aunque la razón quede liberada, ningún conocimiento puede descansar sobre una fundamentación incuestionable, dado que recaería en el dogma y se separaría de la esfera de la razón que determina su validez. Frente al dogma, la modernidad implica la institucionalización de la duda. Todas estas afirmaciones respaldan tanto la interpretación de Popper de la ciencia como conjunto de hipótesis conjeturales expuestas permanentemente a la refutación, así como mi modelo silogístico de la acción que, inspirado en dicha interpretación, describe la aceptación conjetural y la refutación práctica de hipótesis de acción.

Otro aspecto característico de la modernidad es su mundialización. La modernidad no es una civilización entre otras, la decadencia del dominio de Occidente sobre el resto del mundo no resulta de la disminución del impacto de sus dimensiones institucionales sino de su extensión mundial. La modernidad constituye un proyecto occidental pero "es universalizadora no sólo en términos de su impacto global, sino en términos del conocimiento reflexivo fundamental a su carácter dinámico" (Giddens 1990:163). Como se ha adelantado en otras partes de este trabajo, el compromiso con la argumentación discursiva, ampliamente aceptado como consecuencia de la difusión global de la reflexividad moderna, implica criterios lógicos universales que superan las diferenciaciones culturales. Giddens señala la existencia de cuatro dimensiones del proceso de mundialización o globalización moderno, correlativas con las dimensiones institucionales de la modernidad a las que me he referido:

I) La economía capitalista mundial. Los principales centros de poder en la economía mundial son estados capitalistas en los que la empresa económica capitalista constituye la principal forma de producción. En particular la libertad y el poder con los que las corporaciones transnacionales cuentan para desarrollar sus intereses y actividades hace posible la extensión global de su influencia $\mathrm{y}$, en consecuencia, de la de los mercados de productos, incluidos los mercados monetarios.

II) El industrialismo mundial. Sus aspectos más relevantes son la expansión de la división mundial del trabajo, incluyendo las diferenciaciones entre las regiones del mundo más y menos industrializadas, y la creciente aceleración de la interdependencia económica mundial. La difusión del industrialismo y su maquinaria tecnológica ha tenido un fuerte impacto no sólo en el ámbito de la producción, sino también en muchos aspectos de la vida cotidiana. Debido a que uno de sus más importantes efectos ha sido la transformación de las tecnologías de comunicación, el industrialismo ha condicionado nuestra conciencia de vivir en "un solo mundo" profundizando la mundialización cultural iniciada con la invención de la imprenta. Las tecnologías mecanizadas de comunicación han influido profundamente en todos los aspectos de la mundialización constituyéndose en un elemento esencial de la reflexividad de la modernidad y del progresivo surgimiento de una "aldea global" sobre el compartimentado mundo tradicional.

III) El sistema de estados nacionales. La noción de soberanía territorial, unida al establecimiento de límites entre los estados, participa de la reflexividad característica de la modernidad en su conjunto (un estado se reconoce frente a los demás) constituyendo "uno de los principales factores que distinguen al sistema de estados nacionales de los sistemas de otros estados premodernos en los que existían pocas relaciones de esta clase ordenadas reflexivamente, y donde la noción de "relaciones 
internacionales" no tenía ningún sentido" (Giddens 1990:75). Las teorías de las relaciones internacionales sólo son aplicables a los estados nacionales modernos en los que existe mucha más concentración de poder administrativo que la que existió en sus precursores premodernos, acerca de los cuales carece de sentido hablar de "gobiernos" que hayan negociado en nombre de sus naciones. Giddens toma citas de Morgenthau y acepta en general los supuestos del paradigma clásico-realista, en especial el modelo de Estado como actor racional, de manera que sus apreciaciones pueden acoplarse sin problemas a mi interpretación de la sociedad internacional.

IV) El orden militar mundial. El hecho de que la mayoría de los países mantengan una reserva de armamentos tecnológicamente avanzados y hayan modernizado sus fuerzas armadas pone de manifiesto el grado en que la industrialización de la guerra ha llevado a la mundialización del poder militar. Tal mundialización concierne también a las alianzas entre las fuerzas armadas de los distintos países y al carácter global que han adquirido los conflictos a partir de las dos guerras mundiales, especialmente desde el surgimiento del armamento nuclear y del orden mundial por el equilibrio del terror que, aunque ha suavizado sus rasgos en la posguerra fría, subsiste de manera latente resistiéndose a desaparecer.

Se tiene entonces que la modernidad aparece a partir de tres fuentes dinámicas (la separación entre el tiempo y el espacio, el desanclaje y la reflexividad) que favorecen el surgimiento de cuatro dimensiones institucionales características (el capitalismo, el industrialismo, el estado nacional y el poder militar) que en base a ese dinamismo se mundializan dialécticamente, transformándose a medida en que aumenta su influencia global y extendiéndose según cuatro direcciones (la economía capitalista mundial, el industrialismo mundial, el sistema de estados nacionales y el poder militar mundial). Es sobre esta caracterización de la modernidad que Giddens construye su posición respecto a la posmodernidad. Para dicho autor, no estamos entrando en un período que quiebre con la modernidad sino que nos trasladamos a uno en el que sus consecuencias se están radicalizando y universalizando como nunca. Así, mientras los autores de la línea de Lyotard definen a la posmodernidad como el final de la epistemología, del individuo y de la ética, tomando al "yo" como disuelto por la fragmentación de la experiencia, Giddens observa en ella transformaciones que van "más allá" de las instituciones de la modernidad y que hacen posibles activos procesos de reflexión y autoidentidad. Desde esta perspectiva, las pretensiones de verdad no son vistas como históricas o contextualizadas sino que se señala la relevancia de sus rasgos universales en tiempos de supremacía de problemas de índole global. La visión de una modernidad radicalizada resulta inquietante y significativa, ya que sus rasgos característicos (la disolución del evolucionismo, el reconocimiento de su reflexividad constitutiva y la evaporación de la privilegiada posición de Occidente) conducen a un nuevo y perturbador universo de experiencia. Se trata de un período de "alta modernidad" en el que la reflexión permite descubrir "que nada puede saberse con certeza, dado que los preexistentes "fundamentos" de la epistemología han demostrado no ser indefectibles, que la "historia" está desprovista de teleología, que en consecuencia ninguna visión de "progreso" puede ser defendida convincentemente, y que se presenta una nueva agenda social y política con una creciente importancia de las preocupaciones ecológicas y quizás, en general, de nuevos movimientos sociales" (Giddens 1990:52).

Hay que aclarar aquí que Giddens distingue el término posmodernidad del de posmodernismo. El segundo "si es que quiere decir algo" se refiere a estilos o movimientos de la literatura, las artes plásticas y la arquitectura, concerniendo a aspectos de reflexión estética sobre la naturaleza de la modernidad. La posmodernidad se refiere a algo diferente, a un proceso que profundiza el alejamiento de la premodernidad a partir de la radicalización del tipo de organización social de la modernidad. El posmodernismo puede expresar la conciencia de esta transición, pero no explica su existencia.

Dentro del contexto de la posmodernidad y en relación con las cuatro dimensiones institucionales planteadas, Giddens encuentra tendencias importantes y optimistas factibles de ser concretadas: 
I) Redistribución global de la riqueza entre países y regiones, en el marco de un sistema económico post-escasez globalmente coordinado en el que la acumulación capitalista y el crecimiento económico constante sirva para mejorar la calidad de vida de la mayoría de los habitantes del planeta.

II) Humanización de la tecnología, en particular en relación al impacto del desarrollo científico en el medio ambiente puesta de manifiesto constantemente por los movimientos ecológicos. Dado que el problema ecológico tiene un carácter global, también deberán tener alcance mundial las formas de minimización de sus riesgos.

III) Orden político global más coordinado. La progresiva mundialización obliga a los estados a colaborar en cuestiones que antes hubieran tratado de manejar separadamente. Sin embargo, no debe subestimarse, como ha ocurrido, el grado de autonomía soberana de los estados nacionales. El "gobierno mundial" implicaría la formación de políticas globales de cooperación entre estados y de estrategias cooperativas para resolver conflictos, pero no la formación de un superestado con una forma de gobierno semejante al mandato universal del estado nacional. "Las tendencias en este plano aparecen fuertes y claras" (Giddens 1990:157).

IV) Trascendencia de la guerra y desmilitarización. A pesar de que los gastos militares globales y la aplicación de tecnología a la producción de armamentos se mantiene sin disminuir, no debe descartarse la proyección de un mundo sin guerra. En un planeta en el que la difusión del armamento industrializado ha bloqueado la agresión mutua por temor a la destrucción masiva, en el que las fronteras nacionales han sido ya casi completamente fijadas, en el que el agrandamiento territorial ha perdido el significado que tuvo una vez y en el que aumenta la interdependencia con el incremento de situaciones en las que intereses similares son compartidos por todos los estados, "imaginar un mundo sin guerra es ciertamente utópico, pero de ninguna manera carece del todo de realismo" (Giddens 1990:158).

Las tendencias inmanentes señaladas aquí son sólo eso, tendencias en absoluto necesarias en tanto estén sujetas a grandes peligros también inherentes a las consecuencias de la modernidad. La modernidad es un fenómeno de doble filo. Por un lado, el desarrollo y globalización de las instituciones modernas han creado oportunidades mucho mayores para una vida más segura y recompensada que en los tiempos premodernos. Por el otro, la modernidad exhibe un costado sombrío que se ha puesto de manifiesto en este siglo a partir de terribles experiencias totalitarias y militaristas, de la amenaza de hecatombe nuclear, y de la destrucción del medio ambiente. En este sentido, Giddens distingue cuatro riesgos de graves consecuencias en relación a las dimensiones institucionales de la modernidad que sirven de eje a su análisis:

I) El colapso de los mecanismos de crecimiento económico.

II) La desintegración o desastre ecológico.

III) El crecimiento del poder totalitario.

IV) El conflicto nuclear o la guerra a gran escala.

"Al otro lado de la modernidad -como nadie sobre la tierra deja de saber- podríamos encontrar nada más que una "república de insectos y de abrojos" o un puñado de comunidades sociales humanas heridas y traumatizadas. No tiene por qué intervenir ninguna fuerza providencial para salvarnos y ninguna teleología histórica nos garantiza que esta segunda versión de la posmodernidad no desbanque a la primera. El apocalipsis se ha convertido en algo trivial, tan familiar que es como un contrafáctico de la vida cotidiana. Y, sin embargo, como todos los parámetros de riesgo, puede hacerse realidad" (Giddens 1990:161). Giddens asocia la modernidad con el "carro de Juggernaut" en el que según un mito hindú se sacaba en procesión la imagen del dios brahamánico Krichna y cuyas ruedas aplastaban a los fieles que de esa manera se sacrificaban a la divinidad. Como el juggernaut, la modernidad semeja a una desbocada máquina de enorme poderío a la que los hombres podemos manejar hasta cierto punto, pero que también amenaza con escapar de control y 
pasarnos por encima. Mientras las instituciones de la modernidad permanezcan no se podrá controlar totalmente ni el camino ni el ritmo de ese viaje. Nunca podremos sentirnos completamente seguros porque el camino está repleto de riesgos. La seguridad ontológica ha de coexistir con la ansiedad existencial. Confianza y riesgo, oportunidad y peligro, "rasgos polares y paradójicos de la modernidad", permean todos los aspectos de la vida cotidiana reflejando la interpolación de lo local y lo global.

¿Cómo hacer entonces para dirigir al juggernaut de manera de minimizar los peligros y maximizar las oportunidades que ofrece la modernidad? Según Giddens no es precisamente por medio de la idea de que hemos dejado de tener métodos viables para afirmar las pretensiones de conocimiento como lo sustentan Lyotard y otros autores de la "primera línea", sino a través de la creación de modelos de "realismo utópico". Es decir, se necesita la elaboración de análisis que, como el del mismo Giddens, orienten sobre las positivas oportunidades futuras y alerten acerca de los peligros, de manera que su conocimiento impacte en la sociedad mundial y la haga reflexionar sobre la manera como se construye a sí misma. Un elemento esencial de la índole reflexiva de la modernidad, la fuerte naturaleza contrafáctica del pensamiento dirigido al futuro, posibilitaría que la sola propagación de "modelos para una sociedad buena" ayudara a su realización.

La actividad de los intelectuales, así como la de los movimientos sociales "viejos" (movimientos de trabajadores y movimientos democráticos y por la libertad de expresión), y "nuevos" (movimientos por la paz y movimientos ecológicos), al vislumbrar futuros posibles pueden ser en parte vehículos para la concreción de modelos de realismo utópico. Sin embargo, dichas manifestaciones son necesarias en tanto influyen en otros factores fundamentales para alcanzar cualquier tipo de reforma básica: la fuerza de la opinión pública, las políticas de las empresas, de los gobiernos nacionales y de las organizaciones internacionales. "El enfoque del realismo utópico reconoce la inevitabilidad del poder y no percibe su utilización como algo inherentemente nocivo. El poder, en su más amplio sentido,representa el medio de lograr que las cosas se hagan. En una situación de mundialización acelerada, intentar maximizar las oportunidades y minimizar los riesgos de graves consecuencias exige, qué duda cabe, del uso coordinado del poder" (Giddens 1990:152).

El "final de las ideologías" no es el de los ideales ni el de las teorías sino el de los discursos cerrados y omnicomprensivos. La historia no posee forma intrínseca ni teleología total. Lejos de reducir a los hombres al conformismo del "vale todo" o al egoísmo del "sálvese quien pueda", la modernidad radicalizada los invita a no dejarse engañar por el discurso dogmático, al compromiso personal y a la acción reflexiva por un mundo mejor. De esta manera, mi realismo idealista puede ser tomado como una forma de realismo utópico, en tanto ofrece a partir de consideraciones estratégicas pero sin renunciar a la ética o al derecho, un "modelo de sociedad internacional buena" que enfrenta a la peligrosa incertidumbre subsistente en la posguerra fría. En ese sentido, los puntos siguientes procurarán ahondar sobre las oportunidades que la actual coyuntura ofrece para la concreción de las tendencias optimistas señaladas aquí (en particular para la efectivización de un modelo de seguridad colectiva como el propuesto en la tercera parte), así como sobre los factores que pueden llevar a acentuar los peligros de la posmodernidad y que atentan contra cualquier forma de organización que impulse la paz mundial y la vigencia del derecho internacional. 


\section{0- Oportunidades y peligros de la posguerra fría}

\section{1- Posmodernidad y posguerra fría. Las circunstancias propicias para la seguridad colectiva.}

Se le llama posguerra fría a la etapa de distensión abierta con el fin de la disputa ideológica y militar Este-Oeste y marcada por acontecimientos como la caída del muro de Berlín, la reunificación alemana, la Guerra del Golfo y la disolución de la antigua Unión Soviética. Lógicamente, no se trata de una circunstancia surgida de manera espontánea y repentina, sino que puede interpretarse dentro del marco del progresivo proceso de radicalización de la modernidad caracterizado en el anterior capítulo. Desde esa perspectiva se deduce que ni siquiera la férrea cortina soviética habría podido poner freno a los factores dinámicos de la modernidad y a la mundialización y radicalización de sus dimensiones institucionales, a partir de lo cual habría resultado inevitable la comparación reflexiva entre la pujanza económica y las formas de participación democrática de las principales naciones occidentales, y la decadencia económica y el autoritarismo político (justificado con un discurso ideológico dogmatizado) del bloque oriental.

Por ahora, la posguerra fría ha demostrado ser un período de relajamiento de tensiones y aumento de la cooperación que, luego del optimismo inicial (y como después quedó demostrado excesivo) consecuente a la Guerra del Golfo Pérsico, ha marcado el paso de la bipolaridad nuclear a la tripolaridad económica (Estados Unidos, Unión Europea, Japón). Sin embargo, la continuidad de esta etapa de distensión no es de ninguna manera necesaria ya que, como se ha visto, el mencionado proceso de radicalización y mundialización de la modernidad no implica por sí solo el desarrollo sin trabas de las optimistas tendencias inmanentes planteadas por Giddens, sino que está expuesto a riesgos de graves consecuencias. En ese sentido, el actual período de posguerra fría constituye una coyuntura especial en la que se presentan circunstancias propicias para la realización de proyectos de realismo utópico en general, y del modelo de seguridad colectiva auspiciado por mi realismo idealista en particular, que permitan asentar el camino de las tendencias inmanentes de la modernidad minimizando sus peligros. Entre estas circunstancias se destacan las siguientes:

a) La difusión de la democracia como forma de gobierno de los estados y en consecuencia del respeto por el principio de la mayoría, de la mano con el aumento del compromiso con la argumentación discursiva y de la reciprocidad legal y moral.

b) El mencionado fin del conflicto ideológico Este-Oeste y el consiguiente paso de un sistema internacional bipolar heterogéneo a uno multipolar homogéneo, en el que la mayoría de los estados comparten ideales y valores, abre el camino a una mayor confianza y cooperación vía soluciones internas a sus dilemas del prisionero. Como señala Boutros Ghali (1994), las naciones que durante la guerra fría definían sus intereses nacionales mirando a las ideologías contrarias como si fueran el demonio, se encuentran más predispuestas a adaptarse al concepto de un interés común, global o planetario y enfocan su atención sobre los demonios reales: la pobreza, el hambre, las enfermedades, la polución, la ausencia de democracia y la violación de los derechos humanos.

c) Mientras en la guerra fría el peso de la consideración de utilidades relativas condujo a la falta de intereses comunes, a la multiplicación de juegos de estancamiento o de la clase de los de suma cero y, en consecuencia, a la no cooperación, en la posguerra fría la desaparición de la rivalidad ideológica y el surgimiento del interés común por evitar los peligros asociados a la posmodernidad lleva a la proliferación de situaciones de juego más cooperativas (dilema del prisionero, juego de armonía). Las potencias ya no consideran a la destrucción del otro dentro de sus intereses vitales, sino que por el contrario, dejan de apuntarse para buscar formas de cooperación provechosas.

d) Las luchas internas desatadas en países como Yugoslavia pueden ser entendidas de la manera vista en el capítulo 7, como guerras de liberación nacional orientadas a la autonomía política y económica, es decir, a la adquisición del status de actor internacional. Sin embargo, los estados han renunciado, en general, a la fuerza y la conquista para imponer su voluntad a los otros, lo que ha 
puesto freno a la carrera armamentista entre las superpotencias. La vida de los soldados de cada país es tomada cada vez con mayor consideración, hecho que determina que una potencia militar como Estados Unidos (que ha renunciado expresamente a su poder de "policía del mundo") medite cómo asegurarse una mínima cantidad de bajas antes de inmiscuirse en operaciones como las de Irak, Haití, o Bosnia. Asimismo, la influencia y el poder de las potencias pasan más ahora por el comercio y la tecnología que por la anexión de territorios y el mantenimiento de costosas fuerzas de ocupación provocadoras de tensiones y alimentadoras del peligro de debacle nuclear. Se dice en ese sentido que Mercurio tiende a reemplazar a Marte, o bien que la guerra tiende a dejar de ser la forma de comercio entre naciones descripta por Clausewitz. En consecuencia, las sanciones económicas en poder de las Naciones Unidas toman ahora una mayor importancia y efectividad.

e) Se multiplican las tareas encargadas a las Naciones Unidas que, junto a otras organizaciones colectivas como la Unión Europea o la Organización Mundial del Comercio, ponen de manifiesto el importante rol a cumplir por las instituciones internacionales.

f) La clave para que las potencias acepten un mecanismo de seguridad colectiva como el propuesto en estas páginas consiste en demostrarles, en línea con el institucionalismo, que en el marco de la posguerra fría dicho mecanismo resulta no sólo moralmente preferible sino también estratégicamente más beneficioso que el balance de poderes.

\section{2- Factores de peligro para la seguridad en la posguerra fría. La irracionalidad del fundamentalismo.}

He coincidido con Giddens en que la posguerra fría se da en un marco de modernidad radicalizada entre cuyas tendencias inmanentes se encuentra el paso a una sociedad global más coordinada. Cité también una serie de auspiciosas circunstancias en esa dirección propiciadas por el actual momento de la realidad internacional. Es así que en base al conjunto de mis reflexiones se pueda interpretar la presente situación internacional como una oportunidad para que las Naciones Unidas, un proyecto de neta inspiración moderna, "radicalicen" su accionar y se aboquen a cumplir la función original para la cual fueron creadas: la de constituirse en un auténtico mecanismo de seguridad colectiva que garantice de manera eficaz la paz y la seguridad internacionales. Para lograr este cometido deberán saberse aprovechar las mencionadas circunstancias, que como se señaló no son ni necesarias ni eternas, buscando minimizar los riesgos de graves consecuencias de la propia modernidad planteados por Giddens: el colapso de los mecanismos de crecimiento económico, el desastre ecológico, el totalitarismo y la guerra nuclear.

En ese sentido, deberá también hacerse frente a una serie de factores que amenazan con conducir al mundo hacia tales peligros, en dirección contraria a las circunstancias favorables al desarrollo de las optimistas tendencias inmanentes planteadas por Giddens. Los factores a los que me refiero son los siguientes:

1) El dogmatismo ideológico. Se ha visto ya cómo la radicalización de la modernidad lleva asociada la extensión de su índole reflexiva a todos los aspectos de la vida humana, la institucionalización de la duda y de la conjetura y, en consecuencia, una crítica a las exacerbaciones totalizantes y uniformadoras que se escudan detrás de la razón moderna. Frente a esto, el dogmatismo aparece como la actitud contraria de la reflexividad, es decir de la razón moderna bien entendida, constituyendo como se afirmó en la primera parte, un modo de actuar irracional en el que el agente detiene la recolección de evidencia negándose a considerar nuevos elementos de juicio aportados por la experiencia. El dogmático se resiste a aceptar cualquier información probada o probable disponible que conduzca a la refutación de hipótesis o creencias rígidas que desea mantener como absolutamente verdaderas e indiscutibles, achacando sus fracasos explicativos y predictivos a factores accesorios. En ese sentido, las "verdades absolutas" a ser defendidas pueden estar ligadas a un conjunto de ideas o bien a la superioridad o "destino manifiesto" de una nación, raza o religión. Allí radica el "peligro social" del dogmático, ya que éste no se conforma por lo general con elevar 
su creencia a verdad incontrovertible, sino que intenta imponerla a los demás usando la coerción y la coacción. Cuando el dogmático tiene éxito, el otro tiene sólo dos opciones: o acata o se convierte en transgresor.

El dogmatismo ideológico consiste en la adopción de un conjunto de ideas (de una ideología) como absolutamente verdadero e irrefutable. Es el caso de la forma tomada por el comunismo de carácter totalitario, especialmente por el stalinismo (no sólo el soviético) y el maoísmo de la "revolución cultural", bajo los cuales se consideraba a los heterodoxos que no compartían la "verdad" oficial como rebeldes recalcitrantes que debían ser encarcelados o como enfermos mentales a ser recuperados en una clínica. Convertidos en dirigentes, los dogmáticos ideológicos, nuevos y antiguos, se lanzan contra la conciencia crítica temiendo que el pueblo "se desvíe", intentando exorcizar el demonio de la duda ajena para no visitar la propia.

2) El nacionalismo extremista. Cuando la "verdad indiscutible" incluye creencias referidas a la superioridad de una raza o al "destino manifiesto" de una nación, el dogmatismo ideológico se convierte en nacionalismo extremo. Como señala Vargas Llosa (1993) tomando a Aleix VidalQuadras, el nacionalismo en general consiste en "un producto intelectual inferior, de ideas rudimentarias, que no se propone fundamentar racionalmente una verdad sino revestir con la apariencia de una doctrina lo que es nada más que una pasión, un instinto y un acto de fe", por lo que no resulta casual que nunca haya habido grandes pensadores nacionalistas. Sustentado en prejuicios y miedos atávicos que no resisten el análisis racional, el empeño doctrinario del nacionalismo extremo consiste en el paralogismo de querer transformar la contingencia de vivir en ciertas circunstancias espacio-temporales en un absoluto sacralizado. Es normal que un individuo quiera y se identifique con el país y la gente entre la que nació y creció. "Pero convertir al accidente geográfico que es el nacimiento en una fatalidad ontológica, valor moral o distinción trascendente que comporta responsabilidades irrenunciables, es una aberración dogmática y una servidumbre que recorta la soberanía del individuo negándole una de las más admirables conquistas de la civilización que es la que confirió al ser humano la posibilidad de elegir su propio destino" (Vargas Llosa 1994). El nacionalismo extremo debe distinguirse del sentimiento nacional sano de un pueblo que por ejemplo busca librarse de una opresión extranjera y del patriotismo que, a diferencia del primero, constituye "un sentimiento solidario y afirmativo de lo propio y de lo próximo" (Vargas Llosa 1993) que no excluye al otro ni menosprecia lo ajeno.

El miedo y la violencia son los componentes inevitables de todo nacionalismo extremo. Miedo al otro, a lo diferente y a lo nuevo, a cambiar e innovar, al mestizaje, al pluralismo, a la coexistencia en la diversidad esencial a la cultura democrática. Violencia que surge cuando a la natural propensión de individuos y colectividades a mezclarse y confundirse (en un mundo cada vez más interrelacionado), el nacionalismo extremo tiene que oponerle la coerción para no perder su razón de ser. La coerción, desde ya, puede incluir el genocidio, la "limpieza étnica" o la defensa de acciones como el asesinato y la expulsión de extranjeros en virtud de alguna imprecisa y reduccionista "identidad cultural".

A pesar de la pobreza conceptual y filosófica que lo sostiene, el nacionalismo extremo resulta motivador porque descansa en instintos y atavismos enraizados en la naturaleza humana: "la propensión natural de la especie es la horda, no el individuo, la servidumbre y no la rebeldía, la superstición y la magia y no la averiguación inteligente de los fenómenos, la pasión y el instinto en vez de la racionalidad" (Vargas Llosa 1993). "La seguridad que proporciona la conciencia de pertenecer a un grupo homogéneo, el odio o el temor a lo que es distinto o extraño, la satisfacción narcisista de percibir el universo a través de lo que uno es o pretende ser y la necesidad de autoafirmación frente a los demás laten en el núcleo oscuro y oculto de los fervores nacionalistas" (Fragmento de Cuestión de fondo de Vidal-Quadras citado por Vargas Llosa 1993). Para tomar sólo un ejemplo de esta peligrosa tendencia visible en numerosos países, desarrollados y subdesarrollados, baste hacer alusión al caso de las milicias ultraderechistas norteamericanas implicadas en el atentado llevado a cabo en Oklahoma y extendidas por todo Estados Unidos. Tales grupos tienen en común su desprecio por el otro (el no WASP), su racismo, su mesianismo y su 
temor por un nuevo orden mundial de tolerancia y seguridad colectiva al que ven como "un complot de las Naciones Unidas contra la soberanía norteamericana". Los fascistas norteamericanos, como los neonazis europeos opuestos a la integración del viejo mundo, son partidiarios del mayor egoísmo anticooperativo, se niegan a pagar impuestos, luchan contra el gobierno federal y están en contra de las restricciones a las ventas de armas, buscando tanto a nivel nacional como internacional una sociedad anárquica y violenta en la que reine el más fuerte y en la que los rifles hagan valer la "supremacía blanca". Hablan también de religión y de identidad cristiana (en esto rozan, como se verá enseguida, con el fundamentalismo), pero sus actos se revelan profundamente inmorales, cualquiera sea el criterio religioso o moral no metafísico con el que se los juzgue. Todo esto ha llevado a un gran número de internacionalistas y figuras políticas mundiales, entre ellas el Secretario General de las Naciones Unidas Boutros Ghali, a señalar al nacionalismo extremo como al factor de mayor riesgo para la seguridad colectiva en la posguerra fría.

3) El fundamentalismo. Cuando el conjunto de creencias "incontrovertibles" es de naturaleza religioso-política, es válido calificar al dogmatismo como fundamentalismo. Como señala Sosa (1994), el fundamentalismo recurre siempre a un sustento o apelación trascendente de donde se extrae y en donde se sostiene el carácter fundamental, esencial, intergiversable de la doctrina y, por ende, la justificación de la coerción y la coacción para quienes no la acepten. El dogma del fundamentalista no sólo es indiscutible sino por sobre todo sagrado, lo que ayuda a entender el fanatismo de sus seguidores. Así, la división que el fundamentalista hace de la humanidad no es entre "respetuosos" y "transgresores" o entre "nacionalistas" y "extranjerizantes" sino entre fieles y extraños o infieles, a los que se condena por herejes. Cabe agregar que los pueblos que no han separado el campo religioso del político, aquéllos cuya religión es un componente esencial de su historia y nacionalidad, tienen tendencia a constituirse en estados nacionalistas extremos, fundamentalistas o ambas cosas a la vez.

Se tiene que los tres factores de riesgo de la posguerra fría analizados hasta aquí tienen como base el tipo de acción irracional a la que denominé dogmatismo, distinguiéndose un factor de otro según si este tipo de acción se ejecuta en referencia a creencias políticas, culturales o religiosas. En ese sentido, puede interpretarse que si bien vale esperar, como señala Huntington (1993), que los próximos conflictos sean más culturales que económicos o ideológicos, estos no deberían necesariamente tener por protagonistas a las "civilizaciones" ni por escenario a las líneas de falla entre esas civilizaciones. Me parece más natural entrever conflictos entre dogmáticos y no dogmáticos, entre premodernos y modernos no radicalizados, entre premodernos entre sí, entre modernos no radicalizados y radicalizados, entre marginados e integrados a los beneficios de la modernidad, tanto en el interior de una misma civilización como entre civilizaciones distintas, aunque en este último caso no de manera homogénea sino cruzada, por ejemplo entre dogmáticos de una civilización y modernos no radicalizados de otra o entre premodernos de dos civilizaciones distintas. Se trataría de luchas entre sociedades "cerradas" y "abiertas", según la famosa distinción establecida por Popper (1944), o bien entre distintas clases de sociedades cerradas. Afortunadamente, como afirma Vargas Llosa (1994), ni la religión ni la nacionalidad ni la cultura, son hoy los alambrados infranqueables dentro de los cuales vivía confinado el hombre primitivo, sino que en buena parte del mundo constituyen opciones que el individuo puede elegir libremente. El "espíritu de la tribu" del que también hablaba Popper en referencia al nacionalismo extremo, el integrismo religioso y el totalitarismo, ha sufrido serios reveses que han elevado el papel de la racionalidad y de la elección individual ofreciendo oportunidades para la concreción de una sociedad mundial internacionalizada, pluricultural, democrática, justa, segura y en paz. Sin embargo, se trata sólo de un retroceso de las distintas formas de dogmatismo que, lejos de ser derrotadas, continúan como factores de peligro para la sociedad internacional de la posguerra fría. Tal retroceso podrá ser sólo circunstancial o definitivo, hecho que dependerá de la manera en que la humanidad sepa aprovechar las oportunidades de cooperación del actual momento de distensión mundial.

Paso ahora a enumerar otros factores de peligro. 
4) El "mercantilismo salvaje": la indiferencia de los países desarrollados por los problemas derivados del subdesarrollo que afectan a una gran proporción de la población mundial tiende a poner en peligro la estabilidad de los propios países subdesarrollados y del planeta en general. Se impone, entonces, un genuino programa de desarrollo, con un fuerte financiamiento a través de los mecanismos sugeridos en 6.5, que evite el acentuamiento de la división del mundo entre ricos y pobres. La ayuda al desarrollo constituye no sólo un deber moral de toda la comunidad internacional, sino también un deber estratégico de los países industrializados.

5) La superpoblación. Se estima que, a menos que se haga algo al respecto, la población llegará a 9.000 millones en el 2.050. Un aumento descontrolado de la cantidad de habitantes atentaría contra el desarrollo social y económico planetario y agravaría los peligros de la modernidad planteados por Giddens: el colapso de los mecanismos de crecimiento económico, el desastre ecológico, el totalitarismo y la guerra a gran escala. Puede decirse que la superpoblación, ligada a la pobreza y el desconocimiento, constituye un problema de características premodernas, al que se trata de poner fin a través de la mundialización coordinada de modernos métodos de anticoncepción. Sin embargo, dichos intentos tienen como principal obstáculo la oposición de distintos dogmatismos religiosos contrarios a todo control de la natalidad, tal como quedó demostrado el la Conferencia de las Naciones Unidas sobre Población y Desarrollo llevada a cabo en El Cairo en 1994.

6) La persistencia en el uso de la fuerza. Se habla frecuente e imprecisamente de la irracionalidad de la guerra. Sin embargo, las naciones recurren a la fuerza en defensa de sus "intereses vitales", para reforzar su seguridad extendiendo o preservando el poder, el control y la influencia sobre su entorno. En consecuencia, como se ha señalado en toda la segunda parte, dentro de un marco de anarquía internacional la guerra ha resultado estratégicamente racional y, en casos como la respuesta a una agresión injustificada, hasta moralmente racional. La irracionalidad de la guerra surge de la comparación entre un mundo en el que ésta es admitida, tolerada y por lo tanto necesaria, con otro mundo posible en el que la cooperación permitiría el paso a la paz y al respeto del derecho internacional. En estas páginas he desarrollado un modelo de realismo utópico que incluye las bases de un enfoque que he denominado realismo idealista, favorable a la constitución de un auténtico mecanismo internacional de seguridad colectiva que elimine la incertidumbre y permita el paso a la cooperación o al menos a la no agresión. Para que ese paso sea posible, debe generarse una toma de conciencia, tanto a nivel de los estados como de los habitantes del planeta, acerca de los beneficios de la seguridad colectiva. Si ayudando a que esto ocurra, mi trabajo contribuye al logro de la paz, la cooperación y el respeto por los derechos del hombre, a cincuenta años de la creación de las Naciones Unidas y a doscientos de la publicación de La paz perpetua de Kant, se habrá cumplido la mayor de mis aspiraciones. 


\section{Resumen de conclusiones de la quinta parte}

1) La explicación acerca de los motivos por los que, habiéndose negado hasta ahora, las potencias habrían de avenirse a dejar de lado el ser conflictivo del balance de poderes para pasar al deber ser cooperativo de la seguridad colectiva debe buscarse en las características propias de la posmodernidad en general y de la posguerra fría en particular.

2) Del análisis de la modernidad, entendida como consecuencia de la modernidad, se desprenden los siguientes elementos:

a) Cuatro dimensiones fundamentales de la modernidad (posmodernidad):

I) El capitalismo.

II) El industrialismo.

III) El estado nacional.

IV) El poder militar.

b) Dos características esenciales, la reflexividad (institucionalización de la duda frente al dogma) y la mundialización de las dimensiones fundamentales según la forma siguiente:

I) Economía capitalista mundial.

II) Industrialismo mundial.

III) Sistema de estados nacionales.

IV) Orden militar mundial.

3) La anterior descripción permite entrever distintas tendencias posibles en relación a las cuatro dimensiones fundamentales:

a) Tendencias positivas:

I) Redistribución global de la riqueza entre países y regiones.

II) Humanización de la tecnología.

III) Orden político global más coordinado.

IV) Trascendencia de la guerra y desmilitarización.

b) Tendencias negativas:

I) El colapso de los mecanismos de crecimiento económico.

II) La desintegración o desastre ecológico.

III) El crecimiento del poder totalitario.

IV) El conflicto nuclear o la guerra a gran escala.

4) La posguerra fría ofrece oportunidades para la realización de las tendencias positivas de la posmodernidad pero también incluye una serie de factores de peligro que podrían llevar a la concreción de las tendencias negativas.

a) Oportunidades ofrecidas por la posguerra fría:

a1) Difusión de la democracia, mayor compromiso con la argumentación discursiva y reciprocidad legal y moral.

a2) Fin del conflicto ideológico Este-Oeste y paso de un sistema internacional bipolar heterogéneo a uno multipolar homogéneo. 
a3) Proliferación de situaciones de juego más cooperativas (dilema del prisionero, juego de armonía).

a4) Mercurio tiende a reemplazar a Marte.

a5) Manifestación del importante rol de las instituciones internacionales.

a6) Un auténtico mecanismo de seguridad colectiva aparece no sólo como moralmente preferible sino también como estratégicamente más beneficioso que el balance de poderes.

b) Factores de peligro en la posguerra fría:

b1) El dogmatismo ideológico.

b2) El nacionalismo extremo.

b3) El fundamentalismo.

b4) El "mercantilismo salvaje".

b5) La superpoblación.

b6) La persistencia en el uso de la fuerza.

5) La modernidad (posmodernidad) es un fenómeno de doble filo que ofrece oportunidades y riesgos. En ese sentido, la manera de minimizar los peligros y maximizar las oportunidades es a través de la creación de modelos de "realismo utópico", es decir, de análisis que orienten sobre las positivas oportunidades futuras y alerten acerca de los peligros, de manera que su conocimiento impacte en la sociedad mundial y la haga reflexionar sobre la manera como se construye a sí misma. En ese sentido, el enfoque realista idealista que se ha tratado de construir en este trabajo constituye una forma de realismo utópico, en tanto ofrece, a partir de consideraciones estratégicas pero sin renunciar a la ética o al derecho, un "modelo de sociedad internacional buena" que procura brindar elementos para la superación de la peligrosa incertidumbre subsistente en la posguerra fría. 


\title{
Silogismo práctico y elección racional: una formalización completa del modelo interpretativo de la acción y su racionalidad
}

\begin{abstract}
a) Introducción.
Como se advirtió oportunamente, esta sección constituye un complemento en el que se pretende llevar a cabo, tomando como fuente de inspiración al análisis aristotélico del silogismo práctico, una formalización más completa del modelo interpretativo de la acción individual y su racionalidad desarrollado en el capítulo 2. En ese sentido, no será mi intención, en primera instancia, dar cuenta de (ni polemizar con) los numerosos intérpretes y estudiosos que, como Allan (1955), Anscombe (1957), Kenny (1963), von Wright (1963) y (1971) o como Guariglia (1992) y (1993), se han ocupado del tema del silogismo práctico, para lo cual carezco de tiempo y espacio, sino que intentaré elaborar una perspectiva distinta $\mathrm{y}$, a mi entender, abarcadora de las referidas interpretaciones.
\end{abstract}

Para terminar, se enumerarán las conexiones del modelo con otras teorías y disciplinas.

\section{b) El silogismo práctico aristotélico.}

El genio de Aristóteles no se limitó a sentar las bases de la mayoría de las actuales disciplinas científicas, sino que también fue el primero en considerar el estudio de la acción desde el punto de vista del agente que elige racionalmente entre distintas vías posibles, en una situación dada. En efecto, Aristóteles fue el que propuso por primera vez un análisis del razonamiento que conduce a la acción, el silogismo práctico. Es en De motu animalium VII, 701 a 707, donde se trata de establecer la causa común de los movimientos de los animales (incluido el hombre), el texto en el que Aristóteles presenta, de manera más completa, las pautas de tal silogismo. Allí dice lo siguiente: "Parece ocurrir algo semejante a lo que ocurre cuando pensamos y razonamos sobre los objetos invariables; con la diferencia de que aquí el fin es una especulación -en efecto, cuando se piensa las dos premisas, se piensa inmediatamente y se infiere la conclusión-, allá, en cambio, a partir de las dos premisas la conclusión que se infiere se convierte en la acción, como por ejemplo cuando uno piensa que todo hombre debe caminar y que uno es un hombre, inmediatamente camina, o si piensa que en una determinada situación ningún hombre debe caminar, y que uno es un hombre, inmediatamente permanece en reposo; y en ambos casos realiza la acción, a menos que algo lo impida o lo fuerce; otro ejemplo: debo producir un bien; una casa es un bien, inmediatamente produzco la casa (...); que la acción es la conclusión resulta evidente; las premisas que conducen a la acción son de dos especies, por medio de un bien y por medio de lo que es posible" (la cita está tomada de Guariglia 1993).

Se tiene que, mientras que en el silogismo teórico (silogismo en Bárbara) se llega a una conclusión (que es una proposición universal afirmativa), en el práctico se infiere una acción (la conclusión es el enunciado de una acción).

Por lo tanto se puede pasar, a partir de los ejemplos presentes en la cita y de otros tomados de la Etica Nicomaquea, a efectuar un primer análisis de la forma lógica del silogismo aristotélico.

I) Todo hombre (en una situación 1) debe caminar.

Yo soy un hombre (en una situación 1).

Camino. 
II) Ningún hombre (en una situación 2) debe caminar.

Yo soy un hombre (en una situación 2).

No camino.

III) Todo lo dulce (en una situación 3) debe gustarse.

Esto es dulce (en una situación 3).

Lo como.

IV) Todo lo dulce (en una situación 4) no debe gustarse.

Esto es dulce (en una situación 4).

No lo como.

La interpretación más aceptada, recogida por Guariglia (1993), sostiene que:

1) La acción es para Aristóteles una forma de racionalidad que concluye en la actividad misma, es decir, Aristóteles propone una estructura racional de la acción.

2) La conjunción de las dos premisas hace necesaria la conclusión.

3) En todos los ejemplos, cada silogismo tiene dos premisas de distinto tipo:

1- Una premisa mayor, universal, "por medio de un bien" según Aristóteles, que señala una acción o el producto de una acción, que es un bien para todo individuo de una cierta clase.

2- Una premisa menor, particular, "por medio de lo que es posible" según Aristóteles, que establece las posibilidades que están al alcance del agente para poder realizar el fin propuesto por la premisa mayor.

Coincido en general con estas apreciaciones, aunque tengo algunos reparos con la interpretación que Guariglia (1992) y (1993) hace a partir de ellas. Guariglia sostiene la coincidencia en términos generales del silogismo práctico con el proceso de deliberación presentado por Aristóteles. En ese sentido, las premisas de lo posible constituirían un ejemplo de lo que Aristóteles denomina "tà pròs ta téle" (lo que está en relación a los fines y conduce a ellos), sobre lo que versa la deliberación. Guariglia toma la argumentación de Wiggins de que no se debe entender "tà pròs ta téle" de un modo muy restringido, como los medios distintos del fin, sino como componentes que ya son parte del fin y están a nuestro alcance. No obstante, analizando el esquema de su interpretación, parece entenderse que la premisa menor establece los medios que permiten realizar el fin, que identifica con la acción enunciada en la premisa mayor.

Creo yo, sin embargo, que resulta más correcto analizar a la acción como medio que permite al agente adecuarse a una situación dada, realizar sus fines, que en general van más allá de la acción misma. Empezaré mi "versión libre" del silogismo aristotélico haciendo notar que el "debe" de la premisa mayor no expresa una obligación moral, sino una necesidad, como cuando alguien dice: "estoy agotado, debo descansar" o "estoy hambriento, debo comer". Guariglia suscribe ésto, pero agrega que "la acción cuya realización es postulada como una necesidad por la premisa mayor, es presentada por ésta justamente sub specie boni, bajo el aspecto del bien que constituye el fin de la acción en la situación (dada)" (Guariglia 1993). Esta afirmación no parece clara, ya que si el bien es el fin de la acción, la acción es el medio para lograr ese bien, y por otro lado, si la acción es el bien, se tendría la proposición "la acción es el fin de la acción" que no parece aplicable a los ejemplos (a pesar de que Aristóteles distingue entre "praxis" y "poiésis", el silogismo práctico no se refiere sólo 
a la segunda de estas dimensiones, es decir, a las acciones como "correr" cuyo objetivo es la realización de la acción misma). Mi posición es que, en el caso de dichos ejemplos, tanto descansar como comer son bienes en cuanto resultan acciones adecuadas (buenas, correctas, apropiadas) en las situaciones en que son ejecutadas, sin embargo, se trata también y especialmente de medios (de buenos medios) en cuanto tienden a satisfacer ciertos fines precisos, la desaparición del cansancio y del hambre.

Retomando brevemente el tema de la deliberación, se tiene que ésta consiste en el establecimiento de juicios de valor sobre la realidad. Para ello, quien formula la premisa mayor debe hacer un balance entre los fines (objetivos que se propone) y los medios a su disposición. Para Aristóteles, lo bueno (adecuado, correcto, apropiado), tanto en sentido estratégico como moral, en una situación dada, es establecido por la recta razón, que es la razón del hombre prudente. En ese sentido, la razón del hombre prudente actúa como criterio objetivo de referencia, tanto en el terreno estratégico como en el moral (por ahora me referiré a su implicancia en el terreno estratégico, al que pertenecen los ejemplos citados).

El hombre prudente tiene la experiencia que le permite armonizar los medios y los fines de cada situación, llevando a cabo la deliberación que concluye con el establecimiento de la premisa mayor. Aquí hay que marcar la distinción entre los medios materiales necesarios para ejecutar las acciones, y las acciones mismas como distintos medios posibles para el logro de los fines. Cuando Aristóteles afirma que "se delibera sobre los medios y no sobre los fines" se refiere a las acciones, teniendo en cuenta a su vez que es imposible deliberar sobre la posibilidad de efectuar una acción si no se cuenta con los medios materiales necesarios para llevarla a cabo. Los fines (al igual que las preferencias de la teoría de la elección racional) vienen dados, sobre ellos no se delibera. Puede afirmarse, por lo tanto, que la deliberación no es equivalente al silogismo práctico, sino que se trata de dos cosas distintas. Mientras la deliberación del phrónimos concluye en la elaboración "objetiva" de un juicio de valor estratégico relativo a cierta situación (la subjetividad del hombre prudente es tomada como criterio normativo objetivo de racionalidad), en el silogismo práctico el agente examina de manera subjetiva si su situación se corresponde con la tenida en cuenta en el juicio de valor. En el silogismo práctico el agente examina la premisa menor "tà pròs ta téle" que, como sugiere más naturalmente la traducción de la frase griega, se refiere a los fines y no a los medios, intentando corroborar si su situación (que incluye sus propósitos) entra en el caso general expuesto en la premisa mayor, para entonces deducir y efectuar la acción que logre los referidos propósitos.

Volvamos ahora al análisis del "debe" de la premisa mayor. Tomando a Kant, puede decirse que expresiones como "estoy hambriento, debo comer" constituyen imperativos hipotéticos. En su análisis del concepto del deber, Kant distingue dos tipos de proposiciones de deber (imperativos), las categóricas, en las que el deber está no condicionado (usado moralmente), y las hipotéticas. Los imperativos hipotéticos no son morales, sino que establecen una relación medios a fines, una relación causal de la forma "si quieres ganar dinero, entonces debes matar a esa persona". En ellos, la acción expresada en el consecuente del condicional, es un medio para lograr el fin propuesto en el antecedente. Hay que aclarar que la forma condicional de la oración no alcanza para distinguir los dos tipos de imperativos, ya que resulta posible formular imperativos categóricos de manera condicional e hipotéticos de manera incondicional. La diferencia se presenta en la "modalidad" del imperativo, es decir si la acción aparece como buena en sí o como buena para otra cosa. Kant (1785) señala que los imperativos hipotéticos (a los que denomina de la habilidad o de la sagacidad), "representan la necesidad práctica de una acción posible, como medio de conseguir otra cosa que se quiere (o que es posible que se quiera)", y también que "si la acción es buena sólo como medio para alguna otra cosa, entonces es el imperativo hipotético". El neokantiano Nelson llama a estos imperativos "imperativos de la prudencia", lo que se ajusta a lo que se dijo acerca de que la deliberación se relacionaba con la adecuación medios a fines que efectua el hombre prudente al constituir la premisa mayor.

Vistas estas consideraciones y en poder de los elementos analizados puede llevarse a cabo una reformulación de las premisas mayores de los ejemplos de la siguiente manera: 
I) Si se es un individuo (en una situación 1), entonces es bueno (adecuado, correcto, apropiado) caminar.

II) Si se es un individuo (en una situación 2), entonces es bueno no caminar.

III) Si se es un individuo (en una situación 3), entonces es bueno gustar lo dulce.

IV) Si se es un individuo (en una situación 4), entonces es bueno no gustar lo dulce.

¿Cuáles son los cambios que se han introducido?

1) En primer lugar se ha cambiado la formulación universal de la premisa mayor de los ejemplos, por la forma condicional lógicamente equivalente.

2) En atención a la reflexión sobre el carácter instrumental del "debe" de la premisa mayor, se ha reemplazado "debe" por "ser bueno" (en el sentido visto de correcto, adecuado o apropiado a la situación del antecedente del condicional). Es decir, se ha hecho un paso lícito del "debe" instrumental al "bien" instrumental.

3) Por último, se ha introducido la consideración de la situación contemplada subjetivamente por el individuo, que será fundamental en mi versión del silogismo. Cuando Aristóteles dice que todos los hombres deben caminar, no se refiere a todos los hombres en general, sino a aquéllos que se encuentran en una situación tal que pueden hacerlo y para quienes caminar constituirá algo positivo. En ese caso, "todos" no incluye ni a los enfermos, ni a los paralíticos, ni a los que se encuentran al borde de un precipicio, así como tampoco incluirá a los que no les gustan los dulces entre los alcanzados por la premisa mayor acerca de que lo dulce debe gustarse. Será a través de la premisa menor que el agente se reconocerá dentro del "todos", es decir en la situación planteada en el antecedente de la premisa mayor.

Volvamos a considerar mi reconstrucción sui géneris del silogismo práctico aristotélico. Había llegado ya a una transformación de las premisas mayores de los ejemplos de Aristóteles. En el caso del ejemplo I, dicha premisa había pasado de "Todos los hombres deben caminar" a "Si se es un individuo (en una dada situación), entonces es bueno (adecuado, correcto, apropiado) caminar".

Paso ahora, en vista de todo lo analizado en el capítulo 2 en la construcción de mi modelo interpretativo, a efectuar una nueva reformulación de la premisa mayor del primero de los referidos ejemplos:

\section{CA}

I) (x) (Ss (C.P.M.A) x --> A1 x . ACSs x)

$\mathrm{x}=$ variable individual.

$\mathrm{Ss}=$ predicado "estar en una situación subjetiva Ss, definida por las variables C, P, M y A".

$\mathrm{CA}=$ criterio aristotélico de racionalidad (recta razón del hombre prudente).

$\mathrm{A} 1=$ predicado "caminar". A1 pertenece al conjunto A.

$\mathrm{ACS}=$ predicado "actuar de manera correcta en la situación Ss".

El condicional puede leerse de la siguiente forma: "Para todo $\mathrm{x}$, si $\mathrm{x}$ es un individuo en una situación Ss, definida por un conjunto de creencias $\mathrm{C}$, un conjunto ordenado de preferencias $\mathrm{P}$, un conjunto de medios materiales $\mathrm{M}$ y por un conjunto $\mathrm{A}$ de acciones posibles, entonces $\mathrm{x}$ camina $\mathrm{y} \mathrm{x}$ actúa de manera correcta en esa situación Ss".

Nótese que aquí se ha introducido una variante respecto de la forma de la hipótesis vista en el capítulo 2, ya que en el consecuente se explicita que la acción A1 es aquélla que el criterio utilizado lleva a elegir como la adecuada. Por el momento, esta alteración que complica la forma lógica de la hipótesis puede parecer redundante, sin embargo, más adelante se verán los motivos que llevan a adoptarla. 
Antes de comenzar la formalización completa del modelo resultará interesante corroborar el mantenimiento del carácter condicional de la elección racional en situaciones de juego como la del dilema del prisionero definido en la tercera parte de acuerdo al siguiente diagrama de árbol:

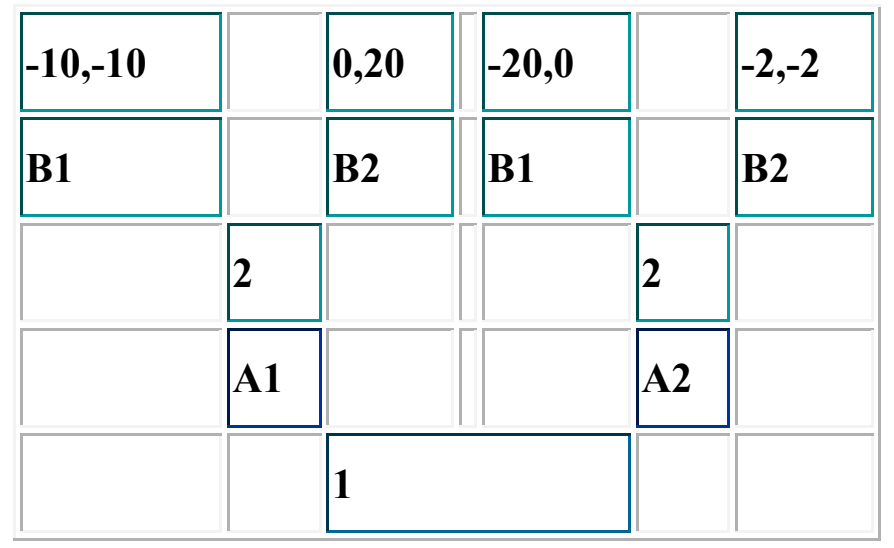

$\mathrm{A} 1=\mathrm{B} 1=$ confesar, $\mathrm{A} 2=\mathrm{B} 2=$ no confesar.

En este caso la situación $\mathrm{S}$ está definida en la caracterización del dilema siendo $\mathrm{C}$ el conjunto de creencias del prisionero 1, que incluye la información acerca de los datos del problema, por ejemplo que el juego no es cooperativo (no puede pactar con el otro prisionero). Además:

$\mathrm{P}=\{0,-2,-10,-20\}$

$\mathrm{M}=\{$ conjunto de medios materiales disponibles en la prisión $\}$ Tales medios no le alcanzan, por ejemplo, para escapar, por lo que tal acción ni siquiera es considerada en el conjunto A.

$\mathrm{A}=\{\mathrm{A} 1$ (confesar), A2 (no confesar) $\}$

Luego de una deliberación acorde con las condiciones y mecanismos de la teoría de la elección racional, el prisionero 1 elige A1 como la acción que resultará más adecuada a su situación. En este caso, A1 resulta también moralmente correcta (en oposición a A2, que supone una mentira), pero sólo de manera casual, ya que el prisionero 1 no se plantea ningún criterio moral. $\mathrm{Si}$, por el contrario, el criterio de la elección racional lo hubiese llevado a no confesar, ésa sería la acción estratégica adecuada que posiblemente hubiera tenido en cuenta, a pesar de su incorrección moral. La hipótesis de la acción deducida tiene entonces la siguiente forma:

ER

Ss (C.P.M.A) p1 ----> A1 p1 . AECSs p1.

Nótese que la expresión del juego en la forma del diagrama de árbol nos permite apreciar el carácter condicional de toda la especulación estratégica. Pongámonos en el lugar del prisionero 2. Si el prisionero 1 elige A1, el prisionero 2 se encuentra en el punto 2 de la izquierda del diagrama ante dos opciones:

1- Si quiero recibir 10 años de prisión, confieso.

2- Si quiero recibir 20 años de prisión, no confieso.

Se tiene que, si el prisionero 2 es estratégicamente racional (busca maximizar su utilidad), elegirá la hipótesis de acción 1 , cuyo resultado es $(-10,-10)$.

En cambio, si el prisionero 1 elige A2, las opciones del prisionero 2 serán las siguientes:

3- Si no quiero recibir condena, confieso.

4- Si quiero dos años de prisión, no confieso.

Es obvio que si el prisionero 2 es racional, elegirá en este caso la hipótesis 3. Sin embargo, quien debe tomar primero la decisión es el prisionero 1, quien considera el problema de manera estratégica, es decir tomando al prisionero 2 como a un actor racional. De ahí que en la 
consideración de su propia situación entren las posibles elecciones del prisionero 2. El prisionero 1 se pone, como se hizo antes, en el lugar del prisionero 2 y deduce las acciones que el mismo elegiría puesto en ese lugar. Dichas conclusiones pasan a formar su conjunto de creencias $\mathrm{C}$ en la elección de su acción. Como ahora sabe que ubicado en el 2 de la izquierda, el prisionero 2 elegirá B1 (-10,10) y que en el 2 de la derecha también elegirá B1 $(-20,0)$, las opciones que se le presentan al prisionero 1 son las siguientes:

5- Si quiero recibir 10 años de prisión, confieso.

6- Si quiero recibir 20 años de prisión, no confieso.

Por lo tanto, el prisionero 1 elige racionalmente la hipótesis 5, que es seguida por la elección de la hipótesis 1 de parte del prisionero 2, siendo el resultado del juego no cooperativo el punto de equilibrio no óptimo $(-10,-10)$. Se corrobora así, el carácter condicional de la acción y de la elección racionales.

Una vez concluida la anterior digresión, hay que decir que tanto Guariglia (1993) como Kenny (1963) sostienen que es inútil pretender construir auténticos silogismos teóricos a partir de los ejemplos aristotélicos, argumentando que tales razonamientos, construidos por medio de premisas hipotéticas, estarían más próximos al cálculo proposicional que a la silogística. No encuentro motivo a esta objeción. La lógica constituye un medio de esclarecimiento intelectual, por lo que renunciar a ella implica dejar de lado un valioso instrumento. Por otra parte, no se trata de construir silogismos teóricos sino precisamente de investigar la forma del silogismo práctico, mediante la cual intentar aclarar la estructura de los ejemplos. Tenida en cuenta esta aclaración, y en base a la formalización efectuada al analizar la premisa mayor, puedo arriesgarme a completar la forma lógica del primer ejemplo:

CA

(x) (Sc (C.P.M.A) x ----> A1 x . ACSc x)

Ss (C.P.M.A) a $=$ Sc a

A1 a. ACSs a

La premisa mayor universal, indica que el resultado de la deliberación de un agente racional para una situación considerada Sc (definida por los parámetros C, P, M y A) es la acción A1 (caminar). En la premisa menor, en cambio, el agente reconoce la coincidencia de su situación subjetiva Ss con la situación Sc planteada en la hipótesis general, es decir equipara sus parámetros C, P, M y A con los de la situación Sc presente en la creencia. El resultado lógico, mediante la aplicación del Modus Ponems, es la deducción de la acción A1 como la acción más apropiada a la situación $\mathrm{Sc}=\mathrm{Ss}$. Recuérdese que el Modus Ponems es una regla lógica, es decir una manera correcta de razonar de la forma: $\mathrm{p}->\mathrm{q}$

\section{$\mathrm{p}$}

\section{q}

Como se ejemplificó en el capítulo 2, el agente puede tener asimilada la hipótesis que dice que aquellos días de sol en los que se goce de tiempo y salud y se disponga de espacio, es "bueno" (correcto, adecuado, apropiado) para todo hombre caminar, y además puede estar esperando un día en el que se cumplan dichas condiciones. En el acto del silogismo, el agente se reconoce como un individuo en esas circunstancias, advirtiendo que cierto día particular es un día soleado, que tiene tiempo, que no posee ninguna enfermedad que le impida caminar, y que, por ejemplo, no se encuentra frente a un precipicio. Una vez hecho esto, deduce (no delibera, dado que ya hubo una deliberación previa de la creencia) que es "bueno" salir a caminar ese día. El esquema es análogo al del individuo particular que ha tomado como máxima personal el salir a caminar cada vez que se cumplen las condiciones $\mathrm{C}, \mathrm{P}, \mathrm{M}$ y A: 
Sc (C.P.M.A) a ----> A1 a . AECSc a

Ss (C.P.M.A) = Sc (C.P.M.A)

A1 a . AECSs a

$\mathrm{CE}=$ criterio estratégico de racionalidad.

$\mathrm{AECSs}=$ "actuar de manera estratégicamente correcta a Ss".

Se sostuvo en el capítulo 2 que, frente a una situación de incertidumbre, el individuo puede elegir una acción a partir de una deliberación directa o bien, en el caso de una situación familiar, deducirla a partir de una hipótesis de acción previamente deliberada. Los ejemplos aristotélicos, la teoría del silogismo práctico en general, se refieren a la segunda de tales formas de elección, la de la deducción de una acción a partir de una creencia aceptada de antemano como racional. Sin embargo, se verá ahora que una sofisticación de mi análisis lógico del silogismo práctico, la consideración del carácter hipotético- deductivo de la acción sostenido por mi modelo de la acción, permitirá llevar a cabo una formalización más completa de la interpretación que dicho modelo hace no sólo de la deducción, sino también de la deliberación.

En ese sentido, se afirmó también en el capítulo 2 que, tanto en el caso de la deliberación directa como en el de la deducción (referencia a una deliberación previa), una vez ejecutada la acción, ésta puede resultar adecuada o bien inadecuada a la situación real, objetiva del agente (So). Esta circunstancia puede formalizarse de la siguiente manera:

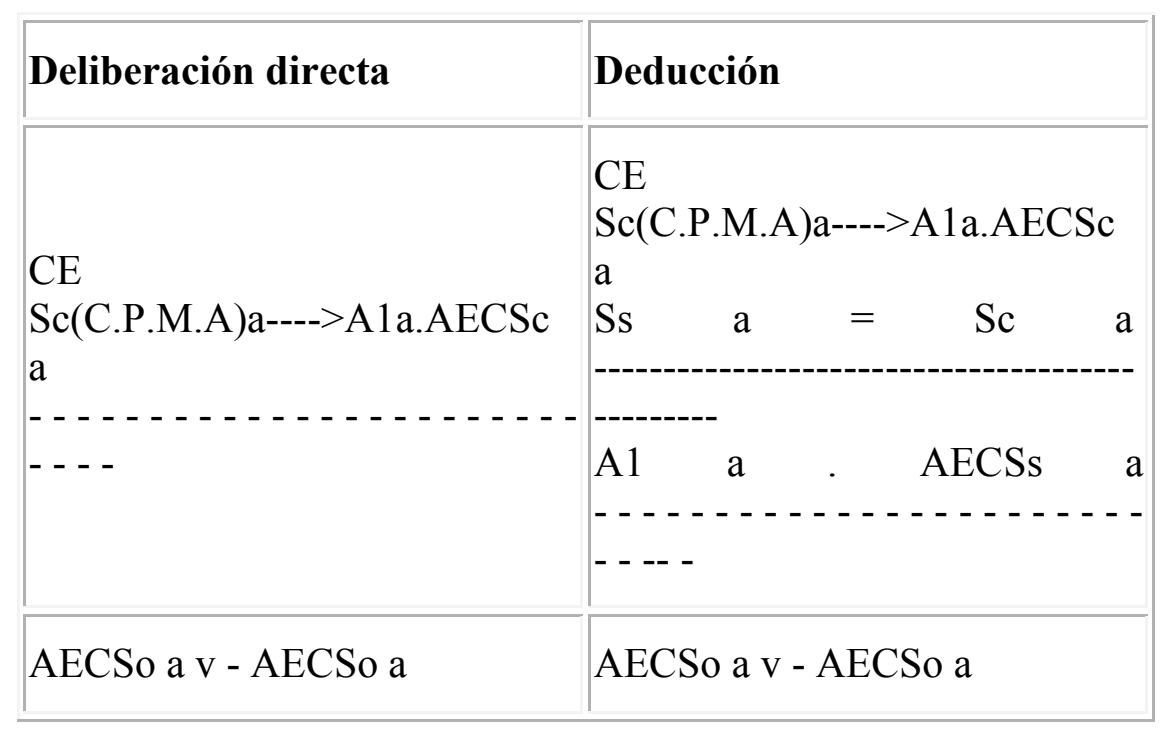

ACSo = "efectuar una acción estratégicamente correcta en So".

La línea de puntos marca la diferencia temporal entre el antes y el después de la ejecución de la acción elegida.

Retomando el ejemplo del té estudiado en la primera parte, supóngase que deseo tomar un té a mi gusto, es decir con tres cucharaditas de azúcar. Poseo todos los medios materiales necesarios excepto cucharitas. Como dispongo en cambio de cucharas grandes, apelo a una creencia de mi conjunto $\mathrm{C}$ que dice que el contenido una cuchara grande equivale al de tres chicas y que, en consecuencia, para tomar un "buen" té debo agregar una cucharada grande de azúcar. Los conjuntos que definían la situación eran los siguientes:

$\mathrm{C}=\{$ Creencias relevantes, incluida la de que una cuchara grande equivale a tres chicas $\}$

$\mathrm{P}=\{\mathrm{fu}(3)=4, \mathrm{fu}(2)=3, \mathrm{fu}(1)=2, \mathrm{fu}(0)=1, \mathrm{fu}(\mathrm{x}>3)=1\}$ 
$\mathrm{X}=$ número de cucharas chicas.

$\mathrm{M}=\{$ todos los medios necesarios excepto cucharas chicas $\}$

$A=\{$ agregar $x$ cantidad de cucharas grandes $\} 0<x<10$

Asimilando mi situación Ss con aquélla ya deliberada en la creencia referida, deduzco la acción:

$\mathrm{CE}$

Sc (C1.P.M.A) a ----> A1 a . AECSc a

$\begin{array}{llll}\text { Ss1 Sc } & \text { Sc } & \text { (C1.P.M.A) }\end{array}$

A1 a $\quad$ AECSs1 a

- AECSo a

A1 = "agregar una cucharada grande".

AECSs1 = "efectuar una acción estratégicamente correcta en

Ss $1 "$.

$\mathrm{C} 1=$ conjunto de creencias 1 .

Sin embargo, pruebo el té y lo encuentro amargo, es decir A1 no resulta adecuada (eso es lo que señala la cuarta premisa). Resulta entonces que la información completa que creía tener no era tal, ya que incluía una creencia equivocada. Nótese que desde el punto de vista subjetivo el razonamiento es correcto, pero desde el punto de vista objetivo de un observador informado es falaz. La falacia objetiva proviene de identificar Sc1 con Ss1 y a esta última con So, y de extender las conclusiones extraídas para Sc a Ss y a So, cuando en realidad Sc y So se contradicen.

Refuto entonces la premisa mayor y paso a tener una nueva descripción de la situación de la acción, pudiendo considerar ahora como más probable el estado de cosas en que tres cucharas chicas equivalen a una y media de las grandes. Tengo entonces una nueva Ss2 a partir de la cual delibero una nueva acción, distinta a la anterior:

$\mathrm{CE}$

Ss2 (C2.P.M.A) a $\quad-->\quad$ A2 a $\quad$ a 2 AESs2 a

- AECSo a

A2 = "agregar una cucharada grande y media" (en realidad sólo media más ya que ya se tiene una de la acción anterior).

$\mathrm{C} 2=$ conjunto de creencias 2 .

Nuevamente encuentro al té falto de azúcar (Ss2 y So se contradicen). La diferencia es que ahora la deficiente caracterización de la situación subjetiva, que provoca la elección de una acción inadecuada, no proviene de una asociación equivocada con una creencia sino de una mala atribución de probabilidades subjetivas. Mientras en el paso anterior la asociación equivocada afectaba a una deducción, en este paso queda afectada una deliberación. Por lo tanto, refuto otra vez la hipótesis de acción y vuelvo a asignar probabilidades subjetivas, dándole la mayor al estado de cosas según el cual tres cucharas chicas equivalen a dos grandes. De nuevo, tengo otra situación (Ss3) a partir de la cual delibero una acción diferente a las anteriores:

$\mathrm{CE}$ 


\section{AECSo a}

A3 = "agregar dos cucharadas grandes" (es decir media más).

$\mathrm{C} 3=$ conjunto de creencias 3 .

Esta vez el té está a mi gusto, la acción resulta adecuada y la hipótesis respectiva corroborada, por lo que la próxima vez que me falten cucharas chicas, ya sabré a qué "premisa mayor" recurrir.

El ejemplo anterior hace referencia a un caso paramétrico- instrumental, sin embargo, como se afirmó en el capítulo 2, el esquema sugerido es perfectamente asimilable a situaciones con implicancias estratégicas, morales o de ambas clases.

Respecto de una situación estratégica, tómese el ejemplo del prisionero que no conoce las funciones de utilidad del otro prisionero acusado y a quien, en tal situación de incertidumbre, le resulta equivalente confesar o no confesar. Supóngase que en esa situación subjetiva elige, de algún modo, no confesar y que tal acción resulta inadecuada a su situación objetiva (que es la descripta por el juego de información completa cuyo diagrama de árbol se analizó).

$\mathrm{CE}$

Ss 1

(C1.P.M.A)

A1

AECSo

a

- AECSo a

$\mathrm{C} 1=$ conjunto de creencias 1 .

$\mathrm{A}=\{\mathrm{A} 1$ (no confesar), A2 (confesar) $\}$

Supóngase que ahora el juez permite la apelación del prisionero, quien a diferencia de la primera vez y sin disponer aún de información completa, conoce que la consecuencia de su acción anterior fue la peor condena que le pudo caber.

ER

Ss2 (C2.P.M.A) ---> A2 a $\quad$ A2 AECSo a

AECSo a

$\mathrm{C} 2=$ conjunto de creencias 1 .

$\mathrm{A}=\{\mathrm{A} 1$ (no confesar), A2 (confesar) $\}$

Si el prisionero actúa racionalmente, elegirá esta vez confesar. Si insiste en no confesar, negándose a aprender del juego anterior, su acción volverá a ser incorrecta, pero ahora también dogmáticamente irracional.

Pasemos a la formalización de la que sería la elección de un agente moral puro, es decir de un agente que guiara su acción sólo por respeto a un criterio moral:

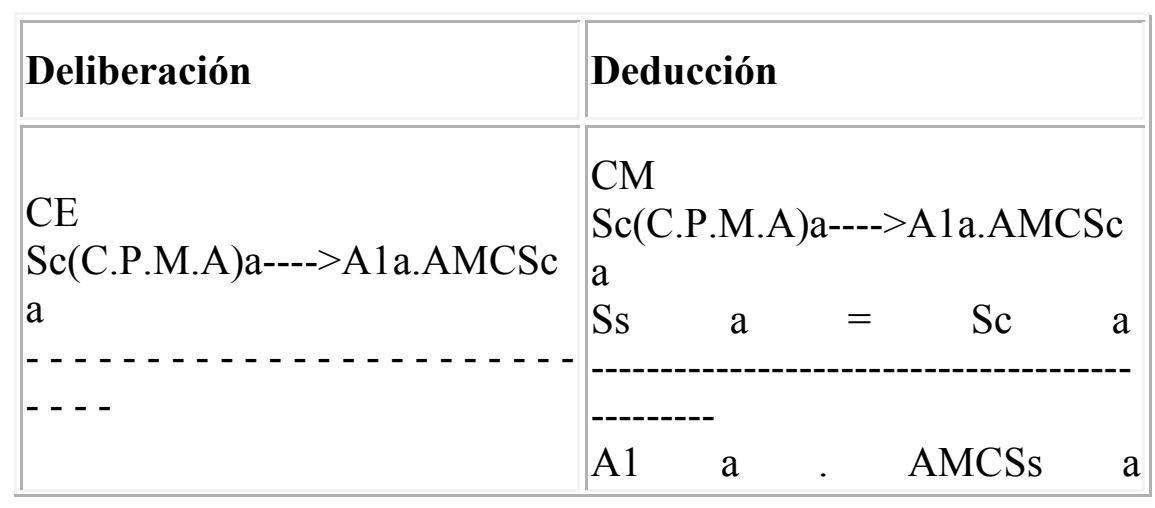




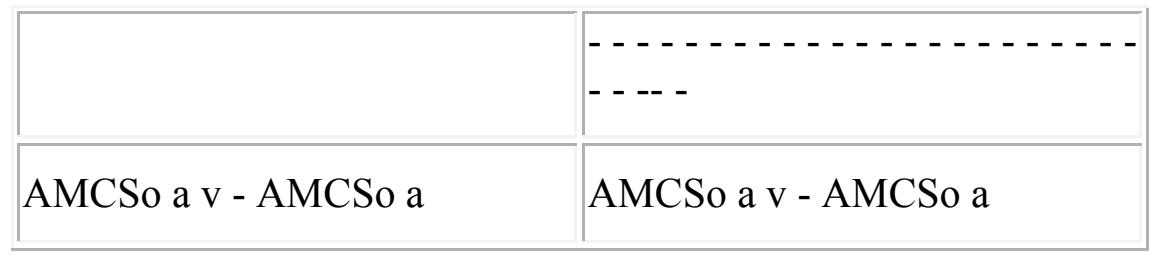

$\mathrm{AMCSc}=$ "efectuar una acción moralmente correcta en la situación $\mathrm{Sc} "$.

La aplicación de un criterio de racionalidad moral (CM) permite al agente deducir una acción A1 éticamente correcta en su situación objetiva, según dicho criterio. No obstante, y por las mismas razones expuestas para la acción estratégica, la acción puede resultar moralmente incorrecta en la situación objetiva So. La clasificación de las acciones morales de acuerdo a su grado de racionalidad también resulta análoga a la de las acciones estratégicas, si se reemplaza al agente estratégico por el agente moral. En cuanto al tipo I de incorrección, el de la acción irracional, la incorrección provendrá del incumplimiento de las pautas del criterio normativo moral tenido en cuenta.

De manera que considerando al agente tanto estratégica como moralmente racional se obtiene la forma lógica más compleja y acabada de mi modelo, que es la que sigue:

Deliberación:

$\mathrm{CE}+\mathrm{CM}$

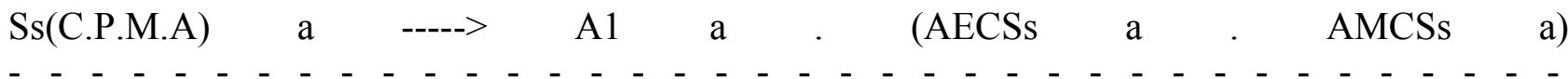

(AECSo a v - AECSo a) . (AMCSo a v - AMCSo a)

Deducción:

$\mathrm{CE}+\mathrm{CM}$

Sc(C.P.M.A) a -----> A1 a . (AECSc a . AMCSc a)

Ss a =

$\mathrm{Sc}$

a

A1 $\quad$ a $\quad$ AECSs a $\quad$ AMCSs a

(AECSo a v - AECSo a) . (AMCSo a v - AMCSo a)

La premisa post acción indica que, por las razones vistas en la tipificación de las acciones incorrectas, la acción bajo riesgo o incertidumbre de un agente estratégica y moralmente racional puede resultar incorrecta en los hechos, ya sea desde el punto de vista estratégico, desde el moral o desde ambos. Es decir, una vez efectuada la acción, existen cuatro resultados posibles.

1) AECSo a . AMCSo a. La acción resulta estratégica y moralmente correcta.

2) - AECSo a . AMCSo a. La acción resulta moralmente correcta pero estratégicamente incorrecta.

3) AECSo a . - AMCSo a. La acción resulta estratégicamente correcta pero moralmente incorrecta.

4) - AECSo a . - AMCSo a. La acción resulta estratégica y moralmente incorrecta.

A modo de ejemplo, supóngase ahora un dilema del prisionero bajo incertidumbre en el que la estrategia adecuada deducida por el prisionero es no confesar. El prisionero dispone también de un criterio moral (un mandamiento religioso por ejemplo) que le ordena, por encima de sus preferencias, no mentir, es decir confesar. Encuentra entonces que de los dos criterios se derivan acciones contradictorias, debiendo optar por una de ellas, por lo que será muy probable, dadas las 
características del juego, que opte por el estratégico y deje de lado el moral. Sin embargo, el juez puede modificar la situación del juego, sea reduciendo la pena establecida por la ley en caso de que confiese, permitiendo el diálogo entre los prisioneros, o dando a conocer parámetros desconocidos, induciendo así un cambio de preferencias que le haga conveniente (más útil) confesar, es decir actuar conforme a la ley y en consecuencia al criterio moral que la inspira (posiblemente el mismo que el prisionero había dejado de lado).

Para terminar esta sección, doy la forma lógica completa de mi modelo trasladado en el capítulo 4 a la interpretación de la acción de los estados y demás actores internacionales:

Deliberación:

$\operatorname{PTD}(\mathrm{CE}+\mathrm{DI})$

Ss(C.P.M.A) ai -----> A1 ai . (AECSs ai . AMCSs ai)

(AECSo ai v - AECSo ai) . (AMCSo ai v - AMCSo ai)

Deducción:

PTD (CE+DI)

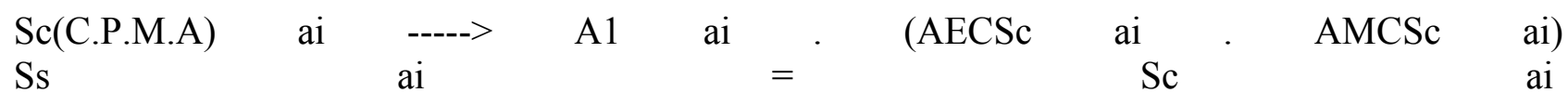

A1 ai $\quad$ AECSs ai a AMCSs a

(AECSo ai v - AECSo ai). (AMCSo ai v - AMCSo ai)

ai $=$ actor internacional (estado, organismo internacional, empresa

multinacional, individuo).

$\mathrm{Sc}=$ situación considerada por el actor internacional en el marco

de la sociedad internacional.

Ss = situación subjetiva del actor internacional en el marco de la

sociedad internacional.

So $=$ situación objetiva del actor internacional en el marco de la

sociedad internacional.

$\mathrm{C}=$ conjunto de creencias e informaciones manejadas por los

tomadores de decisiones.

$\mathrm{P}=$ conjunto de preferencias de los tomadores de decisiones.

$\mathrm{M}=$ conjunto de medios materiales disponibles por el estado

(fuerza militar, económica).

$\mathrm{A}=$ conjunto de acciones posibles del estado en virtud de los

medios disponibles.

$\mathrm{PTD}=$ proceso racional de toma de decisiones.

$\mathrm{ER}=$ criterio estratégico de racionalidad.

$\mathrm{DI}=$ criterio moral de racionalidad (respeto del derecho

internacional. 
$\mathrm{AECSc}=$ ser una acción estratégicamente correcta en la situación

considerada.

AADISc $=$ ser una acción adecuada al derecho internacional en la

situación considerada.

\section{c) Las conexiones teóricas del modelo.}

En el capítulo 2, al hacer una síntesis de los aportes de mi modelo a la interpretación de la acción y su racionalidad, se advirtió acerca de las dificultades para dar cuenta no sólo de todas las influencias y relaciones, sino en especial de las implicaciones y conexiones teóricas de mi modelo con otras perspectivas y disciplinas. En ese sentido, me limitaré a enumerar aquí los que a mi entender constituyen los puntos de contacto más relevantes, y sobre los que sería interesante continuar mi trabajo en el futuro. Tales conexiones son las siguientes:

1) Conexiones con el individualismo metodológico: todo mi análisis de la racionalidad, al igual que el de la teoría de la elección racional se encuentra de acuerdo con las suposiciones del llamado individualismo metodológico. Elster (1982) define al individualismo metodológico como "la doctrina de que todos los fenómenos sociales (su estructura y su cambio) sólo son en principio explicables en términos de individuos (sus propiedades, sus objetivos y sus creencias)". Esta doctrina, según Elster, no es incompatible con ninguno de los siguientes enunciados:

A) Los individuos tienen a menudo objetivos que afectan al bienestar de otros individuos.

B) Los individuos tienen a menudo creencias relativas a entidades supraindividuales que no son reductibles a creencias relativas a individuos.

C) Muchas de las propiedades de los individuos, como la de ser "poderosos", son irreductiblemente relacionales, de modo que una descripción exacta de un individuo puede exigir una referencia a otros individuos.

El individualismo metodológico puede ser analizado desde tres perspectivas. La primera perspectiva hace referencia a la contingencia de la acción. El agente elige su acción, que no está determinada y puede ser de otra manera. Es el agente quien dice qué es lo relevante y trata de dar cuenta de relaciones ocultas por detrás de lo que es. La segunda manera de entender al individualismo metodológico es a partir del sentido único del individuo. La tercera opción, entretanto, sería entender al individualismo metodológico como puente entre el problema del sentido y la causalidad (una vez comprendido el sentido subjetivo, intencional, podrían hallarse relaciones causales).

Esta triple perspectiva de análisis ayuda a aplicar el individualismo metodológico a distintos enfoques, como el de la sociología weberiana, compatible en líneas generales con mi enfoque de la acción.

Weber define una categoría nueva, la comprensión, base de su sociología, centrándola desde un principio en el individuo. La comprensión no es psicológica sino lógica (al respecto reconoce a Husserl en su intento de apartarse de la psicología). La comprensión no se refiere a la interpretación objetiva de la acción individual, sino a la reconstrucción del sentido subjetivo del agente. Al respecto, Weber se refiere al individuo como al único capaz de un comportamiento con sentido, en consecuencia, el individuo aislado y sus obras constituyen la unidad de su sociología comprensiva. La única manera de comprender la acción para Weber, es como acción individual o como un conjunto de acciones individuales. En ese sentido, la tarea de la sociología comprensiva es la de reducir las categorías colectivas para explicarlas en términos de individuos aislados. Weber (1922) señala, sin embargo, la utilidad de considerar al Estado como una persona, pero siempre teniendo en cuenta que su comprensión se basa en la comprensión de las acciones de los individuos que lo forman. 
Así, el individualismo metodológico resulta válido aún para la explicación del Estado burocrático: el burócrata, aunque inserto en la racionalidad medios-fines, nunca deja de estar afectado por la elección. Detrás del mecanismo burocrático está la elección de cada individuo, que ese mecanismo trata de disimular con la necesidad. La tarea de la sociología es entonces la de hacer una deconstrucción del mecanismo burocrático, que permita desnudar las elecciones que se esconden detrás de una necesidad inexistente. Esto es entendible por medio de la comprensión endopática, se comprende al agente cuando se comprende su situación subjetiva.

Todas estas observaciones, asimilables a mi modelo interpretativo de la acción, forman parte de las categorías desde las que he analizado tanto la concepción hobbesiana del Estado como la cooperación internacional.

2) Conexiones con la filosofía de la ciencia: la mayoría de estas conexiones ya han sido reflejadas en el capítulo 2, durante la elaboración de mi modelo. Sin embargo, en relación con el punto anterior, vale la pena marcar una diferencia importante entre el individualismo metodológico de Karl Popper y el de Weber. Popper, al igual que Weber, rechaza la idea de leyes históricas determinadas admitiendo, no obstante, la existencia de reglas o leyes sociales condicionales, causales en el sentido de las leyes físicas. Así, la tarea de la sociología en tanto ciencia es, desde esta perspectiva, la de elaborar hipótesis explicativas que faciliten al individuo lograr sus fines. No obstante, Popper se refiere sólo a la ciencia, deteniendo su análisis al enfrentar las preferencias arbitrarias del individuo. Weber, en cambio, si bien coincide con el planteo general de Popper, va más allá al pretender reconstruir la subjetividad del individuo. Es más, mientras Popper apela sólo a la explicación causal objetiva (nomológico- deductiva), Weber introduce, para el análisis de las ciencias sociales, la explicación intencional (en la que según se ha visto, la causalidad de las hipótesis se establece de manera pragmática- subjetiva).

Se tiene, por lo tanto, que la comprensión subjetiva del individualismo metodológico weberiano (latente en la elección racional), ayuda a comprender que la filosofía de la acción no es indiferente a la filosofía de la ciencia, como sugiere Popper, sino que constituye su misma base.

3) El modelo y la abducción: tal como se explica en el capítulo 2, mi perspectiva de la acción y de la ciencia coincide con la planteada en la compilación de Eco y Sebeok (1992).

4) Las conexiones con el convencionalismo: en el capítulo 2 se observó que mi modelo lleva asociadas una ontología y una teoría de la verdad convencionalistas, por lo cual podría conectarse con enfoques como el de Lewis (1969).

5) Otras conexiones: en tanto que mi modelo silogístico puede ser considerado como una forma subyacente o estructura de la acción racional, ofrece puntos de contacto con el estructuralismo, contactos que sin embargo deben ser tomados con cautela. Más prometedoras parecerían ser las relaciones que pueden ser establecidas con aspectos de la fenomenología de Husserl, de la hermenéutica de Ricoeur $\mathrm{y}$, especialmente, con la teoría psicogenética de la equilibración mayorante.

Por último, resulta muy interesante la perspectiva de una vinculación del modelo con los distintos enfoques computacionales (como los de Simon o Minsky) en los que se apoya la llamada ciencia cognitiva, disciplina actualmente de moda en los Estados Unidos, que trata de integrar los aportes de la inteligencia artificial con los de la lingüística, la neurofisiología, la psicología cognitiva, la lógica y la filosofía, en un estudio interdisciplinario de la cognición. 


\section{Bibliografía y referencias}

Aguiar, Fernando (1991): "La lógica de la cooperación", en Intereses individuales y acción colectiva, Fernando Aguiar (comp.), Ed. Pablo Iglesias, Madrid.

Allan, D. J. (1955): "The Practical Syllogism", en Autour d'Aristote, publicación de la Universidad de Lovaina, Lovaina.

Allison, Graham (1971): Essence of Decision: Explaining the Cuban Missile Crisis, Little Brown, Boston (traducción castellana, La esencia de la decisión. Análisis explicativo de la crisis de los misiles en Cuba, GEL, Buenos Aires, 1988).

Ambrosini, Cristina (1993): "La racionalidad estratégica como modelo de toma de decisiones. Algunas críticas", en La racionalidad en debate, Oscar Nudler y Gregorio Klimovsky (comp.), Centro Editor de América Latina, Buenos Aires, 1993.

Anscombe, Elizabeth (1957): Intention, Basil Blackwell Publisher, Oxford (traducción castellana de Ana Isabel Stellino con prólogo de Jesús Mosterín, Intención, Paidós/ICE-UAB, Barcelona, 1991).

Apel, Karl (1985): "Etica normativa y racionalidad estratégica: el problema filosófico de una ética política", en "Revista de filosofía y de teoría política", número 25, Departamento de Filosofía, Facultad de Humanidades y Ciencias de la Educación Universidad Nacional de La Plata.

Arenal, Celestino del (1984): Introducción a las Relaciones Internacionales, Ed. Tecnos, Madrid.

--(1989): "La teoría de las relaciones internacionales hoy: debates y paradigmas", en revista Estudios Internacionales, número 86, Santiago, abril-junio de 1989.

Aristóteles, Etica Nicomaquea, Ed. Espasa-Calpe, Buenos Aires, 1942.

---De motu animalium, Princeton University Press, Princeton, 1978.

Aron, Raymond (1962): Paz y guerra entre las naciones, Alianza Editorial, Madrid, 1984.

Axelrod, Robert (1984): The Evolution of Cooperation, Basic Books, New York (traducción castellana, La evolución de la cooperación, Alianza Editorial, Madrid, 1986).

Axelrod, Robert y Robert Keohane (1986): "Achieving Cooperation Under Anarchy", en Cooperation Under Anarchy, Kenneth Oye (comp.), Princeton University Press, Princeton.

Baldwin, David (1993): "Neoliberalism, Neorealism, and World Politics", en Neorealism and Neoliberalism: The Contemporary Debate, David Baldwin (comp.), Columbia University Press, New York.

Barranco de Busaniche, Graciela (1993): "Las elecciones en serio", en La racionalidad en debate, Oscar Nudler y Gregorio Klimovsky (comp.), Centro Editor de América Latina, Buenos Aires, 1993.

Bobbio, Norberto (1987): La teoría de las formas de gobierno en la historia del pensamiento político, FCE, México.

Boutros Ghali, Boutros (1992): "Un programa de paz", en revista "Relaciones Internacionales", N 3, noviembre de 1992.

--(1994): "Discurso ante el Consejo Argentino para las Relaciones Internacionales", Consejo Argentino para las Relaciones Internacionales (CARI), Buenos Aires, marzo de 1994.

--(1995):"Suplemento de un programa de paz", en revista "Relaciones Internacionales", No 8, mayo de 1995. 
Brzezinsky, Zbigniew (1994): Out of Control, Collier Books, Macmillan Publishing Company, New York.

Buchanan, James y Tullock, Gordon (1962): El Cálculo del Consenso, partes I y IV, Ed. EspasaCalpe, Madrid, 1980.

"Carta de las Naciones Unidas" (1945), en Tratados y Documentos Internacionales, recopilación y notas de José I. García Ghirelli, Ed. Zavalía, Buenos Aires, 1992.

Cicerón, De los deberes, Imprenta Universitaria, México, 1948.

Clark, Grenville y Louis Sohn (1958): The Peace by the Global Law, Harvard University Press, Cambridge (Mass.), (traducción castellana, La paz por el derecho mundial, Bosch, Barcelona, 1961).

Cohen, Marshall (1984): "Moral Skepticism and International Relations", en revista "Philosophy and Public Affairs", vol. 13.

Colonna d'Istria y Frapet (1980): L'art politique chez Machiavel, Ed. Libraire Philosophique, J Vrin, París.

Daló, Rafael (1993): Análisis del Tratado de la Unión Europea (Maastricht), publicación del Instituto de Relaciones Internacionales de la Facultad de Ciencias Jurídicas y Sociales de la Universidad Nacional de La Plata, Serie Estudios, No2, junio- septiembre de 1993.

--(1994): "Una interpretación crítica de Maquiavelo desde la teoría de la elección racional", en revista "El Príncipe", publicación de la Asociación de Maestros y Especialistas en Ciencia Política de la Provincia de Buenos Aires, No 3, julio- septiembre de 1994.

Davidson, Donald (1963): "Acciones, Razones y Causas", en La filosofía de la acción, A. R. White (comp.), FCE, México, 1976.

--(1980): Essays on Actions and Events, Clarendom Press, Oxford.

Dougherty, James y Robert Pfaltzgraff (1990): Contending Theories of International Relations: A Comprehensive Survey, Harper Collins Publishers, New York (traducción castellana, Teorías en pugna en las Relaciones Internacionales, GEL, Buenos Aires, 1993).

Duryea Smith, Charles (1986): La lucha por la paz, GEL, Buenos Aires.

Eco, Umberto y Thomas Sebeok (comp.) (1992): El signo de los tres. Dupin, Holmes, Peirce, Ed. Lumen, Madrid.

Elster, Jon (1979): Ulises y las sirenas, FCE, México, 1980.

--(1982): "Marxismo, funcionalismo y teoría de juegos. Alegato en favor del individualismo metodológico", en Theory and Society, 11, 1982, traducción de Pilar López en revista "Zona Abierta", no 33, octubre-diciembre de 1984.

--(1983): Sour Grapes. Studies in the subversion of rationality, Maison des Sciences de l'Homme and Cambridge University Press, Cambridge (traducción castellana, Uvas amargas. Sobre la subversión de la racionalidad, Península, Barcelona, 1988).

--(1985): "Nuevas reflexiones sobre marxismo, funcionalismo y teoría de juegos", en revista "Zona Abierta" no 43-44, abril- septiembre de 1987.

--(1986): "Introduction to Jon Elster", en Rational Choice, Jon Elster (comp.), New York University Press, New York, 1986.

--(1989): The Cement of Society, Cambridge University Press, Cambridge (traducción castellana, El cemento de la sociedad, Gedisa, Barcelona, 1991).

--(1990): Salomonic Judgements, Cambridge University Press, Cambridge. 
Gauthier, David (1969): The Logic of Leviathan, Oxford University Press, Oxford.

Giddens, Anthony (1990): The Consecuences of Modernity, Stanford University Press, Stanford (traducción castellana de Ana Lizón Ramón, Consecuencias de la modernidad, Alianza Editorial, Madrid, 1993).

Gilpin, Robert (1981): War and Change in World Politics, Cambridge University Press, New York.

Granovetter, Mark (1978): "Thresholds Models of Collective Behavior", en "American Journal of Sociology", vol. 83, pág. 1420- 1433 (traducción castellana de Fernando Aguiar, "Modelos de umbral de conducta colectiva", en Intereses individuales y acción colectiva, Fernando Aguiar (comp.), Ed. Pablo Iglesias, 1991).

Grieco, Joseph (1988): "Anarchy and the Limits of Cooperation: A Realist Critique of the Newest Liberal Institutionalism", en Neorealism and Neoliberalism: The Contemporary Debate, David Baldwin (comp.), Columbia University Press, New York, 1993.

--(1992): "Understanding the Problem of International Cooperation: The Limits of Neoliberal Institutionalism and the Future of Realist Theory", en Neorealism and Neoliberalism: The Contemporary Debate, David Baldwin (comp.), Columbia University Press, New York, 1993.

Guariglia, Osvaldo (1992): Etica y Política según Aristóteles, Centro Editor de América Latina, Buenos Aires.

--(1993): Ideología, verdad y legitimación, FCE, México.

Habermas, Jürgen (1981): Theorie des kommunikativen Handelns, Suhrkamp, Francfort (traducción castellana, Teoría de la acción comunicativa, Taurus, Madrid, 1988).

--(1985): Der philosophische Diskurs der Moderne, Suhrkamp, Francfort (traducción castellana, El discurso filosófico de la modernidad, Taurus, Madrid, 1989).

Harsanyi, John C. (1961): "Game Theory and the Anallysis of International Conflict", en J. N. Rosenau (comp.), International Politics and Foreign Policy, New York, 2da edición revisada, 1969.

--(1977): "Advances in understanding rational behavior", en Rational Choice, Jon Elster (comp.), New York University Press, New York, 1986.

Hartmann, Frederick (1983): The Relations of Nations, Ed. Macmillan (traducción castellana de Zoraida J. Valcárcel, Las Relaciones Internacionales, Instituto de Publicaciones Navales, Buenos Aires, 1986).

Hidalgo, Cecilia (1993): "Racionalidad y método en ciencias humanas: la noción de comparación adecuada", en La racionalidad en debate, Oscar Nudler y Gregorio Klimovsky (comp.), Centro Editor de América Latina, Buenos Aires, 1993.

Hobbes, Thomas (1651): Leviatán, FCE, México, 1984.

Holsti, K. J. (1985): The Dividing Discipline. Hegemony and Diversity in International Theory, Boston.

Huntington, Samuel (1993): "Las Próximas Guerras", en revista "Foreign Affairs", agosto de 1993, traducido y reproducido en diario "Página 12", Buenos Aires, 29/8/1993.

Kant, Immanuel (1785): Fundamentación de la metafísica de las costumbres, Ed. Espasa-Calpe, Madrid, 1983.

--(1795): La paz perpetua, traducción de Joaquín Abellán, Ed. Tecnos, Barcelona, 1985.

Kaplan, Morton (1957): System and Process in International Politics, Wiley, New York.

Kenny, A. (1963): Action, Emotion and Will, Henley, Routledge and Kegan Paul, Londres. 
Keohane, Robert (1983): "The Demand for Regimes", en International Regimes, Stephen Krasner (comp.), Cornell University Press, Ithaca, 1983.

--(1984): After Hegemony: Cooperation and Discord in the World Political Economy, Princeton University Press, Princeton.

--(1992): "Institutionalist Theory and the Realist Challenge After the Cold War", en Neorealism and Neoliberalism: The Contemporary Debate, David Baldwin (comp.), Columbia University Press, New York, 1993.

Keohane, Robert y Joseph Nye (1972): Trasnational Relations and World Politics, Harvard University Press, Cambridge (Mass.).

--(1977): Power and Interdependence: World Politics in Transition, Little Brown, Boston.

Krasner, Stephen (1983): "Regimes and the Limits of Realism", en International Regimes, Stephen Krasner (comp.), Cornell University Press, Ithaca, 1983.

"La Conferencia de Viena (14 al 25 de junio de 1993). El debate sobre derechos humanos en las relaciones internacionales contemporáneas", recopilación y notas de Fabián Salvioli y Vilma Savegnago, publicación del Instituto de Relaciones Internacionales de la Universidad Nacional de La Plata, Serie: Documentos, No4, noviembre de 1993.

Lewis, D. (1969): Convention, Harvard University Press, Cambridge (Mass.).

Lipson (1984): "International Cooperation in Economic and Security Affairs", en revista "World Politics", No37.

Maquiavelo, Nicolás (1531): Discursos sobre la primera década de Tito Livio, traducción castellana de Luis Navarro, Ed. El Ateneo, Buenos Aires, 1957.

-- (1532): El Príncipe, Espasa-Calpe, Madrid, 1957.

Madanes, Leiser (artículo inédito 1): "Naturaleza y convención en el principado civil de Maquiavelo".

--(artículo inédito 2), "La reflexión ético-política antes y después de Maquiavelo".

Mena, Carlos (1989): Toma de decisiones y políticas, GEL, Buenos Aires.

Morgenthau, Hans (1948): Politics among Nations: The Struggle for Power and Peace, Knopf, New York (traducción castellana: Política entre las naciones, GEL, Buenos Aires, 1986).

Naishtat, Francisco (1992a): "Leyendo Rational Choice de Jon Elster et al.", Boletín de Ciencias Sociales, número 12, FCS, UBA, Buenos Aires.

--(1992b): "Preferencias sociales e instituciones democráticas: reflexiones acerca del Teorema de Arrow", ponencia presentada en el coloquio "Razón fillosófica y espacio público", organizado por el Centro de Estudios Avanzados del Colegio Internacional de Filosofía de París, diciembre de 1992.

--(1993a): "La Filosofía y la Política", en revista "Lo que vendrá", año 1, número 1, FCS, UBA, Buenos Aires.

--(1993b): "El conflicto de la racionalidad en la acción política", en La racionalidad en debate, Oscar Nudler y Gregorio Klimovsky (comp.), Centro Editor de América Latina, Buenos Aires.

Neumann, John von y Oskar Morgenstern (1944): Theory of Games and Economic Behavior, Princeton University Press, Princeton.

Niou, Emerson, Peter Ordeshook y Gregory Rose (1989): The balance of power: stability in international systems, Cambridge University Press, Cambridge.

Olson, Mancur (1965): The Logic of Collective Action, Harvard University Press, Cambridge (Mass.). 
Platón: República, traducción castellana de Antonio Camarero, Eudeba, Buenos Aires, 1984.

Popper, Karl (1935): The Logic of Scientific Discovery, Hutchinson, Londres (traducción castellana, La lógica de la investigación científica, Tecnos, Madrid, 1985).

--(1944): The Open Society and its Enemies, Princeton University Press, Princeton y Routlegdeand Kegan Paul, Londres (traducción castellana, La sociedad abierta y sus enemigos, Paidós, 1957).

--(1972): Objetive Knowledge, The Clarendom Press, Oxford (traducción castellana, Conocimiento Objetivo, Tecnos, Madrid 1982).

Rawls, John (1971): A Theory of Justice, Oxford University Press, Oxford (traducción castellana, La teoría de la justicia, Fondo de Cultura Económica, México, 1991).

--(1985): "Justice as Fairness: Political not Metaphysical", en revista "Philosopy and Public Affairs", vol. 14.

Schelling (1963): The Strategy of Conflict, Oxford University Press, New York.

Sen, Amartya (1982): "Behavior and the Concept of Preference", en Rational Choice, Jon Elster (comp.), New York University Press, New York, 1986.

Shubik, Martin (1982): Game Theory in the Social Sciences. Concepts and Solutions, The MIT Press, Cambridge (Mass.) (traducción castellana, Teoría de juegos en las ciencias sociales, FCE, México, 1992).

Skinner, Quentin (1984): Maquiavelo, Alianza Editorial, Buenos Aires.

-- (1990): "The republican ideal of political liberty", en Machiavelli and Republicanism, Cambridge University Press, Cambridge.

Snyder, Richard, H. W. Bruck y Burton Sapin (1954): "Decision- making as an Approach to the Study of International Politics", en Stanley Hoffman (comp.), Contemporary Theory in International Relations, Prentice Hall, Englewood Cliffs, N. J., 1960 (traducción castellana de M. D. López Martínez, Teorías contemporáneas sobre las relaciones internacionales, Ed. Tecnos, Madrid, 1979).

Sosa, Rubén Antonio (1991): "El fundamentalismo: un pensamiento totalitario", en diario "La Nación", Buenos Aires, 4/6/94.

Stein (1983): "Coordination and Colaboration: Regimes in an Anarchic World", en Neorealism and Neoliberalism: The Contemporary Debate, David Baldwin (comp.), Columbia University Press, New York, 1993.

Steinbruner, John (1974): The Cybernetic Theory of Decision: New Dimensions of Political Analysis, Princeton University Press, Princeton.

Strauss, Leo (1970): ¿Qué es filosofía política?, Ed. Guadarrama, Madrid.

Taylor, Michael (1987): The Possibility of Cooperation, Cambridge University Press, Cambridge.

Tomassini, Luciano (1991): La política internacional en un mundo posmoderno, GEL, Buenos Aires.

Vargas Llosa, Mario (1993): "El nacionalismo, seductor y cruel, gana nuevas víctimas", en diario "La Nación", Buenos Aires, 19/8/93.

--(1994): "La libre elección", en diario "La Nación", Buenos Aires, 10/1/94.

--(1995): "La señal de la cruz", en diario "La Nación", Buenos Aires, 6/9/95.

Waltz, Kenneth (1979): Theory of International Politics, Addison- Wesley, Massachusetts (traducción castellana, Teoría de la política internacional, GEL, Buenos Aires, 1988). 
Weber, Max (1903): El problema de la irracionalidad en las ciencias sociales, Tecnos, Madrid, 1992.

--(1919): El político y el científico, Alianza Editorial, Madrid, 1986.

--(1922): Economía y Sociedad, capítulo I, FCE, México, 1984.

Wright, Georg Henrik von (1963): Norma y Acción, Tecnos, Madrid, 1979.

--(1971): Explicación y comprensión, Alianza Universidad, Madrid, 1987. 